Pacific Northwest

National Laboratory

Operated by Battelle for the

U.S. Department of Energy

\section{Development of a Density Sensor for In-Line Real-Time Process Control and Monitoring of Slurries during Radioactive Waste Retrieval and Transport Operations at DOE Sites}

J. A. Bamberger

M. S. Greenwood

November 2001

Prepared for the U.S. Department of Energy under Contract DE-AC06-76RL01830 


\title{
DISCLAIMER
}

This report was prepared as an account of work sponsored by an agency of the United States Government. Neither the United States Government nor any agency thereof, nor Battelle Memorial Institute, nor any of their employees, makes any warranty, express or implied, or assumes any legal liability or responsibility for the accuracy, completeness, or usefulness of any information, apparatus, product, or process disclosed, or represents that its use would not infringe privately owned rights. Reference herein to any specific commercial product, process, or service by trade name, trademark, manufacturer, or otherwise does not necessarily constitute or imply its endorsement, recommendation, or favoring by the United States Government or any agency thereof, or Battelle Memorial Institute. The views and opinions of authors expressed herein do not necessarily state or reflect those of the United States Government or any agency thereof.

\author{
PACIFIC NORTHWEST NATIONAL LABORATORY \\ operated by \\ BATTELLE \\ for the \\ UNITED STATES DEPARTMENT OF ENERGY \\ under Contract DE-AC06-76RLO 1830
}

\begin{abstract}
Printed in the United States of America
Available to DOE and DOE contractors from the

Office of Scientific and Technical Information, P.O. Box 62, Oak Ridge, TN 37831; prices available from (615) 576-8401.

Available to the public from the National Technical Information Service. U.S. Department of Commerce, 5285 Port Royal Rd., Springfield, VA 22161
\end{abstract}

This document was printed on recycled paper. 
PNNL-13719

UC-721

\section{Development of a Density Sensor for In-Line Real-Time Process Control and Monitoring of Slurries during Radioactive Waste Retrieval and Transport Operations at DOE Sites}

J. A. Bamberger

M. S. Greenwood

November 2001

Prepared for the U.S. Department of Energy

under Contract DE-AC06-76RLO 1830

Pacific Northwest National Laboratory

Richland, Washington 99352 


\section{Acknowledgments}

The density sensor development and deployment have been collaboratively supported by the US Department of Energy Office of Science and Technology Tanks Focus Area (TFA) and the Hanford SY101 Surface Level Rise Remediation Project (SLRRP). TFA oversight was provided by Tom Thomas, Technology Integration Manager for Characterization from Idaho National Engineering and Environmental Laboratory (INEEL), and Glen Bastiaans, Crosscutting Program (CP) Technical Lead for Characterization, Monitoring and Sensor Technology (CMST) from the US Department of Energy Ames Laboratory. Tom May, CH2M Hill Hanford Group provided guidance regarding Tank C-106 deployment. For the deployment at the SY-101 site, project support has been provided by Carl Hanson, Engineering from Cogema, Roger Bauer, SY-101 Project Management from CH2M Hill Hanford Group, and project manager Joe Brothers, Science and Technology Support from Pacific Northwest National Laboratory (PNNL).

At PNNL significant recognition is due to Jim Skorpik and Larry Reid for development and implementation of the computer control hardware, custom designed computer circuit board, and control software and to Juan Valencia for circuit board population and cable manufacture. The densimeter flanged housings were constructed and pressure tested at Hi-Line Engineering, Richland, Washington and the transducer wedges were completed at Xactec, Pasco, Washington. Thanks to Chuck Hymas for assistance during the pipe loop tests in the 336 building and to Keith Witwer and Don Powell for assistance with the densimeter tests in the modified process manifold in the 305 building. Don Daly is recognized for guidance for the statistical analysis. Also thanks to Tom Schneider for liaison with site operations including support from Mike Hay, Instrumentation and Electrical and Butch Hall operations support during densimeter site installation. Tom Schneider also assisted with verification of the densimeter operation at the SY-101 site. 


\section{Summary}

This report describes development of a density sensor (densimeter) for in-line real-time process control and monitoring of slurries during radioactive waste retrieval and transport operations at US Department of Energy (DOE) sites. At these sites millions of gallons of radioactive liquid and sludge wastes must be retrieved from underground storage tanks and transported via underground pipelines for treatment or disposal. A major concern during the transfer operations is plugging of the transfer lines. Blocked transfer lines could significantly escalate the remediation costs both in terms of pipeline replacement costs and costs of maintenance of inactive facilities and operating personnel. The density sensor can be used for real-time process monitoring that could be used to detect conditions that could lead to degraded transport and line plugging. The three main factors that contribute to transfer line plugging are: 1) settling of solid particles during transfer, 2) crystallization of the waste, and 3) gelation of the waste. Depending on the mechanism, plugging or its onset may result in a change in the density or particle size distribution of the slurry. In addition, the onset of pipeline plugging may also lead to an increase in the pressure drop in the transfer lines. The densimeter presents numerous benefits over grab sampling of the waste followed by off-line analysis. Benefits include: early detection and prevention of pipeline plugging events, real-time process data of the density through the transfer process, reduction or elimination of grab sampling and off-line analysis, and reduced radiation exposure for workers

The density sensor, shown in Figure 1, was developed based on the need to provide a small, robust instrument that could be retrofitted into existing pump pit manifolds and transfer lines. The probe uses ultrasonic signal reflection at the fluid-pipe wall interface to quantify density in situ in real time. The sensor is mounted in the wall of the pipe between two connecting flanges. This instrument was selected for monitoring radioactive waste transport based on several characteristic features: the sensing surface is non-intrusive and does not disrupt the slurry flow (the sensor is located flush with the pipeline wall); instrument performance is not affected by slight amounts of entrained air that could be present during waste retrieval and transfer; nor is it affected by electromagnetic noise from nearby pumps and other equipment; and the instrument is compact (the sensor is located on the perimeter of the pipe wall).

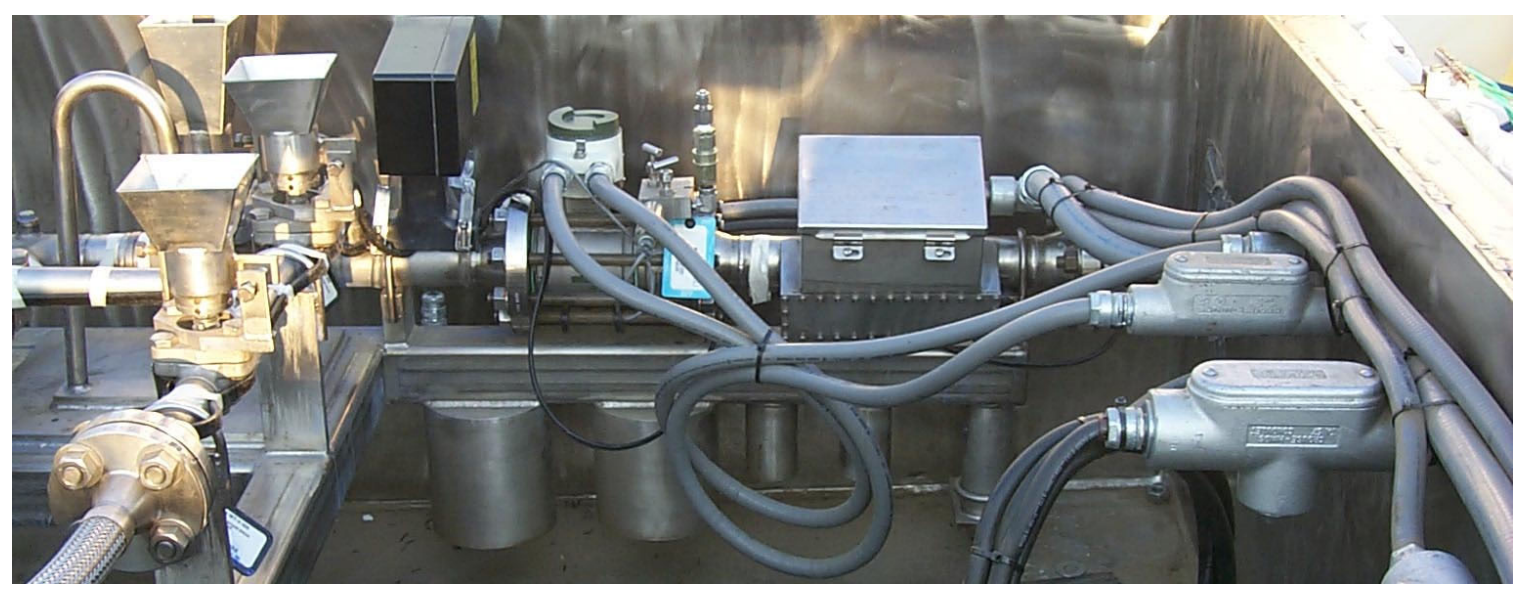

Figure 1 Density sensor installed at Hanford in the SY-101 site in the pump pit (after installation the densimeter was covered with blanket insulation) 
During probe development for deployment in a radioactive waste stream, components were tested for chemical and radiation resistance and the spool piece (flanged insert containing the sensor) was pressure tested in accordance with ASME Process Piping Code B31.3. In addition, because the probe is installed in a transfer line associated with a tank filled with waste with the potential to generate flammable gas, the design was reviewed by the Hanford Site Flammable Gas Equipment Advisory Board to evaluate probe installation and use in an area requiring compliance with Ignition Source Control Set 2. The board ruled that the density sensor components are not formally approved for use in a Class I, Division 2, Group B atmosphere; however, the components are normally non-sparking and provide equivalent safety.

The density sensor performance was evaluated in both vertical (at Oak Ridge National Laboratory) and horizontal (at Pacific Northwest National Laboratory and at Hanford) orientations. In most cases, prediction of density was within $\pm 2 \%$ when compared with reference grab samples.

\section{Deployment and Demonstration}

The density sensor has been deployed as a component in the modified process manifold that is installed in the prefabricated pump pit at Hanford tank SY-101 site. In FY-2001 after completion of densimeter installation and connection of cabling, the probe operation in air was verified. In FY-2002, the density sensor performance will be evaluated during transfers of both water and waste through the pipeline.

\section{Next Generation Through-Wall Density Sensor}

The density sensor design installed in FY-2001 at Tank SY-101 is based on the original densimeter concept proposed in FY-1996 and evaluated at ORNL in FY-1997. Upgrades to the SY-101 densimeter include the ability to operate over an increased pressure range (based on design of a new spool piece) and an enhanced calibration scheme that incorporates the effects of temperature into the methodology.

In a separate project an approach has been demonstrated to develop an ultrasonic sensor that: 1) can be attached permanently to a pipeline wall, possibly as a spool piece inserted into the line or 2) can clamp onto an existing pipeline wall and be movable to another location. Also, an analysis method has been developed to make the measurement self-calibrating. This investigation has shown the path forward to develop clamp-on sensors for measurement of fluid and slurry density. This method is especially attractive for applications such as Hanford where radioactive fluids are routinely transported because the sensors could be applied to existing equipment without the need to penetrate the pipe pressure boundary or to open the system to install new equipment. 


\section{Contents}

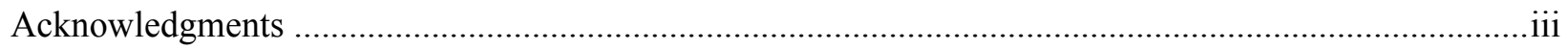

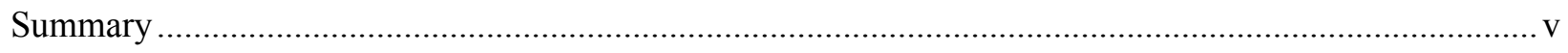

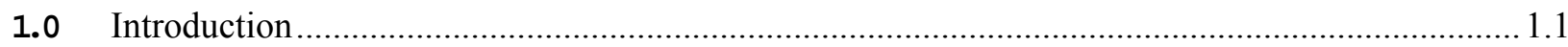

1.1 Pipeline Transport at DOE Sites Historical Background ................................................... 1.1

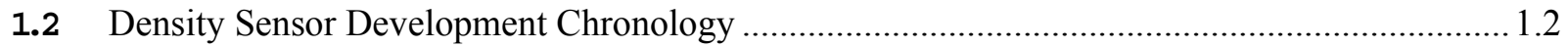

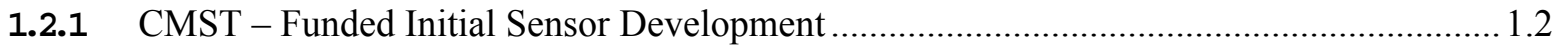

1.2.2 TDI - Funded Initial Deployment Development for Hanford .......................................... 1.2

1.2.3 ASTD Project Included Density Sensor in Review.................................................... 1.3

1.2.4 SLRRP - Incorporated Densimeter into a Deployment at SY-101 .................................. 1.3

1.3 Density Sensor Configurations Evaluated for Deployment ............................................... 1.4

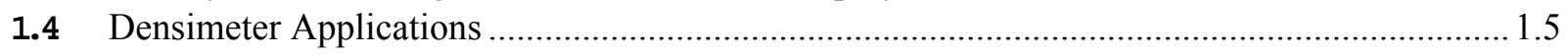

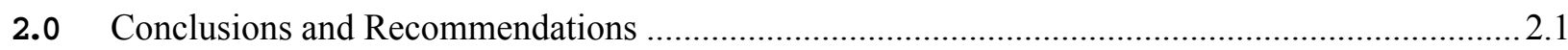

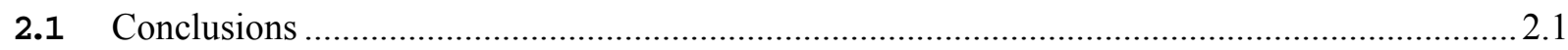

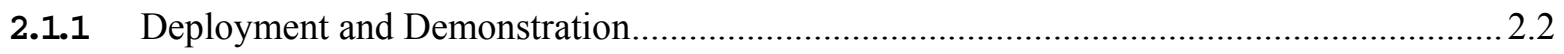

2.1.2 Next Generation Through-Wall Density Sensor ......................................................... 2.2

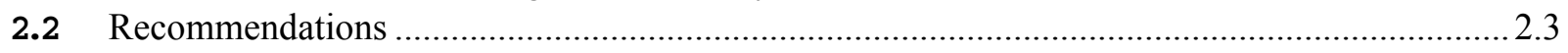

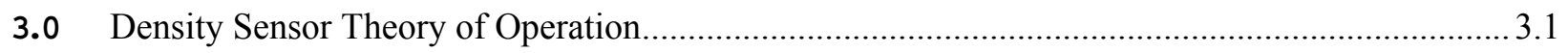

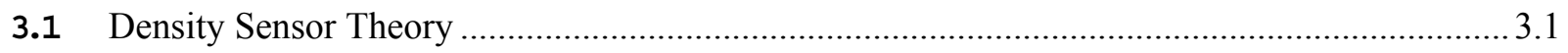

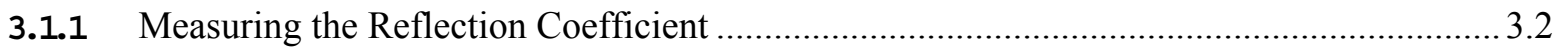

3.1.2 Reflection and Transmission Coefficients .................................................................. 3.2

3.1.3 Determining the Density of a Liquid Using 0 and 60 Degree Angles of Incidence............. 3.3

3.2 Enhancements Applied to Signal Analysis....................................................................... 3.5

4.0 Density Sensor Spool Piece and Hardware Configurations …................................................. 4.1

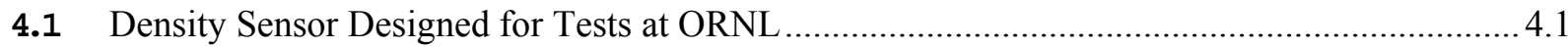

4.2 Initial Hanford Density Sensor Deployment Configuration for C-106 Pump Pit...................... 4.2

4.3 Density Sensor for SY-101 Transfer Line ........................................................................ 4.4

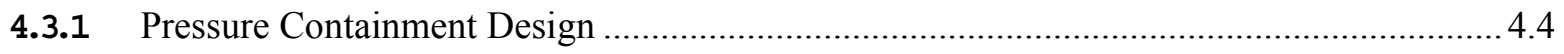

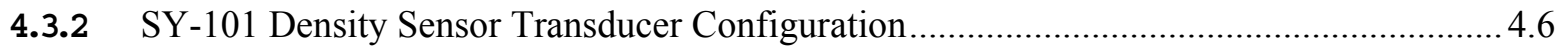

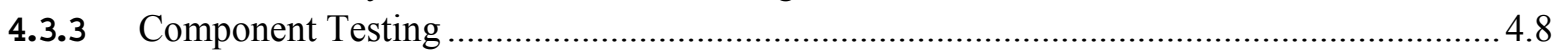

4.4 Computer Controlled Data Acquisition System ............................................................. 4.9

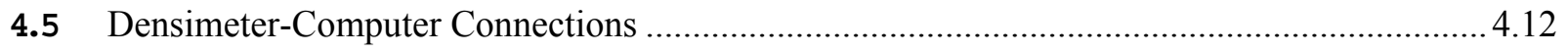

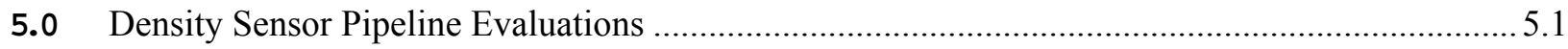

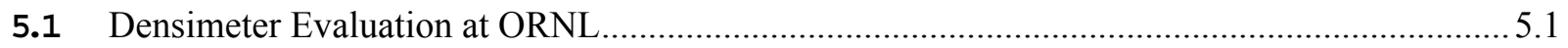

5.2 Densimeter Demonstration in the Instrument Validation Facility .......................................... 5.4

5.3 Tests at 305 Building in Modified Process Manifold............................................................... 5.6

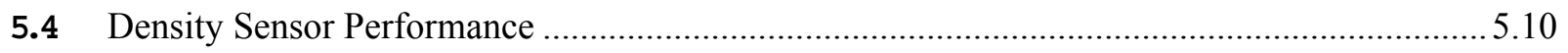

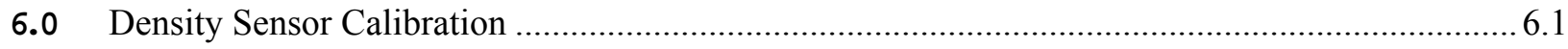

6.1 Approach for Sensor Calibration .................................................................................. 6.1

6.2 Experimental Reflection Coefficients for use in Regression Analysis................................... 6.4 


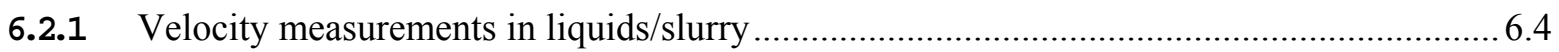

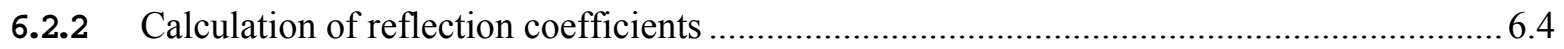

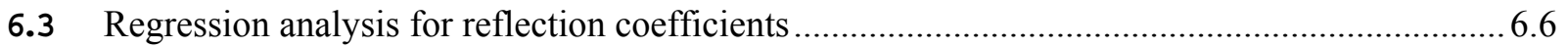

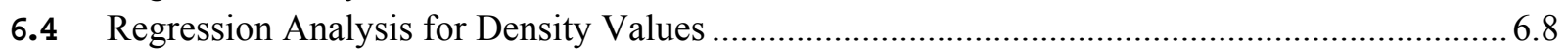

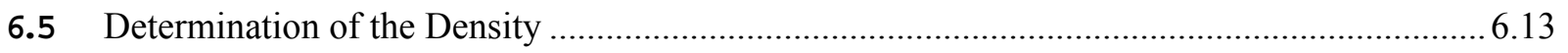

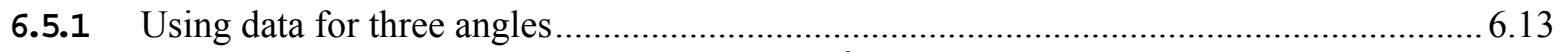

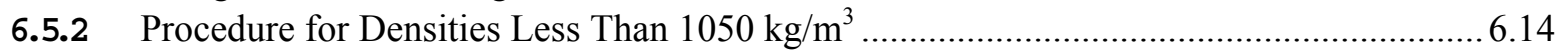

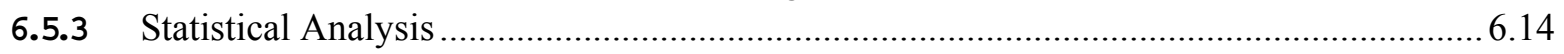

7.0 Computer Control System Operating Instructions ................................................................. 7.1

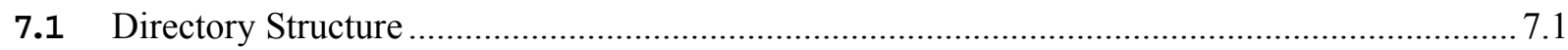

7.2 Input File

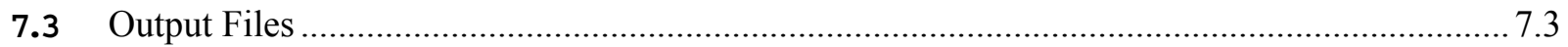

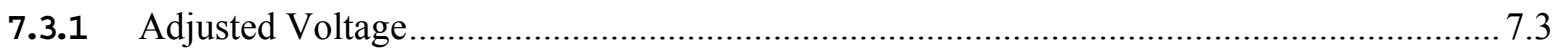

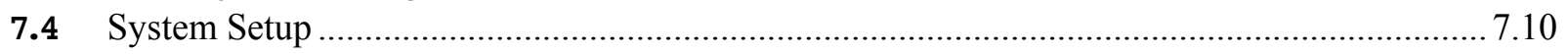

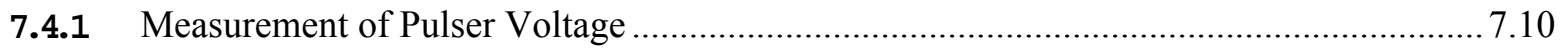

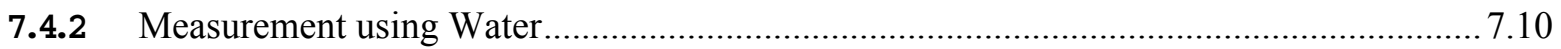

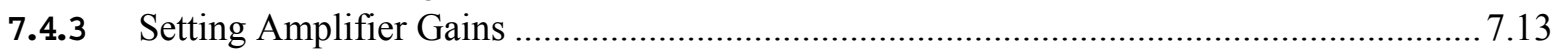

7.4.4 Adjustment to System and/or Changes to Input File.....................................................16

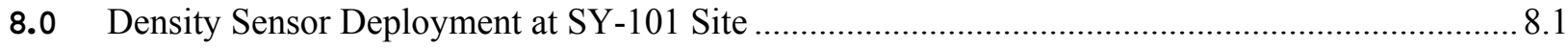

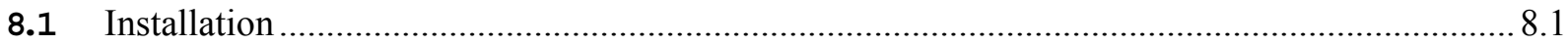

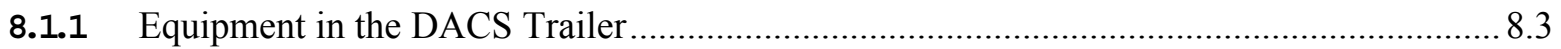

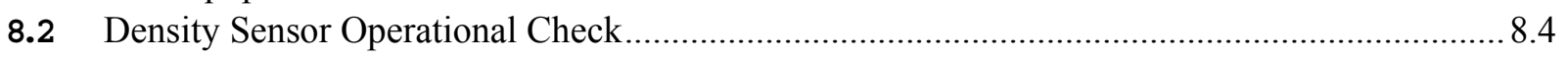

9.0 Density Sensor Improvements - Through-Wall Sensor......................................................... 9.1

9.1 Approach to Through-Wall Measurement of Density …....................................................... 9.1

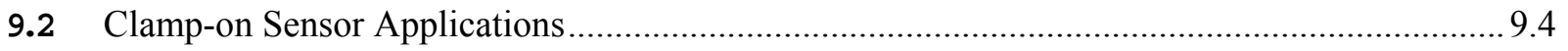

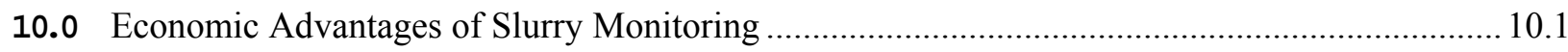

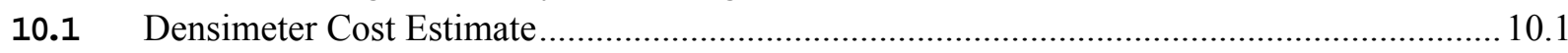

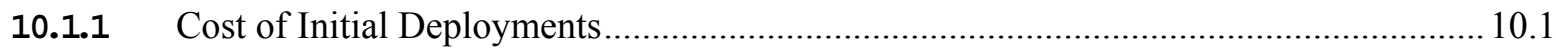

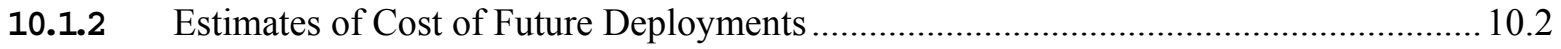

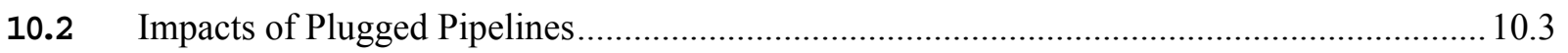

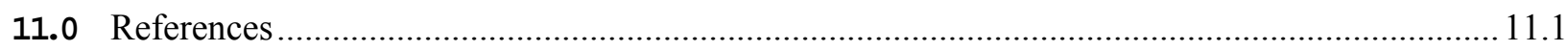

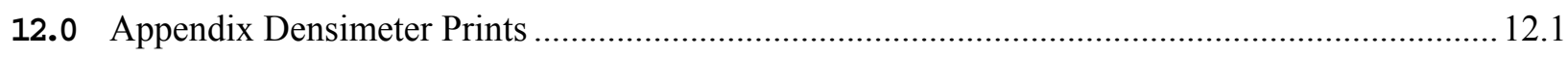

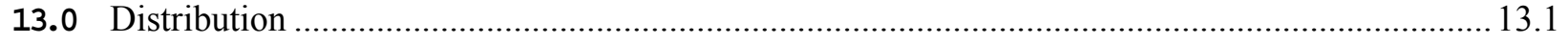




\section{Figures}

Figure 1 Density sensor installed at Hanford in the SY-101 site in the pump pit.....................................

Figure 2.1 Density sensor installed at Hanford in the SY-101 site in the pump pit before and after installation of blanket insulation

Figure 3.1 Schematic diagram of wedge design.

Figure 3.2 Definition of terminology used in equations of reflection and transmission coefficients.......3.3

Figure 3.3 Graph showing the reflection and transmission coefficient for a Rexolite ${ }^{\text {tm }}$ wedge in contact with water.

Figure 4.1 ORNL densimeter spool piece.

Figure 4.3 Proposed transfer configuration from Tank C-106 to Tank AY-102.

Figure 4.4 Densimeter configuration for deployment in the 10-cm (4-in.) transfer line from Tank C-106

to Tank AY-102...

Figure 4.5 Density sensor spool piece

Figure 4.6 Density sensor components showing spool piece $(8,10)$ wedges $(3-60$ degree, $4-47$ degree), and electrical connection box $(9,23)$

Figure 4.7 View showing transducers and wedges positioned on spool piece ................................... 4.7

Figure 4.8 Transducer wedges with transducers and connectors installed

Figure 4.9 View inside transducer housing after pressure test showing labels, connectors and O-ring seal

Figure 4.10 View inside the spool piece showing the transducer wedge and pipe-wall interface........... 4.8

Figure 4.11 Rexolite blocks (A through $\mathrm{H}$ ) exposed to increasing doses of radiation. .......................... 4.9

Figure 4.12 Density sensor control system architecture ............................................................... 4.10

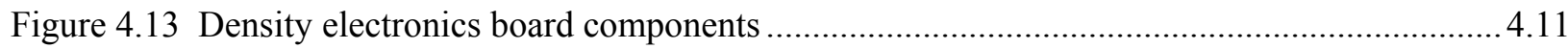

Figure 4.14 Toneburst signal appearing on the computer monitor. ....................................................12

Figure 4.15 Cable connections between densimeter and computer controller.................................... 4.13

Figure 4.16 Labeled lemo and thermocouple connectors ............................................................... 4.13

Figure 4.17 Densimeter cables and computer connections during pipeline tests at 336 building .......... 4.14

Figure 5.1 Vertical installation of densimeter during ORNL pipe loop tests ..................................... 5.1

Figure 5.2 Configuration of the instrument validation facility pipe loop ..............................................5.5

Figure 5.3 Modified process manifold test configuration ................................................................ 5.8

Figure 5.4 Densimeter 1 (left) and densimeter 2 (right) installed in the modified process manifold ....... 5.9

Figure 5.5 Data acquisition computers for the two density sensors...................................................

Figure 5.6 Comparison between densimeter and reference densities ............................................. 5.10 
Figure 6.1 Plots of bottle sample density and temperature for probes 1 (top) and 2(bottom) ................ 6.2

Figure 6.2 Velocity of sound in sugar water as a function of temperature ........................................ 6.5

Figure 6.3 Velocity of sound in kaolin clay slurries in sugar water as a function of temperature............ 6.5

Figure 6.4 Probe 1 variation of reflection coefficient with voltage .................................................. 6.9

Figure 6.5 Probe 2 variation of reflection coefficient with voltage ..................................................... 6.10

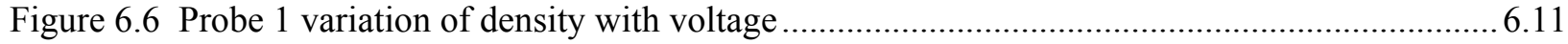

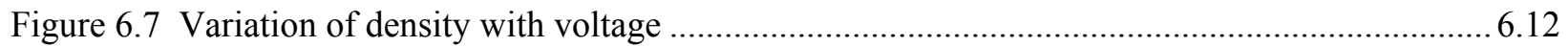

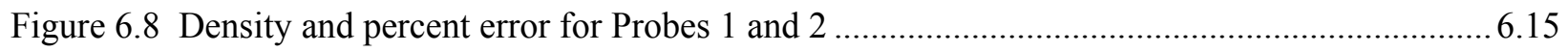

Figure 8.1 Densimeter location in the prefabricated pump pit (upper right corner - penetrating wall) ... 8.1

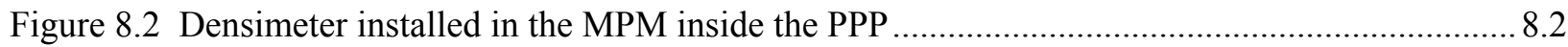

Figure 8.3 Densimeter after installation of blanket insulation ...................................................... 8.2

Figure 8.4 Densimeter cable field connections in PPP (left) and junction box (right) ......................... 8.3

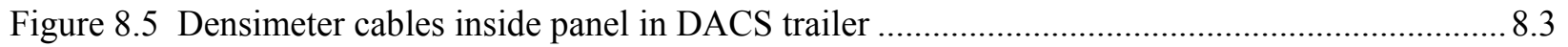

Figure 8.6 Density sensor connector locations on panel in DACS trailer............................................ 8.4

Figure 8.7 Wave form for longitudinal wave transducer pair BC in air ............................................ 8.5

Figure 8.8 Wave form for longitudinal wave transducer pair DE in air ........................................... 8.5

Figure 8.9 Wave form for longitudinal wave transducer FF in air .................................................. 8.6

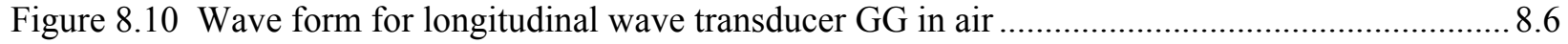

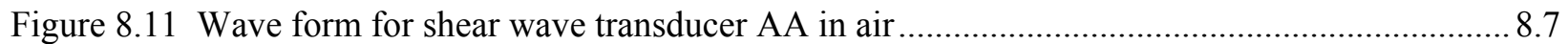

Figure 8.12 Evaluation of pulser voltage obtained in DACS trailer ..................................................... 8.7

Figure 9.1 Clamp-on sensor applied to 2-in. Schedule 40 pipe ......................................................... 9.2 


\section{Tables}

Table 1.1 Details of the highly hazardous radioactive waste stored at the DOE sites .......................... 1.1

Table 1.2 Density sensor configurations evaluated for deployment .................................................... 1.5

Table 4.1 Slurry transport parameters for transfer from Tank C-106 to AY-102 …............................ 4.3

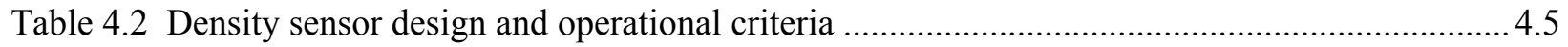

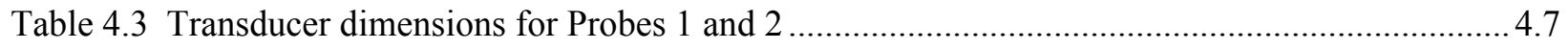

Table 5.1 Density sensor data obtained during the instrument evaluation at ORNL .............................5.2

Table 5.2 Range of fluid properties evaluated during pipe loop tests............................................5.5

Table 5.3 Test sequence and range of operating parameters ............................................................. 5.6

Table 5.4 Comparison between densimeter and reference densities obtained during pipe loop tests.......5.7

Table 6.1 Calculation of the experimental reflection coefficients for Probes 1 and $2 \ldots \ldots \ldots \ldots \ldots \ldots \ldots \ldots \ldots . . .6 .6$

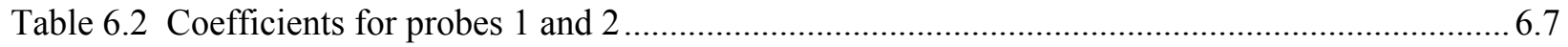

Table 6.3 Percent error in reflection coefficients based on Equation 6.5 compared to experimental values

Table 6.4 Percent error in density based on Equation 6.6 compared to the bottle sample density ...........6.8

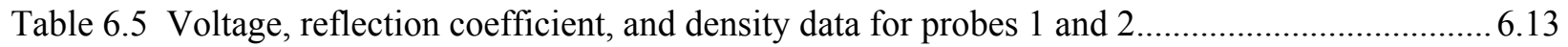

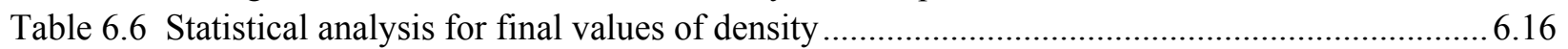

Table 6.7 Comparison of density values with bottle sample density .................................................. 6.16

Table 7.1 Information about output files datasum1.dat or datasum2.dat........................................... 7.4

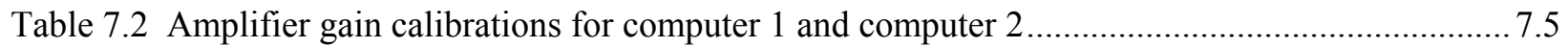

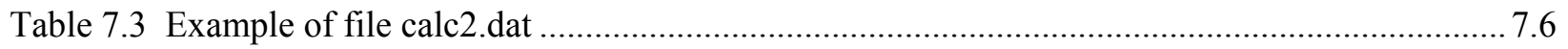

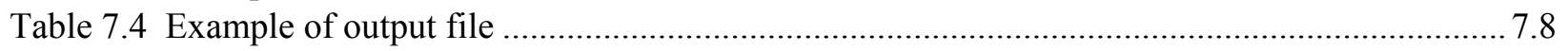

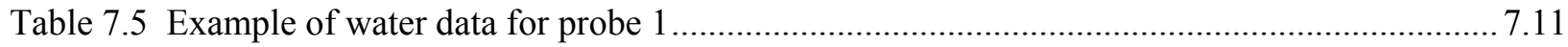

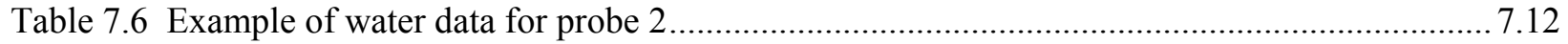

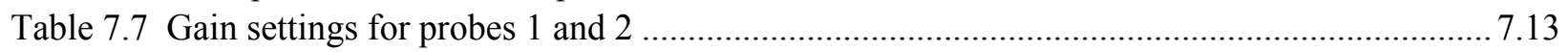

Table 7.8 Example of voltage variation with temperature for Probe 1 ................................................14

Table 7.9 Example of voltage variation with temperature for Probe 2 ............................................. 7.15

Table 8.1 Output from auto test of densimeter with probes in contact with air..................................... 8.8

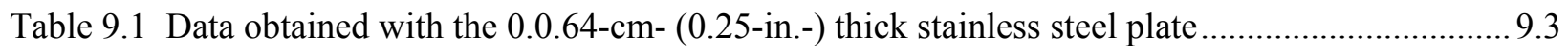

Table 9.2 Data obtained with the 0.38 -cm- $(0.15$-in.-) thick stainless steel plate.................................. 9.3

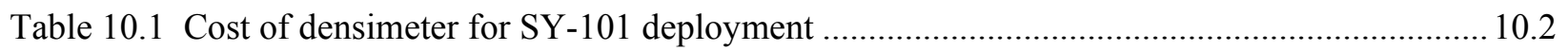

Table 10.2 Estimated cost of future density sensor deployments ................................................... 10.3 


\section{Symbols}

ASTD Accelerated Site Technology Deployment project

$\mathrm{b} 0_{\mathrm{x}}$ to $\mathrm{b} 8_{\mathrm{x}}$ coefficients in polynomial expansion where $\mathrm{x}$ denotes a transducer pair

c speed of sound

$\mathrm{c}_{\mathrm{L}} \quad$ longitudinal speed of sound

$\mathrm{c}_{\mathrm{T}} \quad$ transverse (shear) speed of sound

CMST Characterization, Monitoring, and Sensor Technology

CP Crosscutting Program

$\mathrm{D}_{\mathrm{LL}} \quad$ transmitted longitudinal wave

DACS data acquisition and control system

DOE Department of Energy

DST double-shell tank

EM US Department of Energy Environmental and Waste Management (EM)

G solids quantities

GAAT Gunite and Associated Tanks

GUI graphical user interface

$\mathrm{H} \quad$ solid quantities

HTI Hanford Tanks Initiative

INEEL Idaho National Environmental and Engineering Laboratory

$\mathrm{J} \quad$ solid and liquid quantities

LDRD Laboratory directed research and development

MPM modified process manifold

$\mathrm{N} \quad$ sum of solid and liquid quantities

ORNL Oak Ridge National Laboratory

ORP Hanford Site Office of River

PC personal computer

PNNL Pacific Northwest National Laboratory

PPP prefabricated pump pit

$\mathrm{RC}_{\mathrm{liq}} \quad$ reflection coefficient in liquid

$\mathrm{RC}_{\mathrm{T}}$ theoretical value of reflection coefficient at a given angle

$\mathrm{RC}_{\text {water }}$ reflection coefficient in water

$\mathrm{RC}_{\mathrm{X}} \quad$ experimental value of the reflection coefficient at a given angle

$\mathrm{RC}_{\mathrm{Z}} \quad$ experimental value for the perpendicular reflection

$\mathrm{RF}$ radio frequency

$\mathrm{R}_{\mathrm{LL}} \quad$ reflection coefficient for reflected longitudinal wave

$\mathrm{R}_{\mathrm{LLX}} \quad$ reflection coefficient at a non-zero angle

$\mathrm{R}_{\mathrm{TL}} \quad$ reflection coefficient for reflected shear wave

SLRRP SY-101 Surface Level Rise Remediation Project

SST single-shell tank

SW sugar water

T temperature

TDI Slurry Monitoring Technology Deployment Initiative

TFA Tanks Focus Area

TOF time of flight 
UDMS ultrasonic density measurement system

UT ultrasound

$\mathrm{V}_{\text {liq }} \quad$ voltage in liquid

$\mathrm{V}_{\text {water }} \quad$ voltage in water

$\mathrm{V}_{\mathrm{x}} \quad$ voltage at $0 \mathrm{~dB}$ amplifier gain

$Z_{\text {liq }} \quad$ acoustic impedance of liquid

$Z_{\text {solid }} \quad$ acoustic impedance of solid

\section{Greek Symbols}

$\begin{array}{ll}\alpha & \text { angle } \\ \alpha_{\mathrm{L}} & \text { angle of longitudinal wave } \\ \alpha_{\mathrm{T}} & \text { angle of transverse wave } \\ \mu & \text { viscosity } \\ \rho & \text { density of liquid } \\ \rho_{\mathrm{s}} & \text { density of solid } \\ \sigma & \text { standard deviation }\end{array}$




\subsection{Introduction}

Staff at Pacific Northwest National Laboratory (PNNL) are developing ultrasonic sensing systems to monitor radioactive waste rheological and other physical properties during transport (Greenwood, Skorpik and Bamberger, 1997 and 1999), to detect stratification and onset of sedimentation (Fort et al. 1993), and to measure particle size and concentration (Bamberger, Kytomaa, and Greenwood 1998) of slurries during processing. The technologies are also being applied in various industries to characterize pulp fiber composition, characterize physical changes during refining, track development of hydrates during oil production and transport, and visualize fluid processes in real-time (Bamberger, Bond, and Greenwood 1999 and Bamberger, Greenwood Bond 1999).

The development of a density sensor for deployment at DOE sites to measure fluid and slurry density has been in progress for several years and is covered by several US Patents (Greenwood 2000a, b, Greenwood and Harris 1999, Greenwood and Lail 1998). The need for real-time process monitoring and control during pipeline transport and fluid mixing at DOE sites is evident. Background information that supports this is presented in Section 1.1. A review of the background of the densimeter development is presented in Section 1.2 and 1.3. Potential densimeter applications are summarized in Section 1.4.

\subsection{Pipeline Transport at DOE Sites Historical Background}

The U. S. Department of Energy (DOE) is responsible for eventual disposal of millions of gallons of radioactive liquid and sludge wastes which are stored in the underground storage tanks at Hanford and other DOE sites (Table 1.1). Remediation plans for most of the hazardous radioactive waste stored in underground storage tanks at several of the DOE sites include: 1) retrieval operations to remove the wastes from storage tanks and 2) transport and staging operations to transfer the wastes to treatment or storage facilities. Retrieval operations involve mixing solid and liquid wastes to create slurries that can be transported to specified locations.

Table 1.1 Details of the highly hazardous radioactive waste stored at the DOE sites

\begin{tabular}{|l|c|c|c|c|c||}
\hline \multirow{2}{*}{ Site } & \multirow{2}{*}{ Number of Tanks } & \multicolumn{2}{|c|}{ Waste Volume } & \multicolumn{2}{c||}{ Radioactivity } \\
\cline { 3 - 6 } & & $\mathbf{m}^{\mathbf{3}}$ & $\mathbf{M ~ g a l}$ & $\left.\mathbf{P ~ B q ~ ( 1 0} \mathbf{1 0}^{\mathbf{1 5}} \mathbf{B q}\right)$ & M Curies \\
\hline Hanford & 177 & 204,000 & 54 & 7400 & 200 \\
\hline INEEL & 11 & 5,300 & 1.4 & 18 & 0.5 in tanks \\
\hline Oak Ridge & 40 & 1630 & 0.43 & 1.7 & 0.047 \\
\hline Savannah River & 49 & 132,000 & 35 & 16000 & 420 \\
\hline West Valley & 3 & 180 & 0.047 & 22 & 0.6 \\
\hline \hline
\end{tabular}

Currently at Hanford all wastes transfers between tanks and tank farms occur via pipeline. The possibility of pipeline plugging remains a significant issue regarding timely delivery of the feed to meet DOE remediation milestones. Also, blockage of transfer lines could significantly escalate the remediation costs both in terms of pipeline replacement costs and costs of maintenance of inactive facilities and operating personnel. 
Plugging of underground slurry transfer pipelines is not uncommon. Cross-site transfer lines between 200 East and 200 West Areas of the Hanford Site have existed for about forty years. Plugging of the cross-site transfer lines has occurred several times throughout the history of the Hanford site. In many cases, the plugs were successfully removed by high-pressure flushing. However, some transfer lines could not be unplugged and to date, of the six transfer lines that have been built four are permanently plugged.

At Hanford, the tank waste must be staged to provide the required composition feed in the correct sequence to the vitrification plant. This can lead to multiple transfers of the slurry before it is treated at the vitrification facility. For instance, sludge in the $200 \mathrm{~W}$ area Single Shell Tanks (SSTs) must be first transferred to the Double Shell Tank (DST) SY farm. This waste must be resuspended and mixed and then transferred cross-site to either the AN or AP tank farm. The waste may then again be resuspended and mixed and transferred to the AY farm before it is eventually sent to the vitrification facility. The numerous blending and transfers before the waste is finally sent to the vitrification plant increase the probability of a pipeline plugging event occurrence.

The three main factors that contribute to transfer line plugging are: 1) settling of solids particles during transfer, 2) crystallization of the waste, and 3) gelation of the waste. Depending on the mechanism, plugging or its onset may result in a change in the particle size distribution or the density of the slurry. In addition, the onset of pipeline plugging may also lead to an increase in the pressure drop in the transfer lines. Therefore, monitoring the particle size distribution and density of the slurry and the pressure drop in the transfer lines represent several of the methods for the early detection and prevention of pipeline plugging.

\subsection{Density Sensor Development Chronology}

Density sensor development has been funded since 1996.

\subsubsection{CMST - Funded Initial Sensor Development}

Density sensor development for pipeline deployment was initially funded in 1996 by the US Department of Energy Environmental and Waste Management (EM) 50 through the Characterization, Monitoring, and Sensor Technology (CMST) Crosscutting Program (CP). The sensing approach was selected as a novel technique with promise for characterizing slurry density. The sensor is unique because the measurement is made at the slurry-probe interface enabling measurement of very dense, highly attenuative slurries. In 1997, the initial densimeter configuration was installed in a pipe spool piece and its performance was evaluated during tests at Oak Ridge National Laboratory (Hylton et al. 1998).

\subsubsection{TDI - Funded Initial Deployment Development for Hanford}

Also, in 1997, the densimeter was included as a part of the Slurry Monitoring Technology Deployment Initiative (TDI) proposal to evaluate instrumentation for characterizing slurry properties during pipeline transport. This proposal was selected for funding, and in 1998, work was initiated to develop a densimeter design in a $10.2 \mathrm{~cm}$ (4 in.) pipeline for monitoring slurry properties during waste 
transfer from Tank C-106 to Tank AY-102. In late 1998, the Hanford Site priorities changed and the date for deployment and probe evaluation in the Tank C-106 transfer line became uncertain. Therefore, a new deployment location was sought.

\subsubsection{ASTD Project Included Density Sensor in Review}

Additional evaluation of density sensor performance occurred as a part of the Accelerated Site Technology Deployment (ASTD) project that was funded to reduce the likelihood of pipeline blockage during waste-transfer operations by evaluating instrumentation. The ASTD project, with collaboration from Waste Retrieval Sluicing System Project, Hanford SY-101 Surface Level Rise Remediation Project (SLRRP) and Hanford Tanks Initiative (HTI), evaluated three online slurry monitoring devices for use at the Hanford and ORNL sites. These instruments included: 1) the Lasentec M600 Particle Size Analyzer developed by Laser Sensor Technology, Inc., Redmond, Washington, 2) the Red Valve Pressure sensor manufactured by Red Valve Company, Inc., Pittsburgh, Pennsylvania, and 3) the ultrasonic densimeter developed at the Pacific Northwest National Laboratory (PNNL).

The Hanford Tanks Initiative was the original Hanford Site customer for the slurry monitoring technology. The HTI planned to remove a hard heel from single-shell tank (SST) 241-C-106 with a vehicular deployed retrieval system, and transfer the waste to double-shell tank 241-AY-102. Due to Hanford budget constraints, the HTI project was delayed. Some portions of HTI have been picked up by the project that will retrieve waste from SST 241-C-104 and transfer the waste to 241-AY-101. The slurry monitoring technology from the ASTD study may be deployed during this transfer. The project to sluice waste from 241-C-106 to 241-AY-102 successfully demonstrated the Red Valve Pressure sensors. Oak Ridge National Laboratory successfully demonstrated the Lasentec particle size measurement technology during clean out of the Gunite and Associated Tanks (GAAT). The Hanford SY-101 Surface Level Rise Remediation Project will demonstrate the densimeter. The results of this densimeter demonstration will be published after the completion of this transfer.

The ASTD review (Bontha et al. 2000) showed that slurry monitors present numerous benefits over the baseline instrumentation plan that calls for grab sampling of the waste followed by off-line analysis. Benefits include:

- Early detection and prevention of pipeline plugging events

- Real-time data of the particle size distribution, density, and pressure drop through the transfer process

- Reduction or elimination of grab sampling and off line analysis

- Reduced radiation exposure for workers.

\subsubsection{SLRRP - Incorporated Densimeter into a Deployment at SY-101}

In May 1999, the SY-101 Surface Level Rise Remediation Project (SLRRP) and the Tanks Focus Area (TFA) developed a Memorandum of Understanding to permit redirecting an ongoing project to develop and demonstrate an in-line slurry monitoring instrument to measure waste density during planned pipeline waste transfer operations between SY-101 and SY-102. The Ultrasonic Density Measurement System (UDMS) being developed by Pacific Northwest National Laboratory was selected after SLRRP concluded that this technology offered a significant size advantage that would enable it to be installed in 
the limited available space. TFA and SLRRP agreed under the terms of a Memorandum of Understanding to attempt to complete the design, fabrication and demonstration of this developmental technology on a very aggressive schedule in an effort to have it available for use by the project. Development and deployment of a density measurement capability was not required for execution of the SY-101 SLRRP transfers, but was being pursued as a desirable enhancement to the baseline transfer system capabilities. UDMS data would be used to analyze various aspects of the transfer process and diagnose potential difficulties, but would not be used in "real-time" to control transfer operations. The anticipated primary use of the data provided by the UDMS is to make possible an accurate mass balance during and after the transfer process.

PNNL has fabricated two UDMS in-line sensor spool pieces for SLRRP transfer line, the second providing a backup unit. A data acquisition system has also been developed. Following completion of bench-top testing of the sensors, PNNL installed both units in a pipe-loop test facility in the Hanford 336 Building and conducted testing of the sensor to provide data for calibration of the system. A series of tests using a sugar-water solution and sugar-water-kaolin solution were completed and a demonstration was provided to PNNL, TFA, and SLRRP project staff on December 10, 2000. A real-time response was observed to changes in density as sugar was added to the batch tank feeding the pipe loop. As expected, the system measured an initial spike in density and then leveled off as the sugar mixed thoroughly as it was pumped around the pipe loop.

In FY-2000, the densimeter was installed in the 241-SY-101 modified process manifold. To support deployment the densimeter performance was evaluated in a test of the manifold component operation in the Fluor Hanford Engineering Laboratory in the 305 building. In FY-2001, this manifold was installed at SY-101 in the prefabricated pump pit. In FY-2002, the densimeter performance will be evaluated during planned line flushes with water and during waste transfers. This demonstration will complete an outstanding TFA key deliverable from 1999 for demonstration of the unit under radioactive waste transfer conditions. Data and calibrations from this demonstration will be reviewed with TFA and SLRRP staff.

Based on the sensor process monitoring evaluations at Oak Ridge, PNNL and tests at Fluor Hanford, the densimeter is expected to meet requirements for measuring slurry density during slurry transfer operations at Hanford and other DOE sites.

\subsection{Density Sensor Configurations Evaluated for Deployment}

Based on these projects, three density sensor designs have been completed and two density sensor spool pieces have been designed, constructed, calibrated, and tested for deployment as shown in Table 1.2. The initial densimeter model was evaluated at PNNL and at tests in a pipeline at Oak Ridge National Laboratory (ORNL). A second densimeter was developed for deployment at Hanford and was tested at PNNL and at Hanford prior to installation in FY-2001 in a pipeline at the Hanford site. 
Table 1.2 Density sensor configurations evaluated for deployment

\begin{tabular}{|l|c|c|c|c|c|c|l||}
\hline \multirow{2}{*}{ Site } & \multicolumn{2}{|c|}{ Pipe Diameter } & \multicolumn{2}{|c|}{ Design Pressure } & Installed & Operated & \multirow{2}{*}{ Planned Operation } \\
\cline { 2 - 7 } & $\mathbf{c m}$ & in. & MPa (g) & psig & & & \\
\hline ORNL & 5.1 & 2 & 0.5 & 67 & FY-1997 & FY-1997 & Test completed \\
\hline Hanford C-106 & 10.2 & 4 & 2.1 & 310 & No & No & Not scheduled \\
\hline $\begin{array}{l}\text { Hanford SY- } \\
101\end{array}$ & 5.1 & 2 & 2.8 & 400 & FY-2001 & No & FY-2002 \\
\hline \hline
\end{tabular}

\subsection{Densimeter Applications}

The in-line density sensor was developed initially for monitoring retrieval operations from radioactive waste storage tanks at the Hanford Site in eastern Washington (Greenwood and Lail 1998, Greenwood, Skorpik, and Bamberger 1998). The sensor can be used to measure density in a pipeline for process control in many process industries including the petrochemical industry, in the production of chemical reagents, in food processing, in the production of paper, and in the production of textiles. If an array of sensors is placed around the perimeter of a horizontal pipe, the sensor at the top can be used to detect presence of air bubbles or partially fully pipe flow; the sensor along the side can be used to detect the bulk density, and the sensor along the bottom of the pipe can be used to detect the onset of sedimentation or stratified flow. The sensor can also be placed in a vessel for the determination of the density of the contents, and several sensors at different elevations and radial locations in the vessel can be used to determine the homogeneity of the vessel contents. In addition to the density, the sensor measures the speed of sound in a liquid or slurry, which is of interest for materials characterization, and also measures the response to a shear wave, which can provide information about the viscosity of the fluid. 


\subsection{Conclusions and Recommendations}

This report describes development of a density sensor (densimeter) for in-line real-time process control and monitoring of slurries during radioactive waste retrieval and transport operations at US Department of Energy (DOE) sites. At these sites millions of gallons of radioactive liquid and sludge wastes must be retrieved from underground storage tanks and transported via underground pipelines for treatment or disposal. A major concern during the transfer operations is plugging of the transfer lines. Blocked transfer lines could significantly escalate the remediation costs both in terms of pipeline replacement costs and costs of maintenance of inactive facilities and operating personnel. The density sensor can be used for real-time process monitoring that could be used to detect conditions that could lead to degraded transport and line plugging. The three main factors that contribute to transfer line plugging are: 1) settling of solid particles during transfer, 2) crystallization of the waste, and 3) gelation of the waste. Depending on the mechanism, plugging or its onset may result in a change in the density or particle size distribution of the slurry. In addition, the onset of pipeline plugging may also lead to an increase in the pressure drop in the transfer lines. The densimeter presents numerous benefits over grab sampling of the waste followed by off-line analysis. Benefits include: early detection and prevention of pipeline plugging events, real-time process data of the density through the transfer process, reduction or elimination of grab sampling and off-line analysis, and reduced radiation exposure for workers.

\subsection{Conclusions}

The density sensor, shown in Figure 2.1, was developed based on the need to provide a small, robust instrument that could be retrofitted into existing pump pit manifolds and transfer lines. The probe uses ultrasonic signal reflection at the fluid-pipe wall interface to quantify density in situ in real time. The sensor is mounted in the wall of the pipe spool piece. This instrument was selected for monitoring radioactive waste transport based on several characteristic features: the sensing surface is non-intrusive and does not disrupt the slurry flow (the sensor is located flush with the pipeline wall); instrument performance is not affected by slight amounts of entrained air that could be present during waste retrieval and transfer; nor is it affected by electromagnetic noise from nearby pumps and other equipment; and the instrument is compact (the sensor is located on the perimeter of the pipe wall).

During probe development for deployment in a radioactive waste stream, components were tested for chemical and radiation resistance and the spool piece was pressure tested in accordance with ASME Process Piping Code B31.3. In addition, because the probe is installed in a transfer line associated with a tank filled with waste with the potential to generate flammable gas, the design was reviewed by the Hanford Site Flammable Gas Equipment Advisory Board to evaluate probe installation and use in an area requiring compliance with Ignition Source Control Set 2. The board ruled that the density sensor components are not formally approved for use in a Class I, Division 2, Group B atmosphere; however, the components are normally non-sparking and provide equivalent safety. 

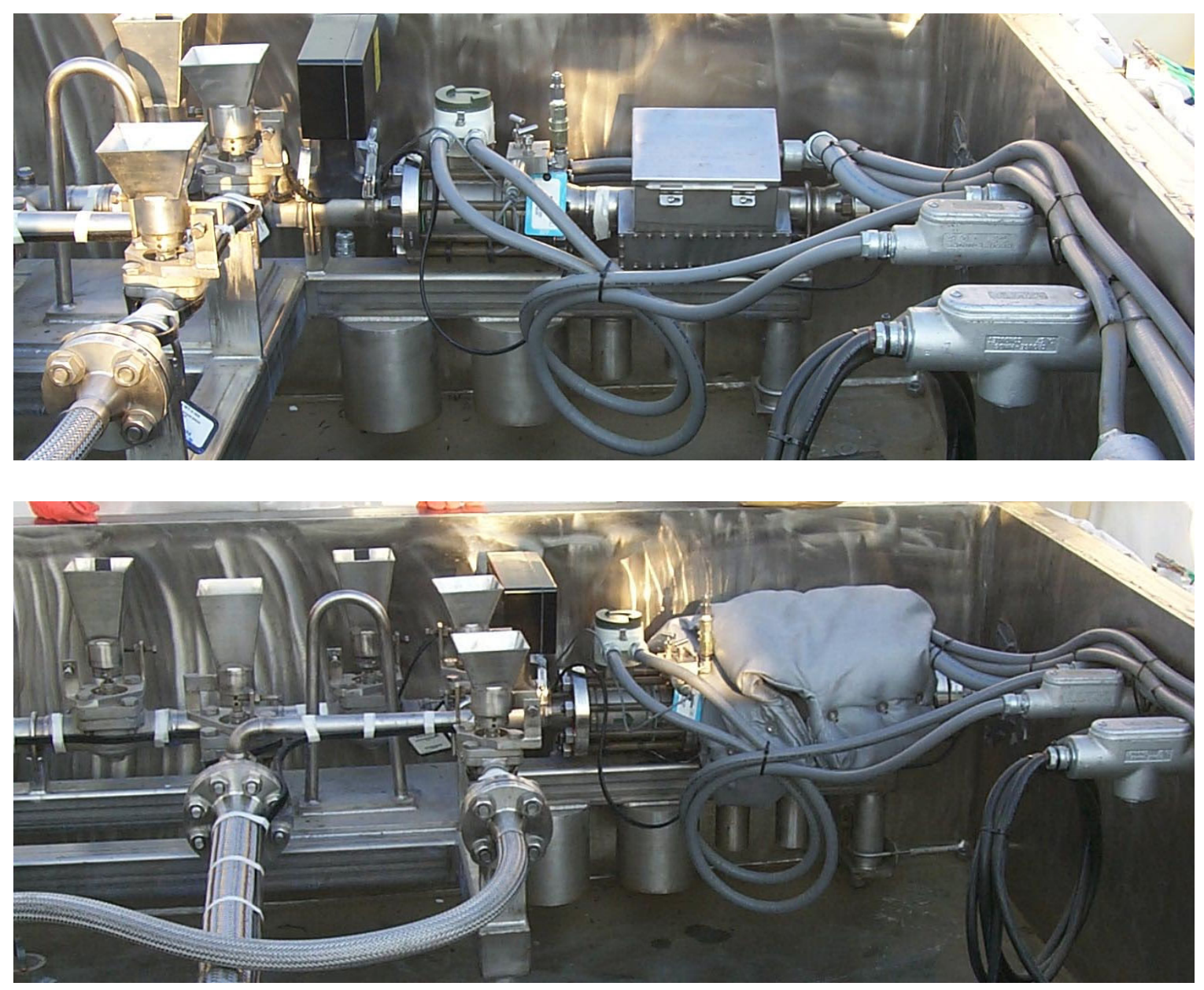

Figure 2.1 Density sensor installed at Hanford in the SY-101 site in the pump pit before and after installation of blanket insulation

\subsubsection{Deployment and Demonstration}

The density sensor has been deployed as a component in the modified process manifold that is installed in the prefabricated pump pit at Hanford tank SY-101 site. In FY-2001 after completion of densimeter installation and connection of cabling, the probe operation in air was verified. In FY-2002, the density sensor performance will be evaluated during transfers of both water and waste through the pipeline.

\subsubsection{Next Generation Through-Wall Density Sensor}

The density sensor design installed in FY-2001 at Tank SY-101 is based on the original densimeter concept proposed in FY-1996 and evaluated at ORNL in FY-1997. Upgrades to the SY-101 densimeter include the ability to operate over an increased pressure range (based on design of a new spool piece) and an enhanced calibration scheme that incorporates the effects of temperature into the methodology. Also, an approach has been demonstrated to develop an ultrasonic sensor that: 1) can be attached permanently to a pipeline wall, possibly as a spool piece inserted into the line, or 2) can clamp onto an existing pipeline wall and be movable to another location. An analysis method has been developed to make the 
measurement self-calibrating. This investigation has shown the path forward to develop clamp-on sensors for measurement of fluid and slurry density. This method is especially attractive for applications such as Hanford where radioactive fluids are routinely transported because the sensors could be applied to existing equipment without the need to penetrate the pipe pressure boundary or to open the system to install new equipment.

\subsection{Recommendations}

The goal of the density sensor development is to provide a useful real-time measurement of slurry density throughout all of operations of radioactive waste transport at US Department of Energy Sites. As a step in attaining this goal, the densimeter has been developed and installed at the SY-101 Site. The following anticipated activities would permit evaluation of densimeter performance in a radioactive waste environment and provide valuable information regarding future deployments.

- Evaluate the performance of the density sensor during transport of water (such as precedes or follows each transport)

- Evaluate the performance of the density sensor during transport of a range of radioactive waste slurries

- Evaluate the performance of the density sensor during transport of partially full lines

- Evaluate the long-term sensor performance to detect any trends that could be attributed to changes induced by contact with the waste chemicals or radioactivity.

To support rapid sensor deployment several aspects of additional development are recommended:

- Develop a density sensor that 1) can be attached permanently to a pipeline wall without penetrating the pipe pressure boundary, possibly as a spool piece inserted into the line or 2) can clamp onto an existing pipeline wall and be movable to another location.

- Ensure that the sensor is self calibrating. An analysis method has been developed to make the measurement self-calibrating which is a very important feature, because with a clamp-on sensor signal strength is sensitive to the pressure with which the transducer is coupled to the pipe.

- Develop the densimeter control system to permit wireless data transmission between the deployment site and the data acquisition site.

These additional features will make the densimeter much easier and less costly to deploy and reduce the radiation dose to workers by eliminating the need to penetrate piping that had transported radioactive waste, and by eliminating the need to install a significant amount of wiring in the potentially contaminated areas between the sensor and the data acquisition site. 


\subsection{Density Sensor Theory of Operation}

The density sensor theory of operation was developed based on an elegant yet simple single-wedge transducer configuration in contact with the fluid or slurry to be interrogated. This approach is described below.

\subsection{Density Sensor Theory}

The ultrasonic density sensor, shown schematically in Figure 3.1, consists of longitudinal (B, C, D, E, and F) and shear wave (A) transducers mounted upon a plastic wedge. Rexolite ${ }^{\mathrm{tm}(\mathrm{a})}$ was selected for the wedge based on its acoustic properties coupled with the ability to operate in a high pH solution and resist radiation damage. Analysis of the signals reflected from the wedge-fluid interface is used to determine the fluid properties of density $(\rho)$, speed of sound (c), and viscosity $(\mu)$. The transducers have a center frequency of $2.25 \mathrm{MHz}$. Transducers $\mathrm{F}$ and A operate in the pulse-echo mode; when ultrasound from transducer F strikes the wedge-liquid interface, part of it is reflected back toward F and the rest is transmitted into the fluid. Transducer pairs B-C and D-E operate in the pitch-catch mode; when ultrasound from transducer B (or D) strikes the interface, some of it is reflected toward transducer C (or E), some mode converts to a shear wave in the wedge, and part is transmitted into the liquid. The reflection coefficient, which describes the amount of ultrasound reflected to the receive transducer, is dependent upon the densities and sound speeds in the liquid and the wedge material. To measure the reflection coefficient compare the voltage on the receiver transducer with the wedge immersed in fluid to the voltage obtained with the wedge immersed in a reference liquid, usually water. The density is obtained by measuring the reflection coefficient at two angles of incidence and then solving for the density of the liquid and speed of sound in the liquid, based upon previously determined properties of the wedge material.

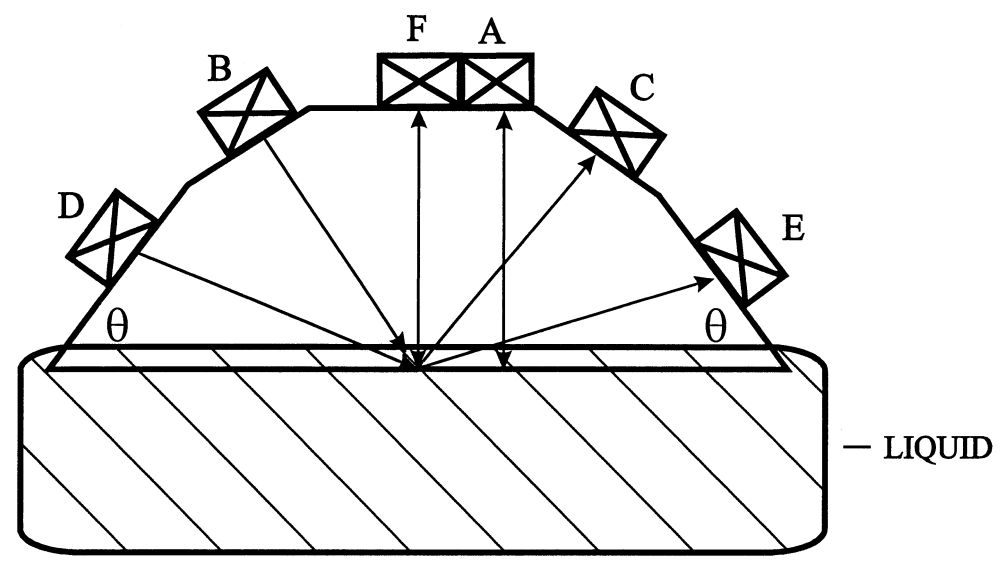

Figure 3.1 Schematic diagram of wedge design.

\footnotetext{
${ }^{\mathrm{a}}$ C-LEC Plastics, Inc. 215-708-7731
} 


\subsubsection{Measuring the Reflection Coefficient}

The measurement is accomplished by sending an ultrasonic toneburst signal to the send transducer and measuring the amplitude of the signal obtained by the receive transducer. In order to determine the reflection coefficient $\left(\mathrm{RC}_{\text {liq }}\right)$, the amplitude of the received signal with the base of the wedge immersed in fluid is compared with that with the base immersed in water $\left(\mathrm{RC}_{\text {water }}\right)$, or any other reference liquid or air. The voltage of the received signal is directly proportional to the pressure and to the reflection coefficient; therefore, the following relationship is obtained:

$$
\mathrm{RC}_{\text {liq }} / \mathrm{RC}_{\text {water }}=\mathrm{V}_{\text {liq }} / \mathrm{V}_{\text {water }}
$$

where $\mathrm{V}_{\text {liq }}$ and $\mathrm{V}_{\text {water }}$ refer to the voltage amplitude of the toneburst. This equation is rearranged as follows:

$$
\mathrm{RC}_{\text {liq }}=\mathrm{RC}_{\text {water }}\left(\mathrm{V}_{\text {liq }} / \mathrm{V}_{\text {water }}\right)
$$

The reflection coefficient for water $\left(\mathrm{RC}_{\text {water }}\right)$ can be determined theoretically because the speeds of sound and densities of the wedge material and water are known. Therefore, the reflection coefficient for the liquid can be obtained from voltage measurements and the calculated reflection coefficient for water, for a given angle of incidence.

\subsubsection{Reflection and Transmission Coefficients}

When ultrasound traveling in a solid strikes the liquid interface perpendicularly, the reflection coefficient is given by

$$
\mathrm{RC}=\left(\mathrm{Z}_{\text {liq }}-\mathrm{Z}_{\text {solid }}\right) /\left(\mathrm{Z}_{\text {liq }}+\mathrm{Z}_{\text {solid }}\right)
$$

where the acoustic impedance of the liquid $\left(Z_{\mathrm{liq}}\right)$ is the product of the density of the liquid $(\rho)$ and the speed of sound in the liquid (c), and the acoustic impedance of the solid $\left(Z_{\text {solid }}\right)$ is the product of the density of the solid $\left(\rho_{\mathrm{s}}\right)$ and the longitudinal speed of sound $\left(c_{\mathrm{L}}\right)$. When $Z_{\text {liq }}$ is less than $Z_{\text {solid, }}$, the reflection coefficient has a negative value. This means that the longitudinal wave undergoes a $180 \mathrm{deg}$ phase change upon reflection.

The reflection and transmission coefficients for the acoustic pressure are given by Krautkramer and Krautkramer (1983) using the notation shown in Figure 3.2. Since the relationship for the reflected longitudinal reflection coefficient is used so often, the notation is simplified as follows:

$$
\begin{aligned}
& \mathrm{G}=\left(\mathrm{c}_{\mathrm{T}} / \mathrm{c}_{\mathrm{L}}\right)^{2} \sin 2 \alpha_{\mathrm{L}} \sin 2 \alpha_{\mathrm{T}} \\
& \mathrm{H}=\cos ^{2} 2 \alpha_{\mathrm{T}} \\
& \mathrm{J}=\rho \mathrm{c} \cos \alpha_{\mathrm{L}} / \rho_{\mathrm{s}} \mathrm{c}_{\mathrm{L}} \cos \alpha
\end{aligned}
$$




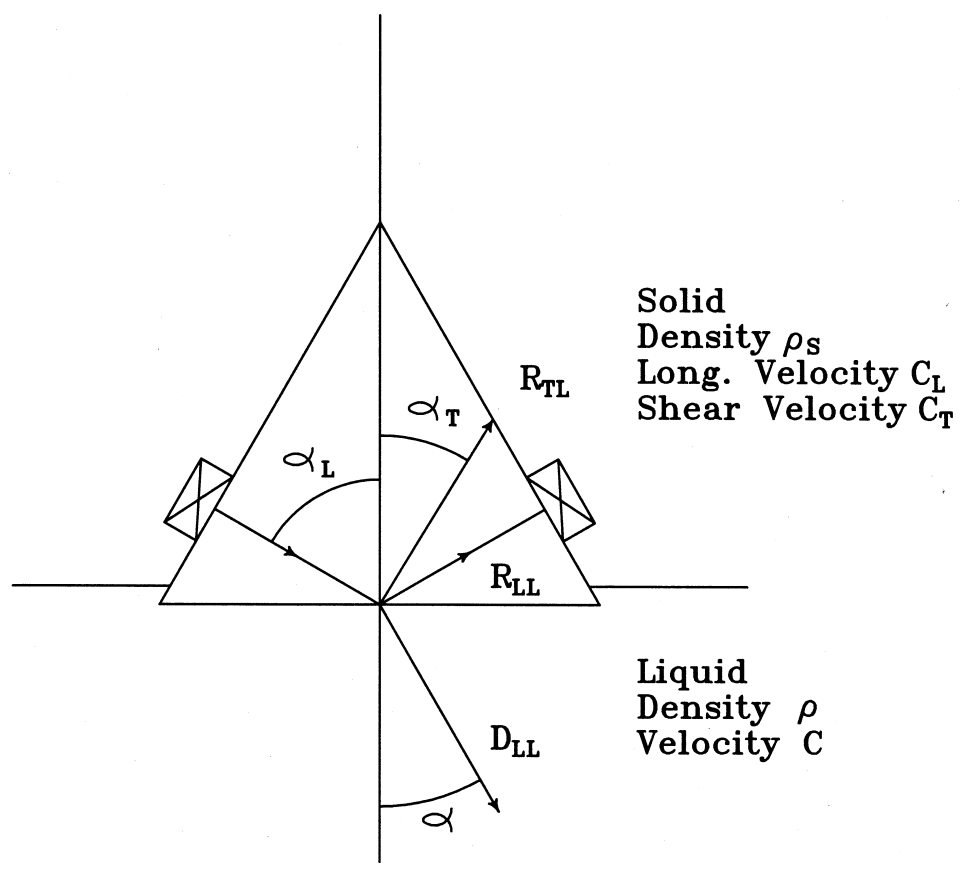

Figure 3.2 Definition of terminology used in equations of reflection and transmission coefficients.

The reflection coefficient for the reflected longitudinal wave $\left(\mathrm{R}_{\mathrm{LL}}\right)$ is given by

$$
\mathrm{R}_{\mathrm{LL}}=(1 / \mathrm{N})(\mathrm{G}-\mathrm{H}+\mathrm{J})
$$

where

$$
\mathrm{N}=\mathrm{G}+\mathrm{H}+\mathrm{J}
$$

The terms $\mathrm{G}$ and $\mathrm{H}$ involve only quantities concerning the solid, while $\mathrm{J}$ contains those of the liquid and solid. This division makes the reverse problem--using reflection coefficients to determine the density of the liquid and its speed of sound--quite simple. When $\alpha_{\mathrm{L}}$ is equal to zero, then $\alpha$ and $\alpha_{\mathrm{T}}$ are also zero and Equation 3.7 and Equation 3.8 reduce to Equation 3.3. The reflection coefficients for the reflected shear wave $\left(\mathrm{R}_{\mathrm{TL}}\right)$ and the transmitted longitudinal wave, $\left(\mathrm{D}_{\mathrm{LL})}\right.$ are given as follows:

$$
\begin{aligned}
& \mathrm{R}_{\mathrm{TL}}=(2 / \mathrm{N})\left(\mathrm{c}_{\mathrm{T}} / \mathrm{c}_{\mathrm{L}}\right)^{2} \sin 2 \alpha_{\mathrm{L}} \cos 2 \alpha_{\mathrm{T}} \\
& \mathrm{D}_{\mathrm{LL}}=(2 / \mathrm{N})\left(\rho \mathrm{c} \cos \alpha_{\mathrm{L}} \cos 2 \alpha_{\mathrm{T}}\right) /\left(\rho_{\mathrm{s}} \mathrm{c}_{\mathrm{L}} \cos \alpha\right)
\end{aligned}
$$

\subsubsection{Determining the Density of a Liquid Using 0 and 60 Degree Angles of Incidence}

In order to determine the density of a liquid and the speed of sound in a liquid, the reflection coefficient at two angles must be determined experimentally. This approach is first described for the condition when one angle of incidence must be $0 \mathrm{deg}$. The non-zero angle was chosen to be $60 \mathrm{deg}$. 
Denote $\mathrm{RC}_{\mathrm{Z}}$ as the experimental value for the perpendicular reflection coefficient and $\mathrm{R}_{\mathrm{LLX}}$, as that at a non-zero angle. The density and velocities for the wedge are known. Solving Equation 3.7 for J yields

$$
J=-G+H\left(1+R_{L L}\right) /\left(1-R_{L L}\right)
$$

Since all terms on the right are known, J can be determined. Solving Equation 3.3 for the acoustic impedance of the liquid $Z_{\text {liq }}$ we find

$$
\mathrm{Z}_{\mathrm{liq}}=\mathrm{Z}_{\text {solid }}\left(1+\mathrm{RC}_{\mathrm{Z}}\right) /\left(1-\mathrm{RC}_{\mathrm{Z}}\right)
$$

When $Z_{\text {liq }}$ is substituted into the definition of $\mathrm{J}$ in Equation 3.6, the only unknown in the resulting equation is $\cos \alpha$, which is given by

$$
\cos \alpha=Z_{\text {liq }} \cos \alpha_{\mathrm{L}} / \mathrm{J} \rho_{\mathrm{s}} \mathrm{c}_{\mathrm{L}}
$$

The angle $\alpha$ can be determined because all terms on the right side are known. The speed of sound (c) in the liquid can be found from Snell's law at the interface now that angle $\alpha$ is known.

$$
\mathrm{c}=\mathrm{c}_{\mathrm{L}}\left(\sin \alpha / \sin \alpha_{\mathrm{L}}\right)
$$

The density of the liquid can be obtained because the acoustic impedance $\left(Z_{\text {liq }}\right)$ and the speed of sound (c) are known.

$$
\rho=Z_{\text {liq }} / c
$$

Equation 3.13 is an important step in the inverse problem. The question is, how much does $\cos \alpha$ change when the density of the liquid changes slightly? If $\mathrm{c}$ is less than $\mathrm{c}_{\mathrm{L}}$, then from Equation 3.14 angle $\alpha$ will be less than angle $\alpha_{\mathrm{L}}$. The cosine of an angle changes most rapidly at a larger angle. Therefore, the sensitivity of Equation 3.13 increases as angle $\alpha$, and likewise $\alpha_{L}$, increases. This is one reason why angle $\alpha$ was chosen to be $60 \mathrm{deg}$. In Figure 3.1, the central ray from transducer D makes an angle of $60 \mathrm{deg}$ with the normal to the surface.

In Figure 3.3 the reflection coefficient for ultrasound striking a Rexolite ${ }^{\mathrm{tm}}$-water interface is plotted versus the incident angle. At both $0 \mathrm{deg}$ and $60 \mathrm{deg}$ the slope of the curve is zero. Therefore, the reflection coefficient for rays deviating only slightly from these angles does not change. This characteristic makes it very advantageous to use these two angles for the determination of the density. Another important feature is that the reflection coefficient for water at $38 \mathrm{deg}$ is zero. This means that a small change in the density of the liquid will give a large percentage change in the reflection coefficient for incident angles near this cross-over point. This feature can be used to detect small changes in the density of a liquid. 


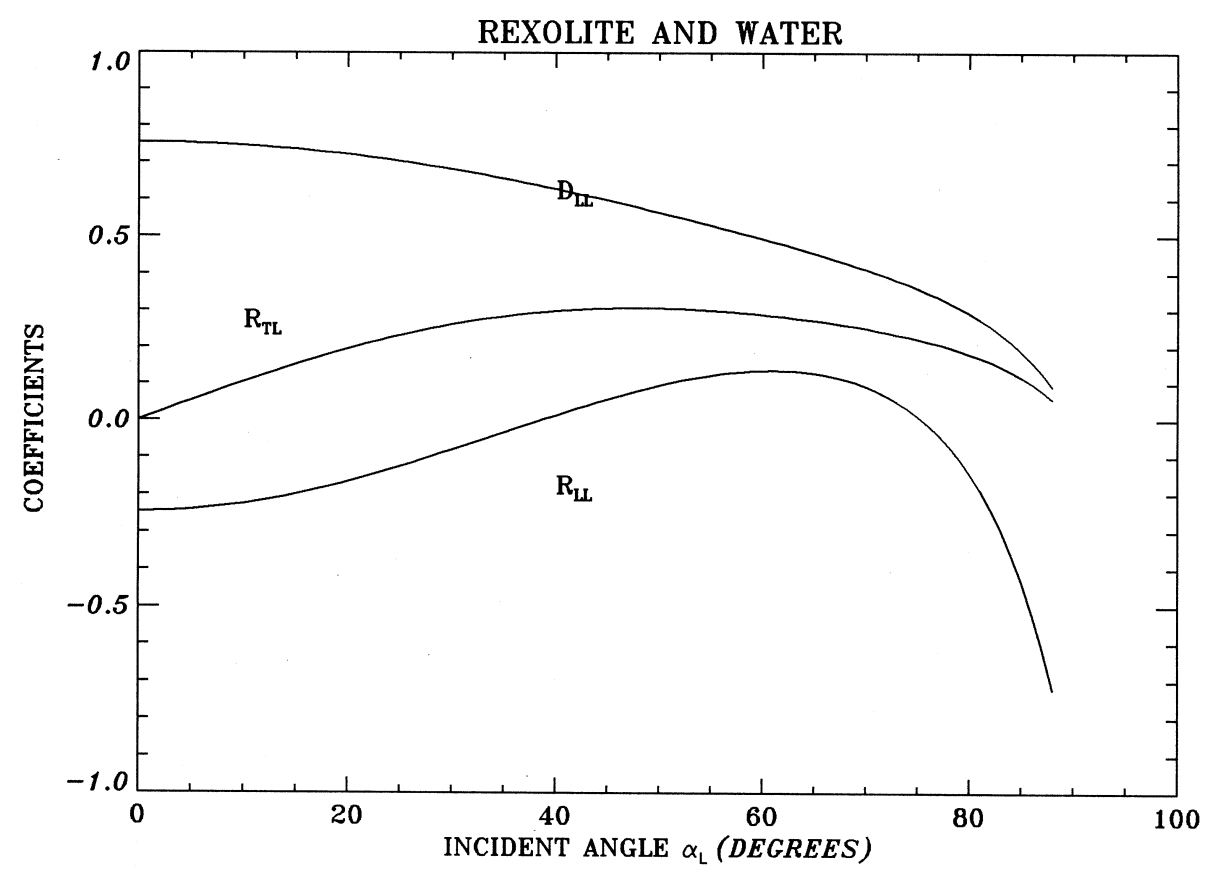

Figure 3.3 Graph showing the reflection and transmission coefficient for a Rexolite ${ }^{\mathrm{tm}}$ wedge in contact with water.

\subsection{Enhancements Applied to Signal Analysis}

The calibration of the sensor is essential to ensure its high performance. To enhance sensor performance over an elevated temperature range the calibration data was analyzed to develop a model that is a function of sensor voltage and temperature. To do this we incorporated an expression of the reflection coefficient as a polynomial expansion in terms of voltage and temperature. This procedure was implemented for the data taken with the densimeter installed in the modified process manifold which was tested in the 305 Bldg. A regression analysis, with a least squares fitting procedure, was carried out for several thousand data points. The model chosen is as follows:

$$
\begin{aligned}
\mathrm{RC}_{\text {liqx }}= & \mathrm{b} 0_{\mathrm{x}}+\mathrm{b} 1_{\mathrm{x}} \mathrm{T}+\mathrm{b} 2_{\mathrm{x}} \mathrm{T}^{2}+\mathrm{b} 3_{\mathrm{x}} * \mathrm{~V}_{\mathrm{x}}+\mathrm{b} 4_{\mathrm{x}} * \mathrm{~V}_{\mathrm{x}}^{2}+\mathrm{b} 5_{\mathrm{x}} \mathrm{TV} \mathrm{V}_{\mathrm{x}}+\mathrm{b} 6_{\mathrm{x}} \mathrm{TV}_{\mathrm{x}}^{2} \\
& +\mathrm{b} 7_{\mathrm{x}} \mathrm{T}^{2} \mathrm{~V}_{\mathrm{x}}+\mathrm{b} 8_{\mathrm{x}} \mathrm{T}^{2} \mathrm{~V}_{\mathrm{x}}{ }^{2}
\end{aligned}
$$

This represents three equations, where $\mathrm{x}$ is a shorthand for any one of the three transducer pairs: BC, DE, or FF. $\mathrm{V}_{\mathrm{x}}$ (at $0 \mathrm{~dB}$ amplifier gain) and $\mathrm{T}$ have been measured, but in order to determine the constants in the polynomial expansion, values of $\mathrm{RC}_{\text {liqx }}$ are needed. This method for determining the constants provided a robust method for predicting the reflection coefficients and density. The application is described in Section 5. 


\subsection{Density Sensor Spool Piece and Hardware Configurations}

Three density sensor spool piece designs have been developed for Oak Ridge pipe loop tests, for C106 transfer monitoring, and for SY-101 transfer monitoring. From these designs, two densimeter spool pieces have been constructed, calibrated, and tested for deployment. The first densimeter model, described in Section 4.1, was evaluated at PNNL and during tests in a pipeline at Oak Ridge National Laboratory (ORNL). The second densimeter spool piece, described in Section 4.3, was developed for deployment at Hanford and was tested at PNNL and at Hanford prior to installation in a pipeline at the Hanford site.

\subsection{Density Sensor Designed for Tests at ORNL}

The transducer wedge in the densimeter spool piece evaluated during tests at ORNL is based on the transducer wedge design shown in Figure 3.1. Figure 4.1 shows the 5.1-cm-diameter, 30.5-cm-long, Schedule 40 stainless steel spool piece design. Figure 4.2 shows photographs of two early models of the density sensor, an immersion probe and the pipeline spool piece evaluated during tests at ORNL. Figure 4.2a shows the tank sensor (Model I), and Figure 4.2b shows a close-up of its probe, which has dimensions of $9.6 \mathrm{~cm} \times 3.5 \mathrm{~cm} \times 5.6 \mathrm{~cm}$. The Rexolite ${ }^{(\mathrm{tm})}$ wedge is placed within the stainless steel case and the angles of incidence are $0 \mathrm{deg}, 40 \mathrm{deg}$, and $60 \mathrm{deg}$. Thermocouples are placed in the wedge very near the base of the wedge and at the top of the wedge in order to determine temperature uniformity of the wedge. A thermocouple in contact with the fluid also measures its temperature. The transducer and thermocouple connections pass through the tube of Model I to the top connector box, where connections to the computer are made. Figure 4.2c shows the pipeline model of the probe (Model II), in which the base of the wedge is aligned with a cutout section in the wall of the pipe to produce a non-invasive pipeline sensor. The wedge design is very similar to that in Model I, except that the angles of incidence are $0 \mathrm{deg}, 42 \mathrm{deg}$, and $60 \mathrm{deg}$. Three thermocouples also measure the temperature at two locations in the wedge and the temperature of the liquid. In both models, the transducers operate at a frequency of 2.25 $\mathrm{MHz}$.
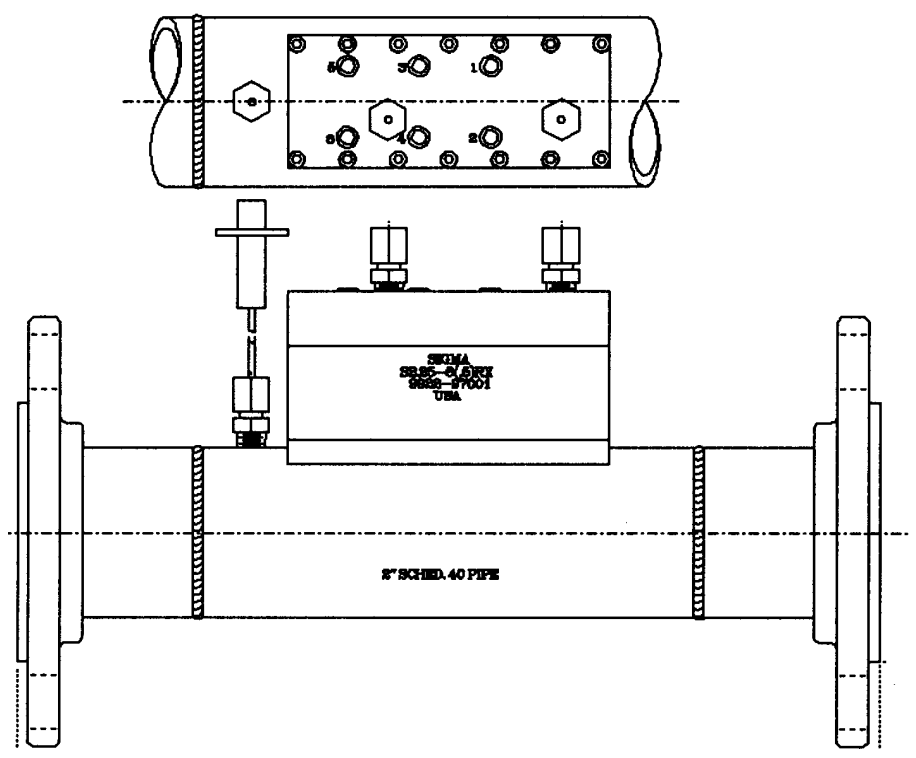

Figure 4.1 ORNL densimeter spool piece 


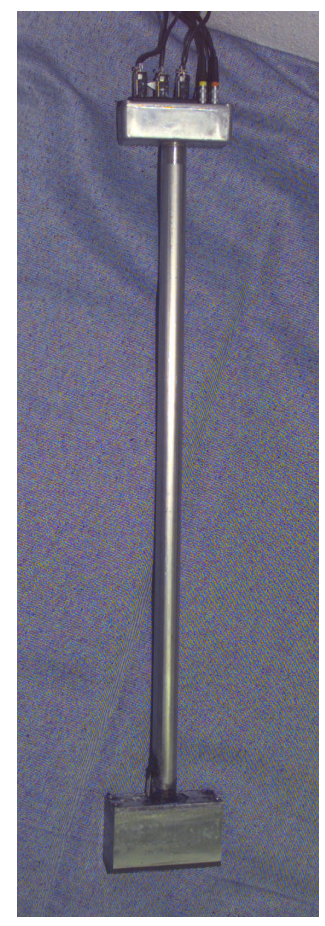

a)

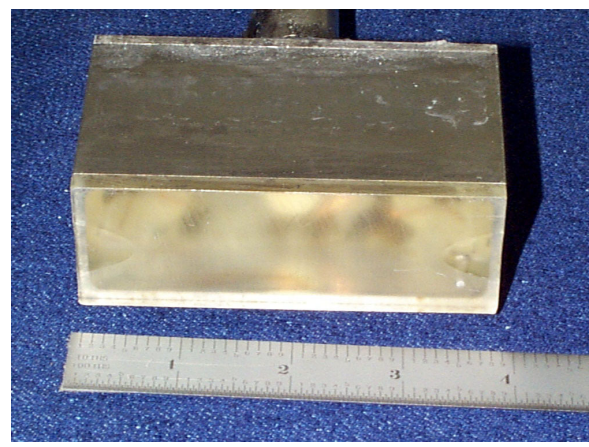

b)

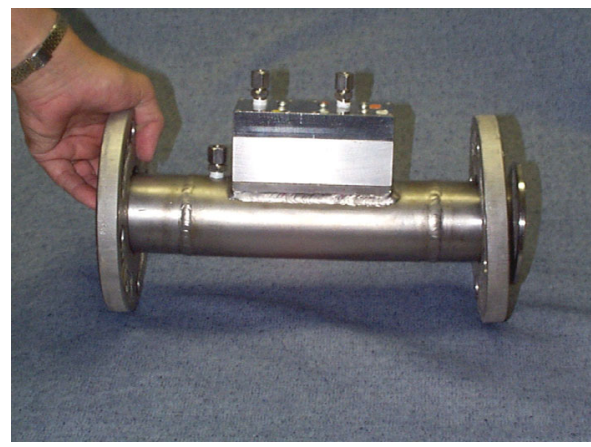

c)

Figure 4.2 Photographs of the Model I tank sensor in a) with a close-up of the base in b) and the Model II pipeline sensor in c).

\subsection{Initial Hanford Density Sensor Deployment Configuration for C-106 Pump Pit}

To support the Hanford Tanks Initiative, the densimeter was selected for installation in the pump pit at the beginning of the transfer line between Tank C-106 and Tank AY-102, shown in Figure 4.3. The densimeter was to be used to measure the density of the slurry transferred between the two tanks.

Process parameters defining this transfer are listed in Table 4.1. A design for a sensor spool piece was developed to meet these operating conditions. The spool piece, shown schematically in Figure 4.4, was designed to be constructed from 4-in. Schedule 40, ASTM 312, Grade 304L stainless pipe using 4-in. Class $300 \mathrm{lb}$ ASTM A182 F304L weld-neck flanges with raised face. The overall length (flange-face to flange-face) was $42.2 \mathrm{~cm}$ (16-5/8 in.). After the spool-piece design was complete but prior to probe construction, the project direction changed to support densimeter deployment in the Tank SY-1015 cm (2-in.) transfer line, instead of the Tank 106-C $10 \mathrm{~cm}$ (4-in.) transfer line. 


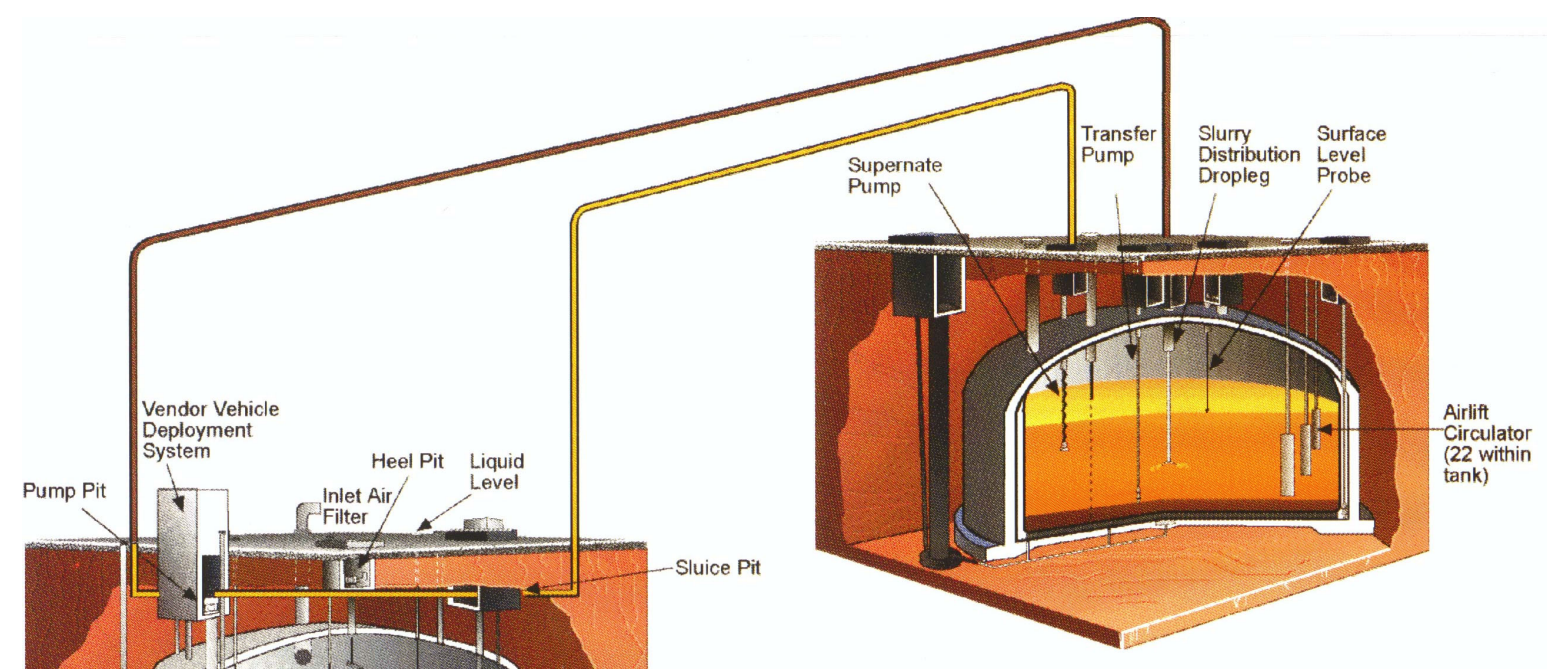

Tk 241-AY-102

Figure 4.3 Proposed transfer configuration from Tank C-106 to Tank AY-102.

Table 4.1 Slurry transport parameters for transfer from Tank C-106 to AY-102.

\begin{tabular}{|c|c|c|c|}
\hline Parameter & \multicolumn{2}{|c|}{ Parameter Range } & Nominal \\
\hline Flow rate & $1136-1818 \mathrm{~L} / \mathrm{min}$ & $250-400 \mathrm{gpm}$ & $1591 \mathrm{~L} / \mathrm{min}(350 \mathrm{gpm})$ \\
\hline Temperature & $4.4-48.9 \mathrm{C}$ & $40-120 \mathrm{~F}$ & $23.9 \mathrm{C}(75 \mathrm{~F})$ \\
\hline Operating Pressure & $0.956-2.14 \mathrm{MPa}$ gauge & $140-310$ psig & $1.14 \mathrm{MPa}$ gauge (165 psig) \\
\hline Viscosity & $4-100 \mathrm{cP}$ & & $15 \mathrm{cP}$ \\
\hline Specific gravity & $1-1.2$ & & 1.15 \\
\hline Percent solids & $0-30 \mathrm{wt} \%$ & & $10 \mathrm{wt} \%$ \\
\hline Particle size & $<<1-3175 \mu \mathrm{m}^{\mathrm{a}}$ & & $\begin{array}{l}50 \mu \mathrm{m} \text { sludge } \\
500 \mu \mathrm{m} \text { hardpan }\end{array}$ \\
\hline Radiation & \multicolumn{2}{|c|}{$\begin{array}{l}60 \mathrm{R} / \mathrm{hr} \text { inside pipe } \\
40 \mathrm{R} / \mathrm{hr} \text { outside pipe } \\
0.5 \mathrm{R} / \mathrm{hr} 3.04 \mathrm{~m}(10 \mathrm{ft}) \text { away from pipe } \\
\end{array}$} & $100 \mathrm{R} / \mathrm{hr}$ in pipeline \\
\hline
\end{tabular}

a The maximum particle size that can pass through the system is $0.64 \mathrm{~cm}(1 / 4 \mathrm{in}$.)

b Calculated using the ISOSHLD code (Engel et al. 1966) 


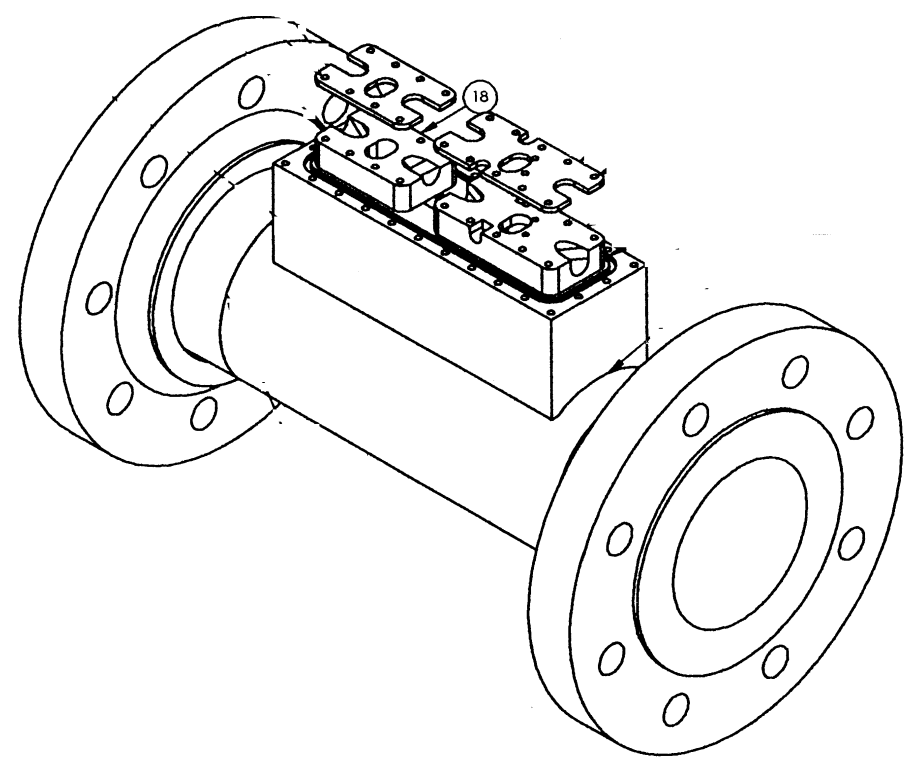

Figure 4.4 Densimeter configuration for deployment in the 10-cm (4-in.) transfer line from Tank C-106 to Tank AY-102.

\subsection{Density Sensor for SY-101 Transfer Line}

Specifications for density sensor deployment in the SY-101 transfer line were developed in conjunction with the SY-101 team. The specifications were based on information provided in the report HNF-3885 Functional Requirements and Technical Criteria for the 241-SY-101 RAPID Mitigation System (Erhart 1999). These criteria are listed in Table 4.2. In addition, because the probe would be installed in a transfer line associated with a tank filled with waste with the potential to generate flammable gas, the design was reviewed by the Hanford Site Flammable Gas Equipment Advisory Board to evaluate probe installation and use in an area requiring compliance with Ignition Source Control Set 2. The board ruled ${ }^{\mathrm{a}}$ that the densimeter components are not formally approved for use in a Class I, Division 2, Group B atmosphere; however, the components are normally non-sparking and provide equivalent safety.

\subsubsection{Pressure Containment Design}

To meet the design pressure requirement of $2.76 \mathrm{MPa}(\mathrm{g})(400 \mathrm{psig})$ and the pressure test requirement of 4.14 MPa (g) (600 psig), the probe (shown in Figure 4.5) was designed using Schedule 80 stainless steel pipe and 300-lb-class flanges. To achieve a pressure boundary between the transducer wedge and the steel housing, two O-ring seals were incorporated into the probe design. These transducer wedges differ from the design shown in Figure 3.1. To accommodate the O-ring seals and still maintain a small profile wedge, the transducers were located on two separate wedges installed in series, as shown in Figure 4.6. Prints for the densimeter design are provided in the Appendix. After the transducers, O-rings, and cover

${ }^{a}$ Flammable Gas Equipment Advisory Board Interpretation/Recommendation Report, FGEAB-99-003, Rev. 0, April 20, 1999. 
plates (shown on Figure 4.6) were installed, the probe assembly was pressure tested. The pressure test was conducted in accordance with ASME Process Piping Code Section B31.3.

Table 4.2 Density sensor design and operational criteria

\begin{tabular}{|c|c|c|}
\hline Parameter & "SY-101 Design Criteria & Density Probe \\
\hline Specific gravity & 1.0 to 1.7 & Tested over range from 980 to $1800 \mathrm{~kg} / \mathrm{m}^{3}$ \\
\hline $\begin{array}{l}\text { Waste maximum } \\
\text { temperature }\end{array}$ & $54 \mathrm{C}(130 \mathrm{~F})$ & $\begin{array}{l}\text { Components good to } 100 \mathrm{C}(212 \mathrm{~F}), \\
\text { calibrated over range from } 20 \mathrm{C} \text { to } 60 \mathrm{C}(68 \\
\mathrm{F} \text { to } 140 \mathrm{~F})\end{array}$ \\
\hline Diluted waste temperature & $43 \mathrm{C}$ to $54 \mathrm{C}(110$ to $130 \mathrm{~F})$ & Probe operates over this range \\
\hline Working pressure & $2.59 \mathrm{MPa}(\mathrm{g})(230 \mathrm{psig})$ & Designed to operate at this pressure \\
\hline Design pressure & & $2.76 \mathrm{MPa}(\mathrm{g})(400 \mathrm{psig})$ \\
\hline Remote readout & In DACS trailer & Provide display for density $\left(\mathrm{kg} / \mathrm{m}^{3}\right)$ \\
\hline ASTM 312 304L & For piping & $\begin{array}{l}\text { For piping } \\
\text { ASTM A240 304L for pipe saddle }\end{array}$ \\
\hline ASME B31.3 Pressure test & At $1.5 \times$ design pressure & $4.14 \mathrm{MPa}(\mathrm{g})(1.5 \times 400 \mathrm{psig}=600 \mathrm{psig})$ \\
\hline $\begin{array}{l}\text { Spool piece length flange- } \\
\text { face to flange-face }\end{array}$ & $\begin{array}{l}\text { Specified by Tony } \\
\text { Benegas }^{\text {a }}\end{array}$ & $48.3 \mathrm{~cm}$ (19 in.) \\
\hline $\mathrm{pH}$ & No range specified & $\begin{array}{l}\text { Rexolite }{ }^{\mathrm{tm}} \text { good to } \mathrm{pH} 14 \text {; confirmed by lab } \\
\text { tests. }\end{array}$ \\
\hline Radiation level & No range specified & $\begin{array}{l}100 \mathrm{rad} / \mathrm{hr} \text { in pipeline; tested to } 1 \times 10^{6} \mathrm{R} \text { total } \\
\text { exposure; Rexolite }{ }^{\text {tm }} \text { good to } 1 \times 10{ }^{10} \mathrm{rad}\end{array}$ \\
\hline
\end{tabular}

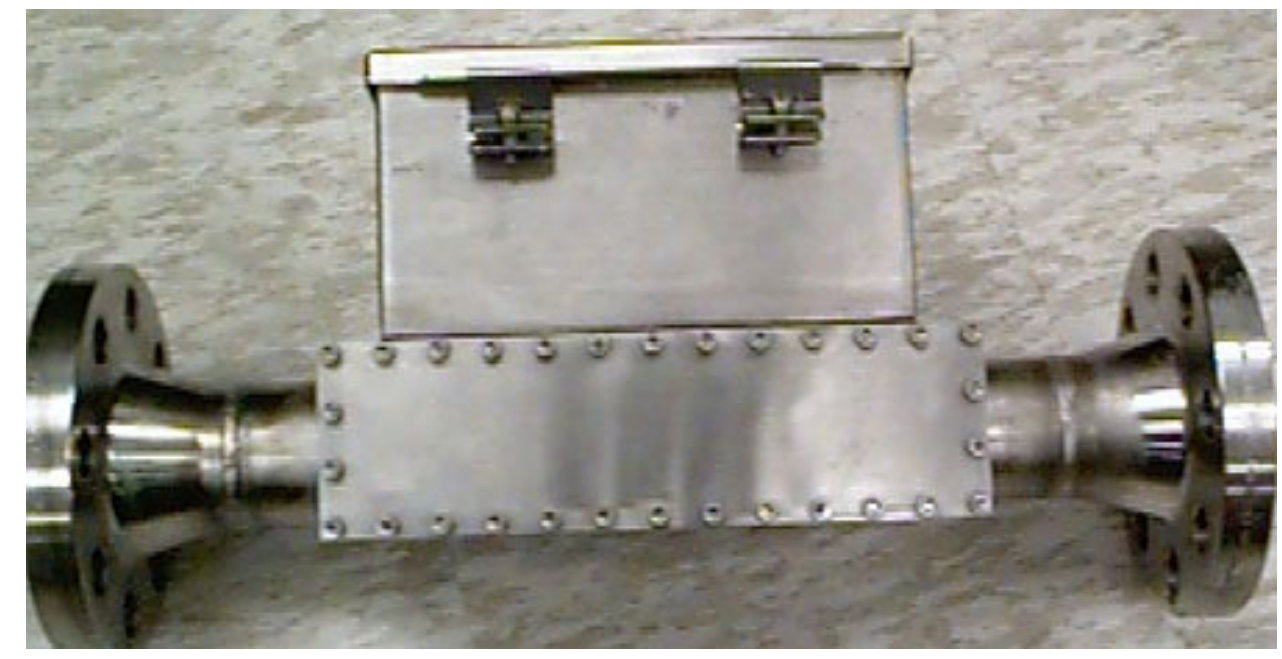

Figure 4.5 Density sensor spool piece

\footnotetext{
${ }^{a}$ Email Communication. From: Benegas, Tony R, Sent: Friday, May 21, 1999 5:33 PM. To: Powell, William J (Bill); Bamberger, Judith A, Cc: Holmes, Carl W; Buchanan, Joseph R; Merriman, Raymond E; Wilk, Jerome L (Jerry); Erhart, Michael F; Hanson, Carl E; Benegas, Tony R. Subject:RE: Densimeter orientation in pipeline.
} 


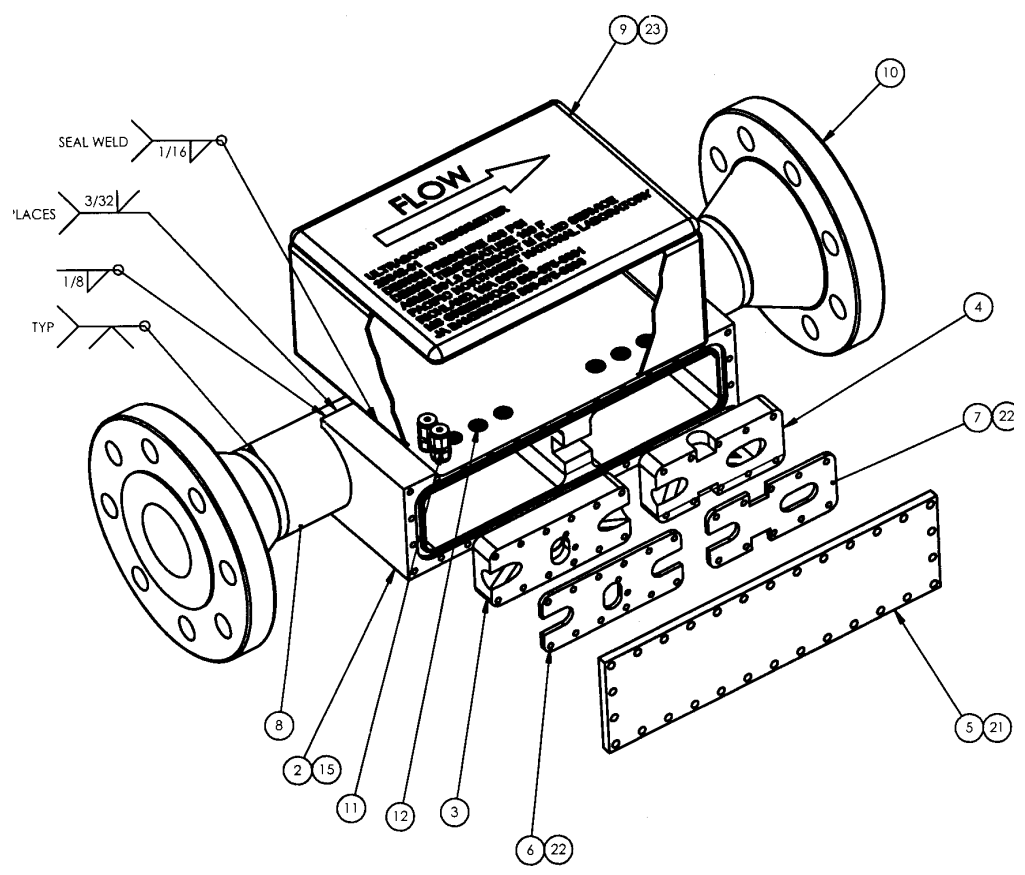

Figure 4.6 Density sensor components showing spool piece $(8,10)$ wedges $(3-60$ degree, 4 47 degree), and electrical connection box $(9,23)$.

\subsubsection{SY-101 Density Sensor Transducer Configuration}

Angles of 0, 47, and 60 degrees were selected for transducer orientation. The 60 degree wedge houses longitudinal wave transducer F (operating in pulse-echo mode) and transducer pair D-E (operating in pitch-catch mode). The 47-degree wedge houses shear wave transducer A and longitudinal wave transducer G (operating in pulse-echo mode) and transducer pair B-C (operating in pitch-catch mode). The transducer locations are shown in Figure 4.7. In this design an additional transducer $\mathrm{G}$ was incorporated into the system. This transducer, whose location is visible on the side of the 47 degree wedge shown in Figure 4.6, is oriented to measure the reflected signal at an air-wedge interface and provides a real-time reference not affected by the fluid. In this probe the wedge-liquid interface is in the near field of the transducers in order to make the wedge small and still use $1.27 \mathrm{~cm}$ diameter PZT7A transducers. This is a change from the original model evaluated at ORNL, in which the wedge-liquid interface was in the far field. Dimensions for the transducers and distance to the base of the wedge are listed in Table 4.3. Two thermocouples were installed in the wedges, one near the base of the wedge and another near the top of the wedge to monitor the temperature and gradients throughout the wedge.

The wedges, shown in Figure 4.8 with the transducers mounted, are installed in the spool piece in Figure 4.9. The longitudinal wave transducers are tuned with a 12.0 microhenry inductor and the shear wave transducer is tuned with a 0.33 microhenry inductor. In the direction of flow, the wedges are machined flush to match the diameter of the pipe and tapered toward the area where the ultrasonic beam is reflected, which is flat. To incorporate transducer A (the shear wave transducer) at the downstream end of the 47 degree wedge, this interface was not machined, thus providing a flat surface for beam reflection, shown in Figure 4.10. 


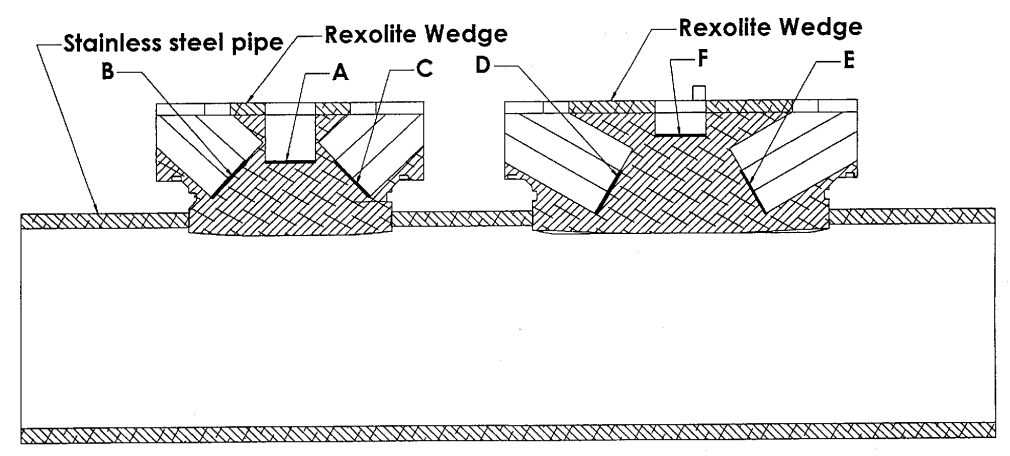

Figure 4.7 View showing transducers and wedges positioned on spool piece

Table 4.3 Transducer dimensions for Probes 1 and 2

\begin{tabular}{|c|c|c|c|c|c|c|c|c||}
\hline \multirow{3}{*}{ Location } & \multicolumn{4}{|c|}{ Probe 1 } & \multicolumn{4}{c||}{ Probe 2 } \\
\cline { 2 - 9 } & $\mathbf{\text { Distance }}$ & \multicolumn{2}{c|}{ Diameter } & \multicolumn{2}{c||}{ Distance } & \multicolumn{2}{c||}{ Diameter } \\
\cline { 2 - 9 } & $\mathbf{c m}$ & in. & $\mathbf{c m}$ & in. & $\mathbf{c m}$ & in. & cm & in. \\
\hline $\mathrm{A}$ & 0.48 & 0.19 & 1.27 & 0.50 & 0.64 & 0.25 & 1.27 & 0.50 \\
\hline $\mathrm{B}$ & 1.81 & 0.71 & 1.27 & 0.50 & 2.16 & 0.85 & 1.27 & 0.50 \\
\hline $\mathrm{C}$ & 1.67 & 0.66 & 1.27 & 0.50 & 2.16 & 0.85 & 1.27 & 0.50 \\
\hline $\mathrm{D}$ & 2.03 & 0.80 & 1.27 & 0.50 & 2.16 & 0.85 & 1.27 & 0.50 \\
\hline $\mathrm{E}$ & 2.03 & 0.80 & 1.27 & 0.50 & 2.16 & 0.85 & 1.27 & 0.50 \\
\hline $\mathrm{F}$ & 2.74 & 1.08 & 1.07 & 0.42 & 2.74 & 1.08 & 1.07 & 0.42 \\
\hline $\mathrm{G}$ & 2.54 & 1.00 & 1.27 & 0.50 & 2.54 & 1.00 & 1.27 & 0.50 \\
\hline
\end{tabular}

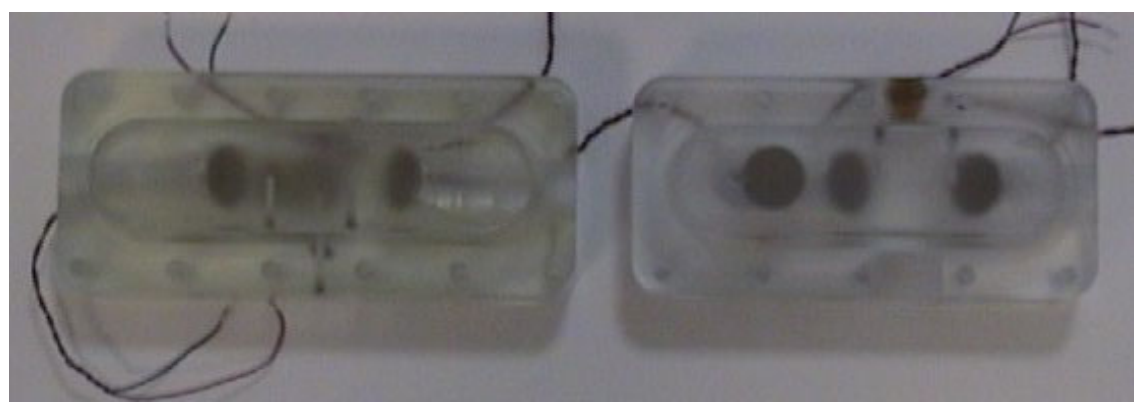

Figure 4.8 Transducer wedges with transducers and connectors installed 


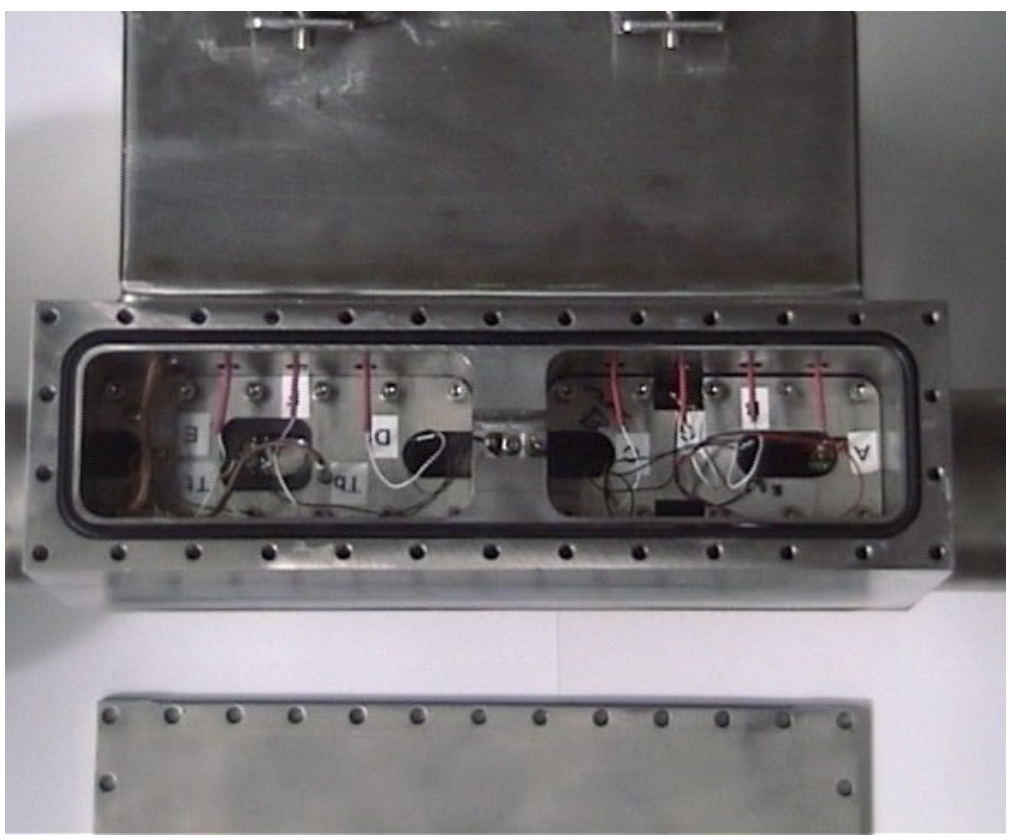

Figure 4.9 View inside transducer housing after pressure test showing labels, connectors and O-ring seal

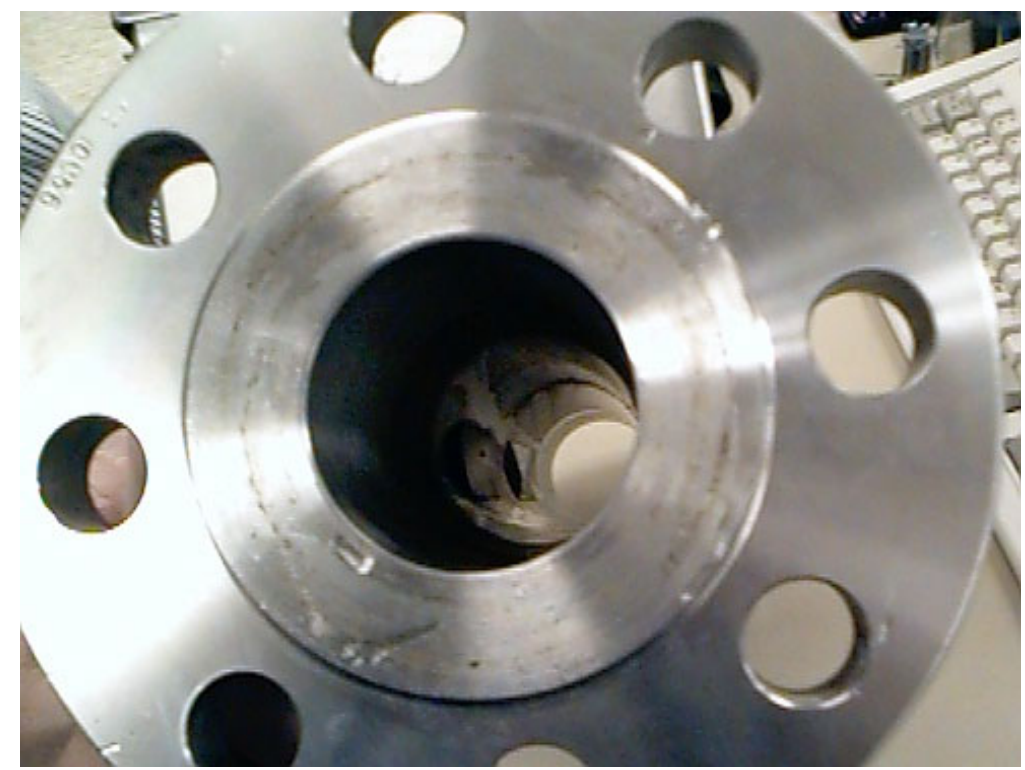

Figure 4.10 View inside the spool piece showing the transducer wedge and pipe-wall interface

\subsubsection{Component Testing}

The densimeter will be installed in a pipeline that will intermittently transport radioactive waste slurries. Therefore, materials for the probe, specifically the Rexolite ${ }^{\mathrm{TM}}$ wedge and O-ring seals, were selected based on their resistance to radiation and resistance to high $\mathrm{pH}$. In addition samples of Rexolite ${ }^{\mathrm{tm}}$ and the O-rings were tested in a gamma radiation field and in a chemical waste simulant. The probe wedge in contact with the slurry was selected to operate up to $\mathrm{pH} 14$. To evaluate the ability of the 
Rexolite $^{\text {tm }}$ block to withstand high $\mathrm{pH}$, it was exposed to $\mathrm{pH} 13$ and $\mathrm{pH} 14$ continuously for 2 weeks. Measurements made after exposure was complete showed no visible changes to the Rexolite ${ }^{\mathrm{tm}}$, no change in size of block and no change in speed of sound. The $\mathrm{pH}$ specified for probe operation will range from $\mathrm{pH} 12$ to 13 . No degradation or changes were observed in the O-rings.

To evaluate resistance to radiation, the probe wedge, transducers, O-rings, and epoxies were exposed to radiation in a gamma pit. The Rexolite ${ }^{\mathrm{tm}}$ exposures were for one to eight hours at an exposure rate of $1.25 \times 10^{5} \mathrm{R} / \mathrm{hr}$ for a total exposure of $5 \times 10^{5} \mathrm{R}$. This is equivalent to a pipeline exposure of $100 \mathrm{R} / \mathrm{hr}$ for 2 to 14 months. The blocks, shown in Figure 4.11, exhibited some color change with increasing exposure but no significant degradation was observed. The O-ring exposures were up to $300 \times 10^{5} \mathrm{R}$.

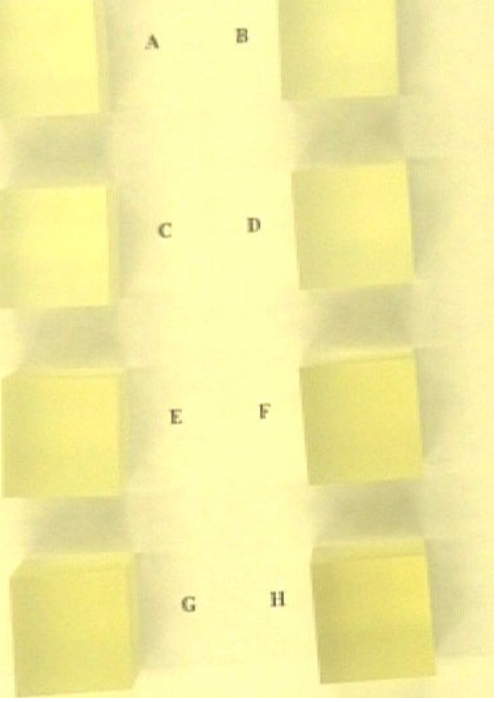

Figure 4.11 Rexolite blocks (A through $\mathrm{H}$ ) exposed to increasing doses of radiation.

\subsection{Computer Controlled Data Acquisition System}

The densimeter is operated and controlled by a personal computer with a single ultrasonic (UT) data acquisition card that is a custom Pacific Northwest National Laboratory (PNNL) design. This control architecture is shown in Figure 4.12. It contains an ultrasonic pulser, receiver, a high-speed, highresolution digitizer, and a multiplexer. The board, shown schematically in Figure 4.13, typically would replace two commercially available cards, but in addition, it offers overall improved performance required for the precision of the measurements. A full-sized printed circuit card using miniature surfacemounted electronic components allows components to be placed on both sides of the board. All design and circuit board layouts were done at PNNL in addition to populating the board with the components. The board is controlled with PNNL custom software that an operator uses via a graphical user interface (GUI). All raw and processed data are displayed in real time and can be archived on hard disk.

The pulser generates an RF (radio frequency) sinusoidal toneburst with the center frequency and number of cycles set by the operator. The center frequency was $2.25 \mathrm{MHz}$ and the number of cycles in the toneburst ranged from 10 to 15 . The ultrasonic receiver provides a gain ranging from 0 to $40 \mathrm{~dB}$ that 
is set by the operator or automatically by using the automatic gain control feature. The digitizer has 12 bits of resolution ( 1 part in 4096) with a sampling rate up to $40 \mathrm{MHz}$. The maximum sampling rate of 40 $\mathrm{MHz}$ means that a sample is obtained every 25 nanoseconds. The custom-written software consists of five modules: 1) instrument setup, 2) data acquisition and display, 3) parameter measurement, 4) data storage, and 5) density determination. The software, written in "C," operates on a DOS-based platform on a personal computer (PC).

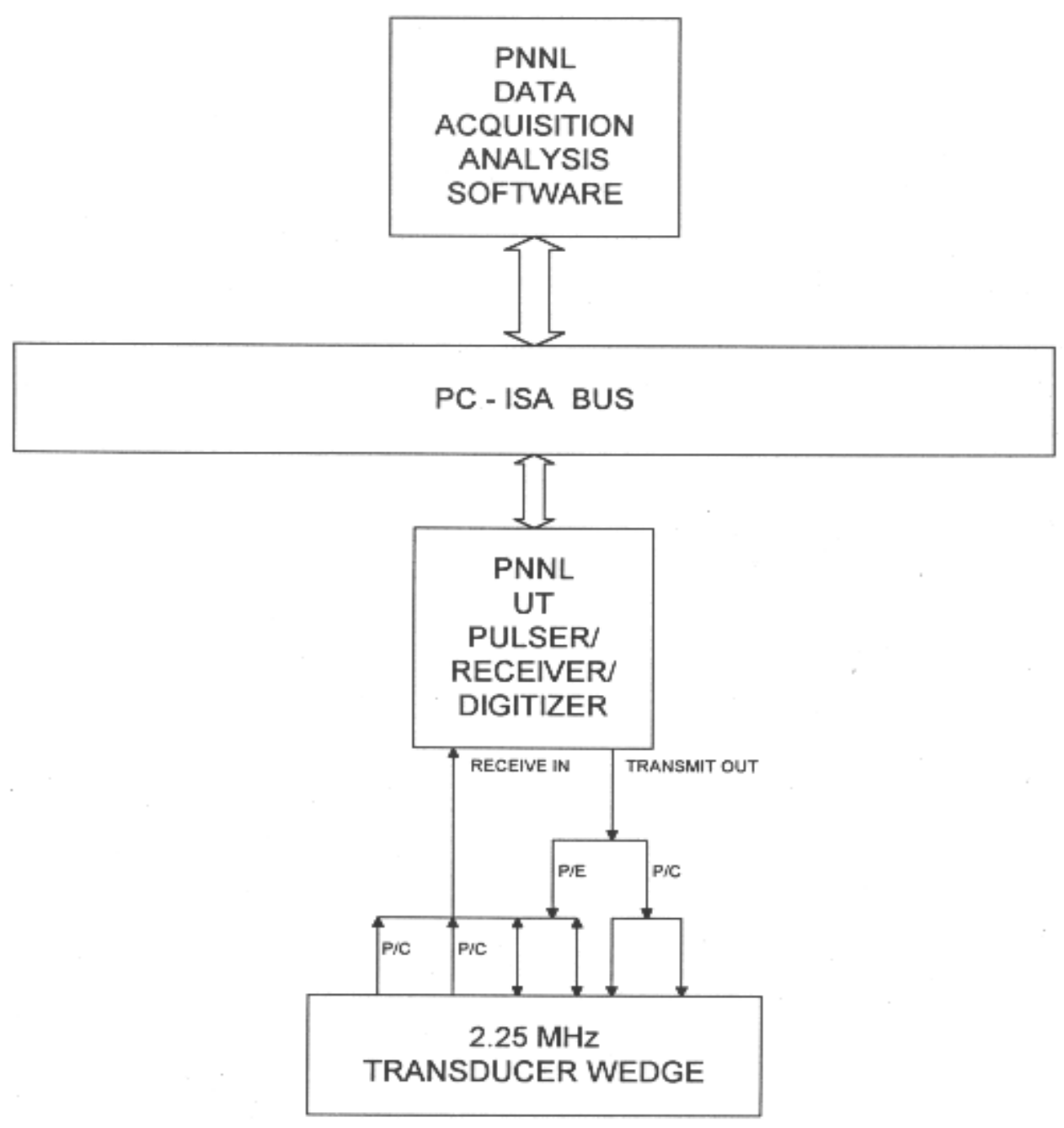

Figure 4.12 Density sensor control system architecture

Averaging is used to factor out random noise. The system finds the peak amplitude and the time of flight for each raw signal, averages the value of each one for the chosen number of signals, and calculates the standard deviation. The maximum and minimum values of the peak are also determined. 
PNNL DENSITY ELECTRONICS BOARD

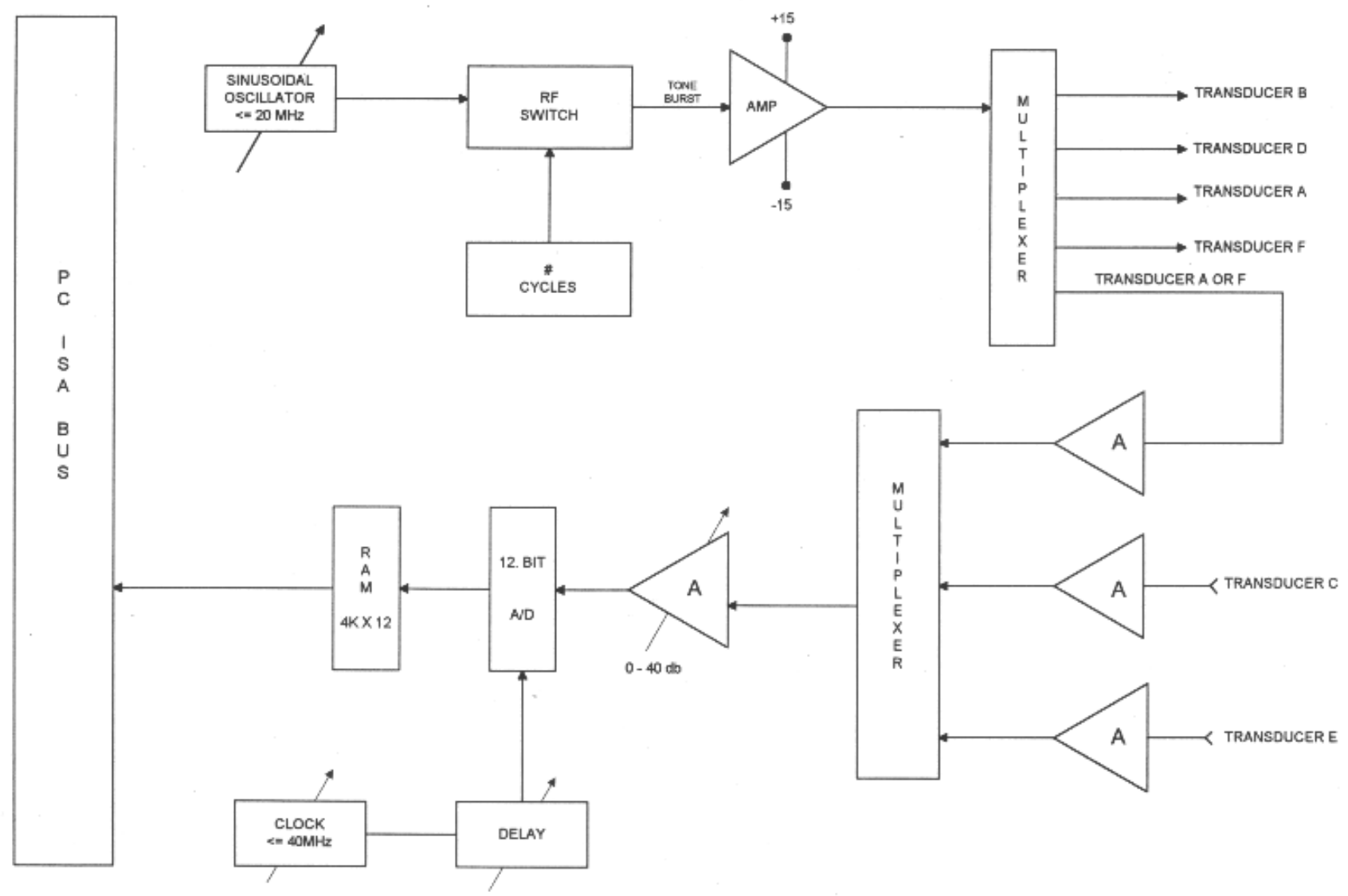

Figure 4.13 Density electronics board components

Instrument setup consists of setting parameters for the pulser (frequency and number of cycles), receiver (gain), and digitizer (sample rate and sample delay) either manually or by invoking the automatic gain control feature. Figure 4.14 shows the receive signal and gates displayed on the computer monitor. The operator sets the software gates: a time-of-flight gate (labeled "TOF" in Figure 4.14) with a defined start time but no end, and an amplitude measurement gate beginning with G1 and ending with G2. A threshold for the TOF gate is shown in Figure 4.14 by a dotted line slightly above the time axis. The peak amplitude is found by examining the peak-to-peak amplitude within the amplitude measurement gate and selecting the largest value. The time of flight is the time for the signal to travel from the send transducer to the receive transducer. It is found by first locating the time point after the TOF gate where the waveform first exceeds the set threshold. Next, the software finds the preceding zero-voltage crossover point, which becomes the resulting time of flight. 


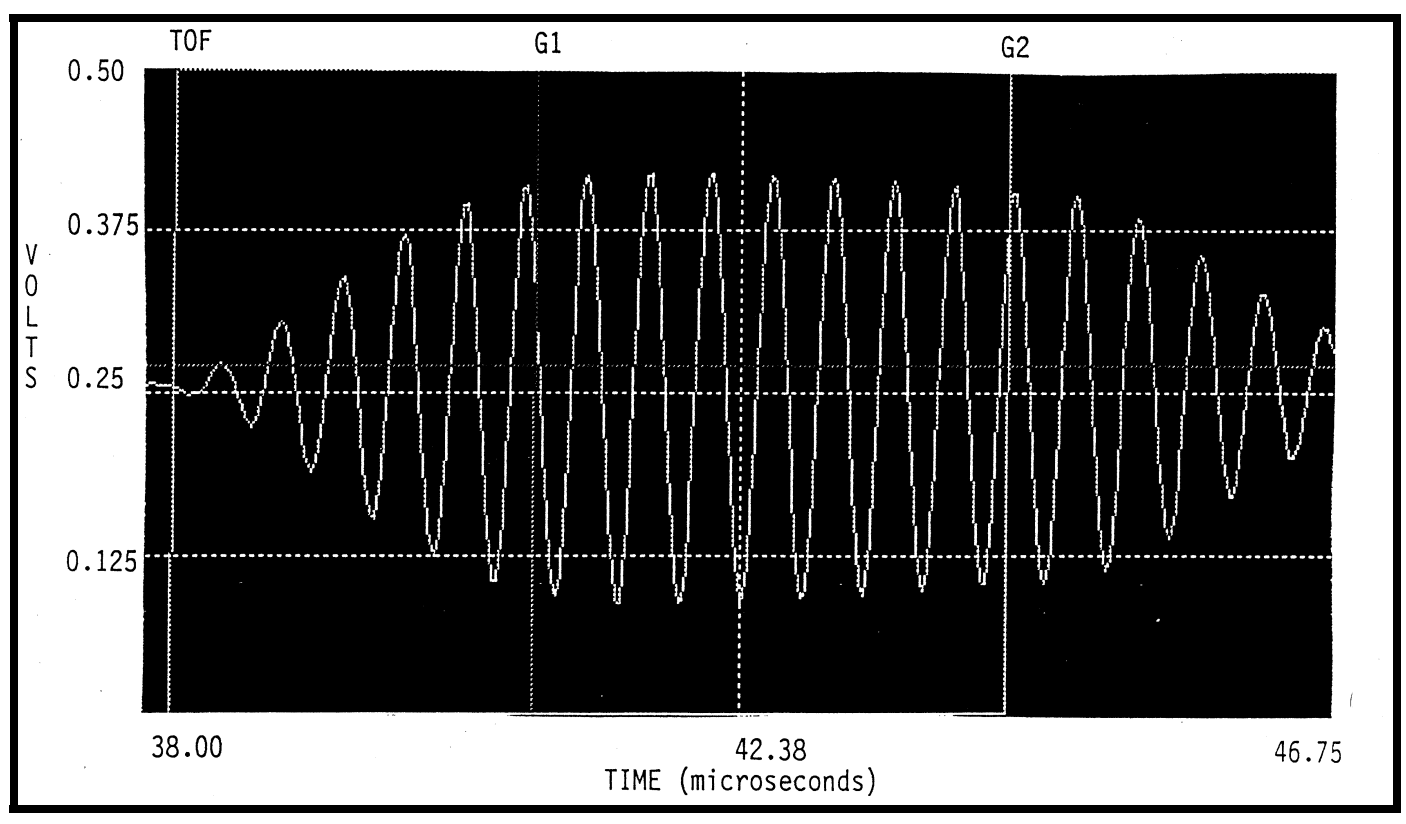

Figure 4.14 Tone burst signal appearing on the computer monitor.

\subsection{Densimeter-Computer Connections}

A schematic diagram of the densimeter system layout and components is shown in Figure 4.15. The three parts include the densimeter, connecting cables, and computer control system. The cable distance between the densimeter and the computer in the field is $107 \mathrm{~m}(350 \mathrm{ft})$ in length. Cables are routed from the computer to a junction box where they are connected with radiation-hardened cables that are connected to the densimeter. The cable connections inside the densimeter electrical box are shown in Figure 4.16. Connections between the densimeter and the computer controller during the probe tests in 336 building are shown in Figure 4.17. 


\section{Densimeter System Layout}

Dimensions: 11.75"Wx11.5"Hx11.25"D

Lunch Box Style Portable PC (33lbs.)

110VAC

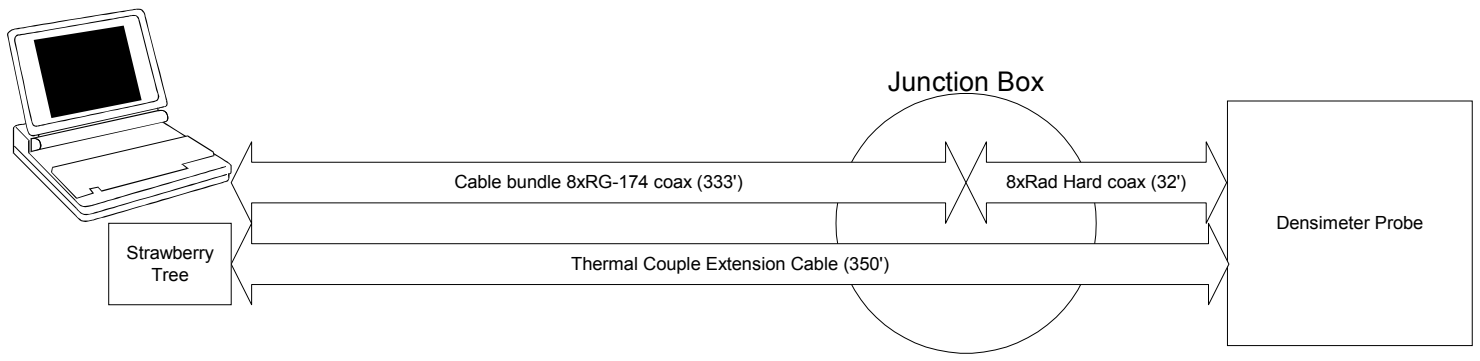

Connectors:

1. Lemo female on end of standard coax at Junction Box.

2. Lemo male on end of standard coax at computer.

3. Lemo male on both ends of Rad Hard coax.

4. Standard Thermal couple connector on end of Thermal couple extension cable at Densimeter Probe.

5. Thermal couple extension cable goes into terminal strip at computer.

Figure 4.15 Cable connections between densimeter and computer controller

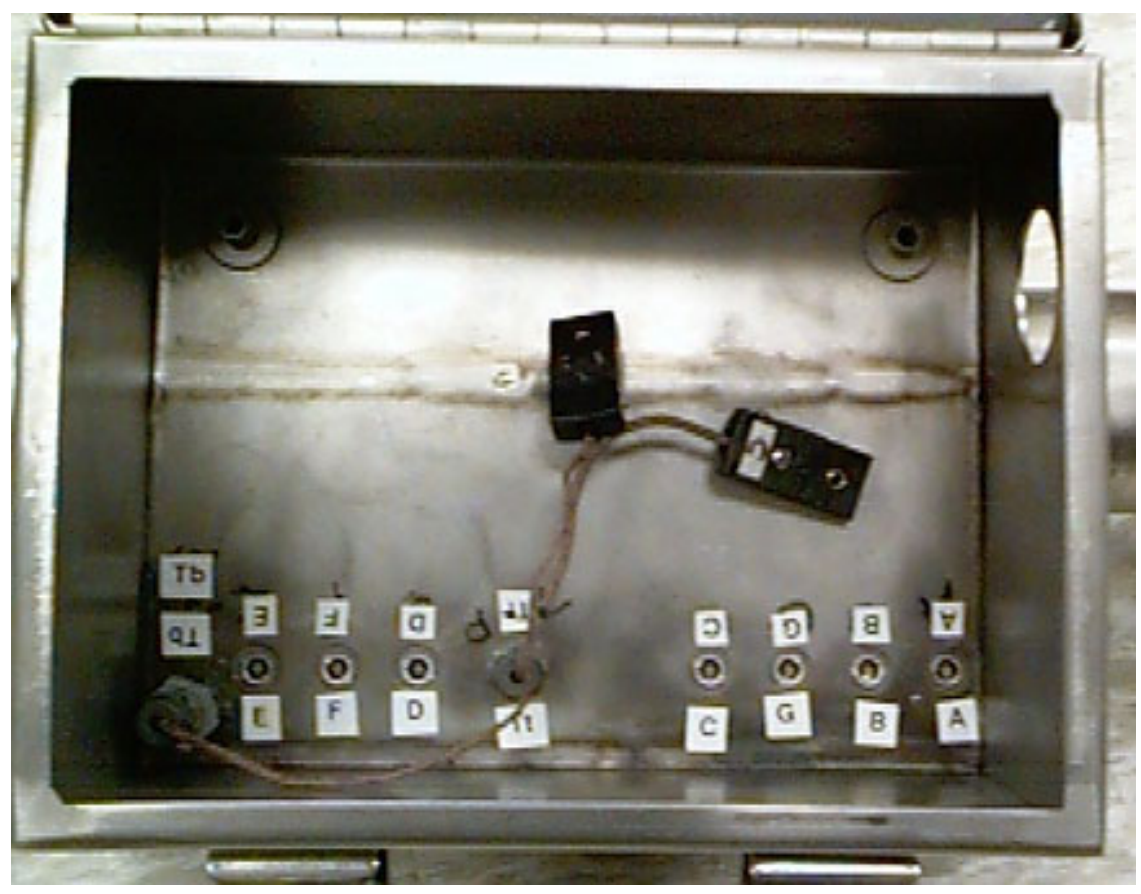

Figure 4.16 Labeled lemo and thermocouple connectors 

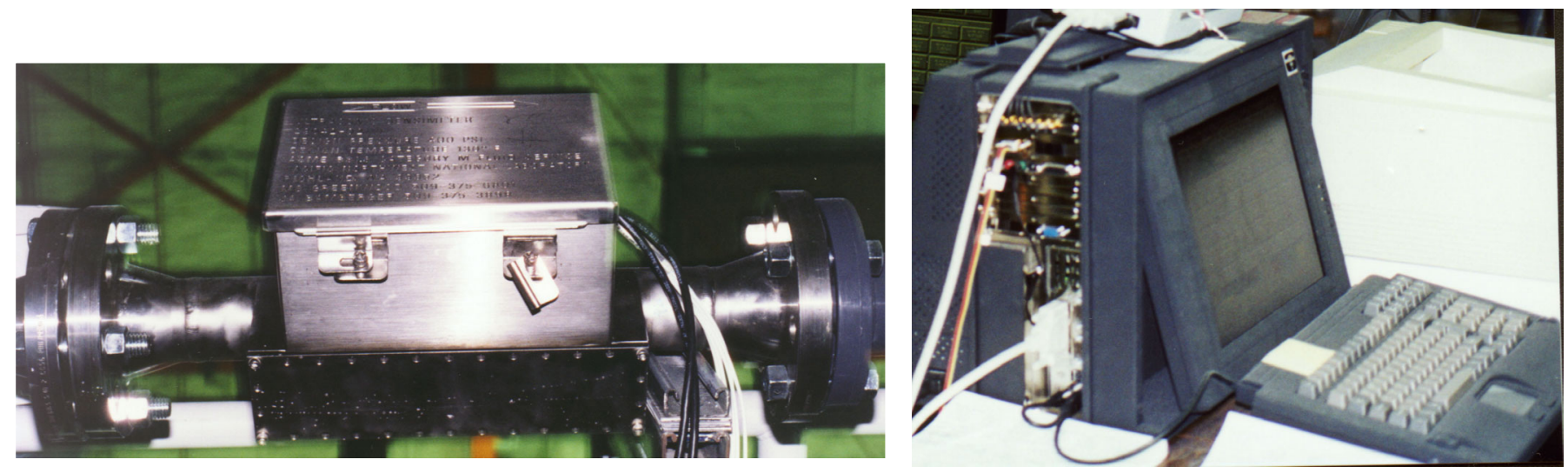

Figure 4.17 Densimeter cables and computer connections during pipeline tests at 336 building 


\subsection{Density Sensor Pipeline Evaluations}

The densimeter probes have been tested in pipelines at Oak Ridge, PNNL, and at Hanford. Pertinent observations from these tests are described.

\subsection{Densimeter Evaluation at ORNL}

In FY-1997 the performance of densimeter models, I and II shown in Figure 4.2, were evaluated during comparative testing of slurry monitors at Oak Ridge National Laboratory (Hylton et al. 1998). During these tests, the densimeter was installed vertically in the pipe loop as shown in Figure 5.1. Flow was vertically upward through the densimeter. This is the only evaluation of the densimeter performance in the vertical orientation. Subsequent tests and the installation at Hanford have the densimeter installed in a horizontal orientation.

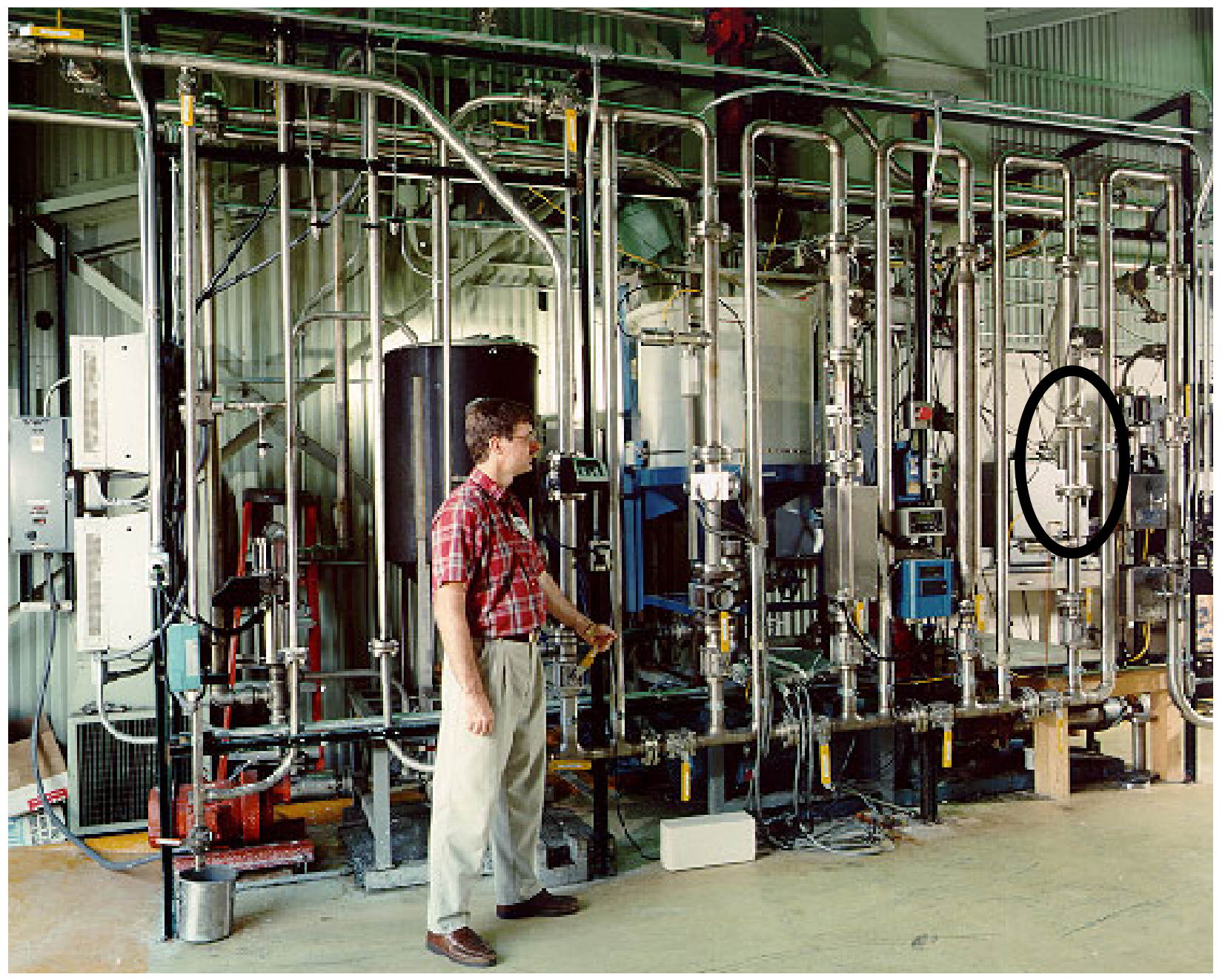

Figure 5.1 Vertical installation of densimeter during ORNL pipe loop tests 
The extensive performance evaluation at ORNL evaluated effects of seven parameters: flow rate, air entrainment, density, viscosity, concentration, particle size, and temperature. The simulants started with water, followed by sugar water (to increase density and viscosity) and then switched to slurries to add effects of increased density, solids concentration, and particle size. The slurries were composed of up to three types of particulate:

- $\quad$ kaolin clay (feldspar EPK Kaolin) with a particle size distribution ranged that to $\sim 90 \mu \mathrm{m}$ and a mean diameter of $\sim 20 \mu \mathrm{m}$

- $\quad$ sand (Quikrete Play Sand). 75\% of the particles ranged between 250 and $500 \mu \mathrm{m}$ and $95 \%$ of the particles ranged between 125 and $500 \mu \mathrm{m}$

- Chert gravel (Rogers Group) with a particle size between 1000 and $4000 \mu \mathrm{m}$.

The slurries were mixed with water or with $50 \mathrm{wt} \%$ sugar water. The eight flow rates evaluated ranged from $0.06 \mathrm{~m} / \mathrm{s}$ to $2.7 \mathrm{~m} / \mathrm{s}(0.2 \mathrm{ft} / \mathrm{s}$ to $9 \mathrm{ft} / \mathrm{s})$ and tests were conducted at two temperatures $25 \mathrm{C}$ and $50 \mathrm{C}$. To evaluate the effects of air entrainment, several tests at fluid velocities of $1.5 \mathrm{~m} / \mathrm{s}(5 \mathrm{ft} / \mathrm{s})$ were infused with an air volumetric flow rate of either $1.57 \times 10^{-4}$ or $3.11 \times 10^{-4} \mathrm{~m}^{3} / \mathrm{s}\left(0.33\right.$ or $\left.0.66 \mathrm{ft}^{3} / \mathrm{min}\right)$ that corresponded to 5 and $10 \mathrm{vol} \%$ air. The test design was both a crossed (factorial) and a hierarchical (nested) design. Slurry temperature, slurry flow rate, and induced air flow rate represent the same factor levels for each slurry matrix and matrix composition. The nested factor levels of the matrix concentration depend upon the slurry matrix type. The water matrix was used to check both the test loop and the functionality of the slurry monitoring instruments and to compare conditions at the beginning of the evaluation with those at the end of the evaluation.

Each test lasted $\sim 20$ to 30 min at each test condition. Each run contains 40 cases, measurements taken every $30 \mathrm{~s}$ for $20 \mathrm{~min}$. A value of the density was determined for each case and the Sensor Average Density is the density of these values. Comparison between the probe measurements and bottle samples obtained during tests at ORNL for a series of the matrix are shown in Table 5.1. Evaluation of the data showed that:

- The density measurements are not affected by the slurry flow rate through the pipeline

- The density measurements are not affected by entrained air

Table 5.1 Density sensor data obtained during the instrument evaluation at ORNL

\begin{tabular}{|c|c|c|c|c|c|c|c|}
\hline \multirow{3}{*}{ Slurry } & \multicolumn{5}{|c|}{ " Nominal Conditions } & \multirow{3}{*}{$\begin{array}{c}\text { Reference } \\
\text { Density } \\
\text { Average } \\
\left(\mathrm{g} / \mathrm{cm}^{3}\right)\end{array}$} & \multirow{3}{*}{$\begin{array}{c}\text { Sensor } \\
\text { Density } \\
\text { Average } \\
\left(\mathrm{g} / \mathrm{cm}^{3}\right)\end{array}$} \\
\hline & \multirow{2}{*}{\begin{tabular}{|l|} 
Temp \\
$(\operatorname{deg} C)$
\end{tabular}} & \multicolumn{2}{|c|}{$\begin{array}{c}\text { Fluid Flow } \\
\text { Rate }\end{array}$} & \multicolumn{2}{|c|}{ Air Flow Rate } & & \\
\hline & & $(\mathrm{m} / \mathrm{s})$ & $(\mathbf{f t} / \mathbf{s})$ & $\left(\mathrm{m}^{3} / \mathrm{s}\right) \times 10^{-4}$ & (cfm) & & \\
\hline \multirow[t]{2}{*}{ Water } & 50 & 1.5 & 5 & 1.57 & 0.33 & 1.2797 & 1.2290 \\
\hline & 50 & 1.5 & 5 & 3.11 & 0.66 & 1.2797 & 1.2776 \\
\hline & & & & & & & \\
\hline & & & & & & & \\
\hline
\end{tabular}




\begin{tabular}{|c|c|c|c|c|c|c|c|}
\hline \multirow{4}{*}{$\begin{array}{l}30 \% \text { Kaolin in } \\
\text { Water }\end{array}$} & $\overline{c 50}$ & 0.91 & 3 & 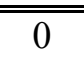 & 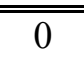 & "1.1918 & $\begin{array}{l}1.1702 \\
\end{array}$ \\
\hline & 50 & 0.30 & 1 & 0 & 0 & 1.1967 & 1.1717 \\
\hline & 50 & 2.7 & 9 & 0 & 0 & 1.1936 & 1.2233 \\
\hline & 50 & 1.5 & 5 & 1.57 & 0.33 & 1.1936 & 1.1730 \\
\hline \multirow{4}{*}{$\begin{array}{l}20 \% \text { Kaolin in } \\
\text { Water }\end{array}$} & 50 & 2.1 & 7 & 0 & 0 & 1.1241 & 1.1887 \\
\hline & 50 & 0.12 & 0.4 & 0 & 0 & 1.1339 & 1.1550 \\
\hline & 50 & 0.91 & 0.3 & 0 & 0 & 1.1344 & 1.1331 \\
\hline & 50 & 1.5 & 5 & 3.11 & 0.66 & 1.1292 & 1.1610 \\
\hline \multirow{5}{*}{$\begin{array}{l}15 \% \text { Kaolin in } \\
\text { Water }\end{array}$} & 50 & 2.1 & 7 & 0 & 0 & 1.3201 & 1.2873 \\
\hline & 50 & 0.91 & 3 & 0 & 0 & 1.3229 & 1.3160 \\
\hline & 50 & 0.30 & 1 & 0 & 0 & 1.3243 & 1.3209 \\
\hline & 50 & 0.24 & 0.8 & 0 & 0 & 1.3244 & 1.3170 \\
\hline & 50 & 1.5 & 5 & 1.57 & 0.33 & 1.3220 & 1.3102 \\
\hline \multirow{5}{*}{$\begin{array}{l}\text { 8.5\% Kaolin } \\
\text { in Sugar } \\
\text { Water }\end{array}$} & 50 & 2.7 & 9 & 0 & 0 & 1.2782 & 1.3747 \\
\hline & 50 & 2.1 & 7 & 0 & 0 & 1.2792 & 1.2633 \\
\hline & 50 & 0.91 & 3 & 0 & 0 & 1.2808 & 1.2995 \\
\hline & 50 & 1.5 & 5 & 1.57 & 0.33 & 1.2797 & 1.2290 \\
\hline & 50 & 1.5 & 5 & 3.11 & 0.66 & 1.2797 & 1.2776 \\
\hline \multirow{4}{*}{$\begin{array}{l}30 \% \text { Kaolin, } \\
\text { Sand in Sugar } \\
\text { Water }\end{array}$} & 50 & 0.91 & 3 & 0 & 0 & 1.4203 & 1.2725 \\
\hline & 50 & 0.30 & 1 & 0 & 0 & 1.4132 & 1.2533 \\
\hline & 50 & 0.49 & 1.6 & 0 & 0 & 1.4268 & 1.2550 \\
\hline & 50 & 1.5 & 5 & 1.57 & 0.33 & 1.4224 & 1.2856 \\
\hline \multirow{5}{*}{$\begin{array}{l}20 \% \text { Kaolin, } \\
\text { Sand in Sugar } \\
\text { Water }\end{array}$} & 50 & 0.91 & 3 & 0 & 0 & 1.3680 & 1.2818 \\
\hline & 50 & 0.30 & 1 & 0 & 0 & 1.3478 & 1.2798 \\
\hline & 50 & 0.18 & 0.6 & 0 & 0 & 1.3525 & 1.2833 \\
\hline & 50 & 0.27 & 0.9 & 0 & 0 & 1.3568 & 1.2965 \\
\hline & 50 & 1.5 & 5 & 1.57 & 0.33 & 1.3717 & 1.2606 \\
\hline \multirow{5}{*}{$\begin{array}{l}\text { 10\% Kaolin, } \\
\text { Sand, Gravel } \\
\text { in Sugar } \\
\text { Water }\end{array}$} & 50 & 1.5 & 5 & 0 & 0 & 1.3043 & 1.3446 \\
\hline & 50 & 0.30 & 1 & 0 & 0 & 1.2757 & 1.3312 \\
\hline & 50 & 0.18 & 0.6 & 0 & 0 & 1.2787 & 1.3056 \\
\hline & 50 & 0.12 & 0.4 & 0 & 0 & 1.2777 & 1.3778 \\
\hline & 50 & 1.5 & 5 & 1.57 & 0.33 & 1.2933 & 1.3257 \\
\hline \multirow{3}{*}{$\begin{array}{l}\text { 20\% Kaolin. } \\
\text { Sand, Gravel } \\
\text { in Sugar } \\
\text { Water }\end{array}$} & 50 & 1.5 & 5 & 0 & 0 & 1.3640 & 1.3103 \\
\hline & 50 & 2.1 & 7 & 0 & 0 & 1.3617 & 1.2874 \\
\hline & 50 & 1.5 & 5 & 1.57 & 0.33 & 1.3640 & 1.3207 \\
\hline
\end{tabular}


The results of the ORNL pipeline demonstration showed the promise of an instrument such as the densimeter. The small size of the densimeter and its tolerance to entrained air, as demonstrated during the qualification tests at ORNL, make it extremely useful for deployment in existing locations and conditions where air may be entrained in the pipeline. The developers also noted that the ultrasonic densimeter:

- Can interrogate extremely dense slurries and settled solids layers because the ultrasonic signal does not need to penetrate the slurry to evaluate the slurry density.

- Has a simple compact design allowing deployment in short pipe spool pieces $\leq 30 \mathrm{~cm}$ (12 in.) long, or in vessels by insertion of a single sensor probe into the fluid, or by attaching the probe to the vessel wall.

- Is not affected by electromagnetic noise and can be located in harsh environments such as pump pits or other areas crowded with machinery.

Based on the results of these qualification tests, the densimeter was selected for demonstration at the Hanford Site as a part of the Hanford Tanks Initiative (HTI).

\subsection{Densimeter Demonstration in the Instrument Validation Facility}

To support HTI deployment, the densimeter performance was evaluated during two sets of nonradioactive transport tests using waste simulants. During the first tests, the densimeter operation was evaluated during tests in the PNNL Instrument Validation facility (Bontha et al. 2000, Reynolds et al 1996). The purpose of the tests was to evaluate densimeter performance over a range of operating conditions simulating transport of water, viscous liquids, and slurry. At the completion of these tests, the decision was made to install the densimeter into a replacement process manifold that would eventually be deployed at the Hanford Site. After the densimeter was installed and the manifold assembly was pressured tested, a similar series of performance evaluation tests were conducted, this time to evaluate the performance of the densimeter in the piping configuration in which it would eventually be deployed. This section describes the results of these two sets of performance evaluations.

In 1999, the performance characteristics of two densimeters were evaluated during pipe loop tests in the Instrument Validation Facility at PNNL, shown in Figure 5.2. Pump process variables and slurry properties were measured during the tests. The densities of slurry samples were periodically measured using a pycnometer. Samples were taken through ports S-3 on the upstream leg of the pipe loop and S-4 on the down stream leg of the pipe loop; the samples were measured immediately in the laboratory and the measurements were obtained at essentially the same temperature as the slurry circulating in the pipe loop. The average of these values was used to specify the density of the flowing slurry. The test matrix was designed to evaluate the density of water, the density of fluids with densities greater than water, and densities of a range of slurries. The test matrix was set up to be conducted sequentially with three fluids: water, sugar water, and kaolin clay in a sugar water suspension. The range of densities and $\mathrm{wt} \%$ of the fluids evaluated during the tests are summarized in Table 5.2 (Bamberger and Greenwood 2000). 
Table 5.2 Range of fluid properties evaluated during pipe loop tests

\begin{tabular}{||l|c|l|l||}
\hline Fluid & Density Range & Wt\% Range & Quantity Of Component \\
\hline Water & $988-994 \mathrm{~kg} / \mathrm{m}^{3}$ & 0 & $503 \mathrm{~kg}(1109 \mathrm{lbm})$ \\
\hline Sugar water & $1005-1108 \mathrm{~kg} / \mathrm{m}^{3}$ & $4.3-27.7 \mathrm{wt} \%$ sugar in water & $22.7-193 \mathrm{~kg}(50-425 \mathrm{lbm})$ \\
\hline $\begin{array}{l}\text { Kaolin clay in } \\
\text { sugar water }\end{array}$ & $1130-1459 \mathrm{~kg} / \mathrm{m}^{3}$ & $\begin{array}{l}3.2-41.8 \mathrm{wt} \% \text { kaolin in sugar } \\
\text { water }\end{array}$ & $22.7-498 \mathrm{~kg}(50-1100 \mathrm{lbm})$ \\
\hline
\end{tabular}

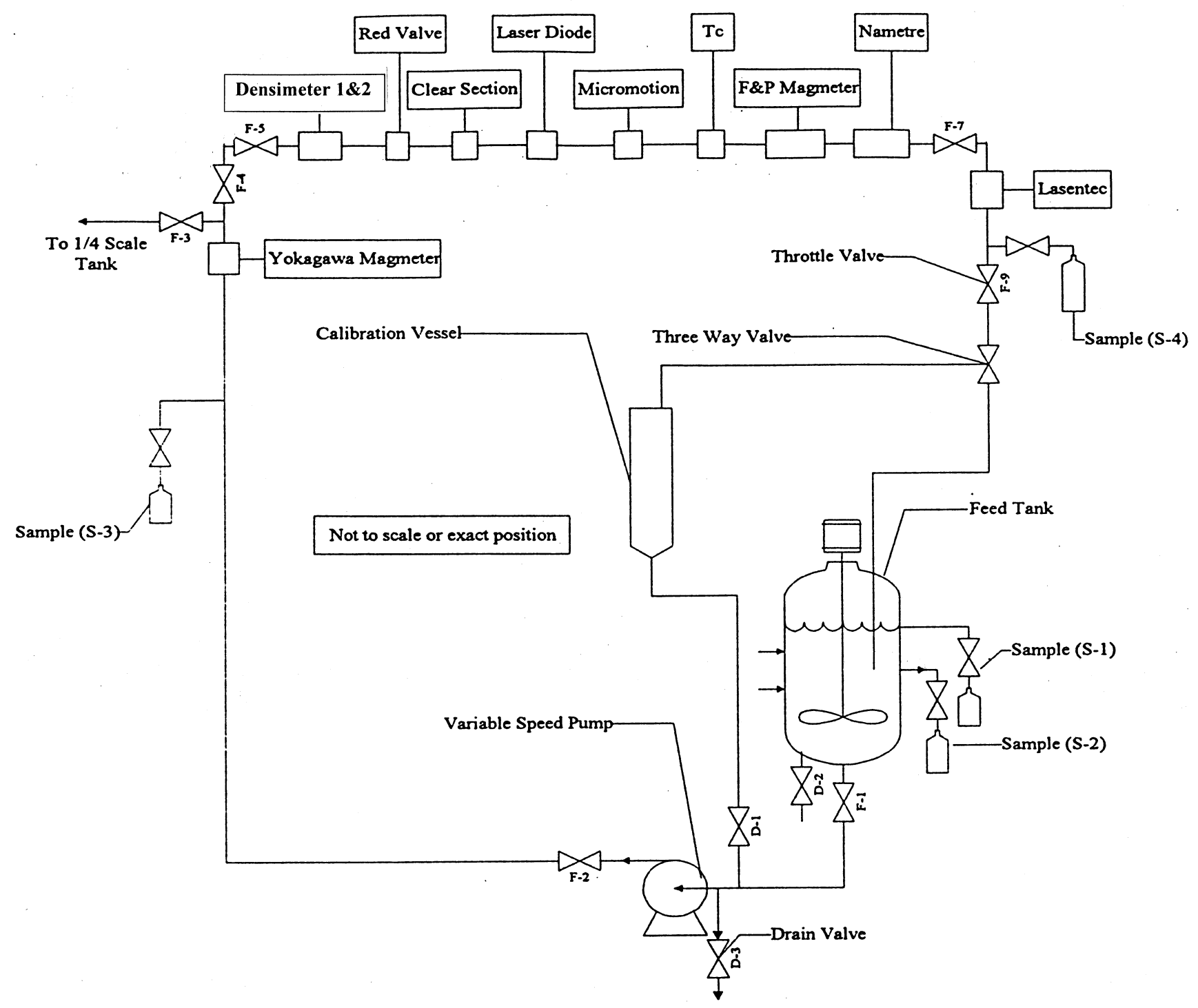

Figure 5.2 Configuration of the instrument validation facility pipe loop 
After the loop was filled with water, the water was pumped continuously through the loop until a steady state temperature was achieved. Density data, grab samples and process data were taken during this transient. After steady state temperature was achieved, the loop was operated continuously to obtain long term operating data. An overview of this sequence is provided in Table 5.3.

Table 5.3 Test sequence and range of operating parameters

\begin{tabular}{||l|l|l|l||}
\hline Fluid & Water & Sugar Water & Kaolin in Sugar Water \\
\hline Duration & $20 \mathrm{hr}$ & $24 \mathrm{hr}$ & $5 \mathrm{hr}$ \\
\hline Temperature range & $50.8-53.8 \mathrm{C}$ & $48.4-50.0 \mathrm{C}$ & $54.7-57.8 \mathrm{C}$ \\
\hline Flow rate range & $0.33 \mathrm{~m}^{3} / \mathrm{min}$ & $0.32-0.33 \mathrm{~m}^{3} / \mathrm{min}$ & $0.26-0.33 \mathrm{~m}^{3} / \mathrm{min}$ \\
& $(87 \mathrm{gpm})$ & $(86-87 \mathrm{gpm})$ & $(68-86 \mathrm{gpm})$ \\
\hline
\end{tabular}

Densimeter transducer received voltages and probe temperatures were recorded continuously throughout the tests. Comparisons between the pipe loop test data and the calibration data obtained in the laboratory over a range of temperatures showed a discrepancy between the two. After much analysis and measurement of other parameters, this discrepancy was tracked to slight but observable changes in the input voltage. The data was analyzed to further understand the effects of the difference in the input voltage levels for the two locations. From this data, densities were calculated. Data obtained from probe 1 was analyzed based on data from the 0,47 , and 60 degree sensors. These calculated densities were compared with the densities obtained from the grab samples and the results are summarized in Table 5.4. Agreements are good, usually within $+/-2 \%$.

\subsection{Tests at 305 Building in Modified Process Manifold}

Performance testing of the densimeter was carried out in the 305 Building, Fluor Hanford, Inc. Engineering Laboratory during September and October 2001 (Witwer 1999 and Witwer et al. 2001). The densimeter was installed in the process (pump outlet) manifold, which will be installed in the 241-SY-101 Prefabricated Pump Pit (PPP). The process manifold had previously undergone minor modification, including installation of the densimeter, followed by acceptance pressure testing, prior to the performance testing documented here. The manifold was connected in line with a pump and a slurry-mixing tank as shown in Figure 5.3. The densimeter computer controllers are visible to the right of the manifold.

The tests were conducted using the two densimeters, shown in Figure 5.4. Densimeter 1 (installed to the left) will be included in the manifold when in is installed at the site. Densimeter 2 (installed to the right downstream from densimeter 1) is installed in the manifold so that both sensors can be evaluated simultaneously during the tests. Densimeter 2 will be removed after testing and will not be installed at the site. Both densimeters were included in the system when it was pressure tested at $4.13 \mathrm{MPa}(\mathrm{g})(600$ psig). To ensure that the densimeter sensor is in contact with the slurry, the densimeters were installed with the transducer wedge oriented at the 3 o'clock position or lower when observed from the upstream end. The data acquisition computers are shown in Figure 5.5. 
Table 5.4 Comparison between densimeter and reference densities obtained during pipe loop tests

\begin{tabular}{|c|c|c|c|}
\hline \multirow[b]{2}{*}{ Fluid } & \multirow{2}{*}{$\begin{array}{c}\text { Density } \\
\text { By Weight } \\
\left(\mathrm{kg} / \mathrm{m}^{3}\right)\end{array}$} & \multicolumn{2}{|c|}{$\overline{\text { Probe } 1}$} \\
\hline & & $\begin{array}{r}\text { Density } \\
\left(\mathrm{kg} / \mathrm{m}^{3}\right)\end{array}$ & $\begin{array}{c}\text { Error } \\
(\%)\end{array}$ \\
\hline \multirow[t]{10}{*}{ Sugar Water } & 1005 & 994 & -1.1 \\
\hline & 1020 & 992 & -2.7 \\
\hline & 1032 & 1017 & -1.5 \\
\hline & 1048 & 1035 & -1.2 \\
\hline & 1061 & 1068 & 0.7 \\
\hline & 1073 & 1085 & 1.1 \\
\hline & 1085 & 1090 & 0.5 \\
\hline & 1096 & 1109 & 1.2 \\
\hline & 1100 & 1114 & 1.3 \\
\hline & 1100 & 1153 & 4.8 \\
\hline \multirow{10}{*}{$\begin{array}{l}\text { Kaolin in } \\
\text { Sugar Water }\end{array}$} & 1130 & 1167 & 3.3 \\
\hline & 1165 & 1196 & 2.7 \\
\hline & 1199 & 1231 & 2.7 \\
\hline & 1226 & 1247 & 1.7 \\
\hline & 1269 & 1272 & 0.2 \\
\hline & 1325 & 1363 & 2.9 \\
\hline & 1384 & 1395 & 0.8 \\
\hline & 1425 & 1424 & -0.1 \\
\hline & 1425 & 1417 & -0.6 \\
\hline & 1455 & 1422 & -2.3 \\
\hline
\end{tabular}

This performance evaluation was conducted using the same procedure and sequence as the pipe loop tests. A series of water, sugar water, and kaolin clay in sugar water simulants were pumped through the manifold. The densimeters were operated continuously during these tests as the fluid density was incrementally increased through addition of sugar and then kaolin clay. Testing with simulants ranging in density from approximately 1,000 to $1,400 \mathrm{~kg} / \mathrm{m}^{3}$ was proposed, but testing was terminated prior to completion of the proposed test matrix because of pump seal failures, combined with schedule constraints. Testing was terminated after obtaining data from a simulant with a density of $1241 \mathrm{~kg} / \mathrm{m}^{3}$. At the completion of the tests, Densimeter 29042-1 remained installed in the process manifold and Densimeter 29042-2 was removed from the process manifold. 


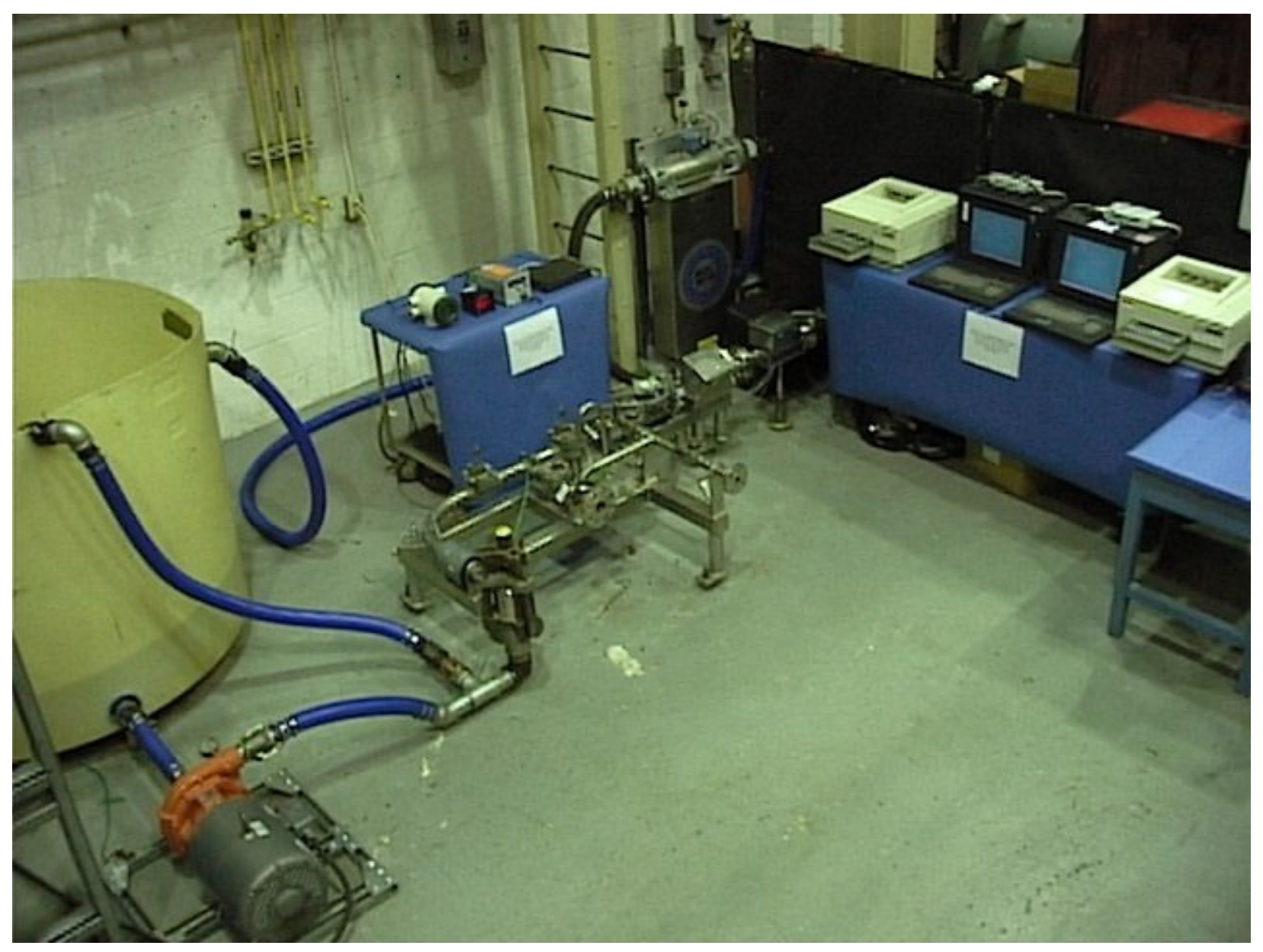

Figure 5.3 Modified process manifold test configuration

The average (mean) density data and standard deviation in the data obtained at each density is compared with a grab sample density, listed in Table 5.4. A grab sample involved obtaining a thoroughly mixed sample of the slurry out of the mixing tank of the same mix as recorded by the densitometer(s). A pycnometer was used to provide a precisely measured volume, which was then measured on a calibrated balance to determine the sample density. The percent error between the mean and bottle sample density is also shown. These deviations ranged from 0 to $1.5 \%$ for probe 1 and slightly higher for probe 2 . 


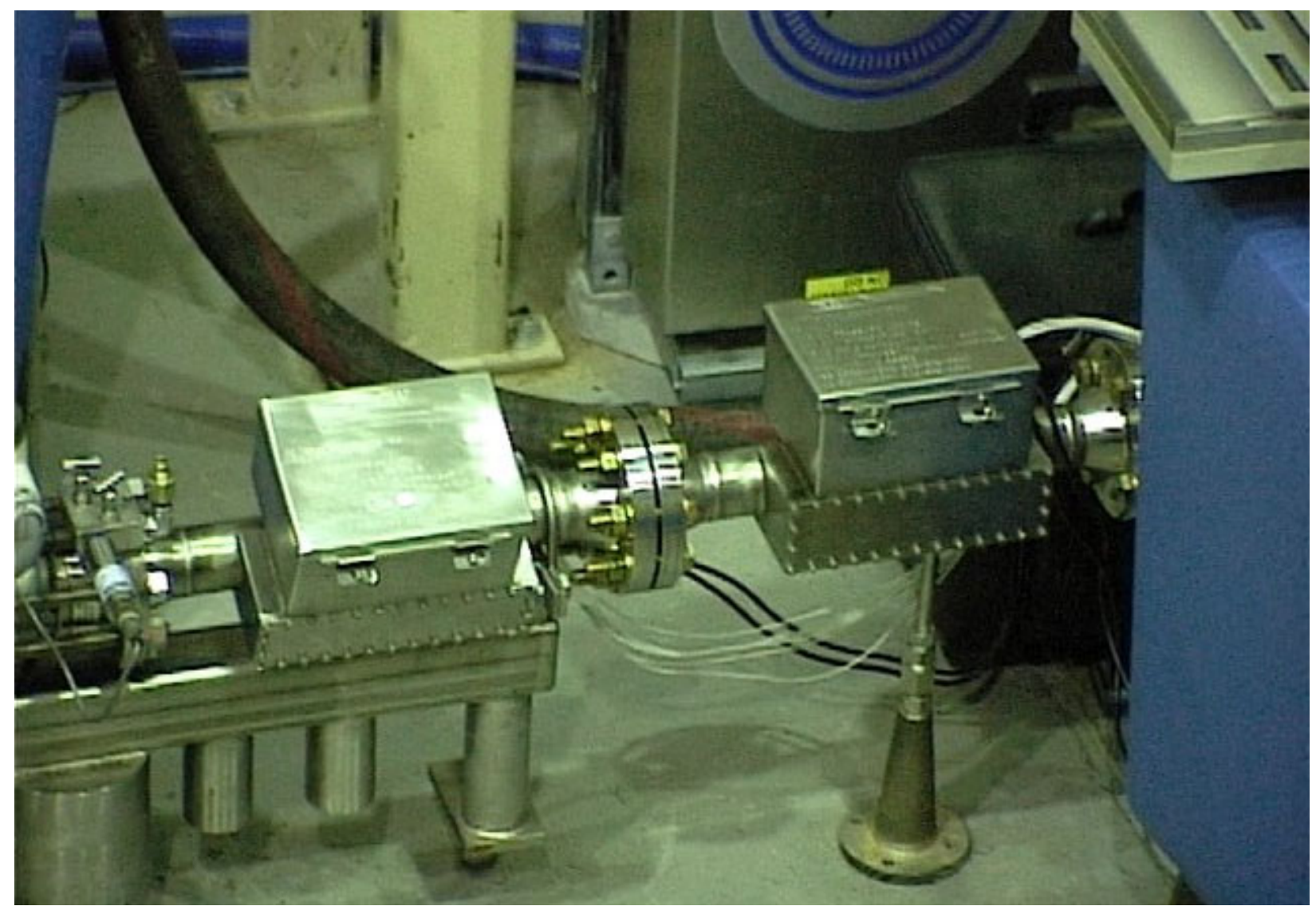

Figure 5.4 Densimeter 1 (left) and densimeter 2 (right) installed in the modified process manifold

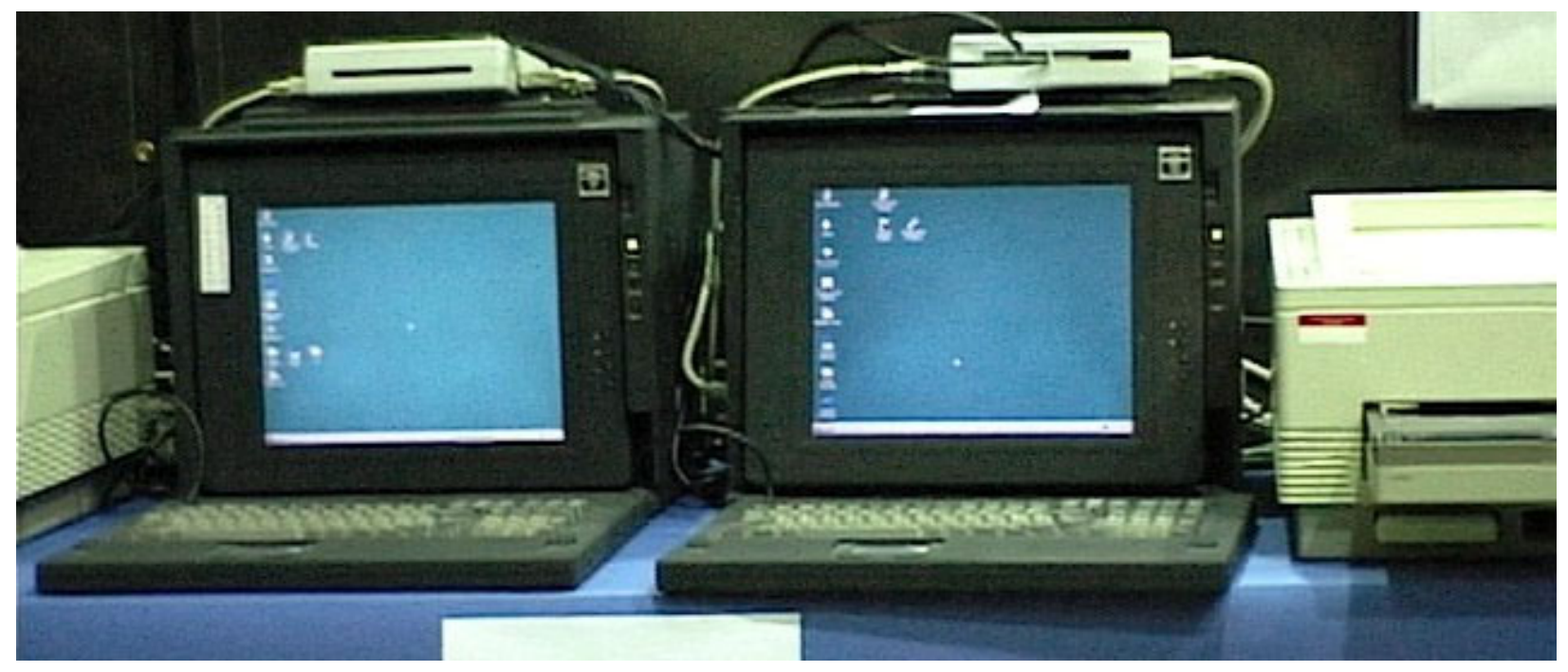

Figure 5.5 Data acquisition computers for the two density sensors. 


\subsection{Density Sensor Performance}

The densimeter performance has been evaluated over the range of operating conditions proposed for deployment (Bamberger et al. 2001). During two sets of process tests, densities ranged from water up to slurries with bulk densities of $1455 \mathrm{~kg} / \mathrm{m}^{3}$. These two data sets are compared in Figure 5.6. Over the range tested, most deviations between the measured and the reference densities are within $+/-2 \%$.

Figure 5.6 Comparison between densimeter and reference densities

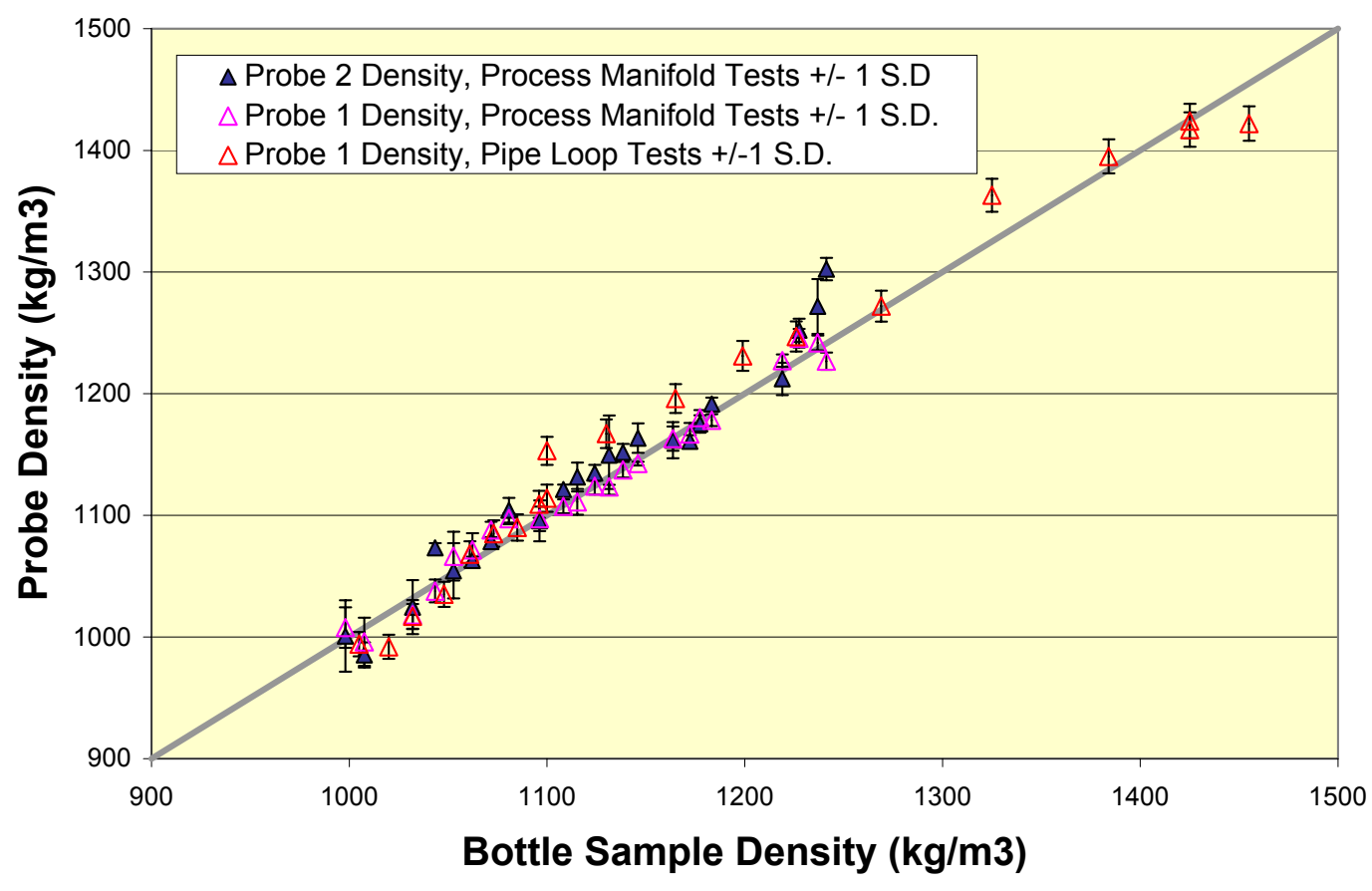




\subsection{Density Sensor Calibration}

In the fall of 2000 , tests of the density sensor were conducted in a pipeline using non-radioactive simulant slurries. This was the last test before the sensor was installed at the SY-101 site. The data presented here are the results of these tests.

Two probes, designated Probe 1 and Probe 2, were constructed and both were calibrated during the tests. The probes were installed in the modified process manifold (MPM) and placed in a pipe loop assembly at the Fluor Hanford Inc. Engineering Laboratory. After completion of the tests, Probe 1 remained installed in the process manifold and Probe 2 was removed and remains a spare. The test began with water. Subsequently sugar was added to the tank to increase the density. The action of the pump caused the temperature of the liquid to rise, and there was no other source of heat. When the density of the sugar water solution reached a weight percentage of about $50 \%$, kaolin clay was added to increase the density. We had hoped to add more kaolin, but, because of pump seal failures, data could not be obtained at a higher density with the existing pump. During the testing the voltage measurements for $\mathrm{V}_{\mathrm{BC}}, \mathrm{V}_{\mathrm{DE}}$, $\mathrm{V}_{\mathrm{FF}}$, and $\mathrm{V}_{\mathrm{AA}}$ were obtained for water, 18 sugar water solutions ranging in density from $1008 \mathrm{~kg} / \mathrm{m}^{3}$ to $1219 \mathrm{~kg} / \mathrm{m}^{3}$, and the sugar-water-kaolin slurries ranging in density from $1227 \mathrm{~kg} / \mathrm{m}^{3}$ to $1241 \mathrm{~kg} / \mathrm{m}^{3}$. Measurements of the temperature were also obtained. For each liquid or slurry concentration, a grab sample was obtained from the tank and its density measured by weighing using a pycnometer. These are referred to as bottle sample density measurements.

From this large set of data, 2796 data points for Probe 1 and 3828 data points for Probe 2 were selected for analysis. This data set included times when the slurry was well mixed. Figure 6.1a and b show plots of the bottle sample density and the temperature at the base of the wedge. Two sets of data were obtained over a large range of temperature, when the pump was turned off overnight, and the sugar water solution cooled down. These are shown in Figure 6.1.

\subsection{Approach for Sensor Calibration}

The calibration of the sensor is obviously an important step to ensure its high performance. Initially, the probes were calibrated referenced to water, as had been done for the original model. However, subsequent tests on the second-generation sensor showed that with this approach the density was determined correctly at room temperature, but not at higher temperatures. This observation is quite puzzling because one can ask: Why should room temperature be "special?" However, philosophical questions aside, the voltages on the receive transducers operated in an expected manner. When the density of the liquid increased, the voltage on transducers BC and DE increased, while the voltage on FF decreased. Therefore, the voltages were indeed supplying information about the density, but to extract the information a more complicated interpretation and calibration were needed. 


\section{Bottle Sample Density and Temperature vs Data Point}

Number, Probe 1

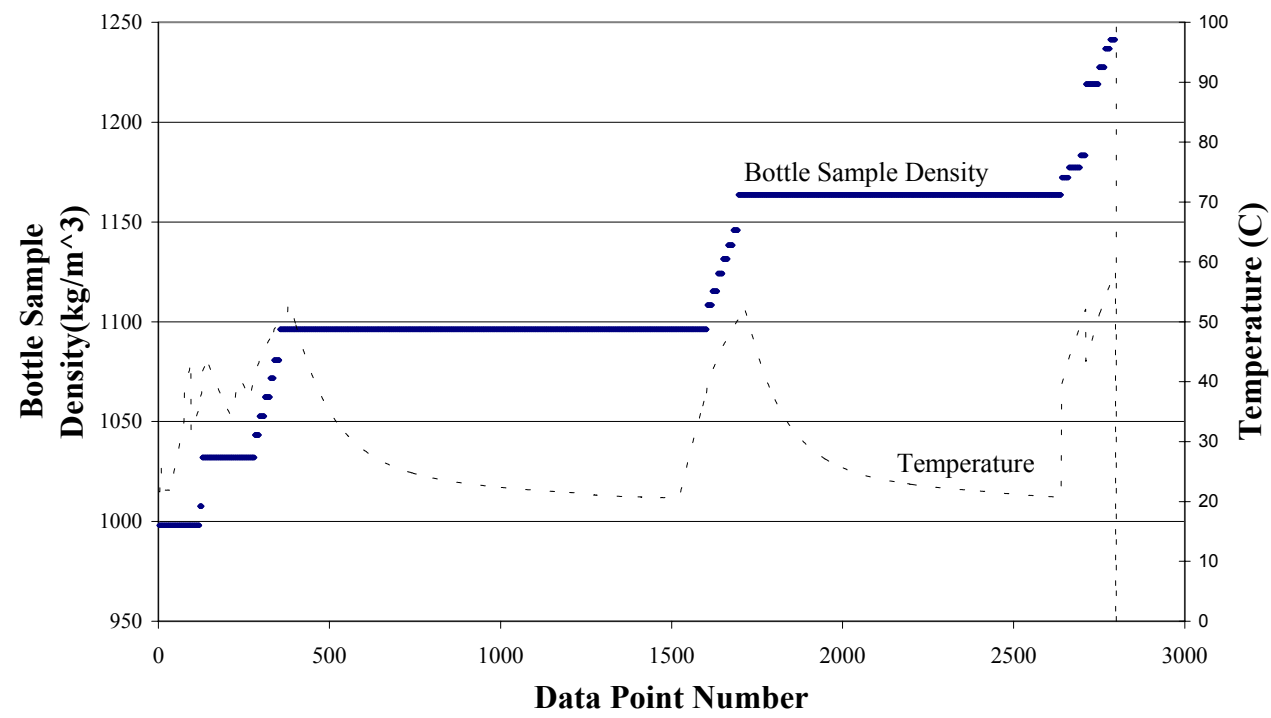

Bottle Sample Density vs Data Point Number, Probe 2

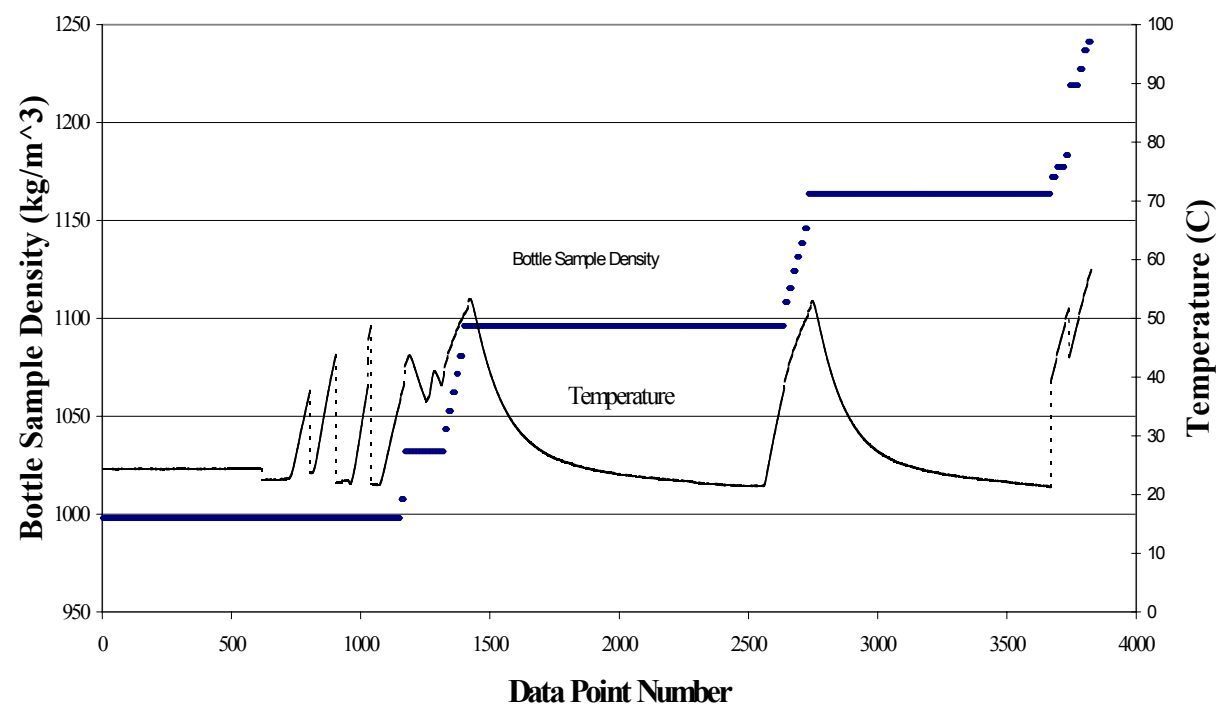

Figure 6.1 Plots of bottle sample density and temperature for probes 1 (top) and 2 (bottom)

The density is obtained by measuring the voltages on two receive transducers. The calibration is needed to relate the voltage measurement to the determination of the reflection coefficient. In turn, the reflection coefficient depends upon the density of the liquid or slurry and the speed of sound in it. Therefore, the determination of two reflection coefficients permits the determination of the density of the liquid and speed of sound. 
The objective was to obtain the reflection coefficient as a polynomial expansion in terms of the voltage and temperature. A regression analysis, with a least squares fitting procedure, was carried out for several thousand data points. That is,

$$
\mathrm{RC}_{\mathrm{x}}=\mathrm{f}_{\mathrm{x}}\left(\mathrm{V}_{\mathrm{x}}, \mathrm{T}\right)
$$

This represents three equations, where $\mathrm{x}$ is a shorthand for any one of the three transducer pairs: $\mathrm{BC}$, $\mathrm{DE}$, or FF. $\mathrm{V}_{\mathrm{x}}$ and $\mathrm{T}$ have been measured, but in order to determine the constants in the polynomial expansion, values of $\mathrm{RC}_{\mathrm{x}}$ are needed. The method for determining the reflection coefficients is described in Section 6.2 and the results of the regression analysis are presented in Section 6.3.

Two reflection coefficients are needed to determine the density and speed of sound in a liquid, as stated above. However, data were obtained for three angles. The procedure for analyzing results using three angles is described in Section 6.5.1.

The tests of the sensor were carried out for liquid/slurry having a density ranging from $998 \mathrm{~kg} / \mathrm{m}^{3}$ up to $1241 \mathrm{~kg} / \mathrm{m}^{3}$. It is well known that, even though Equation 6.1 is valid within this density range, it may not be valid outside of this range, especially where there are terms quadratic in $\mathrm{V}_{\mathrm{x}}$ and $\mathrm{T}$. For this reason, we considered a polynomial expansion in terms of the density of the liquid $(\rho)$ in terms of the voltage $\left(\mathrm{V}_{\mathrm{x}}\right)$ and temperature $(\mathrm{T})$ :

$$
\rho_{\mathrm{x}}=\mathrm{g}_{\mathrm{x}}\left(\mathrm{V}_{\mathrm{x}}, \mathrm{T}\right)
$$

Since all of these quantities were measured during the tests, a regression analysis was carried out to determine the constants for the polynomial expansion. However, a restriction was placed on the expansion: It must be linear in $\mathrm{V}_{\mathrm{x}}$, but was quadratic in terms of the temperature $\mathrm{T}$. For density values outside the range of the tests, Equation 6.2 will be used to determine the density.

The expansion for the density, given in Equation 6.2, is very important for another reason. This relationship can be used to predict density (at a somewhat reduced accuracy) using as few as one of the three transducers. This is a back up position that can be employed if one or more of the transducers cease to operate. Suppose that during the transfer of radioactive waste one of the transducers fails. The transducer FF is a particularly important one, as we shall see. If that occurs, then the density measurements will not be possible, using only reflection coefficients. Two probes are available and were calibrated. Even so, during the transfer it may not be possible to replace Probe 1 with Probe 2. The regression analysis in terms of density in Equation 6.2 provides a means of obtaining information about the density. Therefore, of the three transducers, one operational transducer can provide information about the density. Two operational transducers (even if FF has failed) will provide an average value of the density. However, this procedure may not be as accurate as using the two-reflection-coefficient method for the following reasons. The voltage measured by the transducer is dependent upon both the density of the liquid and the velocity of sound in the liquid. The data obtained during the tests were for sugar water, primarily. Therefore, the voltage measurement is dependent upon the speed of sound in sugar water. A slurry having the same density as the sugar water can have a slightly different speed of sound. Therefore, the accuracy of the density expansion will depend upon the similarity of the speed of sound for that slurry to that for the sugar water. It is expected that this will result in a small error, at least for the smaller 
values of the density. Even though the accuracy is not as great, it will show a trend in the density data and can also provide information to prevent pipeline plugging. Somewhat reduced accuracy is surely far preferable to not obtaining any measurements.

\subsection{Experimental Reflection Coefficients for use in Regression Analysis}

The equations for the reflection coefficients are given in Equations 3.3 through 3.8. These equations show that the reflection coefficients are dependent upon the following parameters:

$\alpha$ incident angle

$\mathrm{c}_{\mathrm{L}}$ longitudinal velocity in wedge

$\mathrm{c}_{\mathrm{T}}$ shear velocity in wedge

$\rho_{\mathrm{s}}$ density of wedge

c longitudinal velocity in liquid

$\rho$ density of liquid

Thus, if these six quantities are known the reflection coefficient can be calculated. The density of the wedge material Rexolite is $1049 \mathrm{~kg} / \mathrm{m}^{3}$, the longitudinal speed $\mathrm{c}_{\mathrm{L}}$ is $2337 \mathrm{~m} / \mathrm{s}$, and the shear speed $\mathrm{c}_{\mathrm{T}}$ is $1157 \mathrm{~m} / \mathrm{s}$. The longitudinal and shear velocities in Rexolite as a function of temperature were measured over the temperature range from temperature from $15.5 \mathrm{C}$ to $82.2 \mathrm{C}$ and the results are given by:

$$
\begin{aligned}
& c_{L}=-0.0064202 T^{2}-1.5906566 \mathrm{~T}+2374.3089 \\
& c_{T}=-0.00316062 \mathrm{~T}^{2}-0.6816773 \mathrm{~T}+1173.4053
\end{aligned}
$$

The velocity of sound in water as a function of temperature was obtained from the equation given by Povey et al. (1997). The bottle sample density is used for the density of the liquid. In order to determine the reflection coefficient, it is necessary to determine the longitudinal velocity in the sugar water and sugar-water-kaolin slurry.

\subsubsection{Velocity measurements in liquids/slurry}

To measure the velocity, a bracket containing two transducers, separated by several $\mathrm{cm}$, was placed in the solution, which was heated. By measuring the time of flight and the temperature, the velocity as a function of temperature was obtained. This procedure was followed for sugar water solutions having a density of $1038 \mathrm{~kg} / \mathrm{m}^{3}$ (10\% sugar by weight [10\% SW]), $1121 \mathrm{~kg} / \mathrm{m}^{3}(30 \% \mathrm{SW})$, and $1230 \mathrm{~kg} / \mathrm{m}^{3}(50 \%$ SW). Figure 6.2 shows the velocity as a function of temperature for these three solutions. Figure 6.3 shows the data obtained for a sample of the sugar-water-kaolin slurry used in the test. Linear interpolation was used to find the velocity for a specific temperature and density.

\subsubsection{Calculation of reflection coefficients}

The reflection coefficients for $\mathrm{BC}, \mathrm{DE}$, and $\mathrm{FF}$ were calculated for the 2796 data points for Probe 1 and the 3828 data points for Probe 2. The last three columns of Table 6.1 show the results of the calculation of the reflection coefficients for six data points for Probe 1 and six, for Probe 2 . These are the so-called experimental reflection coefficients. 


\section{Velocity of Water and Sugar Water}

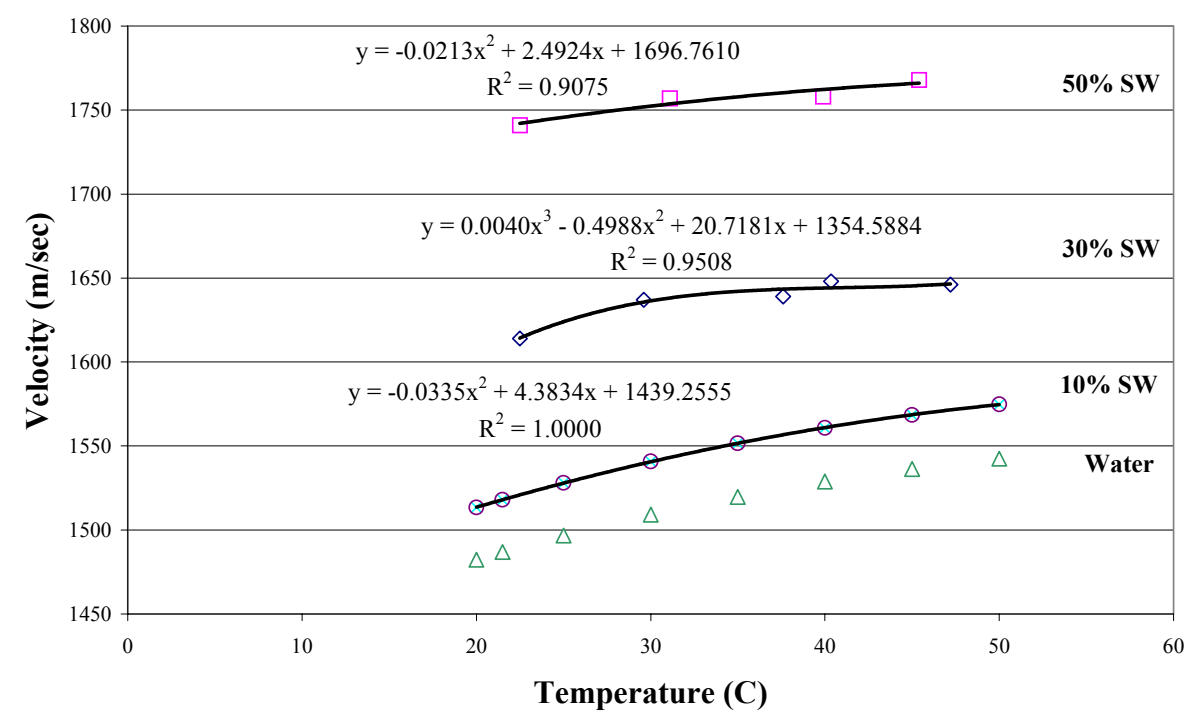

Figure 6.2 Velocity of sound in sugar water as a function of temperature

\section{Kaolin Clay Slurries in Sugar Water from Tests in Modified Process Manifold in 305 Building}

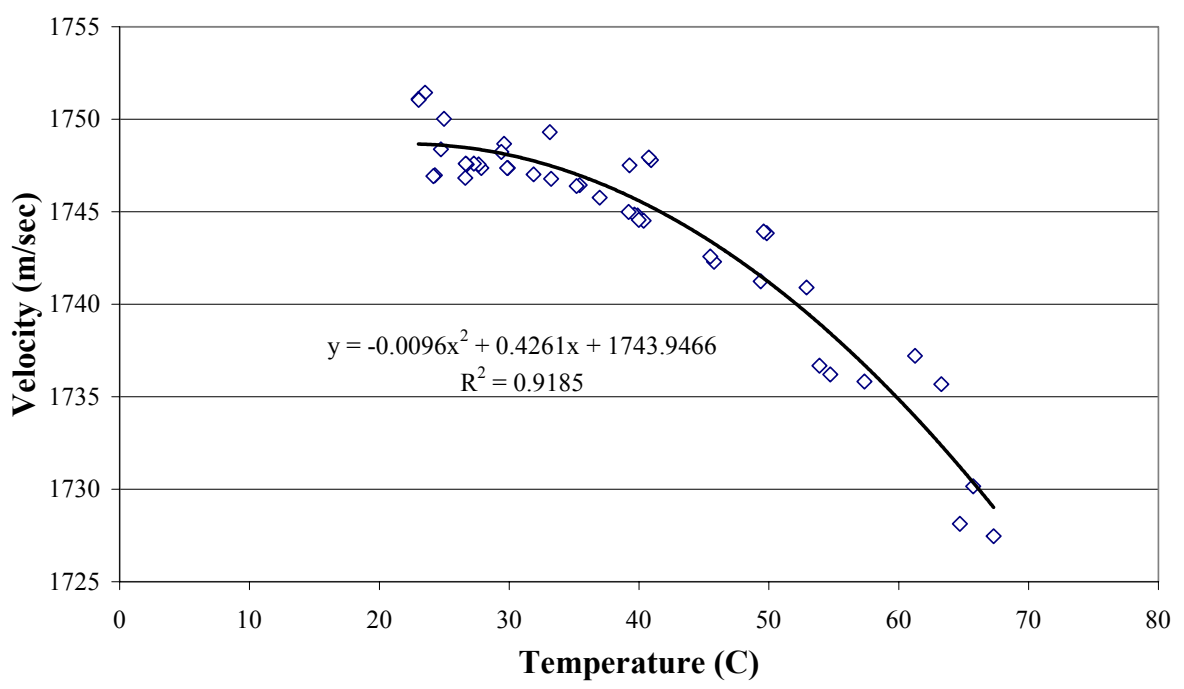

Figure 6.3 Velocity of sound in kaolin clay slurries in sugar water as a function of temperature 
Table 6.1 Calculation of the experimental reflection coefficients for Probes 1 and 2

\begin{tabular}{|c|c|c|c|c|c|c|c|c|c|}
\hline \multirow[t]{2}{*}{ Probe } & \multirow[t]{2}{*}{$\begin{array}{l}\text { Data Pt. } \\
\text { Number }\end{array}$} & \multirow{2}{*}{\begin{tabular}{|c|}
$\begin{array}{c}\text { Bottle } \\
\text { Density }\end{array}$ \\
$\left(\mathrm{kg} / \mathrm{m}^{3}\right)$
\end{tabular}} & \multirow{2}{*}{\begin{tabular}{|c} 
Base Temp \\
(C)
\end{tabular}} & \multirow{2}{*}{\begin{tabular}{|c|} 
Vadj BC \\
(volts)
\end{tabular}} & \multirow{2}{*}{\begin{tabular}{|c|} 
Vadj DE \\
(volts)
\end{tabular}} & \multirow{2}{*}{\begin{tabular}{|c|} 
Vadj FF \\
(volts)
\end{tabular}} & \multirow[t]{2}{*}{ RC BCexp } & \multirow[t]{2}{*}{ RC DEexp } & \multirow[t]{2}{*}{ RC FFexp } \\
\hline & & & & & & & & & \\
\hline 1 & 17 & 998 & 21.9 & 0.01562 & 0.03618 & 0.08081 & 0.07477 & 0.13811 & -0.24540 \\
\hline 1 & 212 & 1032 & 35.7 & .02087 & 0.03367 & 0.06653 & 0.11338 & 0.17746 & -0.20498 \\
\hline 1 & 325 & 1072 & 7.5 & 329 & 188 & 5259 & 127 & 624 & 6512 \\
\hline 1 & 383 & 1096 & 52.8 & 0.02375 & 0.03075 & 0.04526 & 0.17033 & 0.23568 & -0.14469 \\
\hline 1 & 1896 & 1164 & 29.3 & 0.03532 & 0.05118 & 0.04069 & 0.19721 & 0.26038 & -0.10941 \\
\hline 1 & 2786 & 1241 & 57.6 & 0.03441 & 0.03847 & 0.01597 & 0.25679 & 0.32281 & -0.04786 \\
\hline 2 & 10 & 998 & 24.3 & 0.00873 & 0.01167 & 0.04752 & 0.07809 & 0.14164 & \begin{tabular}{|l}
-0.24233 \\
\end{tabular} \\
\hline 2 & 1350 & 1053 & 45.3 & 0.01179 & 0.01286 & 0.03289 & 0.13695 & 0.20181 & -0.18079 \\
\hline 2 & 2816 & 1164 & 41.3 & 0.01790 & 0.01815 & 0.02075 & 0.20729 & 0.27184 & -0.10111 \\
\hline 2 & 3764 & 1219 & 47.5 & 0.01979 & \begin{tabular}{|l|l|}
0.01884 \\
\end{tabular} & 0.01200 & 0.24528 & 0.31095 & -0.06019 \\
\hline 2 & 3801 & 1237 & 54.4 & 0.01911 & 0.01731 & 0.00969 & 0.25398 & 0.31983 & -0.05067 \\
\hline 2 & 3812 & 1241 & 56.4 & 0.01857 & 0.01650 & 0.00924 & 0.25626 & 0.32217 & -0.04824 \\
\hline
\end{tabular}

\subsection{Regression analysis for reflection coefficients}

A regression analysis was carried out using the following model equation:

$$
\begin{aligned}
\mathrm{RC}_{\text {liqu }}= & \mathrm{b} 0_{\mathrm{x}}+\mathrm{b} 1_{\mathrm{x}} \mathrm{T}+\mathrm{b} 2_{\mathrm{x}} \mathrm{T}^{2}+\mathrm{b} 3_{\mathrm{x}} * \mathrm{~V}_{\mathrm{x}}+\mathrm{b} 4_{\mathrm{x}} * \mathrm{~V}_{\mathrm{x}}^{2}+\mathrm{b} 5_{\mathrm{x}} \mathrm{TV}_{\mathrm{x}}+\mathrm{b} 6_{\mathrm{x}} \mathrm{TV}_{\mathrm{x}}^{2} \\
& +\mathrm{b} 7_{\mathrm{x}} \mathrm{T}^{2} \mathrm{~V}_{\mathrm{x}}+\mathrm{b} 8_{\mathrm{x}} \mathrm{T}^{2} \mathrm{~V}_{\mathrm{x}}^{2}
\end{aligned}
$$

where $\mathrm{x}$ is a shorthand notation for $\mathrm{BC}, \mathrm{DE}$, or FF. $\mathrm{T}$ is the temperature and $\mathrm{V}_{\mathrm{x}}$ is the voltage at $0 \mathrm{~dB}$ amplifier gain. A regression analysis was carried out for each transducer to determine the nine coefficients in Equation 6.5. The input data is similar to that shown in Table 6.1. Table 6.2 lists the values of the coefficients for Probe 1 and Probe 2.

The question is, of course: How well can nine constants fit several thousand data points? For all of the data points, the value of $\mathrm{RC}_{\text {liqDE }}$, say, was calculated using the temperature and value of $\mathrm{V}_{\mathrm{DE}}$. The absolute value of the error between $\mathrm{RC}_{\text {liqDE }}$ and $\mathrm{RC}_{\text {expDE }}$ was calculated. The average value of the error and the standard deviation were obtained. Similar calculations were carried out for $\mathrm{RC}_{\text {liqBC }}$ and $\mathrm{RC}_{\text {liqDE}}$. Table 6.3 shows the error in the reflection coefficient $\mathrm{RC}_{\text {liqx }}$ for Probe 1 and Probe 2. The errors seem quite reasonable. The errors for Probe 1 are smaller than those for Probe 2.

Figures 6.4 and 6.5 show the variation in the reflection coefficients as a function of the voltage, when a given constant temperature is substituted into Equation 6.5 for the three transducer pairs for Probes 1 and 2 respectively. 
Table 6.2 Coefficients for probes 1 and 2

\begin{tabular}{|c|c|c|c|c|}
\hline & \multicolumn{4}{|c|}{ Polynomial Expansion Coefficients for } \\
\hline & \multicolumn{2}{|c|}{ Reflection Coefficients } & \multicolumn{2}{|c|}{ Density } \\
\hline & Probe 1 & Probe 2 & Probe 1 & Probe 2 \\
\hline b0BC & 0.00007 & $1.4880 \mathrm{E}-01$ & $1.0173 \mathrm{E}+03$ & $9.8551 \mathrm{E}+02$ \\
\hline b1BC & 0.00000 & $-9.7451 \mathrm{E}-03$ & $-8.8795 \mathrm{E}+00$ & $-7.4660 \mathrm{E}+00$ \\
\hline $\mathrm{b} 2 \mathrm{BC}$ & 0.00000 & 1.1371E-04 & $1.0743 \mathrm{E}-01$ & $8.4090 \mathrm{E}-02$ \\
\hline b3BC & 0.00001 & $-9.9982 \mathrm{E}+00$ & $4.2031 \mathrm{E}+03$ & $1.2636 \mathrm{E}+04$ \\
\hline $\mathrm{b} 4 \mathrm{BC}$ & 0.06041 & $6.3885 \mathrm{E}+02$ & & \\
\hline b5BC & 0.00019 & $1.1441 \mathrm{E}+00$ & $2.0258 \mathrm{E}+02$ & $1.6022 \mathrm{E}+02$ \\
\hline b6BC & -0.00147 & $-1.1050 \mathrm{E}-02$ & $-1.5914 \mathrm{E}+00$ & $-1.0932 \mathrm{E}-01$ \\
\hline b7BC & 0.00000 & $-3.5075 \mathrm{E}+01$ & & \\
\hline $\mathrm{b} 8 \mathrm{BC}$ & -0.00004 & $3.5836 \mathrm{E}-01$ & & \\
\hline b0DE & -0.00006 & $-2.9235 \mathrm{E}-01$ & $9.3123 \mathrm{E}+02$ & $9.6796 \mathrm{E}+02$ \\
\hline b1DE & 0.00001 & $2.3529 \mathrm{E}-02$ & $-1.4845 \mathrm{E}+01$ & $-1.1992 \mathrm{E}+01$ \\
\hline b2DE & 0.00000 & $-4.0835 \mathrm{E}-04$ & $2.2695 \mathrm{E}-01$ & $1.5126 \mathrm{E}-01$ \\
\hline b3DE & 0.00767 & $5.7966 \mathrm{E}+01$ & $1.4286 \mathrm{E}+03$ & $1.2240 \mathrm{E}+04$ \\
\hline $\mathrm{b} 4 \mathrm{DE}$ & -0.10433 & $-1.6926 \mathrm{E}+03$ & & \\
\hline b5DE & -0.00046 & $-3.7408 \mathrm{E}+00$ & $3.8101 \mathrm{E}+02$ & $3.4706 \mathrm{E}+02$ \\
\hline b6DE & 0.01047 & $6.6076 \mathrm{E}-02$ & $-3.9290 \mathrm{E}+00$ & $-1.5643 \mathrm{E}+00$ \\
\hline b7DE & 0.00001 & $1.3453 \mathrm{E}+02$ & & \\
\hline b8DE & -0.00023 & $-2.2738 \mathrm{E}+00$ & & \\
\hline b0FF & -0.00071 & $2.3837 \mathrm{E}-01$ & $1.4069 \mathrm{E}+03$ & $1.4120 \mathrm{E}+03$ \\
\hline b1FF & 0.00001 & $-1.2809 \mathrm{E}-02$ & $-2.7904 \mathrm{E}+00$ & $-2.1761 \mathrm{E}+00$ \\
\hline $\mathrm{b} 2 \mathrm{FF}$ & 0.00000 & $1.5567 \mathrm{E}-04$ & $1.8491 \mathrm{E}-02$ & $6.4875 \mathrm{E}-03$ \\
\hline b3FF & -0.00546 & $-1.9777 \mathrm{E}+01$ & $-3.6296 \mathrm{E}+03$ & $-6.0740 \mathrm{E}+03$ \\
\hline b4FF & -0.05269 & $2.5103 \mathrm{E}+02$ & & \\
\hline b5FF & 0.00034 & 9.0394E-01 & $-3.1991 \mathrm{E}+01$ & $-8.0462 \mathrm{E}+01$ \\
\hline $\mathrm{b} 6 \mathrm{FF}$ & -0.01540 & $-1.1709 \mathrm{E}-02$ & $2.3620 \mathrm{E}-01$ & $6.3480 \mathrm{E}-01$ \\
\hline $\mathrm{b} 7 \mathrm{FF}$ & -0.00002 & $-1.5795 \mathrm{E}+01$ & & \\
\hline $\mathrm{b} 8 \mathrm{FF}$ & 0.00033 & $1.9714 \mathrm{E}-01$ & & \\
\hline
\end{tabular}


Table 6.3 Percent error in reflection coefficients based on Equation 6.5 compared to experimental values

\begin{tabular}{||l|l|l|l||}
\hline \hline & $\begin{array}{l}\text { \% error } \\
\text { for RCliqBC }\end{array}$ & $\begin{array}{l}\text { \% error } \\
\text { for RCliqDE }\end{array}$ & $\begin{array}{l}\text { \% error } \\
\text { for RCliqFF }\end{array}$ \\
\hline \hline Probe 1 & $1.00 \pm 1.08$ & $0.73 \pm 0.70$ & $1.10 \pm 1.63$ \\
\hline Probe 2 & $1.38 \pm 1.46$ & $1.04 \pm 0.96$ & $1.28 \pm 1.60$ \\
\hline (a) $\quad \begin{array}{l}\text { For all of the data points used in the } \\
\text { analysis, the average value of the percent } \\
\text { error and the standard deviation of the } \\
\text { percent error are shown. }\end{array}$ \\
\hline
\end{tabular}

\subsection{Regression Analysis for Density Values}

A regression analysis was carried out for the density using the following model equations:

$$
\rho_{\mathrm{x}}=\mathrm{b} 0_{\mathrm{x}}+\mathrm{b} 1_{\mathrm{x}} \mathrm{T}+\mathrm{b} 2_{\mathrm{x}} \mathrm{T}^{2}+\mathrm{b} 3_{\mathrm{x}} \mathrm{V}_{\mathrm{x}}+\mathrm{b} 5_{\mathrm{x}} \mathrm{TV} \mathrm{V}_{\mathrm{x}}+\mathrm{b} 6_{\mathrm{x}} \mathrm{T}^{2} \mathrm{~V}_{\mathrm{x}}
$$

where $\mathrm{x}=\mathrm{BC}, \mathrm{DE}$, or $\mathrm{FF}$, as before. $\mathrm{V}_{\mathrm{x}}$ is the voltage on the appropriate transducer, $\mathrm{T}$ is the temperature, and $\rho_{\mathrm{x}}$ is the bottle sample density. The expansion is quadratic in terms of the temperature, but is linear in terms of $\mathrm{V}_{\mathrm{x}}$. (Note that the coefficients in Equation 6.6 have a different definition than in Equation 6.5) Table 6.2 lists the six coefficients for Probe 1 and Probe 2 for each value of $\mathrm{x}$.

For all of the data points in the analysis, the measured temperature and voltage were substituted into Equation 6.6 in order to predict the value of the density. Table 6.1 shows the temperature, voltage, and bottle density for six data points for Probe 1 and Probe 2. Table 6.4 compares the value of density ( $\rho$ ) predicted from Equation 6.6 with the bottle sample density. The average value of the error and the standard deviation of the error are shown. These results show that Equation 6.6 is an excellent representation of the data.

Table 6.4 Percent error in density based on Equation 6.6 compared to the bottle sample density

\begin{tabular}{|l|l|l|l||}
\hline & $\begin{array}{l}\text { \% errora for } \\
\text { Density for BC }\end{array}$ & $\begin{array}{l}\text { \% error for } \\
\text { Density for DE }\end{array}$ & $\begin{array}{l}\text { \% error for } \\
\text { Density for FF }\end{array}$ \\
\hline \hline Probe 1 & $0.26 \pm 0.30$ & $0.25 \pm 0.29$ & $0.28 \pm 0.30$ \\
\hline Probe 2 & $0.26 \pm 0.27$ & $0.34 \pm 0.29$ & $0.33 \pm 0.28$ \\
\hline a) & $\begin{array}{l}\text { The average value and standard deviation for the } \\
\text { percent error are shown for all of the data points } \\
\text { used in the analysis }\end{array}$ \\
\hline
\end{tabular}

Figures 6.6 and 6.7 show the variation in the density as a function of the voltage for Probes 1 and 2 respectively, when a given constant temperature is substituted into Equation 6.6. 
Probe 1 - RC BC versus V BC adj for Various Temperatures

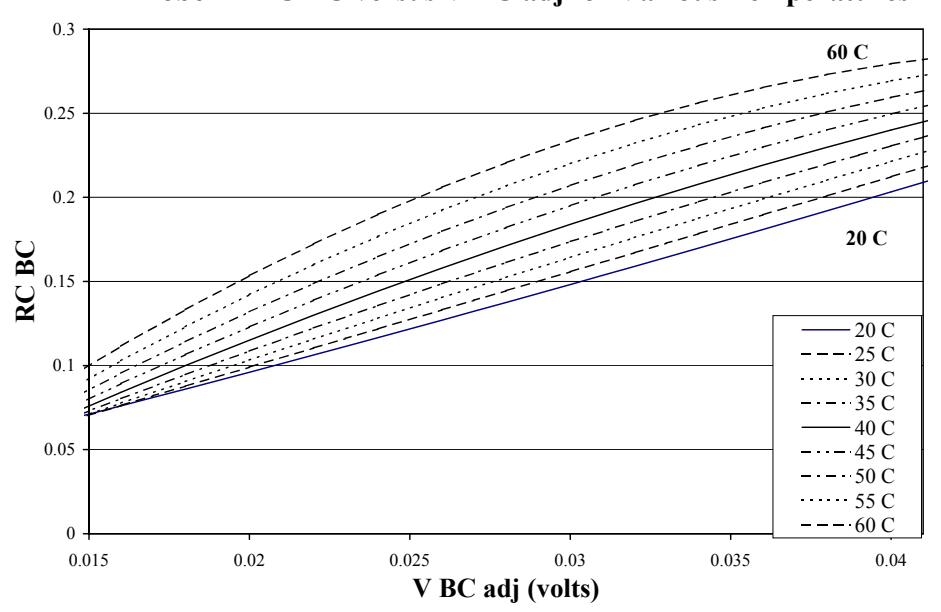

Probe 1 - RC DE versus V DE adj for Various Temperatures

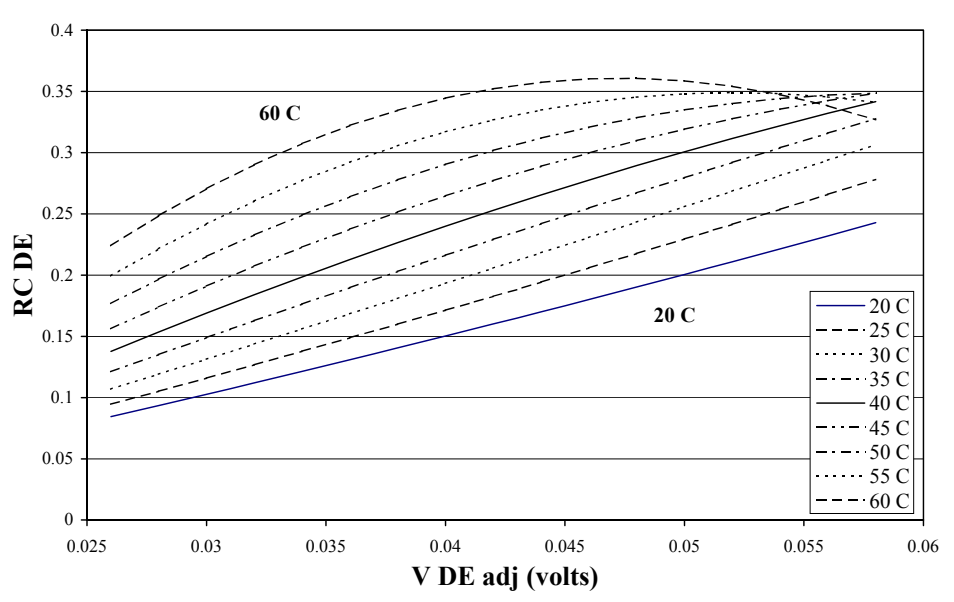

Probe 1 - RC FF versus V FF adj for Various Temperatures

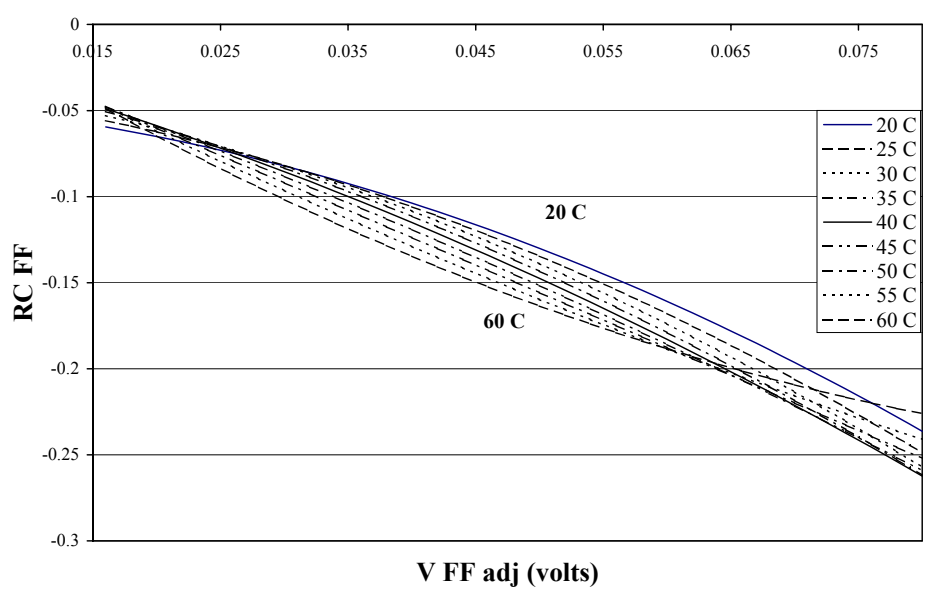

Figure 6.4 Probe 1 variation of reflection coefficient with voltage 
Probe 2 - RC BC versus V BC adj for Various Temperatures

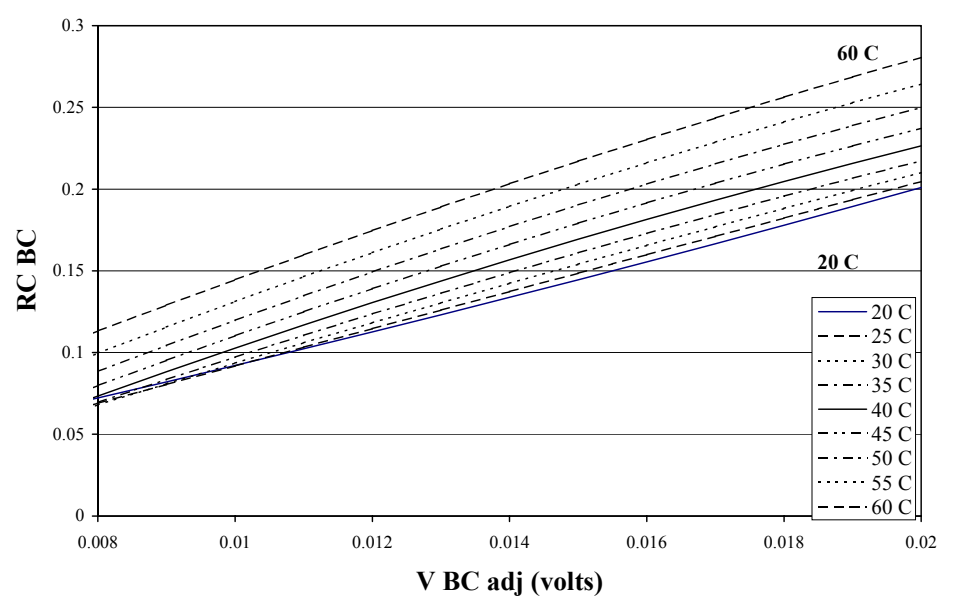

Probe 2 - RC DE versus V DE adj for Various Temperatures2

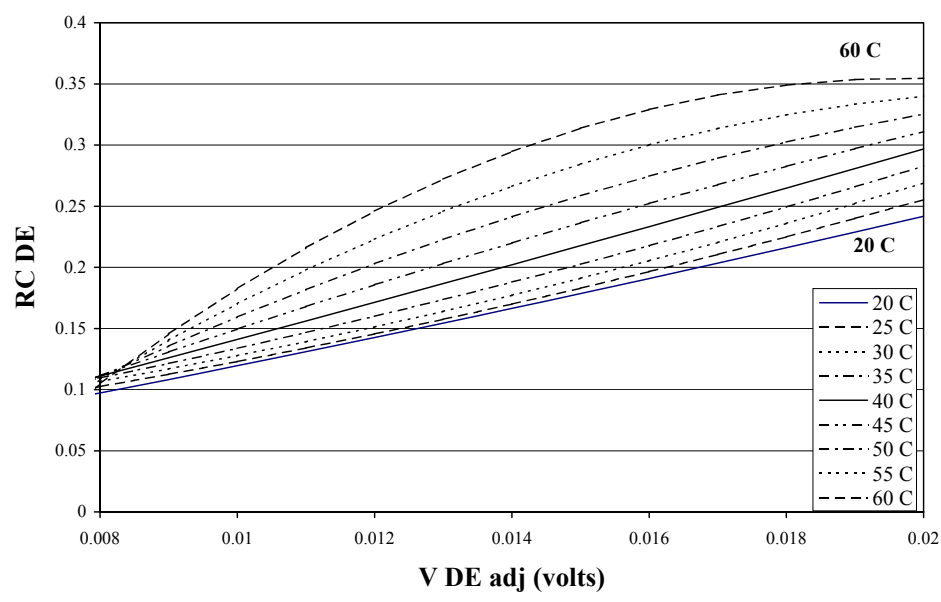

Probe 2 - RC FF versus V FF adj for Various Temperatures

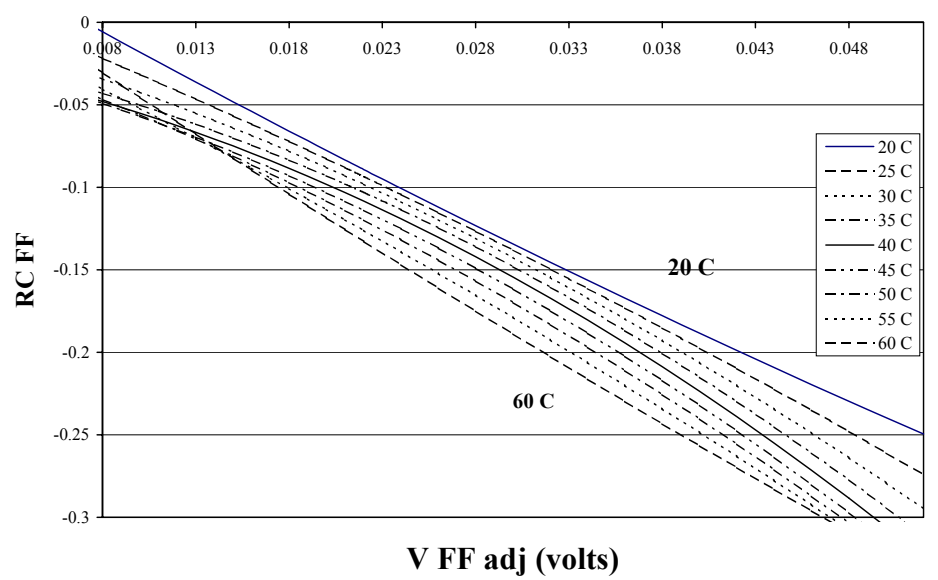

Figure 6.5 Probe 2 variation of reflection coefficient with voltage 
Probe 1- Density versus V BC adj for Various Temperatures

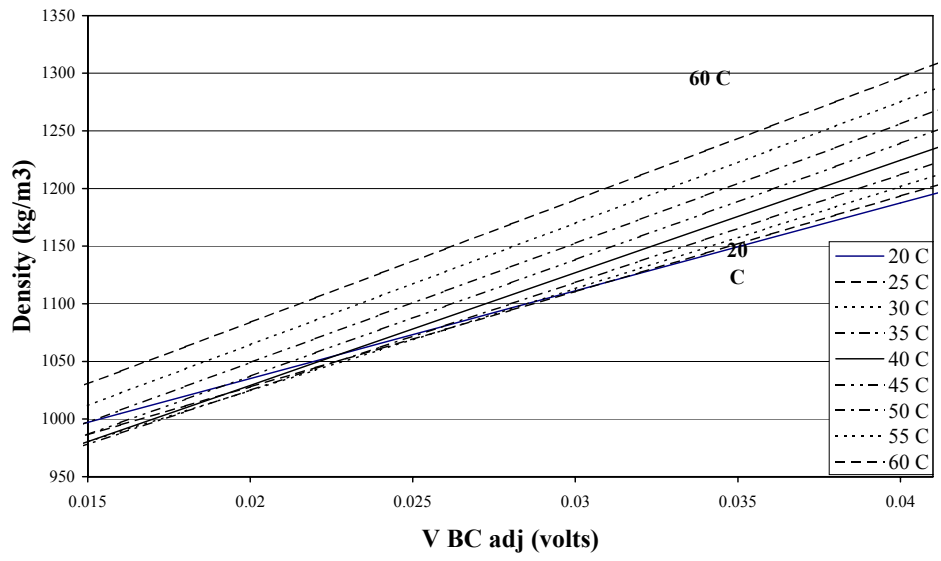

Probe 1 - Density versus V DE adj for Various Temperatures

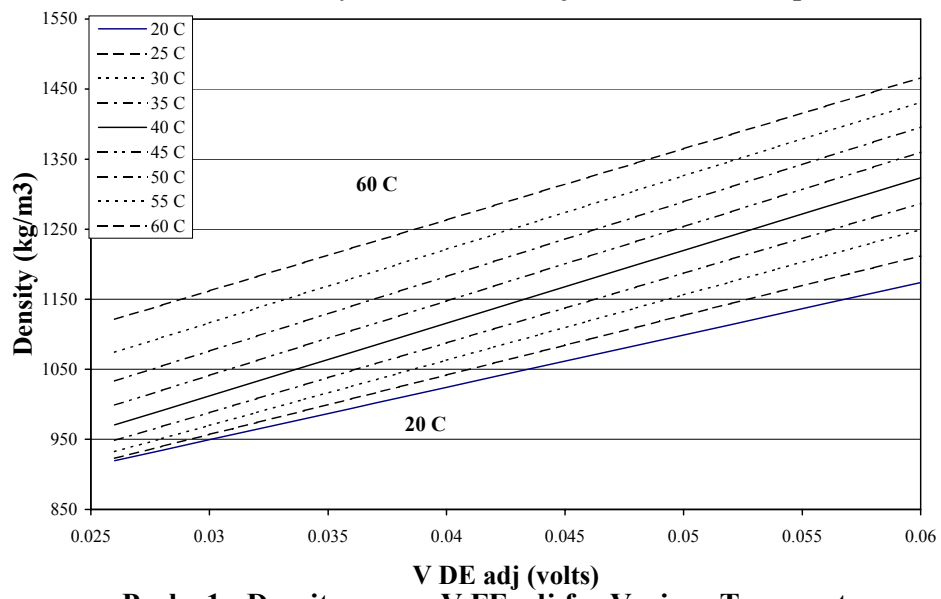

Probe 1 - Density versus V FF adj for Various Temperatures

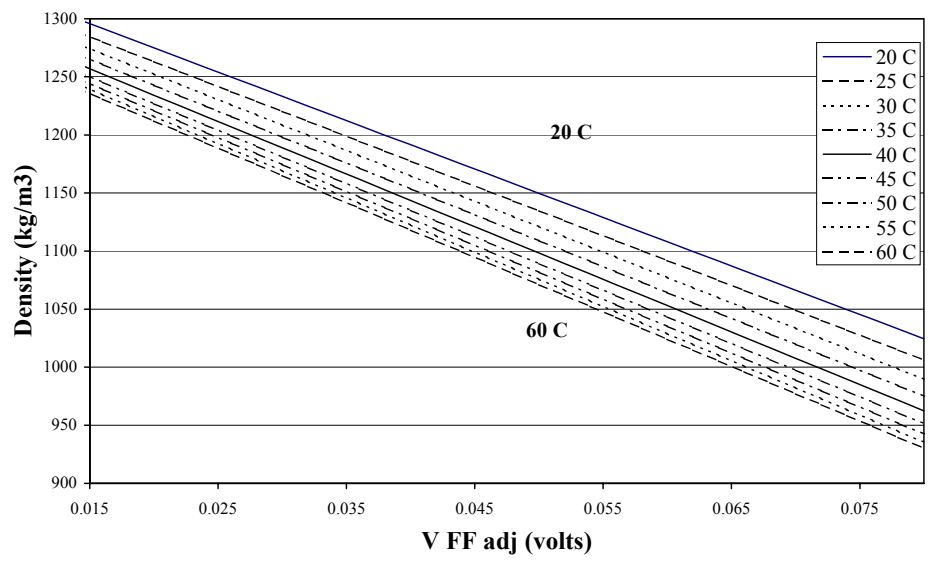

Figure 6.6 Probe 1 variation of density with voltage 
Probe 2 - Density versus V BC adj for Various Temperatures

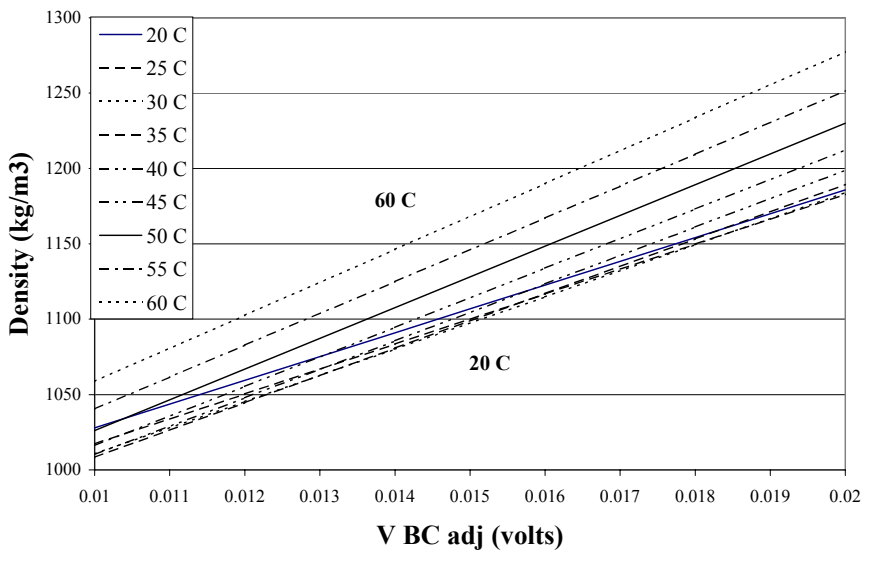

Probe 2 - Density versus V DE adj for Various Temperatures

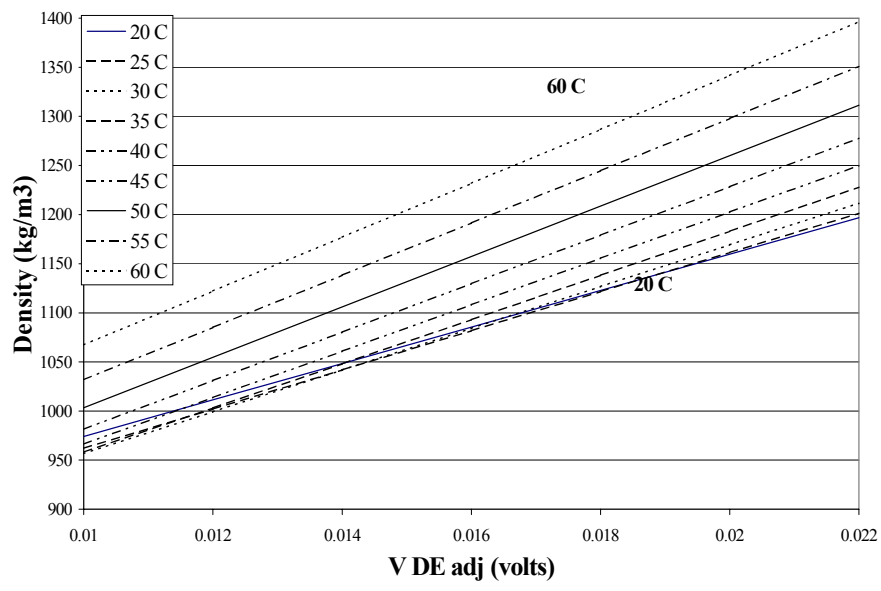

Probe 2 - Density versus V FF adj for Various Temperatures

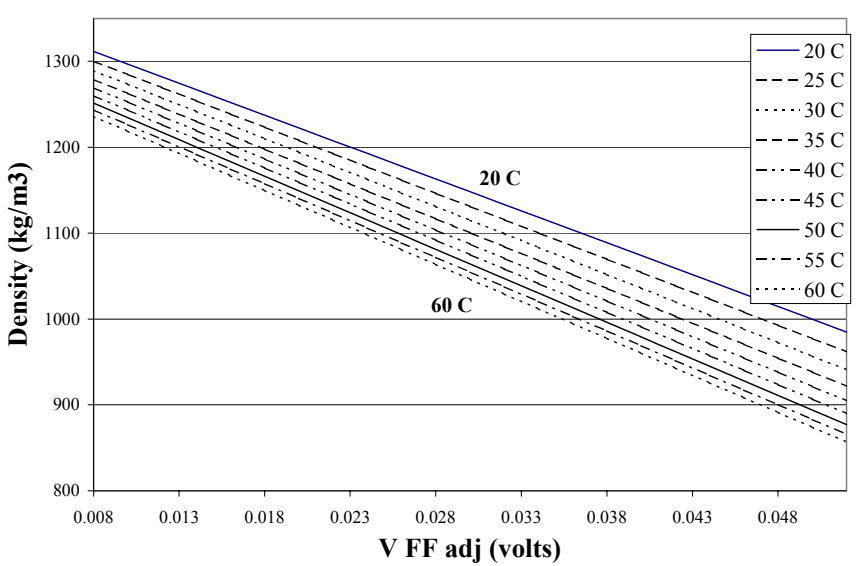

Figure 6.7 Variation of density with voltage 


\subsection{Determination of the Density}

Table 6.5 shows data for Probe 1 and Probe 2. The values $\mathrm{RC}_{\text {liqBC}}, \mathrm{RC}_{\text {liqDE}}$, and $\mathrm{RC}_{\text {liqFF }}$ were calculated using Equation 6.5. These values can be compared with the experimental reflection coefficients $\mathrm{RC}_{\mathrm{BCexp}}, \mathrm{RC}_{\mathrm{DEexp}}$, and $\mathrm{RC}_{\mathrm{FFexp}}$ that are given in Table 6.1. The agreement is very good. When the values of two reflection coefficients are known, the density of the liquid and speed of sound in the liquid can be determined. A simple procedure for this calculation is given in Equations 3.11 through 3.15. The table shows the density (density 0-60) obtained using values of $\mathrm{RC}_{\text {liqDE}}$, and $\mathrm{RC}_{\text {liqFF }}$. Similarly, it shows the density (density $0-47$ ) obtained using values of $\mathrm{RC}_{\text {liqBC }}$ and $\mathrm{RC}_{\text {liqFF }}$. Although Equations 16 through 23 (Greenwood, Skorpik, Bamberger, Harris 1999) illustrate the procedure to obtain the density and speed of sound when one angle is not $0^{\circ}$, the density obtained using $\mathrm{RC}_{\text {liqBC }}$ and $\mathrm{RC}_{\text {liqDE }}$ is not given. The reason is that the error in the value is larger, because there is only a 13 deg difference between these two angles.

Table 6.5 Voltage, reflection coefficient, and density data for probes 1 and 2

\begin{tabular}{|c|c|c|c|c|c|c|c|c|c|c|c|c|}
\hline \multirow[t]{2}{*}{ Probe } & \multirow{2}{*}{$\begin{array}{l}\text { Data Pt. } \\
\text { Number }\end{array}$} & \multirow{2}{*}{\begin{tabular}{|c|}
$\begin{array}{c}\text { Bottle } \\
\text { Density }\end{array}$ \\
$\left(\mathrm{kg} / \mathrm{m}^{3}\right)$ \\
\end{tabular}} & \multirow{2}{*}{\begin{tabular}{|c|}
$\begin{array}{c}\text { Base } \\
\text { Temp }\end{array}$ \\
$(C)$ \\
\end{tabular}} & \multirow{2}{*}{\begin{tabular}{|l|} 
Vadj BC \\
(volts)
\end{tabular}} & \multirow{2}{*}{\begin{tabular}{|c|} 
Vadj DE \\
(volts)
\end{tabular}} & \multirow{2}{*}{\begin{tabular}{|l|} 
Vadj FF \\
(volts)
\end{tabular}} & \multirow[t]{2}{*}{ RCliq BC } & \multirow[t]{2}{*}{ RCliq DE } & \multirow{2}{*}{ RCliq FF } & \multirow{2}{*}{\begin{tabular}{|c|c}
$\begin{array}{c}\text { Density } \\
0-60\end{array}$ \\
$\left(\mathrm{~kg} / \mathrm{m}^{3}\right)$
\end{tabular}} & \multirow{2}{*}{\begin{tabular}{|c|}
$\begin{array}{c}\text { Density } \\
0-47\end{array}$ \\
$\left(\mathrm{~kg} / \mathrm{m}^{3}\right)$
\end{tabular}} & \multirow{2}{*}{\begin{tabular}{|c|}
$\begin{array}{c}\text { Density } \\
0-47-60\end{array}$ \\
$\left(\mathrm{~kg} / \mathrm{m}^{3}\right)$
\end{tabular}} \\
\hline & & & & & & & & & & & & \\
\hline 1 & 17 & 998 & 21.9 & 0.0156 & 0.0362 & 0.0808 & 0.0740 & 0.1384 & -0.2450 & 999 & 1010 & 999 \\
\hline 1 & 212 & 1032 & 35.7 & 0.0209 & 0.0337 & 0.0665 & 0.1155 & 0.1771 & -0.2049 & 1031 & 1015 & 1031 \\
\hline 1 & 325 & 1072 & 47.5 & 0.0233 & 0.0319 & 0.0526 & 0.1538 & 0.2189 & -0.1622 & 1075 & 1076 & 1075 \\
\hline 1 & 383 & 1096 & 52.8 & 0.0238 & 0.0307 & 0.0453 & 0.1693 & 0.2369 & -0.1432 & 1099 & 1116 & 1105 \\
\hline 1 & 1896 & 1164 & 29.3 & 0.0353 & 0.0512 & 0.0407 & 0.1937 & 0.2596 & -0.1099 & 1164 & 1188 & 1172 \\
\hline 1 & 2786 & 1241 & 57.6 & 0.0344 & 0.0385 & 0.0160 & 0.2518 & 0.3229 & -0.0481 & 1247 & 1267 & 1253 \\
\hline 2 & 10 & 998 & 24.3 & 0.0087 & 0.0117 & 0.0475 & 0.0774 & 0.1411 & -0.2426 & 997 & 1002 & 997 \\
\hline 2 & 1350 & 1053 & 45.3 & 0.0118 & 0.0129 & 0.0329 & 0.1366 & 0.2016 & -0.1812 & 1051 & 1052 & 1052 \\
\hline 2 & 2816 & 1164 & 41.3 & 0.0179 & 0.0181 & 0.0208 & 0.2062 & 0.2716 & -0.1033 & 1152 & 1154 & 1153 \\
\hline 2 & 3764 & 1219 & 47.5 & 0.0198 & 0.0188 & 0.0120 & 0.2411 & 0.3035 & -0.0658 & 1221 & 1205 & 1216 \\
\hline 2 & 3801 & 1237 & 54.4 & 0.0191 & 0.0173 & 0.0097 & 0.2523 & 0.3140 & -0.0511 & 1262 & 1246 & 1256 \\
\hline 2 & 3812 & 1241 & 56.4 & 0.0186 & 0.0165 & 0.0092 & 0.2519 & 0.3146 & -0.0459 & 1292 & 1294 & 1293 \\
\hline
\end{tabular}

\subsubsection{Using data for three angles}

Consider using the reflection coefficients $\mathrm{RC}_{\mathrm{liqDE}}$, and $\mathrm{RC}_{\mathrm{liqFF}}$ to find the density and speed of sound in the liquid. Since all variables are now known, the reflection coefficient as a function of angle can be plotted (See Figure3.3). While the reflection coefficients $\mathrm{RC}_{\text {liqDE }}$ and $\mathrm{RC}_{\text {liqFF }}$ will lie exactly on this curve, it is not likely that $\mathrm{RC}_{\text {liqBC }}$ will. Let us denote the value on the curve at $47 \mathrm{deg}$ as $\mathrm{RC}_{\mathrm{tBC}}$. The difference between the theoretical curve and $\mathrm{RC}_{\mathrm{liqBC}}$ is given by:

$$
\text { Dev47 }=\mathrm{RC}_{\mathrm{liqBC}}-\mathrm{RC}_{\mathrm{tBC}}
$$

The objective is to reduce the difference between $\mathrm{RC}_{\mathrm{liqBC}}$ and the final theoretical curve by a factor of two: 


$$
\text { Devadj }=\text { Dev47 (devcon) }
$$

Where devcon is usually taken to be 0.5 . The reflection coefficient at $60 \mathrm{deg}$ is also adjusted. The following are the adjusted reflection coefficients:

$$
\begin{aligned}
& \mathrm{RC}_{\mathrm{adjDE}}=\mathrm{RC}_{\text {liqDE}}+\text { Devadj } \\
& \mathrm{RC}_{\mathrm{adjBC}}=\mathrm{RC}_{\text {liqBC}}+\text { Devadj }
\end{aligned}
$$

The reflection coefficient for FF remains unchanged:

$$
\mathrm{RC}_{\mathrm{adjFF}}=\mathrm{RC}_{\text {liqFF }}
$$

The final solution is obtained by using $\mathrm{RC}_{\mathrm{adjDE}}$ and $\mathrm{RC}_{\text {liqFF }}$ to determine the value of the density and speed of sound. The values in the last column of Table 6.5, labeled density 0-47-60, were obtained in this manner, with one exception that will now be discussed. Data in Table 6.5 shows that the final value of the density is between that for density $0-60$ and density $0-47$, as would be expected.

\subsubsection{Procedure for Densities Less Than $1050 \mathrm{~kg} / \mathrm{m}^{3}$}

The analysis of the data showed that for small values of the density, values less than about 1050 $\mathrm{kg} / \mathrm{m}^{3}$, the regression analysis for the density is more accurate than using the two reflection coefficients, obtained from the regression analysis. Therefore, for this density region, the final value of the density is given by

$$
\text { Density } 0-47-60=\left(\rho_{\mathrm{BC}}+\rho_{\mathrm{DE}}\right) / 2
$$

Where $\rho_{\mathrm{BC}}$ and $\rho_{\mathrm{DE}}$ are determined from Equation 6.6. $\rho_{\mathrm{FF}}$ was not included in the average because Table 6.4 shows that the error is slightly larger for it than the other values.

\subsubsection{Statistical Analysis}

Figure 6.8 shows the final value of the density, density $0-47-60$, plotted versus the data point number and also the percent error relative to the bottle sample density.

One important question is whether the measurement of the density shows any bias. The quantity delta is defined as:

$$
\text { Delta }=\text { density value }- \text { bottle sample density }
$$

where delta can be positive or negative. The bias is defined as:

$$
\text { Bias }=\text { average value of delta }
$$


Table 6.6 shows the bias and the standard deviation of the value of delta. Data in Table 6.6 show that the bias values for both probes are very low. The conclusion is that the density sensor does not show a bias in its determination of the density. The standard deviation of the delta values is lower for Probe 1 than for Probe 2. Table 6.6 also shows the average value of the percent error relative to the bottle sample density for all of the data points. The standard deviation for the percent error is also shown. Table 6.7 shows the comparison of the average value of the density and its standard deviation with the bottle sample density. The percent error is obtained by comparing the average value of the density with the bottle sample density.

\section{Density 0-47-60 vs Data Point Number, Probe 1}

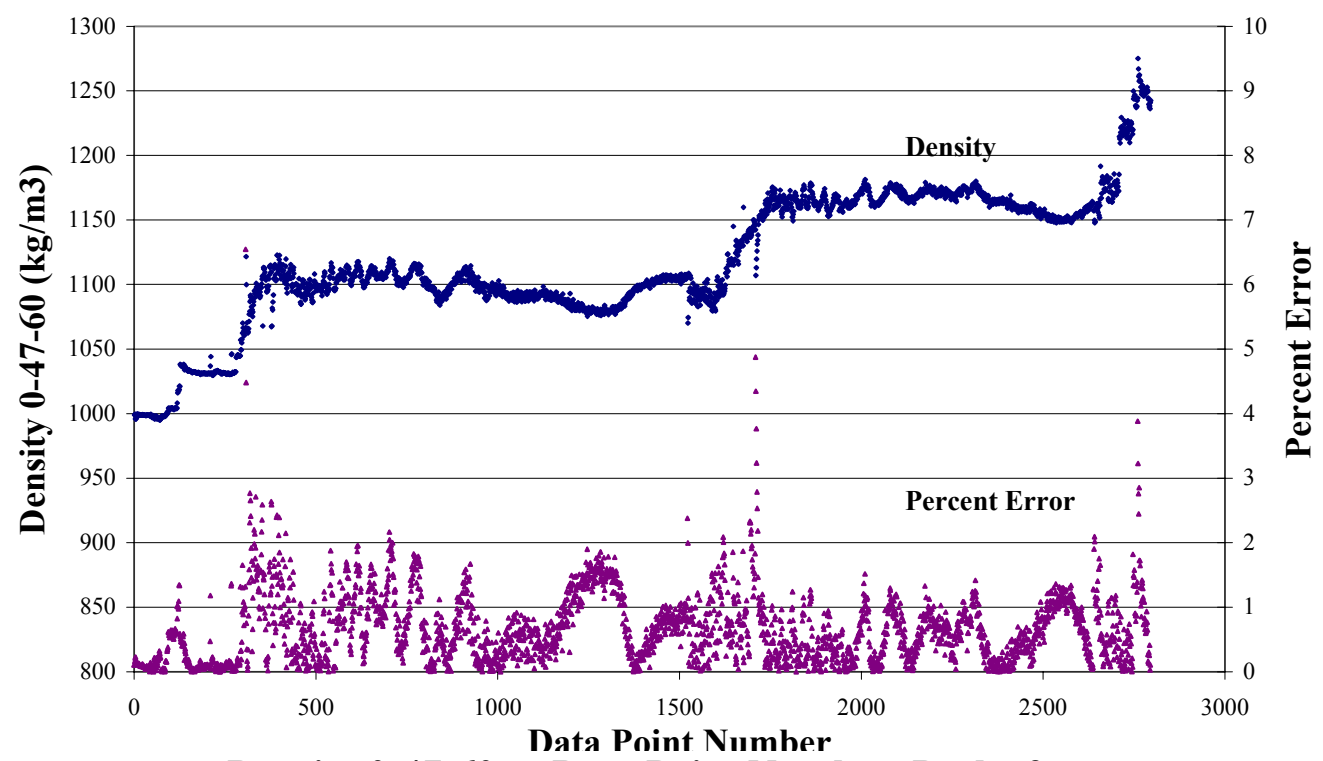

Density 0-47-60 vs Data Point Number, Probe 2

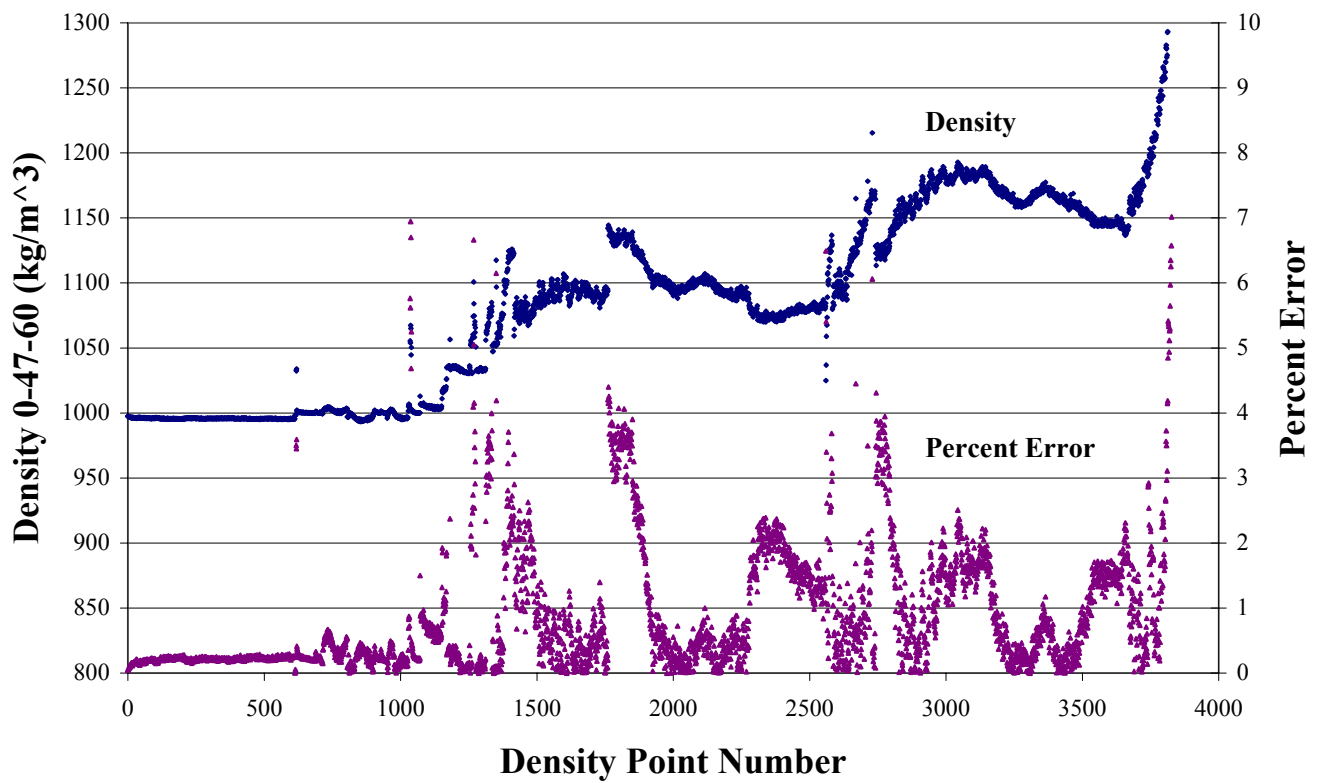

Figure 6.8 Density and percent error for Probes 1 and 2

6.15 
Table 6.6 Statistical analysis for final values of density

\begin{tabular}{||l|l|c|c||}
\hline \hline & Bias & $\begin{array}{c}\text { Standard Deviation } \\
\text { of Delta }\end{array}$ & $\begin{array}{c}\text { Average Percentage } \\
\text { Error }\end{array}$ \\
\cline { 2 - 4 } & $\mathbf{( k g / \mathbf { m } ^ { \mathbf { 3 } } )}$ & $\mathbf{( k g / \mathbf { m } ^ { \mathbf { 3 } } )}$ & $0.66 \pm 0.55$ \\
\hline Probe 1 & 0.70 & 9.64 & $0.90 \pm 0.99$ \\
\hline Probe 2 & 0.59 & 15.00 & 0.00 \\
\hline
\end{tabular}

Table 6.7 Comparison of density values with bottle sample density

\begin{tabular}{|c|c|c|c|c|c|c|}
\hline \multirow{3}{*}{$\begin{array}{c}\text { Bottle } \\
\text { Sample } \\
\text { Density } \\
\left(\mathrm{kg} / \mathrm{m}^{3}\right)\end{array}$} & \multicolumn{3}{|c|}{ Probe 1} & \multicolumn{3}{|c|}{ Probe 2} \\
\hline & \multirow[t]{2}{*}{$\begin{array}{l}\text { No. Data } \\
\text { Points }\end{array}$} & Density & $\begin{array}{c}\text { Percent } \\
\text { Error }\end{array}$ & \multirow[t]{2}{*}{$\begin{array}{c}\text { No. Data } \\
\text { Points }\end{array}$} & Density & $\begin{array}{c}\text { Percent } \\
\text { Error }\end{array}$ \\
\hline & & $\left(\mathrm{kg} / \mathrm{m}^{3}\right)$ & $(\%)$ & & $\left(\mathrm{kg} / \mathrm{m}^{3}\right)$ & $(\%)$ \\
\hline 998 & 119 & $999+3$ & 0.1 & 1155 & $998+6$ & 0.0 \\
\hline 1008 & 7 & $1019 \pm 2$ & 1.1 & 15 & $1019 \pm 3$ & 1.2 \\
\hline 1032 & 154 & $1032 \pm 3$ & 0.0 & 154 & $1039 \pm 13$ & 0.7 \\
\hline 1043 & 13 & $1046 \pm 18$ & 0.2 & 13 & $1079 \pm 3$ & 3.4 \\
\hline 1053 & 16 & $1067 \pm 18$ & 1.4 & 16 & $1059 \pm 19$ & 0.6 \\
\hline 1062 & 16 & $1076 \pm 10$ & 1.3 & 16 & $1062 \pm 5$ & 0.0 \\
\hline 1072 & 11 & $1089 \pm 8$ & 1.6 & 11 & $1077 \pm 6$ & 0.5 \\
\hline 1081 & 17 & $1097 \pm 4$ & 1.5 & 17 & $1105 \pm 8$ & 2.2 \\
\hline 1096 & 1249 & $1097 \pm 10$ & 0.1 & 1243 & $1095 \pm 17$ & -0.1 \\
\hline 1108 & 15 & $1097 \pm 5$ & -1.0 & 15 & $1113 \pm 5$ & 0.4 \\
\hline 1115 & 16 & $1104 \pm 10$ & -1.0 & 16 & $1126 \pm 11$ & 1.0 \\
\hline 1124 & 15 & $1119 \pm 8$ & -0.5 & 15 & $1131 \pm 6$ & 0.6 \\
\hline 1131 & 15 & $1124 \pm 7$ & -0.7 & 14 & $1140 \pm 5$ & 0.7 \\
\hline 1138 & 15 & $1133 \pm 8$ & -0.4 & 15 & $1154 \pm 9$ & 1.4 \\
\hline 1146 & 15 & $1138 \pm 3$ & -0.7 & 15 & $1166 \pm 15$ & 1.8 \\
\hline 1164 & 945 & $1164 \pm 9$ & 0.0 & 940 & $1163 \pm 16$ & -0.1 \\
\hline 1172 & 21 & $1160 \pm 10$ & -1.0 & 21 & $1161 \pm 5$ & -1.0 \\
\hline 1177 & 34 & $1175 \pm 6$ & -0.2 & 34 & $1170 \pm 6$ & -0.7 \\
\hline 1183 & 16 & $1177 \pm 5$ & -0.6 & 15 & $1188 \pm 3$ & 0.4 \\
\hline 1219 & 38 & $1219 \pm 5$ & 0.0 & 38 & $1206 \pm 13$ & -1.1 \\
\hline 1227 & 18 & $1249 \pm 11$ & 1.8 & 17 & $1243 \pm 8$ & 1.3 \\
\hline 1237 & 15 & $1252 \pm 4$ & 1.2 & 16 & $1268 \pm 9$ & 2.5 \\
\hline 1241 & 16 & $1245 \pm 6$ & 0.3 & 16 & $1309 \pm 10$ & 5.5 \\
\hline
\end{tabular}




\subsection{Computer Control System Operating Instructions}

The object of this chapter is to describe the computer code and give information about the input files and output files. It will also describe how to determine if any settings need to be adjusted.

\subsection{Directory Structure}

The following are subdirectories of C: $\mid$ work $\mid c p g m s \backslash d e n 00$ :

- WINDOWS

- DBASE

- LKUP

- MAKE

- MENU

- RUN

- SETUP

- START

- SYS

- TEMP

- UT

- $\mathrm{AD}$

- DATA

The executable file, main.exe, is located in the MAKE subdirectory. The file in which the density is calculated from the measurements is called density.c, which is located in the RUN subdirectory.

The following are steps to running the program:

- Click on the "DOS Prompt Density" icon to get to C:IWindows

- Type "cd .." to get the $\mathrm{C}: \mathrm{I}$

- Type toden00, which executes toden00.bat that takes you to C: $\mid$ work $\backslash$ cpgms $\backslash$ den00

- Type main, which executes main.bat that starts the execution of main.exe. (Another alternative is to go to the MAKE subdirectory and type main to start the execution.)

It should not be necessary to recompile the program, but, if some changes are made, the following steps are used for recompiling:

- In the den00 directory, type "touch setup\defines.h" This ensures that all files are recompiled.

- In the den00 directory, type "mk" (which calls mk.bat and carries out the compilation).

\subsection{Input File}

The input file, constnts.dat, is located in the MAKE subdirectory and supplies parameters used by the program. This file is called in the code density.c in the function named load_data. The following parameters are read from the file, with one parameter per line on the file: corrbc, corrde, corraa, corrff, 
addsubbc, addsubde, addsubaa, addsubff, necho, devcon, and ialtsol. The first ten parameters are entered as decimal values, and the last as an integer without a decimal point.

Before defining each of these parameters, we shall consider how one can make adjustments, if there has been some change in the transducer performance. Ideally, the voltage, obtained by each transducer pair $\mathrm{BC}, \mathrm{DE}, \mathrm{AA}$, and FF when the liquid is water, is the same as that obtained from the calibration. For this ideal case, corrxx $=1.0$ and addsubxx $=0.0$, where $\mathrm{xx}$ is a shorthand for $\mathrm{BC}, \mathrm{DE}, \mathrm{AA}$, and $\mathrm{FF}$.

The voltage on a transducer depends upon the amplifier gain. The adjusted voltage Vadjxx is defined as the voltage adjusted to $0.0 \mathrm{~dB}$ amplifier gain and this is given on the output files as will be discussed shortly. The objective is to use corrxx and addsubxx and adjust the actual (or current value) Vadjxx so that it is equal to the desired value (i.e., the value obtained during calibration.)

$$
\text { Desired value of Vadjxx }=(\operatorname{corrxx}) \text { Vadjxx }+\operatorname{addsubxx}
$$

In order to calculate the viscosity of the liquid, using the voltage on AA, the echo number, necho, must be specified.

The parameter "devcon" is defined in Equation 6.8. A value of 0.5 means that the final theoretical curve passes midway between the reflection coefficients for $47 \mathrm{deg}$ and $60 \mathrm{deg}$. A value of 0.0 means that the curve passes through the reflection coefficient at $60 \mathrm{deg}$. A value of 1.0 means that the curve passes through the reflection coefficient at $47 \mathrm{deg}$.

The parameter "ialtsol" is a parameter indicating an "alternate solution." This parameter can have a value ranging from 0 to 6 . The following specifies how to set this value:

Ialtsol $=0 \quad$ Ideal case and indicates no problems with any of the transducers.

Ialtsol $=1 \quad$ Indicates that transducer $\mathrm{BC}$ is not operational and that the density value is obtained without using this transducer.

Iastsol $=2 \quad$ Indicates that transducer DE is not operational and that the density value is obtained without using this transducer.

Ialtsol $=3 \quad$ Indicates that transducer FF is not operational. The density is obtained using an average value of $\rho_{\mathrm{BC}}$ and $\rho_{\mathrm{DE}}$ obtained from Equation 6.6.

Ialtsol $=4 \quad$ Only transducer BC is operational. The density is obtained using $\rho_{\mathrm{BC}}$

Ialtsol $=5 \quad$ Only transducer $\mathrm{DE}$ is operational. The density is obtained using $\rho_{\mathrm{DE}}$ from Equation 6.6.

Ialtsol $=6 \quad$ Only transducer FF is operational. The density is obtained using $\rho_{\mathrm{FF}}$ from Equation 6.6. 


\subsection{Output Files}

There are five output files: denvisc1.dat, rawdta1.dat, datasum1.dat, calc2.dat, and another in the subdirectory den00\datalsy101. The first four files are located in the MAKE subdirectory.

The output file, denvisc1.dat for Probe 1 or denvisc2.dat for Probe 2, prints the values of the date, time, the final value of the density in $\mathrm{kg} / \mathrm{m}^{3}$, the velocity of sound in $\mathrm{m} / \mathrm{sec}$, and the viscosity in centipoise. When the code is running, the data are APPENDED to this file. At some point, this file will become large. Therefore, it is recommended to copy this file to another name and then delete denvisc1.dat at the start of a new run.

The output file, rawdta1.dat (or rawdta2.dat) prints out information about the voltages and the amplifier gains on one line: date, time, VBC, VDE, VAA, VFF, VGG, gainBC, gainDE, gainAA, gainFF, gainGG. The amplifier gains are given in decibels $(\mathrm{dB})$. As the data is obtained, it is appended to the existing file.

The output file datasum1.dat prints out 40 parameters on one line on the file. When the code is running, the data are APPENDED to this file. This output file can easily be viewed using Excel. Table 7.1 shows the headings for the 40 columns and also provides comments about those parameters whose definitions are not obvious. The parameter irhoexp was not defined in Table 7.1. In the code density.c, irhoexp is initially set equal to 0 . This value can change under two conditions:

- If the den0-60 is less than $1050 \mathrm{~kg} / \mathrm{m}^{3}$, then the density is calculated using the regression analysis in terms of density, given by Equation 6.6. In this case, irhoexp is set equal to 1. A velocity of sound cannot be determined in this case and it is set equal to $999 \mathrm{~m} / \mathrm{sec}$, to serve as a flag.

- The regression analysis for the reflection coefficient is valid between density values of $998 \mathrm{~kg} / \mathrm{m}^{3}$ and $1241 \mathrm{~kg} / \mathrm{m}^{3}$. Outside of this region the regression analysis in terms of density is used and irhoexp is set equal to 2 .

It should be pointed out that the final value of the density and velocity of sound, given in the output file denvisc1.dat, are the values den0-47-60 and c0-47-60 when irhoexp is equal to 0 . When irhoexp is equal to 1 or 2, the regression analysis in terms of density (Equation 6.6) is used and this value of the density becomes the so-called final value of the density.

\subsubsection{Adjusted Voltage}

We shall consider two types of voltages. The first is the voltage measured by the instrument with a certain amplifier gain. The second is the adjusted voltage that results by calculating the voltage at $0.0 \mathrm{~dB}$ amplifier gain (which means that there is no amplifier gain.) The relationship between them is given by:

$$
\text { Adjusted voltage }=(\text { measured voltage }) \times 10^{-(\text {amplifier gain in } \mathrm{dB} / 20)}
$$


Table 7.1 Information about output files datasum1.dat or datasum2.dat

\begin{tabular}{|c|c|c|c|c|c|c|c|c|}
\hline Date & Time & Temp_Base & Temp_Top & VadjBC & VadjDE & VadjAA & VadjFF & VadjGG \\
\hline & & (C) & (C) & (volts) & (volts) & (volts) & (volts) & (volts) \\
\hline & & & & & & & & \\
\hline & & & & & & & & \\
\hline vtref $2 B C$ & vtref2DE & vtref $2 \mathrm{AA}$ & vtref2FF & $\begin{array}{c}\text { vtref } 2 \mathrm{G} \\
\mathrm{G}\end{array}$ & RCliqBC & RCliqDE & RCliqAA & RCliqFF \\
\hline (volts) & (volts) & (volts) & (volts) & (volts) & & & & \\
\hline & & & & & & & & \\
\hline den $0-60$ & $\mathrm{c} 0-60$ & den0-47 & $\mathrm{c} 0-47$ & rhobc & rhode & rhoff & denrhoex & viscosity \\
\hline$\left(\mathrm{kg} / \mathrm{m}^{3}\right)$ & $(\mathrm{m} / \mathrm{sec})$ & $\left(\mathrm{kg} / \mathrm{m}^{3}\right)$ & $(\mathrm{m} / \mathrm{sec})$ & $\left(\mathrm{kg} / \mathrm{m}^{3}\right)$ & $\left(\mathrm{kg} / \mathrm{m}^{3}\right)$ & $\left(\mathrm{kg} / \mathrm{m}^{3}\right)$ & $\left(\mathrm{kg} / \mathrm{m}^{3}\right)$ & (cP) \\
\hline & & & & & & & & \\
\hline $\operatorname{den} 0-47-60$ & $\mathrm{c} 0-47-60$ & necho & corrbc & corrde & corraa & corrff & addsubbc & addsubde \\
\hline$\left(\mathrm{kg} / \mathrm{m}^{3}\right)$ & $(\mathrm{m} / \mathrm{sec})$ & & & & & & & \\
\hline & & & & & & & & \\
\hline & & & & & & & & \\
\hline addsubaa & addsubff & irhoexp & ialtsol & & & & & \\
\hline & & & & & & & & \\
\hline Comments & & & & & & & & \\
\hline $\mathrm{xx}$ stands $\mathrm{f}$ & or $\mathrm{BC}, \mathrm{DE}$, & $\mathrm{AA}, \mathrm{FF}$, and & or GG & & & & & \\
\hline Vadjxx are & the voltage & s adjusted to & $0.0 \mathrm{~dB}$ ampli & ifier gain. & & & & \\
\hline vtref $2 x x$ ar & e the water & reference vol & tages at $0.0 \mathrm{c}$ & $\mathrm{BB}$ at a giv & en tempera & ure. & & \\
\hline RCliqxx ar & e the reflec & tion coefficier & nts calculatec & using the & regression & analysis, E & uation 6.5 & \\
\hline den0-60 an & $\mathrm{d} \mathrm{c} 0-60$ are & the density a & nd velocity o & f sound ot & tained usir & g 0 and 60 & degree angl & \\
\hline den0-47 an & $\mathrm{d} \mathrm{c} 0-47$ are & the density a & nd velocity o & f sound ob & tained usir & g 0 and 47 & degree angl & \\
\hline den $0-47-60$ & and $\mathrm{c} 0-47$ & 60 values are & obtained usi & ing 0,47 , & and 60 deg & ee angles. & & \\
\hline rhoxx $(\rho x x$ & ) are the de & nsity values o & btained using & $g$ the regre & ssion analy & sis for den & ity, Equatio & 6.6. \\
\hline denrhoex is & the averag & e value of the & applicable $\mathrm{v}$ & alues of rl & $10 x x$ & & & \\
\hline
\end{tabular}

\section{End of Table 7.1}

The amplifier gain has also been calibrated and is usually not exactly an integer. Table 7.2 gives the values of the amplifier gains for each $\mathrm{dB}$ setting. 
Table 7.2 Amplifier gain calibrations for computer 1 and computer 2

\begin{tabular}{|c|c|c|}
\hline & Probe 1 & Probe 2 \\
\hline dB Setting & Board \#1 & Board \#2 \\
\hline 1 & 0.82 & 0.98 \\
\hline 2 & 1.72 & 1.82 \\
\hline 3 & 2.92 & 2.86 \\
\hline 4 & 3.94 & 3.67 \\
\hline 5 & 4.88 & 4.62 \\
\hline 6 & 5.87 & 5.84 \\
\hline 7 & 6.72 & 6.82 \\
\hline 8 & 7.77 & 7.81 \\
\hline 9 & 8.82 & 8.61 \\
\hline 10 & 9.88 & 9.86 \\
\hline 11 & 11.14 & 11.12 \\
\hline 12 & 12.02 & 12.21 \\
\hline 13 & 12.85 & 13.21 \\
\hline 14 & 13.97 & 14.25 \\
\hline 15 & 15.03 & 15.09 \\
\hline 16 & 16.27 & 16.11 \\
\hline 17 & 17.23 & 17.14 \\
\hline 18 & 18.1 & 18.23 \\
\hline 19 & 19.11 & 19.43 \\
\hline 20 & 20.03 & 20.27 \\
\hline 21 & 21.04 & 20.83 \\
\hline 22 & 22.28 & 21.82 \\
\hline 23 & 23.21 & 22.88 \\
\hline 24 & 24.23 & 24.15 \\
\hline 25 & 25.11 & 25.17 \\
\hline 26 & 26.05 & 26.02 \\
\hline 27 & 27.26 & 26.98 \\
\hline 28 & 28.28 & 27.89 \\
\hline 29 & 29.2 & 28.92 \\
\hline 30 & 30.21 & 30.16 \\
\hline 31 & 30.87 & 31.02 \\
\hline 32 & 31.96 & 32.02 \\
\hline 33 & 32.93 & 32.84 \\
\hline 34 & 33.91 & 33.74 \\
\hline 35 & 34.78 & 34.89 \\
\hline 36 & 35.32 & 35.88 \\
\hline 37 & 35.69 & 36.75 \\
\hline 38 & 35.91 & 37.51 \\
\hline 39 & 35.97 & 37.92 \\
\hline
\end{tabular}




\begin{tabular}{||l|c|c||}
\hline \multicolumn{1}{|c|}{40} & 36.02 & 38.13 \\
\hline & & \\
\hline Notes: \\
\hline $\begin{array}{l}\text { 1. High Voltage off. } \\
\text { 2. Board \#1 0-40 dB window was shifted }+1.8 \mathrm{~dB} \text { to set } \\
\text { the } 0 \mathrm{~dB} \text { point }\end{array}$ \\
\hline
\end{tabular}

The file calc2.dat, shown in Table 7.3, is very useful when water is the liquid in the pipeline and you want to check the calibration of the density sensor. Usually, the data are listed in a line sequentially as $\mathrm{BC}, \mathrm{DE}, \mathrm{AA}$, and FF. The voltages for the current liquid are shown in the line labeled "Voltages=". The next line shows the adjusted voltages (“Adj volt:") obtained using the exact gain settings ("gainadj:"). The next three lines show the same quantities for the reference fluid, which is water. Therefore, if the current fluid in the pipeline is water, then the values listed under "Adj volt:" should be the same as those listed under "Adj volt ref:" If they are not, then they can be corrected by using appropriate values of corrxx and addsubxx. This file gives information only about the last complete data set. That is, the next set of data writes over the preceding set and the data is obviously, not appended to the existing file. (The example shown of calc2.dat is not representative because this example is reading data from a file, with the pulser turned off. The adjusted voltages should be less than the voltages and they are not here.) It should also be noted that the adjusted voltage for the liquid and for reference (water) are also given in the file datasum1.dat, as explained above.

Table 7.3 Example of file calc2.dat

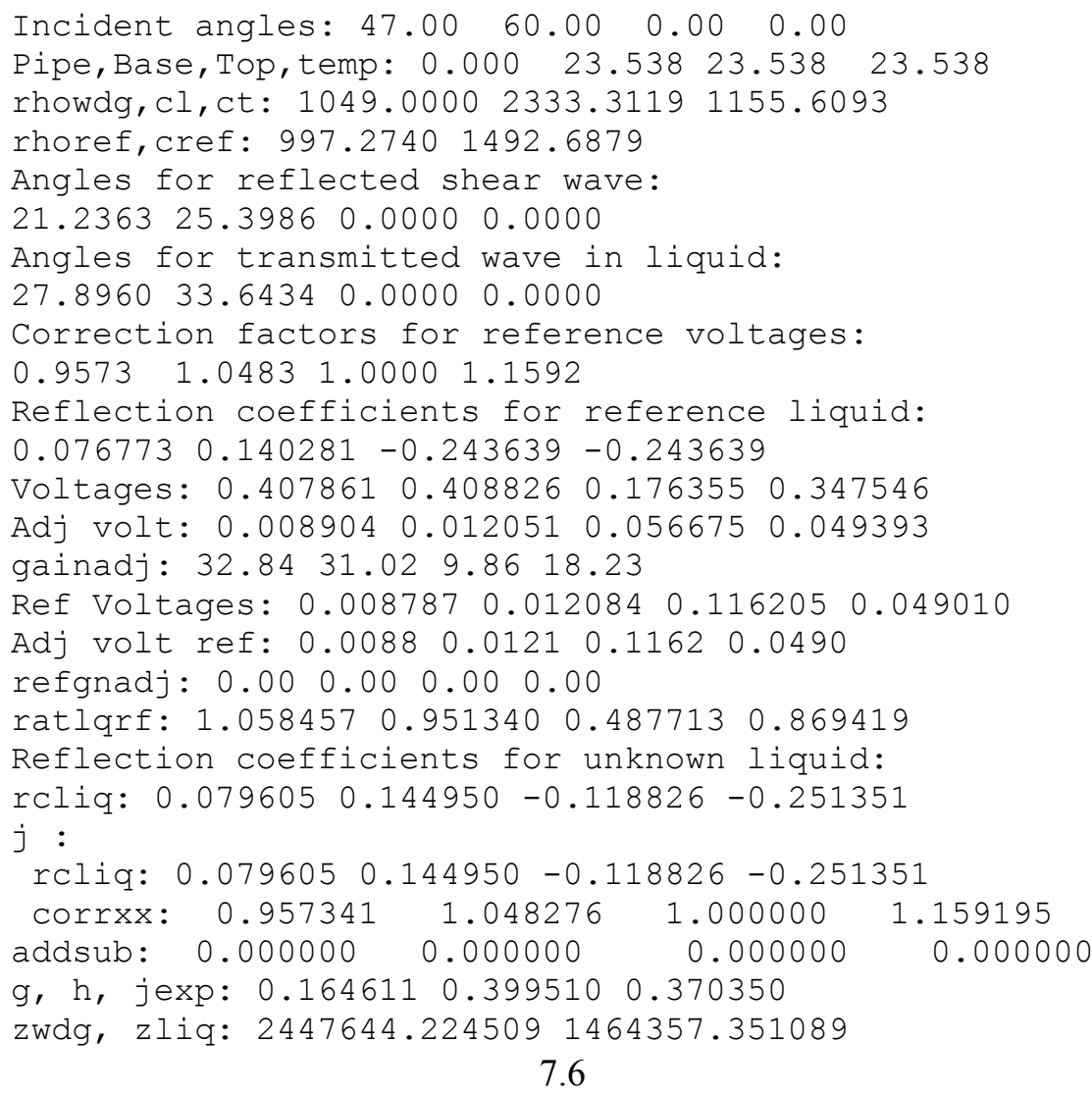




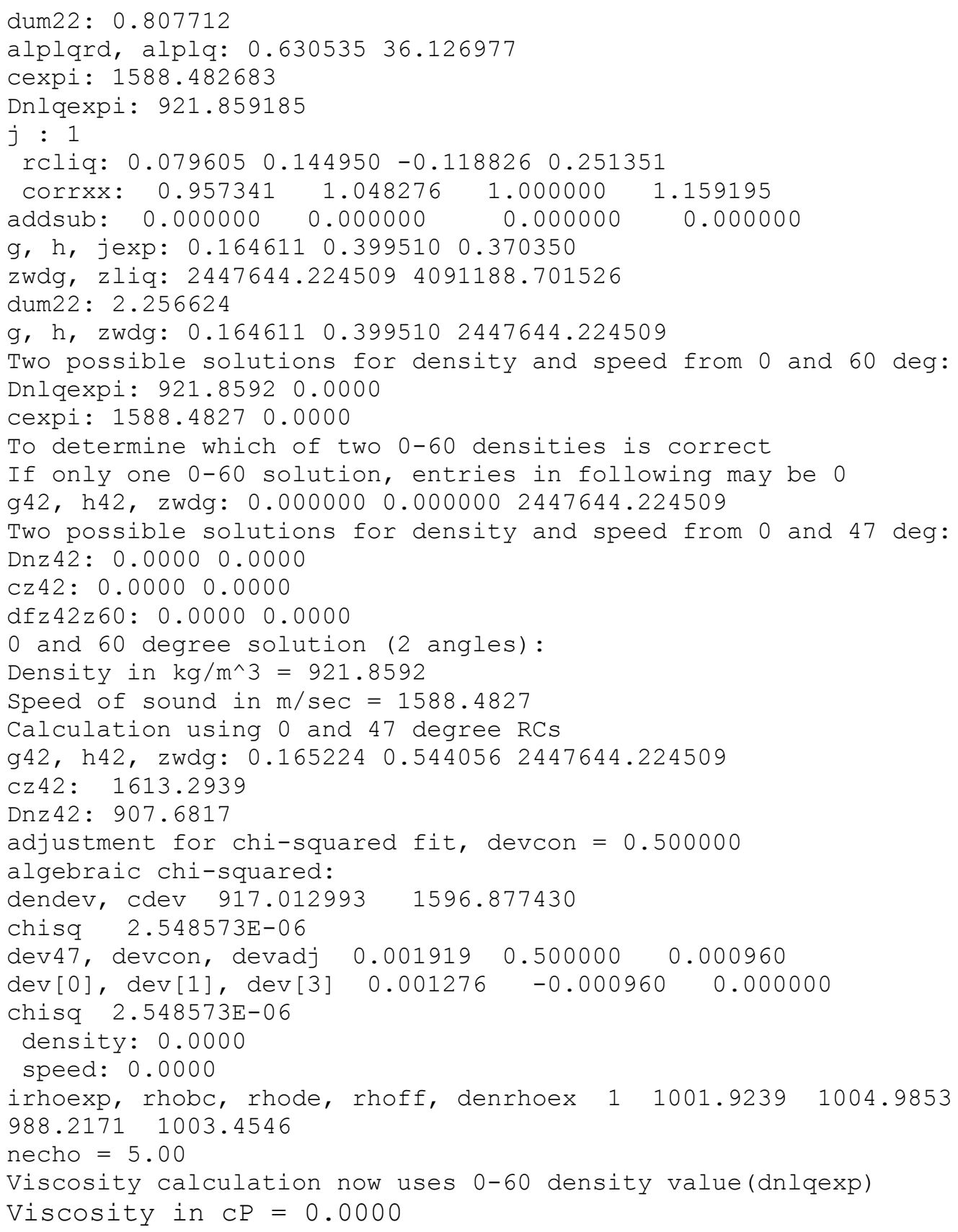

\section{End of Table 7.3}

One type of output file is located in C: $\mid$ work $\backslash$ cpgms $\backslash$ den00\datalsy 101 . When a loop test is selected to take the data, a subdirectory under sy101 is listed with a title involving the date and time. Under this subdirectory are listed the data files for each pass through the loop. This is the usual type of output. Table 7.4 shows an output file for one pass through the loop. The first five lines in the table give information about the transducer pairs: BC, DE, AA, FF, and GG. GG is a pulse-echo transducer with the wedge base in contact with air. It is not used in the calculation of the density. Below the table, the density, velocity, and viscosity values are displayed. These are the final values of the density and velocity and are the same as those that are recorded in denvisc1.dat. In the line where "Dnz $42=$ " is at the 
beginning of the line, the first value is now the den $0-60$ and the second value is c0-60. It is a good check to compare the value of den0-60 with the final value of the density, given above. In the line for "Vtref2=", the values are, sequentially, the water reference values for BC, DE, AA, and FF. The values in the bottom part of the file are the various settings used when one looks at the signal and sets up the data acquisition system.

Table 7.4 Example of output file

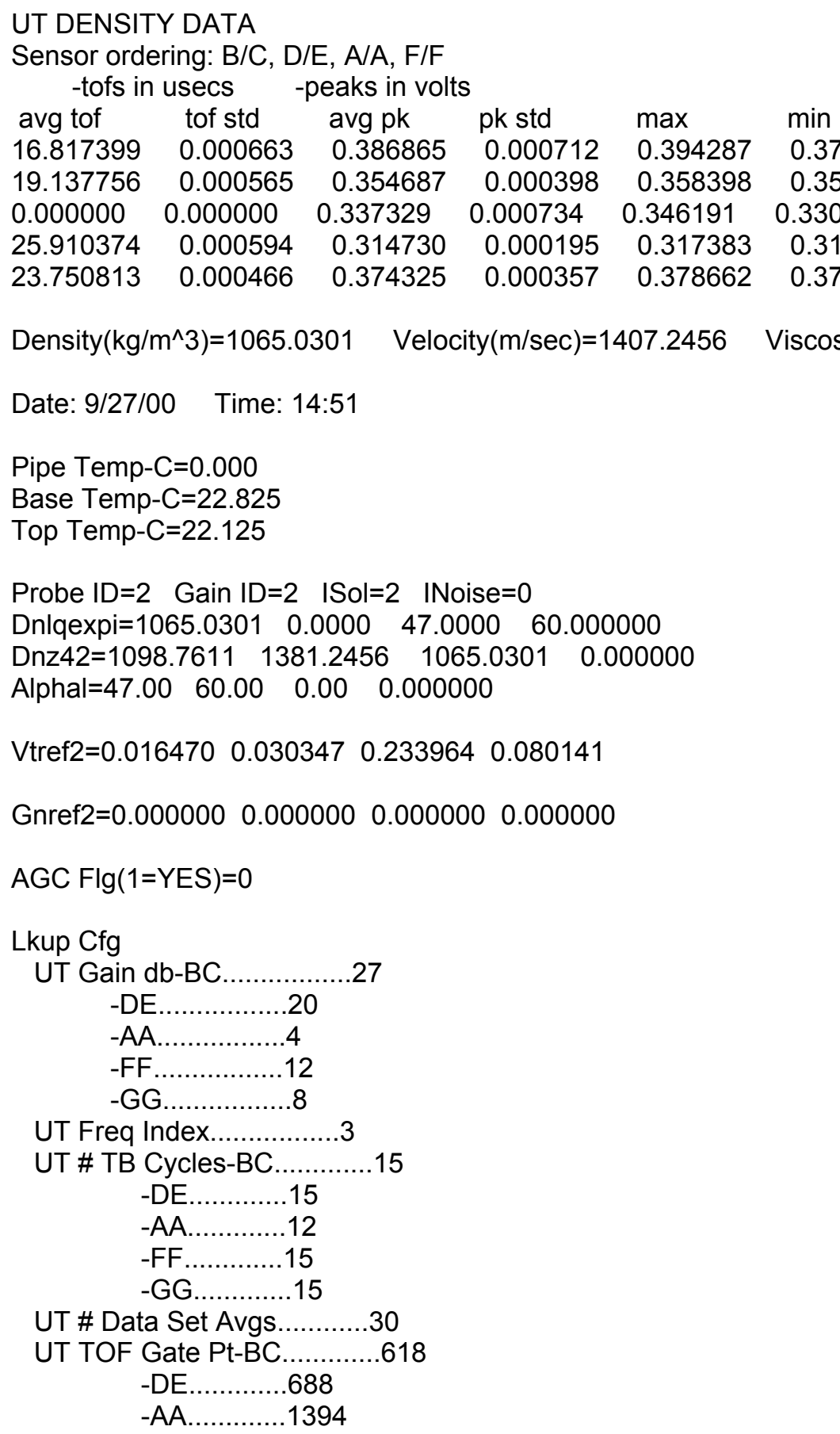




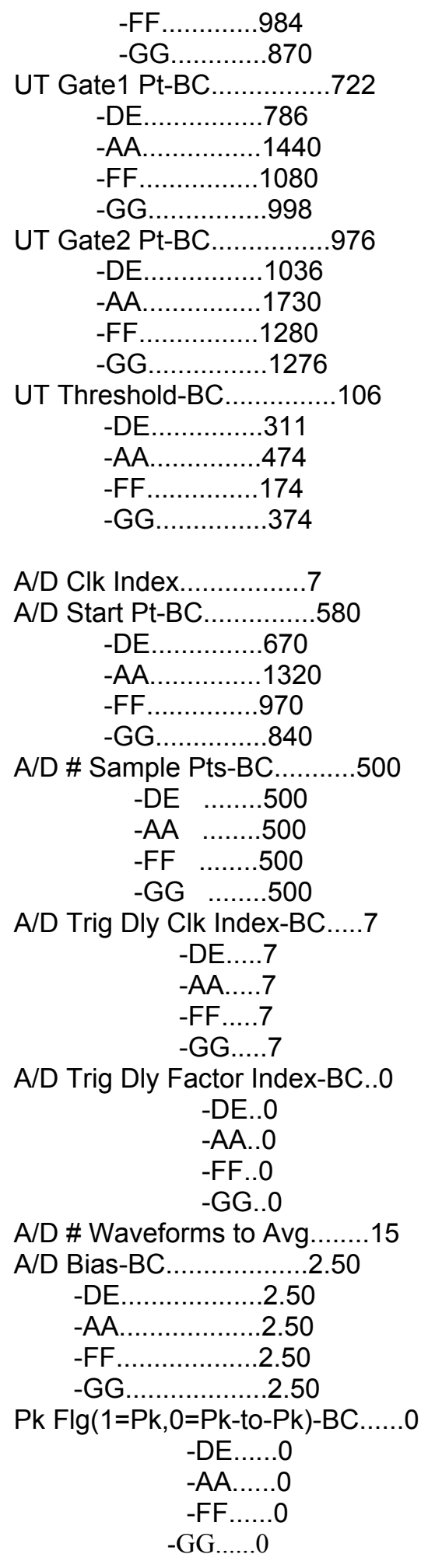

End of Table 7.4 


\subsection{System Setup}

There are three steps in setting up the computer system and density sensor: 1) measure the pulser voltage, 2) with the probe full of water, compare voltages with the water reference values, and 3) make adjustments to system and/or changes to input file.

\subsubsection{Measurement of Pulser Voltage}

To carry out these measurements, an oscilloscope and a 17-foot cable are needed. The first step is to exit the code and turn off the high voltage.

At the end of the 17-foot cable, a small section of cable is usually attached using lemo connectors. This small section of cable has been modified so that, at one end, a $50 \mathrm{ohm}$ resistor is connected between the ground and the hot wire in the center of the cable. A 10-to-1 probe is used by attaching the clip to the "hot" side of the resistor and the ground-connection clip to the "ground" side of the resistor. The 10-to-1 probe is input to Channel 1 of the oscilloscope, which has been set to AC 1 meg ohm. The other end of the 17-foot cable is inserted in the FF connector on the density-sensor board in the computer. The next step is to start the code, go to the FF display, and start it on the manual mode to get the voltage sent to the FF connector. The oscilloscope trigger is set to trigger on $\mathrm{Ch} 1$. The voltage can now be determined using the oscilloscope reading.

For Probe 1 the oscilloscope reading should be $50.0 \mathrm{~V}$ peak-to-peak. For Probe 2, it should be 26.13 $\mathrm{V}$ peak-to-peak. These are the values that we used for the water calibration and also when the data were obtained in the tests in Bldg. 305. The voltages certainly should be very close to these values. However, the voltage output is somewhat dependent upon temperature, as we have observed and so it may be necessary to adjust the voltage. It is also helpful to wait about 10 minutes for the electronics to stabilize prior to taking the first measurement.

The pulser output voltage can be adjusted in the following manner. The back cover of the computer must be removed. The voltage is adjusted with a screw adjustment (very small) on the pulser board. The location of the pulser can be easily found, since it is near the heat radiator on the board.

The first step is to check the pulser setting and to adjust it to the values given above. The next step is to test with water.

\subsubsection{Measurement using Water}

When water is in the pipeline, you will want to assess as quickly as possible whether the voltages are those expected, based upon previous calibrations, and, in particular, with the calibration carried out at Bldg. 305. When the code is operating in the "loop" mode, the screen will display the voltages shown in the table at the top of Table 7.4. These voltages are affected by amplifier gains.

Tables 7.5 and 7.6 show the data obtained for water for Probe 1 and Probe 2. There are two sets of data. The first set is called the "water calibration." Here, the adjusted voltages (defined as the voltage with no amplifier gain) are used. From the data at Bldg. 305 and previous water calibration data, a graph 
of voltage versus temperature is plotted for each transducer pair (BC, DE, AA, and FF). A polynomial expansion is then obtained for the voltage as a function of temperature. From this expansion, the voltage as a function of temperature is obtained. The results are shown in Table 7.5 and 7.6 under the heading of water calibration.

Table 7.5 Example of water data for probe 1

\begin{tabular}{|c|c|c|c|c|c|c|c|}
\hline$\frac{\text { Temp }}{\mathrm{C}}$ & \begin{tabular}{|c|} 
Water \\
VBC 305 \\
series eqn \\
\end{tabular} & $\begin{array}{c}\text { Water Cal } \\
\text { BC water } \\
\text { cal }\end{array}$ & $\begin{array}{c}\text { VDE } 305 \\
\text { series eqn }\end{array}$ & $\begin{array}{c}\text { DE water } \\
\text { cal }\end{array}$ & $\begin{array}{c}\text { VFF } 305 \\
\text { series eqn }\end{array}$ & $\begin{array}{c}\text { FF water } \\
\text { cal }\end{array}$ & $\begin{array}{c}\text { AA water } \\
\text { cal }\end{array}$ \\
\hline 20 & .015131 & 0.016100 & 0.036497 & 0.036904 & 0.086353 & 0.082498 & 0.320737 \\
\hline 21 & 15440 & .016256 & 0.036174 & 0.036497 & 0.085410 & 0.081576 & 317355 \\
\hline 22 & 0.015718 & 0.016403 & 0.035847 & 0.036089 & 0.084495 & 0691 & 3515 \\
\hline 23 & .015965 & 0.016541 & 0.035516 & 0.035682 & 0.083608 & 0.079843 & 309240 \\
\hline 24 & 16185 & 0.016670 & 0.035180 & 0.035275 & 0.082747 & 0.079033 & 04556 \\
\hline 25 & 378 & 790 & 838 & 0.034868 & 912 & 261 & 299486 \\
\hline 26 & 547 & 0.016901 & 0.034489 & 0.034461 & 0.081103 & 0.077526 & 294054 \\
\hline 27 & 691 & 7003 & 0.034134 & 0.034054 & 318 & 0.076828 & 88286 \\
\hline 28 & 313 & 96 & 772 & 647 & 58 & 6168 & 32205 \\
\hline 29 & 0.016913 & 0.017180 & 0.033402 & 0.033240 & 0.078822 & 0.075546 & 275835 \\
\hline 30 & 92 & 255 & 0.033023 & 0.032833 & 0.078108 & 0.074961 & 69202 \\
\hline 31 & 052 & 321 & 0.032636 & 0.032426 & 417 & 0.074414 & 52328 \\
\hline 32 & 0.017093 & 0.017378 & 0.032239 & 0.032018 & 0.076749 & 0.073904 & 255239 \\
\hline 33 & 15 & 426 & 332 & 0.031611 & 102 & 432 & 47959 \\
\hline 34 & & & & & & & 0511 \\
\hline 35 & 0.017106 & 0.017495 & 0.030986 & 0.030797 & 0.074870 & 0.072600 & 0.232921 \\
\hline 36 & 076 & 7516 & 545 & 0.030390 & 0.074286 & 0.072240 & 25213 \\
\hline 37 & & & 092 & & & 918 & 217411 \\
\hline 38 & 968 & 531 & 0.029625 & 0.029576 & 175 & 1633 & 0.209539 \\
\hline 39 & 891 & 525 & 0.029145 & 0.029169 & 0.072649 & 0.071386 & 0.201621 \\
\hline 40 & 798 & 10 & 649 & 8762 & 142 & 176 & 93682 \\
\hline 41 & 690 & 486 & 138 & 0.028355 & 654 & 1004 & 85747 \\
\hline 42 & 567 & 7453 & 7611 & 0.027947 & 183 & 0.070021 & 0.177839 \\
\hline 43 & 530 & 7411 & 0.027066 & 0.027540 & 0.070731 & 0.069460 & 0.169983 \\
\hline 44 & 279 & 360 & 6503 & 0.027133 & 296 & 8894 & 0.162203 \\
\hline 45 & 5113 & 7300 & 0.025921 & 0.026726 & 0.069879 & 0.068324 & 0.154523 \\
\hline 46 & 0.015933 & 0.017231 & 0.025318 & 0.026319 & 0.069479 & 0.067750 & 0.146967 \\
\hline 47 & 5739 & 0.017153 & 0.024693 & 0.025912 & 0.069095 & 0.067172 & 0.139561 \\
\hline 48 & 0.015531 & 0.017066 & 0.024046 & 0.025505 & 0.068729 & 0.066590 & 0.132328 \\
\hline 49 & 0.015309 & 0.016970 & 0.023374 & 0.025098 & 0.068379 & 0.066003 & 0.125293 \\
\hline 50 & 0.015073 & 0.016865 & 0.022676 & 0.024691 & 0.068045 & 0.065412 & 0.118479 \\
\hline 51 & 0.014822 & 0.016751 & 0.021950 & 0.024284 & 0.067727 & 0.064817 & 0.111912 \\
\hline 52 & 0.014558 & 0.016628 & 0.021196 & 0.023876 & 0.067425 & 0.064218 & 0.105615 \\
\hline
\end{tabular}




\begin{tabular}{||l|l|l|l|l|l|l|l|}
\hline \hline 53 & 0.014279 & 0.016496 & 0.020410 & 0.023469 & 0.067139 & 0.063615 & 0.099613 \\
\hline 54 & 0.013986 & 0.016355 & 0.019591 & 0.023062 & 0.066869 & 0.063007 & 0.093930 \\
\hline 55 & 0.013679 & 0.016205 & 0.018737 & 0.022655 & 0.066614 & 0.062395 & 0.088590 \\
\hline 56 & 0.013357 & 0.016046 & 0.017845 & 0.022248 & 0.066374 & 0.061779 & 0.083618 \\
\hline 57 & 0.013020 & 0.015878 & 0.016913 & 0.021841 & 0.066149 & 0.061159 & 0.079038 \\
\hline 58 & 0.012668 & 0.015701 & 0.015938 & 0.021434 & 0.065940 & 0.060535 & 0.074874 \\
\hline 59 & 0.012301 & 0.015515 & 0.014916 & 0.021027 & 0.065745 & 0.059906 & 0.071151 \\
\hline 60 & 0.011918 & 0.015320 & 0.013844 & 0.020620 & 0.065565 & 0.059273 & 0.067892 \\
\hline
\end{tabular}

Table 7.6 Example of water data for probe 2

\begin{tabular}{|c|c|c|c|c|c|c|c|}
\hline$\frac{\text { Temp }}{\mathrm{C}}$ & $\begin{array}{c}\text { Water } \\
\text { VBC 305 } \\
\text { series eqn }\end{array}$ & $\begin{array}{c}\text { Water cal } \\
\text { BC water } \\
\text { cal }\end{array}$ & $\begin{array}{c}\text { VDE } 305 \\
\text { series eqn }\end{array}$ & $\begin{array}{c}\text { DE water } \\
\text { cal }\end{array}$ & $\begin{array}{c}\text { VFF } 305 \\
\text { series eqn }\end{array}$ & $\begin{array}{c}\text { FF water } \\
\text { cal }\end{array}$ & $\begin{array}{c}\text { AA water } \\
\text { cal }\end{array}$ \\
\hline 20 & 0.008113 & 0.008494 & 0.011284 & 0.012052 & 0.050221 & 0.050950 & 0.136053 \\
\hline 21 & 0.008286 & 0.008584 & 0.011422 & 0.012068 & 0.049600 & 0.050401 & 0.130265 \\
\hline 22 & 0.008445 & 0.008668 & 0.011542 & 0.012079 & 0.048999 & 0.049853 & 0.124617 \\
\hline 23 & 0.008591 & 0.008747 & 0.011645 & 0.012084 & 0.048415 & 0.049305 & 0.119108 \\
\hline 24 & 0.008724 & 0.008820 & 0.011731 & 0.012083 & 0.047849 & 0.048756 & 0.113739 \\
\hline 25 & 0.008844 & 0.008887 & 0.011802 & 0.012076 & 0.047301 & 0.048208 & 0.108509 \\
\hline 26 & 0.008952 & 0.008948 & 0.011857 & 0.012063 & 0.046768 & 0.047660 & 0.103419 \\
\hline 27 & 0.009049 & 0.009003 & 0.011899 & 0.012045 & 0.046251 & 0.047111 & 0.098469 \\
\hline 28 & 0.009133 & 53 & 926 & 021 & 750 & 46563 & 3658 \\
\hline 29 & 0.009207 & 0.009097 & 0.011940 & 0.011992 & 0.045263 & 0.046014 & 0.088987 \\
\hline 30 & 0.009270 & 0.009134 & 0.011941 & 0.011956 & 0.044791 & 0.045466 & 0.084456 \\
\hline 31 & 0.009322 & 167 & 0.011930 & 915 & 332 & 0.044918 & 80064 \\
\hline 32 & 0.009364 & 0.009193 & 0.011907 & 0.011868 & 0.043887 & 0.044369 & 0.075812 \\
\hline 33 & 0.009396 & 0.009213 & 0.011873 & 0.011816 & 0.043455 & 0.043821 & 0.071699 \\
\hline 34 & 0.009418 & 0.009228 & 0.011827 & 0.011757 & 0.043035 & 0.043273 & 0.067726 \\
\hline 35 & 0.009430 & 0.009236 & 0.011770 & 0.011693 & 0.042627 & 0.042724 & 0.063893 \\
\hline 36 & 0.009433 & 0.009239 & 0.011703 & 0.011624 & 0.042232 & 0.042176 & 0.060199 \\
\hline 37 & 0.009428 & 0.009236 & 0.011626 & 0.011548 & 0.041848 & 0.041628 & 0.056645 \\
\hline 38 & 0.009413 & 0.009227 & 0.011538 & 0.011467 & 0.041474 & 0.041079 & 0.053231 \\
\hline 39 & 0.009389 & 0.009213 & 0.011441 & 0.011380 & 0.041112 & 0.040531 & 0.049956 \\
\hline 40 & 0.009358 & 0.009192 & 0.011335 & 0.011287 & 0.040761 & 0.039982 & 0.046821 \\
\hline 41 & 0.009318 & 0.009166 & 0.011219 & 0.011189 & 0.040420 & 0.039434 & 0.043826 \\
\hline 42 & 0.009269 & 0.009134 & 0.011095 & 0.011085 & 0.040088 & 0.038886 & 0.040970 \\
\hline 43 & 0.009214 & 0.009096 & 0.010961 & 0.010975 & 0.039767 & 0.038337 & 0.038254 \\
\hline 44 & 0.009150 & 0.009052 & 0.010819 & 0.010859 & 0.039455 & 0.037789 & 0.035677 \\
\hline 45 & 0.009079 & 0.009003 & 0.010668 & 0.010738 & 0.039152 & 0.037241 & 0.033240 \\
\hline 46 & 0.009000 & 0.008947 & 0.010509 & 0.010611 & 0.038859 & 0.036692 & 0.030943 \\
\hline
\end{tabular}




\begin{tabular}{||l|l|l|l|l|l|l|l||}
\hline \hline 47 & 0.008915 & 0.008886 & 0.010342 & 0.010478 & 0.038574 & 0.036144 & 0.028785 \\
\hline 48 & 0.008822 & 0.008819 & 0.010167 & 0.010339 & 0.038299 & 0.035596 & 0.026767 \\
\hline 49 & 0.008723 & 0.008746 & 0.009984 & 0.010195 & 0.038031 & 0.035047 & 0.024889 \\
\hline 50 & 0.008617 & 0.008667 & 0.009793 & 0.010045 & 0.037772 & 0.034499 & 0.023150 \\
\hline 51 & 0.008504 & 0.008583 & 0.009595 & 0.009889 & 0.037522 & 0.033951 & 0.021551 \\
\hline 52 & 0.008385 & 0.008492 & 0.009389 & 0.009727 & 0.037279 & 0.033402 & 0.020091 \\
\hline 53 & 0.008260 & 0.008396 & 0.009175 & 0.009560 & 0.037044 & 0.032854 & 0.018771 \\
\hline 54 & 0.008128 & 0.008294 & 0.008954 & 0.009387 & 0.036817 & 0.032305 & 0.017591 \\
\hline 55 & 0.007990 & 0.008186 & 0.008726 & 0.009209 & 0.036597 & 0.031757 & 0.016550 \\
\hline 56 & 0.007847 & 0.008072 & 0.008490 & 0.009024 & 0.036385 & 0.031209 & 0.015649 \\
\hline 57 & 0.007698 & 0.007953 & 0.008247 & 0.008834 & 0.036180 & 0.030660 & 0.014888 \\
\hline 58 & 0.007543 & 0.007827 & 0.007997 & 0.008638 & 0.035983 & 0.030112 & 0.014266 \\
\hline 59 & 0.007382 & 0.007696 & 0.007740 & 0.008436 & 0.035792 & 0.029564 & 0.013784 \\
\hline 60 & 0.007216 & 0.007559 & 0.007475 & 0.008229 & 0.035609 & 0.029015 & 0.013442 \\
\hline \hline
\end{tabular}

The second method is to use the regression analysis for density, shown in Equation 6.6. Setting the density $\rho_{\mathrm{x}}$ (rhox) equal to $998 \mathrm{~kg} / \mathrm{m}^{3}$, the voltage $\mathrm{V}_{\mathrm{x}}$ as a function of temperature is obtained:

$$
\mathrm{V}_{\mathrm{x}}=\left(998 .-\mathrm{b} 0_{\mathrm{x}}-\mathrm{b} 1_{\mathrm{x}} \mathrm{T}-\mathrm{b} 2_{\mathrm{x}} \mathrm{T}^{2}\right) /\left(\mathrm{b} 3_{\mathrm{x}}+\mathrm{b} 5_{\mathrm{x}} \mathrm{T}+\mathrm{b} 6_{\mathrm{x}} \mathrm{T}^{2}\right)
$$

This represents three equations, where $\mathrm{x}=\mathrm{BC}, \mathrm{DE}$, and $\mathrm{FF}$. The values of the coefficients are given in Table 6.2. Therefore, the voltage $\mathrm{V}_{\mathrm{x}}$ as a function of temperature is obtained, as shown in Tables 7.5 and 7.6 under the heading "305 series eqn."

Of the two methods, the second method, using Equation 7.3 above, is probably the more accurate, since it was obtained for many liquids over a temperature range of $20 \mathrm{C}$ to $60 \mathrm{C}$. For example, the temperature for the water calibration experiments was obtained up to a temperature of approximately 50 C.

\subsubsection{Setting Amplifier Gains}

Run the code using automatic gain control set to "off." The objective is to set the amplifier gain settings so that one can see, at a quick glance at the data screen, whether the expected voltages are being observed. Table 7.7 lists the dB gain settings for Probe 1 and Probe 2.

Table 7.7 Gain settings for probes 1 and 2

\begin{tabular}{||c|cc|c||}
\hline Transducer Pair & \multicolumn{2}{|c|}{ Gain Settings for Probe 1 } & Gain Settings for Probe 2 \\
\hline & \multicolumn{2}{|c|}{$(\mathbf{d B})$} & $\mathbf{( d B )}$ \\
\hline BC & $27(27.26)$ & $33(32.84)$ \\
\hline DE & $20(20.03)$ & $31 \quad(31.02)$ \\
\hline AA & 2 & $(1.72)$ & $10(9.86)$ \\
\hline FF & 14 & $(13.97)$ & $18 \quad(18.23)$ \\
\hline
\end{tabular}


Table 7.8 and Table 7.9 show the variation of the voltages with temperature. For these calculations, the relationship between the actual (or measured) voltage and the adjusted voltage is obtained by inverting Equation 7.2. The values of the adjusted voltage are those obtained by using the "305 series eqn," as shown in Table 7.5 and 7.6.

Table 7.8 Example of voltage variation with temperature for Probe 1

\begin{tabular}{|c|c|c|c|c|c|c|c|c|}
\hline \multicolumn{9}{|l|}{ Probe 1} \\
\hline Temp & $\begin{array}{c}\text { water } \\
\text { VBC 305 } \\
\text { series eqn }\end{array}$ & $\begin{array}{c}\text { Voltage } \mathrm{BC} \\
\text { reading } \\
\text { at gain } \\
\text { setting } \\
=27 \mathrm{~dB} \\
\end{array}$ & $\begin{array}{r}\text { VDE } 305 \\
\text { series eqn }\end{array}$ & $\begin{array}{c}\text { Voltage DE } \\
\text { reading } \\
\text { at gain } \\
\text { setting } \\
=20 \mathrm{~dB} \\
\end{array}$ & $\begin{array}{c}\text { VFF } 305 \\
\text { series eqn }\end{array}$ & $\begin{array}{c}\text { Voltage FF } \\
\text { reading } \\
\text { at gain } \\
\text { setting } \\
=14 \mathrm{~dB} \\
\end{array}$ & $\begin{array}{c}\text { AA water } \\
\text { cal }\end{array}$ & $\begin{array}{c}\text { Voltage AA } \\
\text { reading } \\
\text { at gain } \\
\text { setting } \\
=2 \mathrm{~dB} \\
\end{array}$ \\
\hline 20 & 0.015131 & 0.349041 & 0.036497 & 0.366233 & 0.00000 & 0.431299 & 0.320737 & 0.390975 \\
\hline 21 & 0.015440 & 0.356170 & 0.036174 & 992 & 0.085410 & 0.426588 & 0.317355 & 0.386852 \\
\hline 22 & 0.015718 & 0.362570 & 0.035847 & 0.359712 & 0.084495 & 0.422018 & 0.313515 & 0.382171 \\
\hline 23 & 0.015965 & 0.368284 & 0.035516 & 0.356388 & 0.083608 & 0.417586 & 0.309240 & 0.376961 \\
\hline 24 & 0.016185 & 0.373352 & 0.035180 & 012 & 0.082747 & 0.413287 & .304556 & 0.371250 \\
\hline 25 & 0.016378 & 0.377809 & 0.034838 & 0.349580 & 0.081912 & 0.409118 & 0.299486 & 0.365070 \\
\hline 26 & 0.016547 & 0.381690 & 0.034489 & 0.346086 & 0.081103 & 0.405076 & 0.294054 & 0.358449 \\
\hline 27 & 0.016691 & 0.38 & 4134 & 524 & 0.0 & 158 & 0.288286 & 0.351418 \\
\hline 28 & 0.016813 & 0.387830 & 0.033772 & 0.338889 & 0.079558 & 0.397361 & 0.282205 & 0.344005 \\
\hline 29 & 0.016913 & 0.390140 & 0.033402 & 0.335175 & 0.078822 & 0.393682 & 0.275835 & 0.336240 \\
\hline 30 & 0.016992 & 0.391972 & 023 & 377 & 108 & 119 & 0.269202 & 0.328154 \\
\hline 31 & 0.017052 & 0.393347 & 0.032636 & 0.327489 & 0.077417 & 0.386668 & 0.262328 & 0.319775 \\
\hline 32 & \begin{tabular}{|l|}
0.017093 \\
\end{tabular} & 0.394281 & 0.032239 & 0.323506 & 0.076749 & \begin{tabular}{|l|}
0.383328 \\
\end{tabular} & 0.255239 & 0.311134 \\
\hline 33 & 0.017115 & 0.394790 & 832 & 423 & 6102 & 096 & 0.247959 & 0.302259 \\
\hline 34 & 0.017119 & 0.394889 & 0.031415 & 0.315232 & 0.075476 & 0.376970 & 0.240511 & 0.293181 \\
\hline 35 & \begin{tabular}{|l|}
0.017106 \\
\end{tabular} & 0.394589 & 0.030986 & 0.310929 & 0.074870 & \begin{tabular}{|l|}
0.373947 \\
\end{tabular} & 0.232921 & 0.283929 \\
\hline 36 & 0.017076 & 0.393903 & 0.030545 & 0.306506 & 0.074286 & 0.371026 & 0.225213 & 0.274532 \\
\hline 37 & 0.017030 & 0.392841 & 0092 & 958 & 3721 & 8205 & 0.217411 & 0.265021 \\
\hline 38 & 0.016968 & 0.391412 & 0.029625 & 0.297276 & 0.073175 & 0.365481 & 0.209539 & 0.255425 \\
\hline 39 & 0.016891 & 0.389624 & 0.029145 & 0.292454 & 0.072649 & 0.362854 & 0.201621 & 0.245774 \\
\hline 40 & 0.016798 & 0.387483 & 0.028649 & 0.287484 & 0.072142 & 0.360321 & 0.193682 & 0.236097 \\
\hline 41 & \begin{tabular}{|c|}
0.016690 \\
\end{tabular} & 0.384997 & 0.028138 & 0.282358 & 0.071654 & \begin{tabular}{|l|}
0.357881 \\
\end{tabular} & 0.185747 & 0.226424 \\
\hline 42 & 0.016567 & 0.382170 & 0.027611 & 0.277066 & 0.071183 & 0.355531 & 0.177839 & 0.216784 \\
\hline 43 & 0.016430 & 0.379008 & 0.027066 & 0.271601 & 0.070731 & 0.353272 & 0.169983 & 0.207207 \\
\hline 44 & \begin{tabular}{|l|}
0.016279 \\
\end{tabular} & 0.375513 & 0.026503 & 0.265951 & 0.070296 & \begin{tabular}{|l|}
0.351100 \\
\end{tabular} & 0.162203 & 0.197723 \\
\hline 45 & 0.016113 & 0.371688 & 0.025921 & 0.260106 & 0.069879 & 0.349016 & 0.154523 & 0.188362 \\
\hline 46 & 0.015933 & 0.367537 & 0.025318 & 0.254056 & 0.069479 & 0.347018 & 0.146967 & 0.179152 \\
\hline 47 & \begin{tabular}{|l|}
0.015739 \\
\end{tabular} & 0.363061 & 0.024693 & 0.247788 & 0.069095 & 0.345103 & 0.139561 & 0.170124 \\
\hline 48 & 0.015531 & 0.358261 & 0.024046 & 0.241289 & 0.068729 & 0.343273 & 0.132328 & 0.161307 \\
\hline
\end{tabular}




\begin{tabular}{||l|l|l|l|l|l|l|l|l||}
\hline \hline 49 & 0.015309 & 0.353136 & 0.023374 & 0.234545 & 0.068379 & 0.341524 & 0.125293 & 0.152731 \\
\hline 50 & 0.015073 & 0.347688 & 0.022676 & 0.227542 & 0.068045 & 0.339857 & 0.118479 & 0.144425 \\
\hline 51 & 0.014822 & 0.341915 & 0.021950 & 0.220263 & 0.067727 & 0.338270 & 0.111912 & 0.136420 \\
\hline 52 & 0.014558 & 0.335816 & 0.021196 & 0.212691 & 0.067425 & 0.336763 & 0.105615 & 0.128744 \\
\hline 53 & 0.014279 & 0.329389 & 0.020410 & 0.204807 & 0.067139 & 0.335334 & 0.099613 & 0.121427 \\
\hline 54 & 0.013986 & 0.322631 & 0.019591 & 0.196590 & 0.066869 & 0.333983 & 0.093930 & 0.114499 \\
\hline 55 & 0.013679 & 0.315539 & 0.018737 & 0.188020 & 0.066614 & 0.332708 & 0.088590 & 0.107990 \\
\hline 56 & 0.013357 & 0.308110 & 0.017845 & 0.179070 & 0.066374 & 0.331511 & 0.083618 & 0.101929 \\
\hline 57 & 0.013020 & 0.300340 & 0.016913 & 0.169716 & 0.066149 & 0.330388 & 0.079038 & 0.096346 \\
\hline 58 & 0.012668 & 0.292223 & 0.015938 & 0.159927 & 0.065940 & 0.329341 & 0.074874 & 0.091271 \\
\hline 59 & 0.012301 & 0.283754 & 0.014916 & 0.149674 & 0.065745 & 0.328369 & 0.071151 & 0.086732 \\
\hline 60 & 0.011918 & 0.274927 & 0.013844 & 0.138920 & 0.065565 & 0.327470 & 0.067892 & 0.082760 \\
\hline
\end{tabular}

Table 7.9 Example of voltage variation with temperature for Probe 2

\begin{tabular}{|c|c|c|c|c|c|c|c|c|}
\hline \multicolumn{9}{|l|}{ Probe 2 } \\
\hline Temp & $\begin{array}{c}\text { Water } \\
\text { VBC } 305 \\
\text { series eqn }\end{array}$ & $\begin{array}{c}\text { Voltage } \mathrm{BC} \\
\text { reading } \\
\text { at gain } \\
\text { setting } \\
=33 \mathrm{~dB} \\
\end{array}$ & $\begin{array}{c}\text { VDE } 305 \\
\text { series eqn }\end{array}$ & $\begin{array}{c}\text { Voltage DE } \\
\text { reading } \\
\text { at gain } \\
\text { setting } \\
=31 \mathrm{~dB} \\
\end{array}$ & $\begin{array}{c}\text { VFF } 305 \\
\text { series eqn }\end{array}$ & $\begin{array}{c}\text { Voltage FF } \\
\text { reading } \\
\text { at gain } \\
\text { setting } \\
=18 \mathrm{~dB} \\
\end{array}$ & $\begin{array}{c}\text { AA water } \\
\text { cal }\end{array}$ & $\begin{array}{c}\text { Voltage AA } \\
\text { reading } \\
\text { at gain } \\
\text { setting } \\
=10 \mathrm{~dB}\end{array}$ \\
\hline 20 & 0.008113 & 0.355798 & 0.011284 & 0.401306 & 0.050221 & 0.409621 & 0.136053 & 0.423359 \\
\hline 21 & 0.008286 & 0.363370 & 0.011422 & 0.406211 & 0.049600 & 0.404560 & 0.130265 & 0.405348 \\
\hline 22 & 0.008445 & 0.370344 & 0.011542 & 0.410476 & 0.048999 & 0.399653 & 0.124617 & 0.387772 \\
\hline 23 & 0.008591 & 0.376735 & 0.011645 & 0.414129 & 0.048415 & 0.394895 & 0.119108 & 0.370630 \\
\hline 24 & 0.008724 & 0.382562 & 0.011731 & 0.417199 & 0.047849 & 0.390280 & 0.113739 & 0.353922 \\
\hline 25 & 0.008844 & 0.387839 & 0.011802 & 0.419712 & 0.047301 & 0.385804 & 0.108509 & 0.337649 \\
\hline 26 & 0.008952 & 0.392583 & 0.011857 & 0.421690 & 0.046768 & 0.381461 & 0.103419 & 0.321811 \\
\hline 27 & 0.009049 & 0.396809 & 0.011899 & 0.423155 & 0.046251 & 0.377246 & 0.098469 & 0.306407 \\
\hline 28 & 0.009133 & 0.400530 & 0.011926 & 0.424128 & 0.045750 & 0.373156 & 0.093658 & 0.291437 \\
\hline 29 & 0.009207 & 0.403761 & 0.011940 & 0.424628 & 0.045263 & 0.369187 & 0.088987 & 0.276902 \\
\hline 30 & 0.009270 & 0.406514 & 0.011941 & 0.424672 & 0.044791 & 0.365333 & 0.084456 & 0.262802 \\
\hline 31 & 0.009322 & 0.408802 & 0.011930 & 0.424277 & 0.044332 & 0.361592 & 0.080064 & 0.249136 \\
\hline 32 & 0.009364 & 0.410638 & 0.011907 & 0.423456 & 0.043887 & 0.357961 & 0.075812 & 0.235904 \\
\hline 33 & 0.009396 & 0.412033 & 0.011873 & 0.422225 & 0.043455 & 0.354435 & 0.071699 & 0.223107 \\
\hline 34 & 0.009418 & 0.412999 & 0.011827 & 0.420597 & 0.043035 & 0.351011 & 0.067726 & 0.210745 \\
\hline 35 & 0.009430 & 0.413546 & 0.011770 & 0.418583 & 0.042627 & 0.347687 & 0.063893 & 0.198817 \\
\hline 36 & 0.009433 & 0.413685 & 0.011703 & 0.416195 & 0.042232 & 0.344460 & 0.060199 & 0.187323 \\
\hline 37 & 0.009428 & 0.413426 & 0.011626 & 0.413444 & 0.041848 & 0.341326 & 0.056645 & 0.176264 \\
\hline 38 & 0.009413 & 0.412779 & 0.011538 & 0.410339 & 0.041474 & 0.338284 & 0.053231 & 0.165640 \\
\hline 39 & 0.009389 & 0.411753 & 0.011441 & 0.406890 & 0.041112 & 0.335330 & 0.049956 & 0.155450 \\
\hline 40 & 0.009358 & 0.410358 & 0.011335 & 0.403105 & 0.040761 & 0.332462 & 0.046821 & 0.145694 \\
\hline 41 & 0.009318 & 0.408602 & 0.011219 & 0.398992 & 0.040420 & 0.329679 & 0.043826 & 0.136373 \\
\hline
\end{tabular}




\begin{tabular}{||l|l|l|l|l|l|l|l|l||}
\hline \hline 42 & 0.009269 & 0.406494 & 0.011095 & 0.394559 & 0.040088 & 0.326977 & 0.040970 & 0.127486 \\
\hline 43 & 0.009214 & 0.404041 & 0.010961 & 0.389812 & 0.039767 & 0.324356 & 0.038254 & 0.119034 \\
\hline 44 & 0.009150 & 0.401252 & 0.010819 & 0.384757 & 0.039455 & 0.321812 & 0.035677 & 0.111017 \\
\hline 45 & 0.009079 & 0.398135 & 0.010668 & 0.379402 & 0.039152 & 0.319344 & 0.033240 & 0.103434 \\
\hline 46 & 0.009000 & 0.394697 & 0.010509 & 0.373751 & 0.038859 & 0.316951 & 0.030943 & 0.096285 \\
\hline 47 & 0.008915 & 0.390945 & 0.010342 & 0.367809 & 0.038574 & 0.314630 & 0.028785 & 0.089571 \\
\hline 48 & 0.008822 & 0.386885 & 0.010167 & 0.361581 & 0.038299 & 0.312380 & 0.026767 & 0.083292 \\
\hline 49 & 0.008723 & 0.382526 & 0.009984 & 0.355072 & 0.038031 & 0.310200 & 0.024889 & 0.077446 \\
\hline 50 & 0.008617 & 0.377872 & 0.009793 & 0.348285 & 0.037772 & 0.308088 & 0.023150 & 0.072036 \\
\hline 51 & 0.008504 & 0.372931 & 0.009595 & 0.341225 & 0.037522 & 0.306042 & 0.021551 & 0.067060 \\
\hline 52 & 0.008385 & 0.367708 & 0.009389 & 0.333894 & 0.037279 & 0.304062 & 0.020091 & 0.062518 \\
\hline 53 & 0.008260 & 0.362209 & 0.009175 & 0.326297 & 0.037044 & 0.302146 & 0.018771 & 0.058411 \\
\hline 54 & 0.008128 & 0.356441 & 0.008954 & 0.318435 & 0.036817 & 0.300293 & 0.017591 & 0.054738 \\
\hline 55 & 0.007990 & 0.350408 & 0.008726 & 0.310311 & 0.036597 & 0.298502 & 0.016550 & 0.051500 \\
\hline 56 & 0.007847 & 0.344116 & 0.008490 & 0.301928 & 0.036385 & 0.296772 & 0.015649 & 0.048697 \\
\hline 57 & 0.007698 & 0.337570 & 0.008247 & 0.293287 & 0.036180 & 0.295102 & 0.014888 & 0.046327 \\
\hline 58 & 0.007543 & 0.330775 & 0.007997 & 0.284391 & 0.035983 & 0.293491 & 0.014266 & 0.044393 \\
\hline 59 & 0.007382 & 0.323736 & 0.007740 & 0.275241 & 0.035792 & 0.291937 & 0.013784 & 0.042893 \\
\hline 60 & 0.007216 & 0.316458 & 0.007475 & 0.265839 & 0.035609 & 0.290442 & 0.013442 & 0.041827 \\
\hline
\end{tabular}

\subsubsection{Adjustment to System and/or Changes to Input File.}

If there have been no changes in the transducer performance, since the tests in Bldg 305, then the voltages shown on the data sheet for a loop test should be the same as those in Table 7.8 (or 7.9) when water is in the pipeline. If they are, then no adjustments are needed.

However, if they are not the same, then some adjustments are needed. The two most important transducers for the measurement of density are DE and FF. The first step is to use the adjustment of the pulser voltage. One reason is that the cable lengths used on site may not be exactly the same as those used during the calibration. The difference in cable lengths can be adjusted by changing the pulser voltage. For example, suppose that the voltage on DE and FF are below the expected value in Table 7.8 (or 7.9). By increasing the pulser voltage, we can increase the voltage on DE and FF and try to get them equal to the desired values. Ideally, both $\mathrm{DE}$ and $\mathrm{FF}$ will do that. If not, then the values of corrde, corrff, addsubde, and addsubff need to be changed to accomplish this. The objective is to use the correction factors so that whatever voltage is measured, the correction factor converts the measured value to the desired value. The multiplicative correction factor corrx will probably work the best. If one can obtain data on the voltage values as a function of temperature, then one can determine corrx and addsubx from the data for two temperatures. One notes that the correction factors in Equation 7.1 refer to the adjusted voltages, so that all voltages are on an "equal footing," regardless of the amplifier gain. 


\section{Example}

1. At $20 \mathrm{C}$, the voltage measured on $\mathrm{DE}$ is 0.340 volts at an amplifier gain of $20.03 \mathrm{~dB}$. The adjusted voltage is 0.033883 volts. The expected voltage at this temperature is 0.366 volts, as shown in Table 7.8. This adjusted voltage is 0.036497 volts.

2. At $40 \mathrm{C}$, the voltage measured on $\mathrm{DE}$ is 0.270 volts at an amplifier gain of $20.03 \mathrm{~dB}$. The adjusted voltage is 0.026907 volts. The expected voltage at this temperature is 0.287484 volts, which gives an adjusted voltage of 0.028648 volts.

The two equations become:

$$
\begin{aligned}
& 0.036497=\text { corrde } 0.033883+\text { addsubde } \\
& 0.028648=\text { corrde } 0.026907+\text { addsubde }
\end{aligned}
$$

Solving these two equations for corrde and addsubde, we find corrde $=1.125$ and addsubde $=-0.002621$ volts.

If the voltages on the transducers are not the same as the expected values, then the first step is to adjust the pulser voltage, as stated above. The second step is then to use the correction factor. Some judgment is needed to determine exactly how this is done. The above example serves only as a guide. 


\subsection{Density Sensor Deployment at SY-101 Site}

In FY-2001, the density sensor was installed at the SY-101 site. In FY-2002 the densimeter performance will be demonstrated during water flushes and waste transfers from tank SY-101. Tank SY101 is being used as a staging tank for interim stabilization of salt well pumping liquors that are removed from the single-shell tanks. Salt well pumping liquors, retrieved from the SSTs are stored in SY-101 prior to cross-site transport. Based on the densimeter location in the prefabricated pump pit, all fluids stored in tank SY-101 that are transported out of this tank will pass through the densimeter.

\subsection{Installation}

In FY-2001 the densimeter incorporated as a part of the modified process manifold (MPM) was installed in the prefabricated pump pit (PPP) at the SY-101 site. The PPP configuration is shown in Figure 8.1. The densimeter installation, before and after addition of the insulating jacket, is shown in Figures 8.2 and 8.3. The densimeter was installed with the wedges at an angle of 22.5 deg below horizontal, as observed by the tilt of the densimeter cover in Figure 8.2. This orientation was selected so that the sensor would be in contact with the bulk of the fluid layer and not be affected by any pockets of air that could accumulate at the top of the pipe or any solids that could potentially settle on the face of the sensor. Electrical connections are made in the field (Figure 8.4) and in the DACS trailer (Figures 8.5 and 8.6).

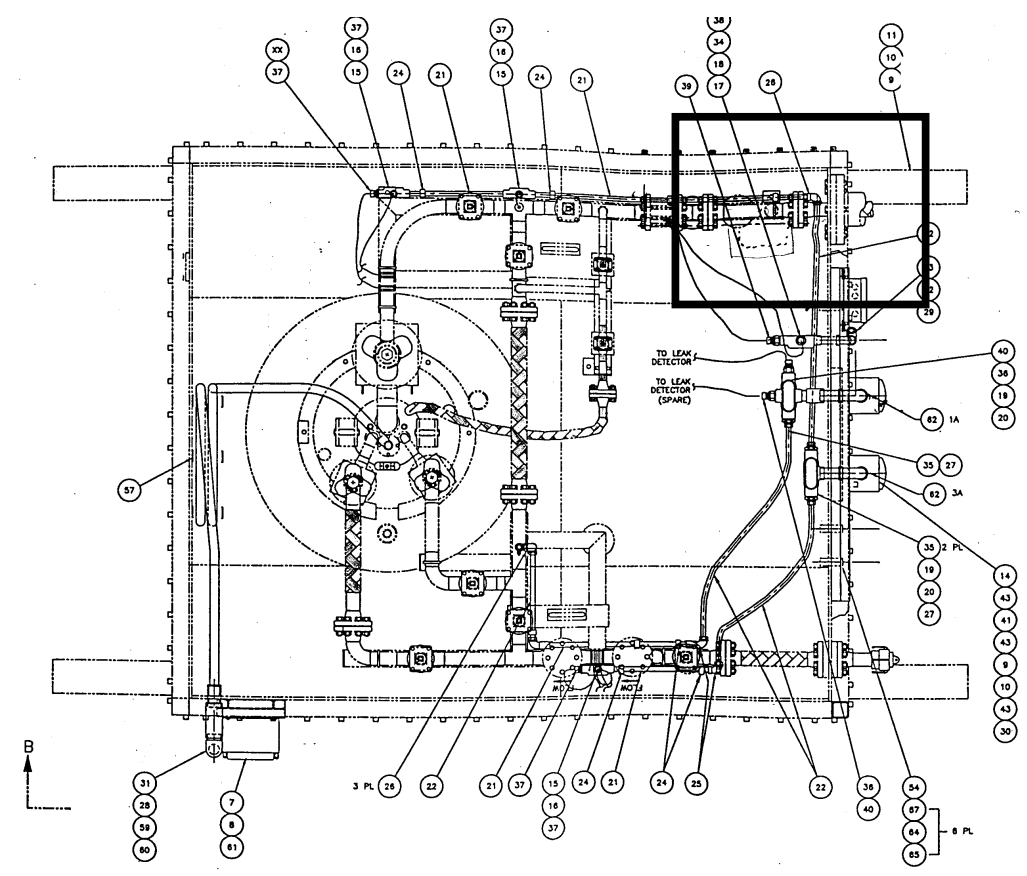

(1) ASSEMBLY, PPP

Figure 8.1 Densimeter location in the prefabricated pump pit (upper right corner - penetrating wall) 


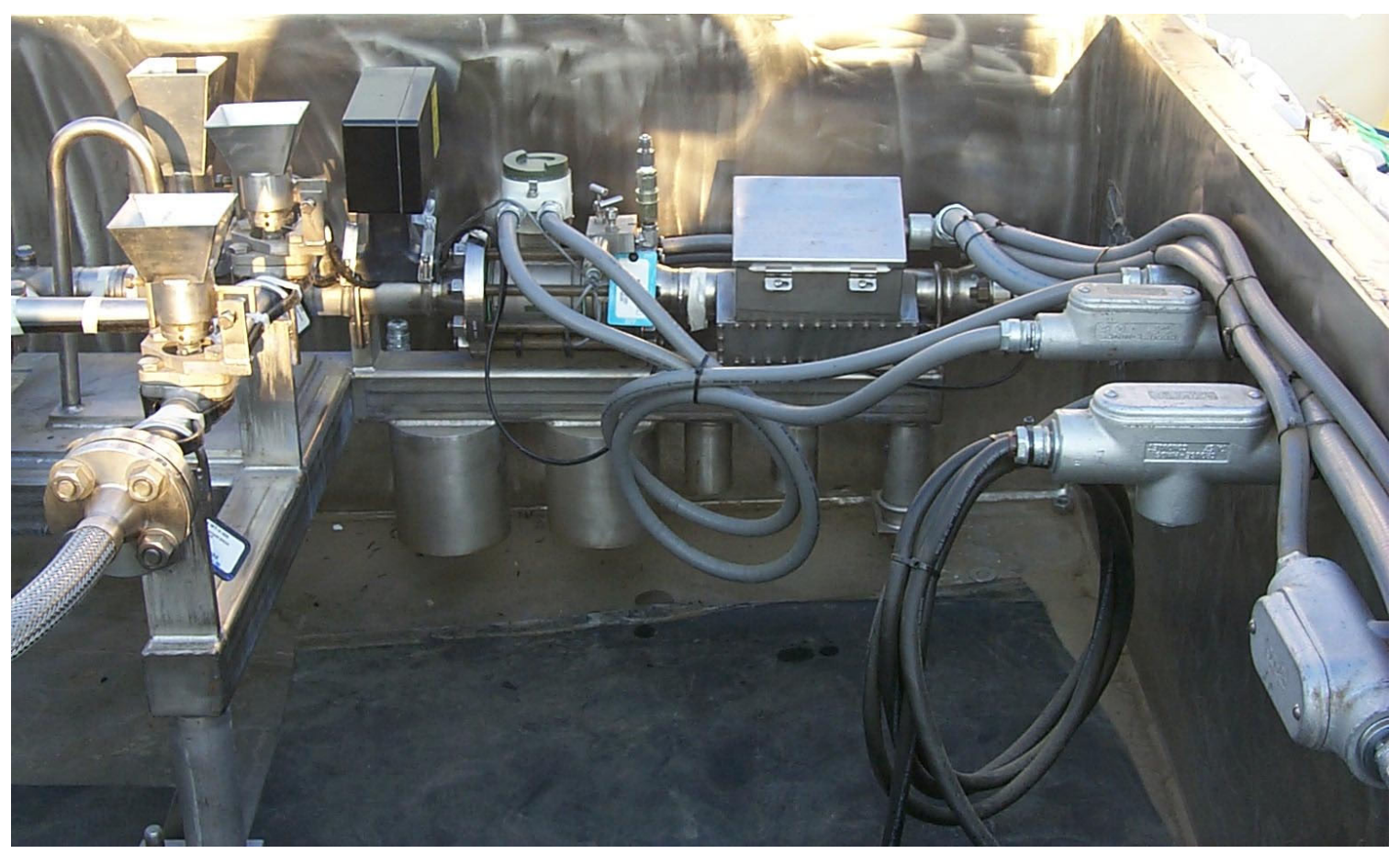

Figure 8.2 Densimeter installed in the MPM inside the PPP

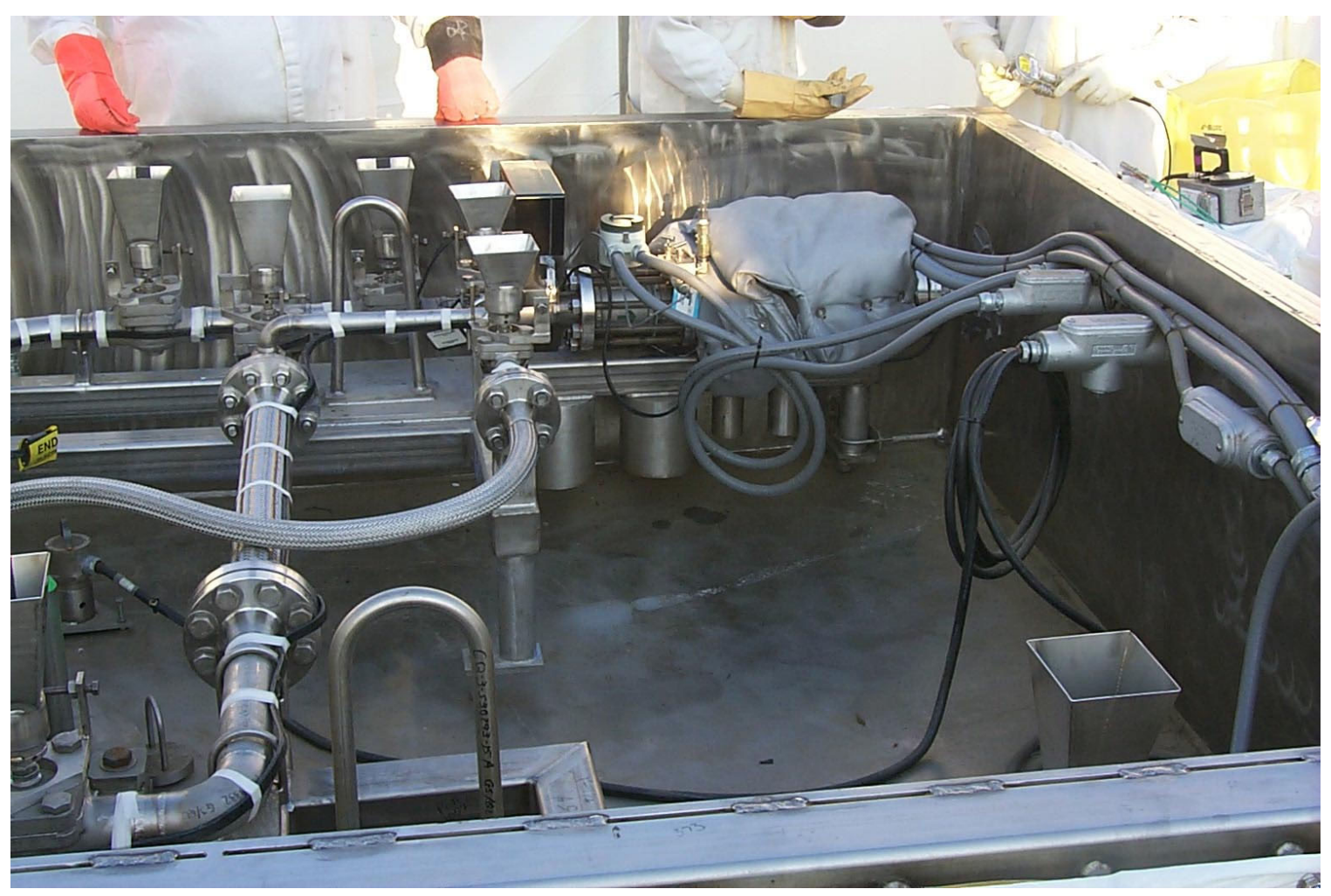

Figure 8.3 Densimeter after installation of blanket insulation 


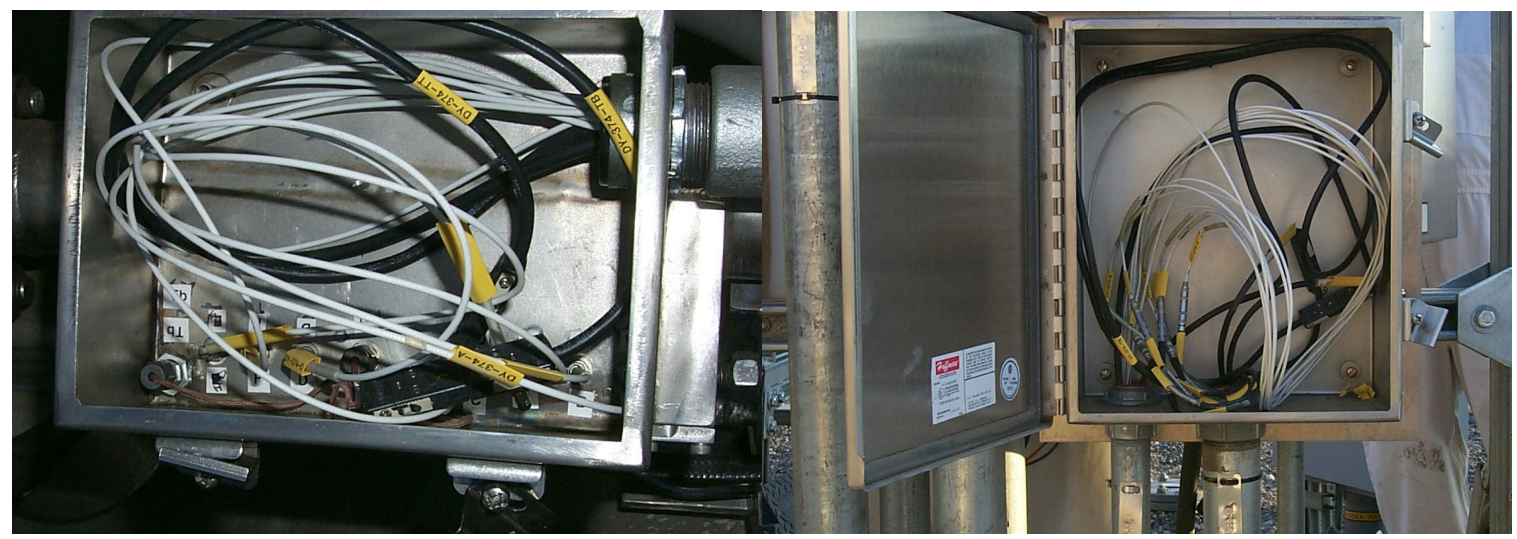

Figure 8.4 Densimeter cable field connections in PPP (left) and junction box (right)

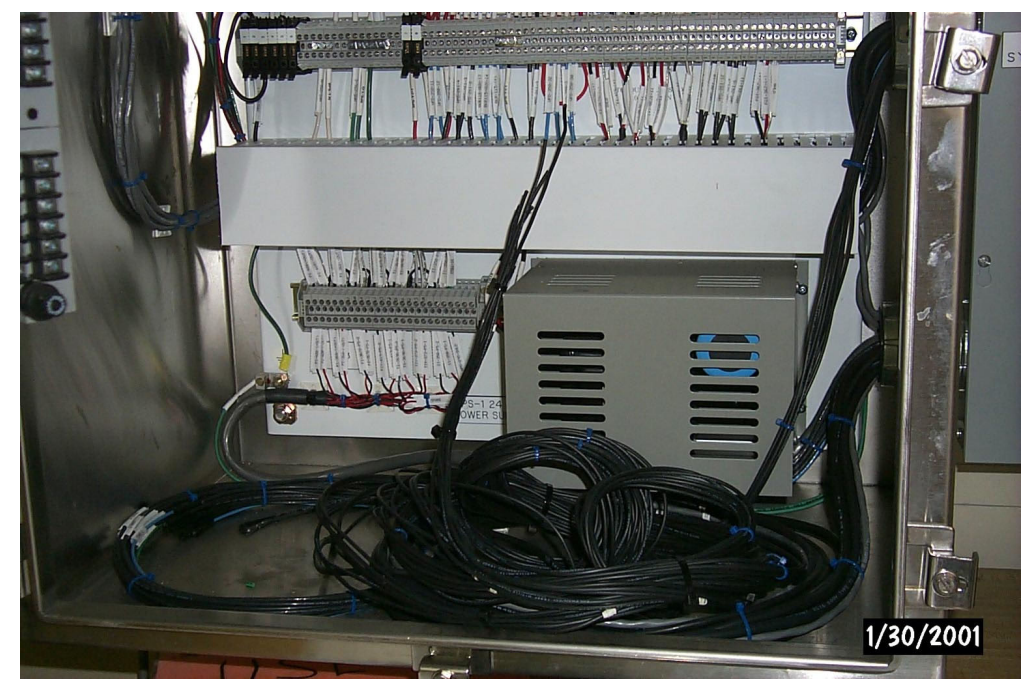

Figure 8.5 Densimeter cables inside panel in DACS trailer

\subsubsection{Equipment in the DACS Trailer}

The densimeter computer controller, described in Section 4.4, will be operated from the data acquisition and control system (DACS) trailer. The density computer system has 3 components:

1. Computer: foot print of $51 \mathrm{~cm} \times 61 \mathrm{~cm}$ (20 in wide $\mathrm{x} 24$ in deep) or minimally could use a space $56 \mathrm{~cm}$ deep with a $5 \mathrm{~cm} 22$ in deep with 2 in overhang

2. Strawberry tree data shuttle, for temperature measurements: foot print of $15 \mathrm{~cm}$ wide $\times 31 \mathrm{~cm}$ deep ( 6 in. wide $x 12$ in. deep). If this is stored on edge then its foot print would be $5 \mathrm{~cm}$ wide $\mathrm{x}$ $31 \mathrm{~cm}$ deep ( 2 in. wide $x 12$ in. deep)

3. Printer Laserjet III: foot print of $48 \mathrm{~cm}$ wide $\mathrm{x} 48 \mathrm{~cm}$ deep (19 in. wide $\mathrm{x} 19 \mathrm{in}$. deep), if the printer is mounted with an overhang. 


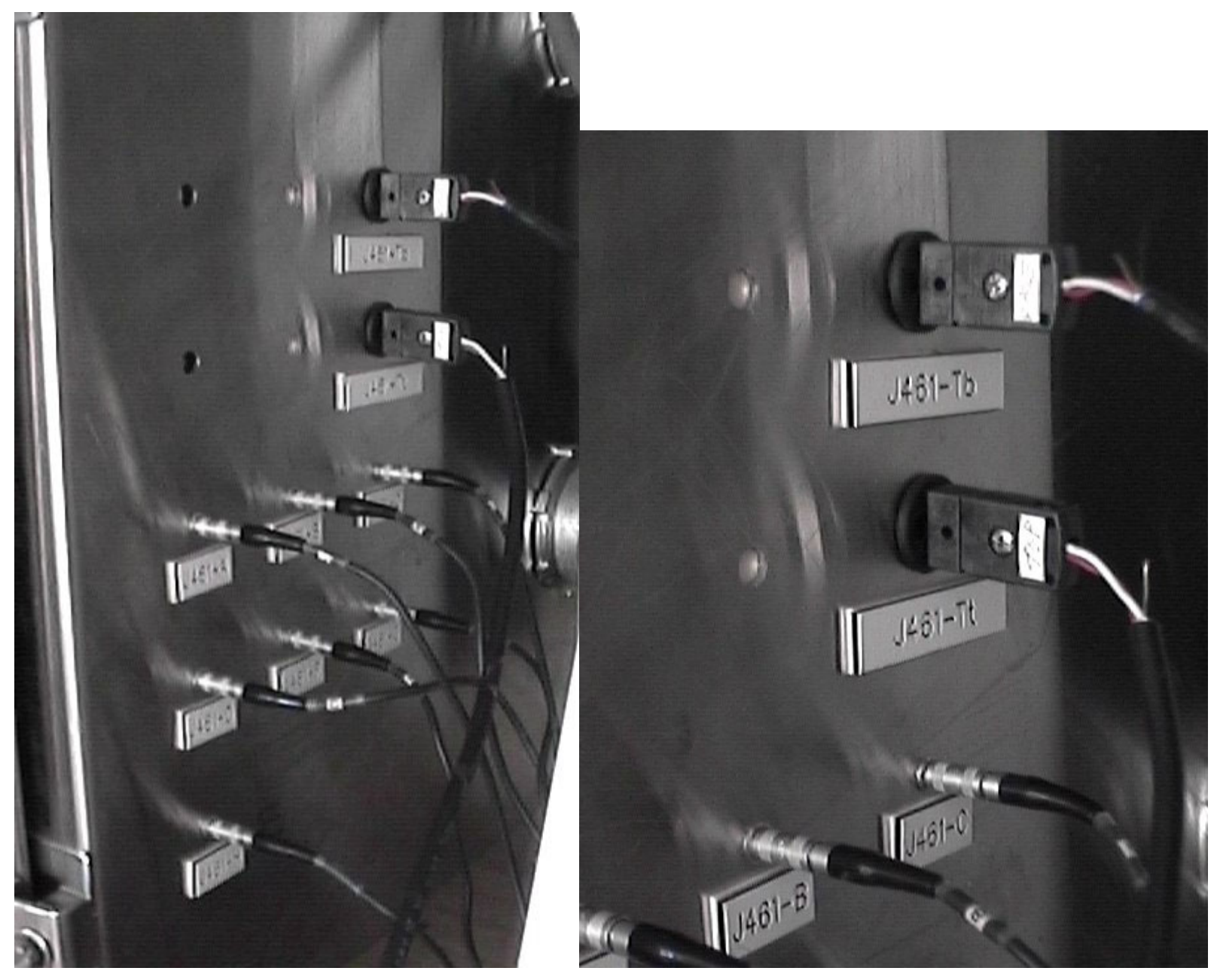

Figure 8.6 Density sensor connector locations on panel in DACS trailer

\subsection{Density Sensor Operational Check}

After the density sensor and cabling were installed at SY-101 and prior to the last planned work in the PPP, system operation was verified by observing the wave forms for each transducer with the transducer exposed to the air in the MPM piping. The waveforms, which are unique in shape, for each of the transducer, are shown in Figures 8.7 through 8.11. The densimeter was run for one cycle using the auto test command. The results of this run, which represent data obtained with the probes in air, are shown in Table 8.1. In addition, the pulser voltage was measured to determine whether it varied from the value obtained during tests in 305 Building. The pulser voltage is shown in Figure 8.12. The voltage obtained $(49.8 \mathrm{~V})$ was very similar to the $50 \mathrm{~V}$ measured in 305 Building. To measure the pulser voltage a 4.6- $\mathrm{m}$ (15-ft) cable was connected to transducer FF at the computer; this was connected to the oscilloscope using a 10:1 probe. The output measured is shown in Figure 8.12. 


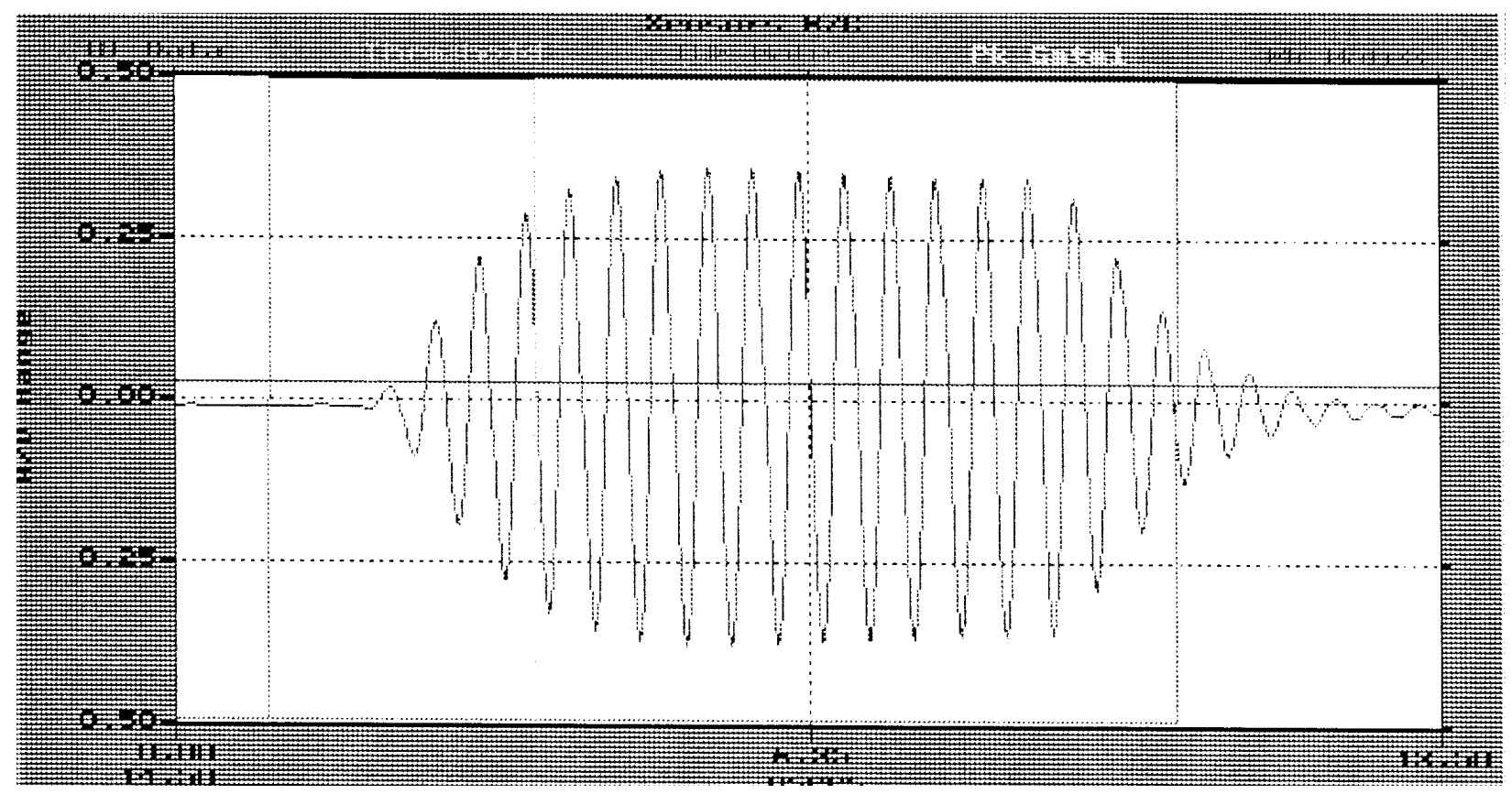

Figure 8.7 Wave form for longitudinal wave transducer pair BC in air

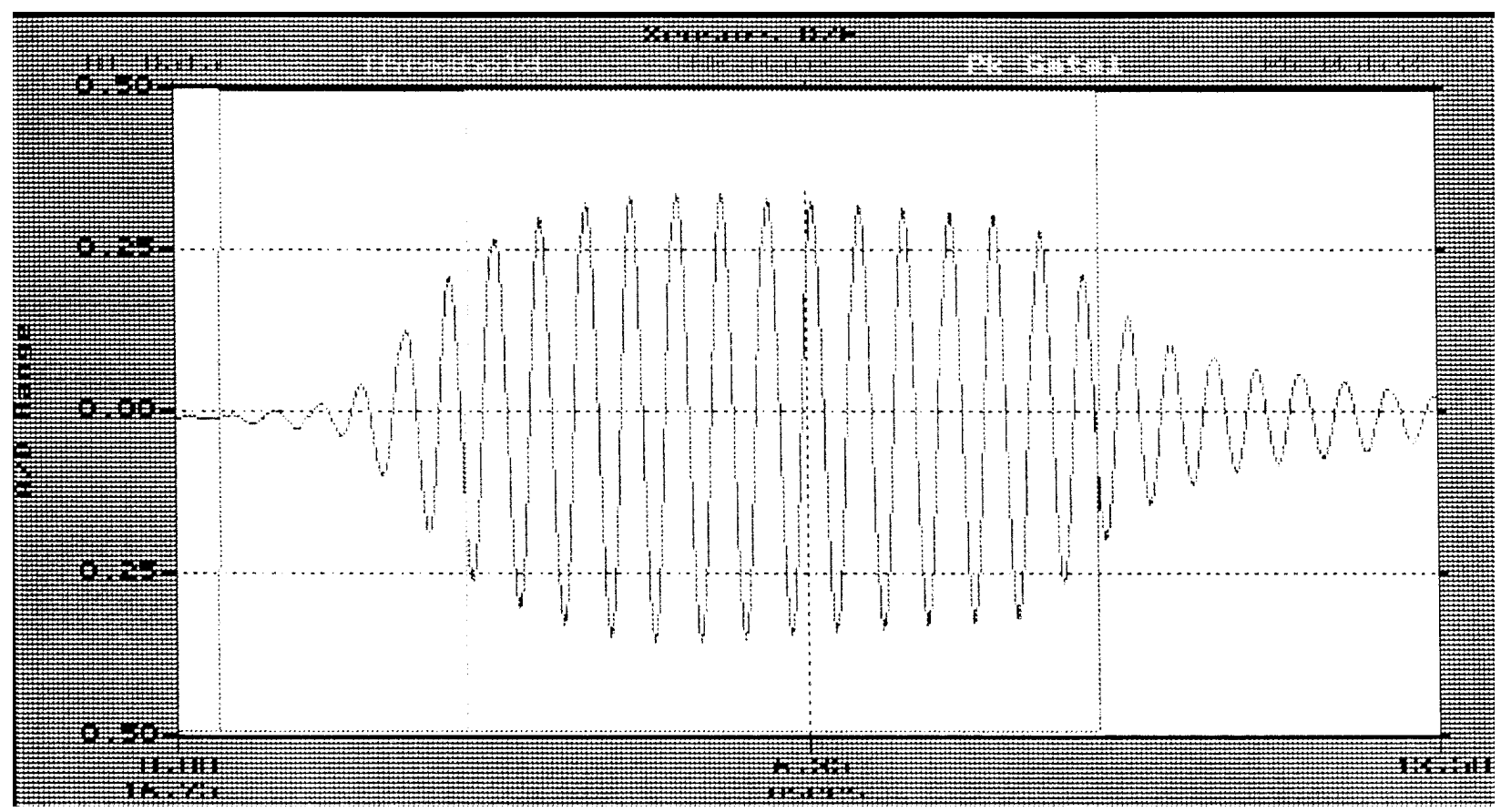

Figure 8.8 Wave form for longitudinal wave transducer pair DE in air 


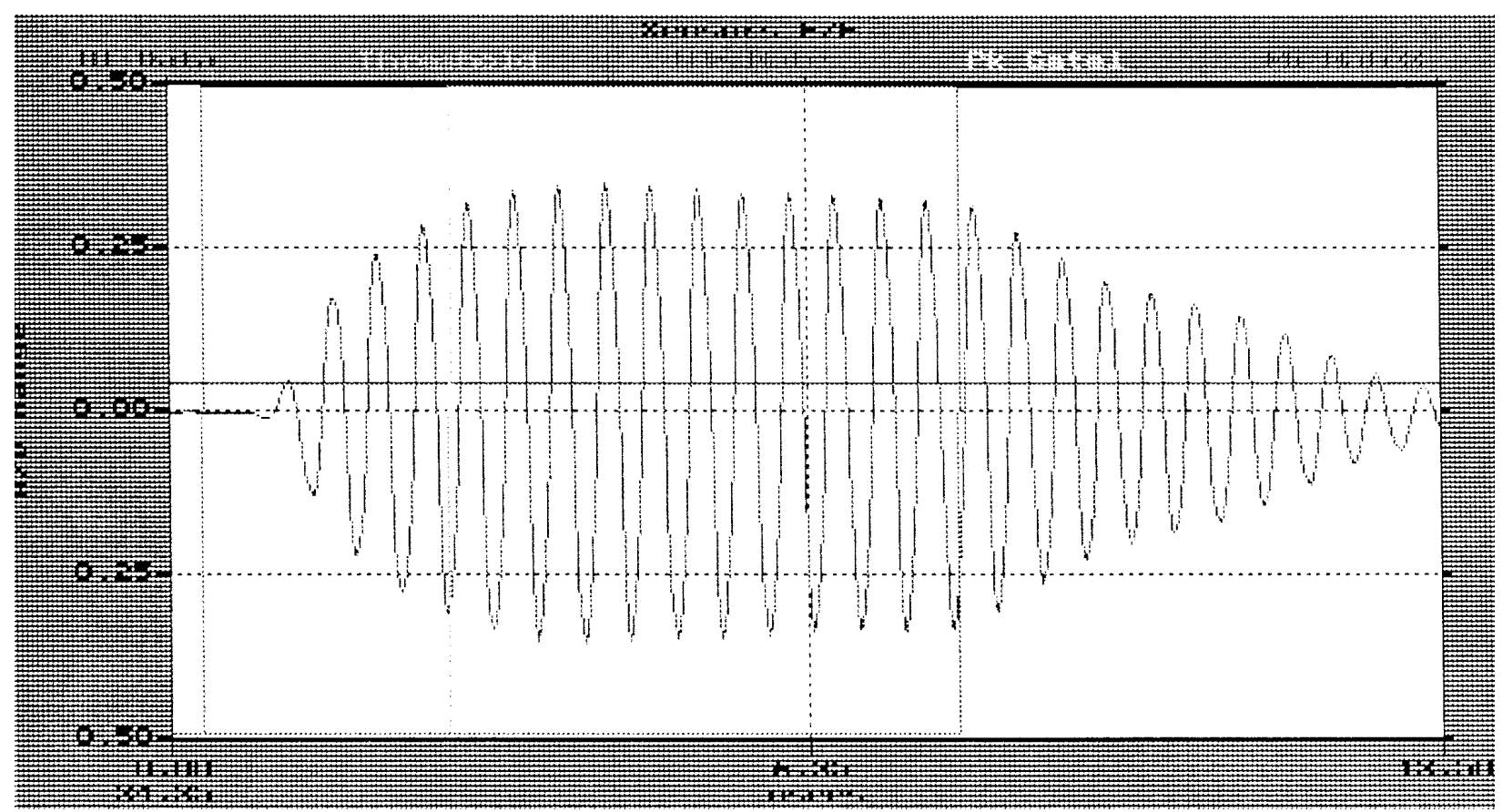

Figure 8.9 Wave form for longitudinal wave transducer FF in air

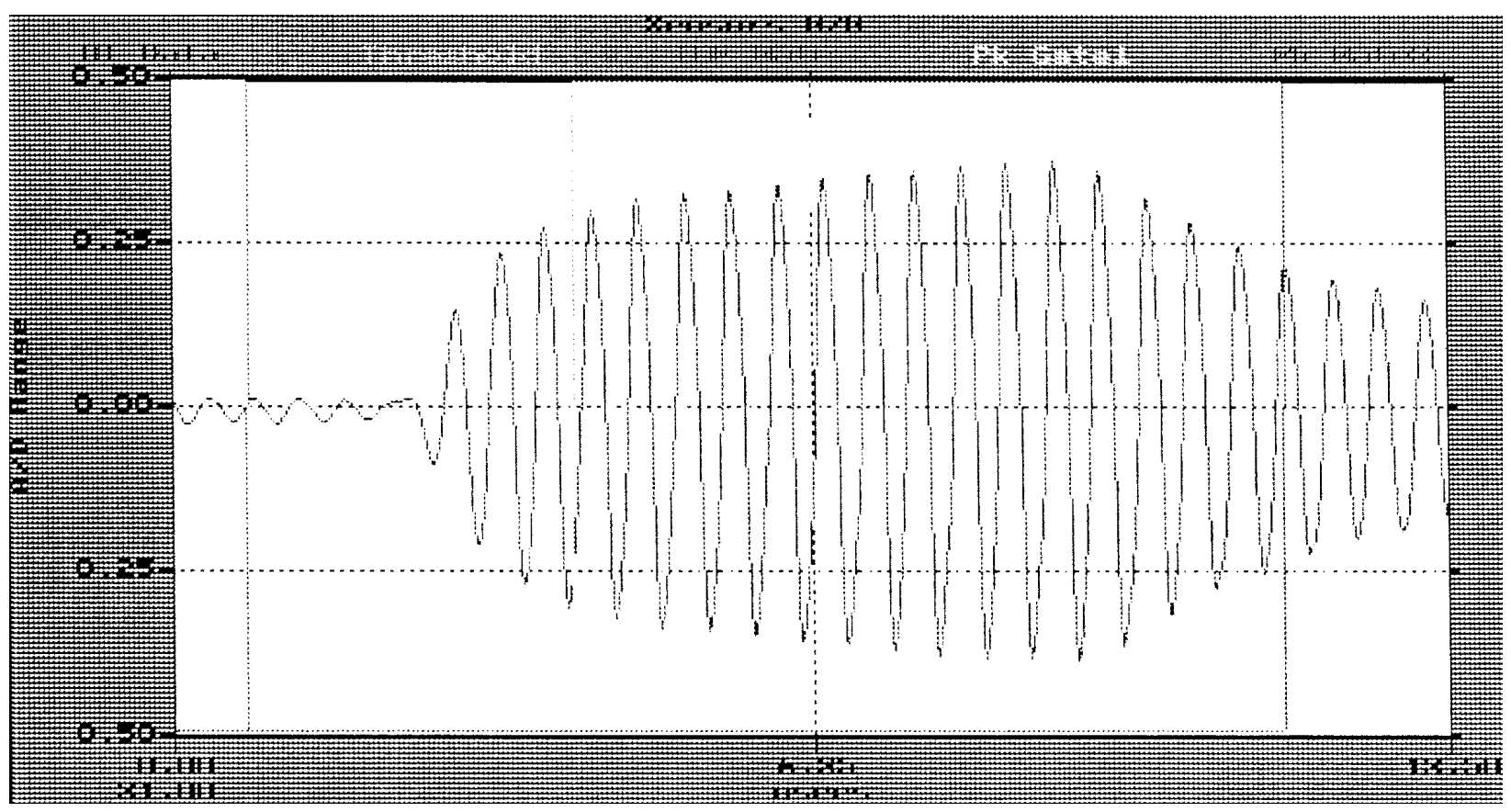

Figure 8.10 Wave form for longitudinal wave transducer GG in air 


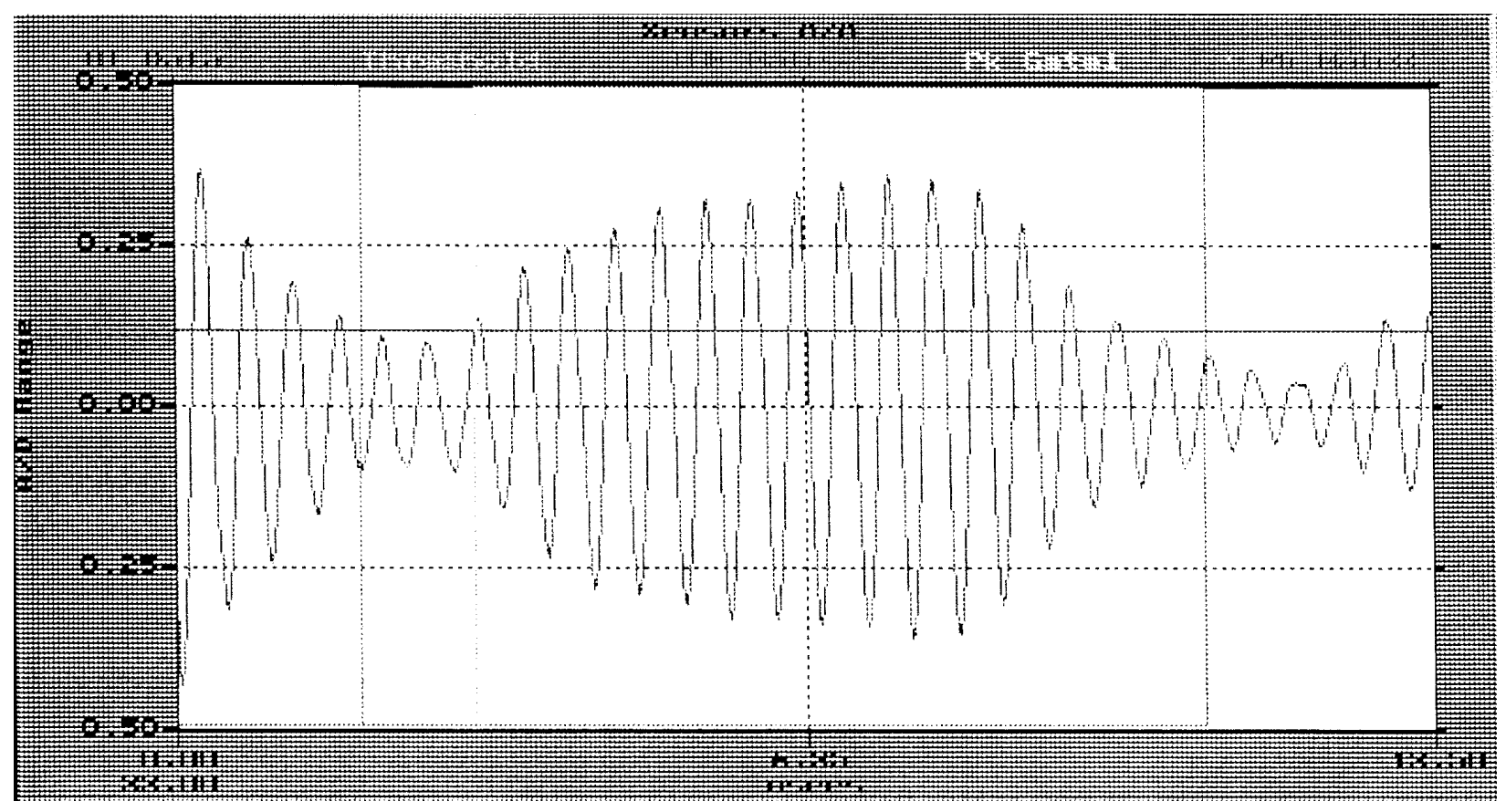

Figure 8.11 Wave form for shear wave transducer AA in air

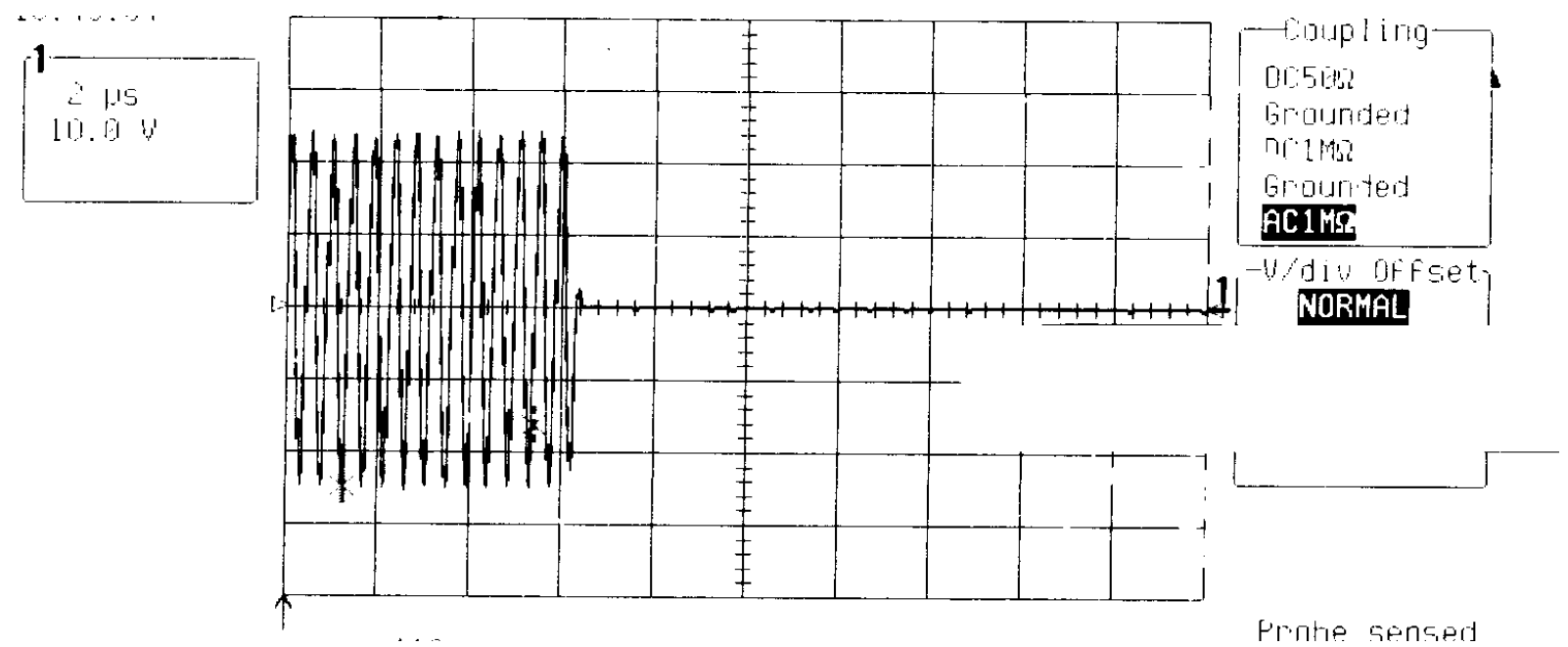

Figure 8.12 Evaluation of pulser voltage obtained in DACS trailer

Results obtained from these operational tests showed that the densimeter is correctly connected and ready for operation during planned activities of line flushing and waste transfers. The data taken in air will serve as a baseline for comparison prior to the initiation of any transfers. 
Table 8.1 Output from auto test of densimeter with probes in contact with air.

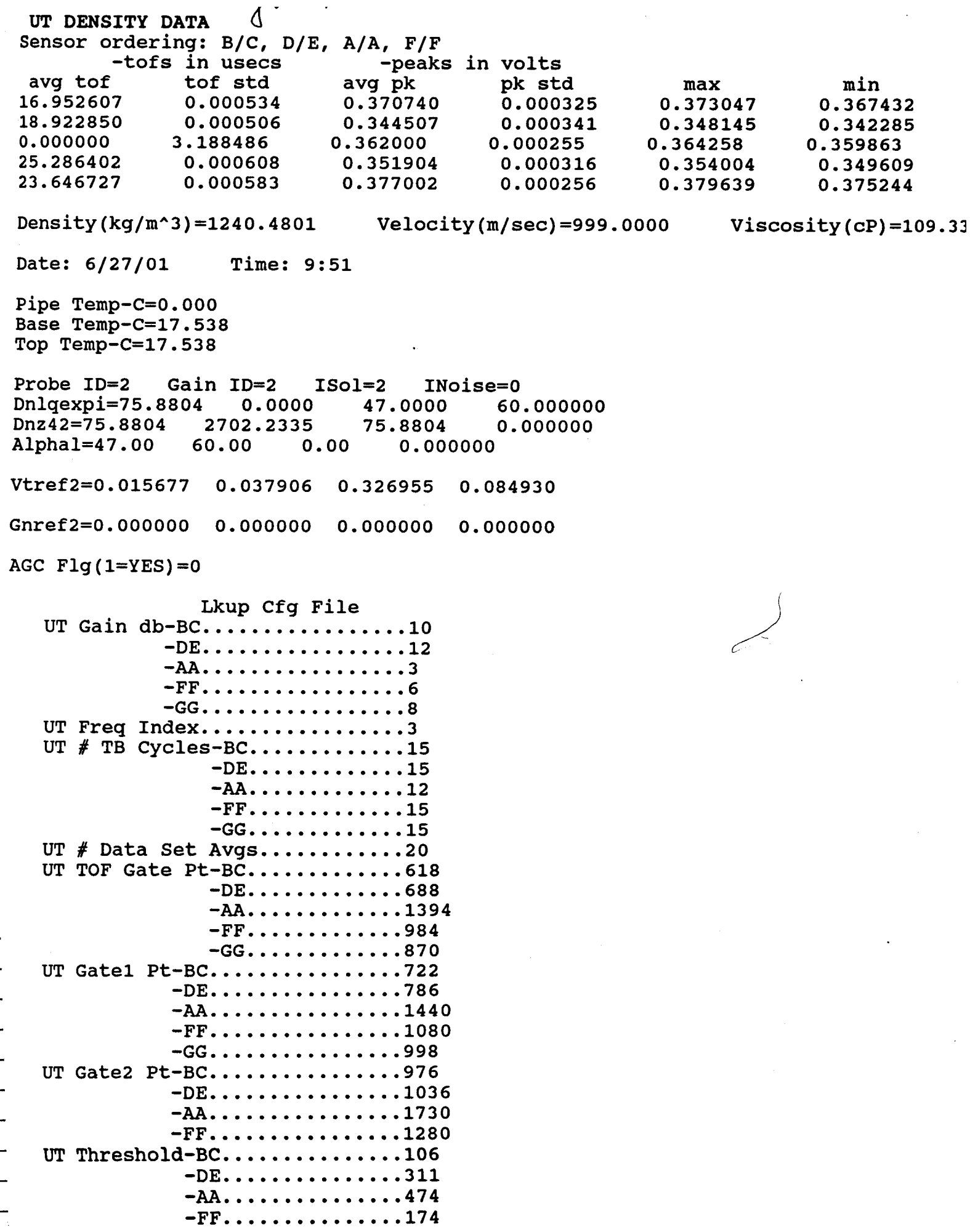


-GG...............374

A/D Clk Index............

A/D start Pt-BC....................

-DE...........670

-AA............. 1320

-FF...........9970

-GG............840

A/D \# Sample Pts-BC........5500

-DE $\quad \ldots \ldots \ldots 500$

-AA $\quad \ldots \ldots \ldots 500$

-FF $\quad \ldots \ldots \ldots 500$

-GG $\ldots \ldots \ldots 500$

A/D Trig Dly Clk Index-BC....7

$-D E \ldots . .7$

$-\mathrm{AA} \ldots . . .7$

$-F F \ldots . .7$

-GG..... 7

A/D Trig Dly Factor Index-BC..0

$-D E . .0$

$-A A . .0$

-FF.. 0

-GG.. 0

A/D \# Waveforms to Avg......15.00

A/D Bias-BC.............. 2.50

-DE................. 50

$-A$. ............... 2.50

-FF.................. 50

-GG.................. 50

Pk $F l g(1=P k, 0=P k-t o-P k)-B C \ldots . .0$

-DE.....

$-A A \ldots . . .0$

-FF......

-GG...... O 


\subsection{Density Sensor Improvements - Through-Wall Sensor}

The density sensor design installed in FY-2001 at Tank SY-101 is based on the original density sensor concept proposed in FY-1996 and evaluated at ORNL in FY-1997. The original plan was to demonstrate this concept at Hanford in FY-1998. However, based on project cancellations and reassignments the initial densimeter concept will finally be demonstrated in FY-2002. Upgrades to the SY-101 densimeter include the ability to operate over an increased pressure range (based on design of a new spool piece) and an enhanced calibration scheme that incorporates the effects of temperature into the methodology.

Concurrent with the density sensor demonstration project, Laboratory Directed Research and Development (LDRD) funded research to investigate coupling transducers directly to metal, eliminating the need for a plastic wedge. This approach could lead to coupling the transducers directly to the external surface of a pipe or even a transducer arrangement that can be clamped onto the pipe.

Interesting developments from the FY-2000 and FY-2001 LDRD that lead to a new configuration density sensor are now presented.

\subsection{Approach to Through-Wall Measurement of Density}

New methods are needed to characterize liquids and slurries that involve real-time, nonintrusive sensors. A new approach has been found to measure the density through the stainless steel wall of the pipe or vessel. While stainless steel is used in many applications, the method is also applicable to walls of other materials, such as glass.

The objective is to develop an ultrasonic sensor that: 1) can be attached permanently to a pipeline wall, possibly as a spool piece inserted into the line or 2) can clamp onto an existing pipeline wall and be movable to another location. An analysis method has been developed to make the measurement selfcalibrating. This is a very important feature, since it makes a clamp-on sensor feasible because the signal strength is sensitive to the pressure with which the transducer is coupled to the pipe.

This approach is very similar to the approach used for the density sensor, with stainless steel substituted for the "non-traditional" plastic wedge. In the new approach, a transducer $(1.3 \mathrm{~cm} \mathrm{x} 2.5 \mathrm{~cm} \mathrm{x}$ $0.16 \mathrm{~cm}[0.5$ in. $\mathrm{x} 1$ in. $\mathrm{x} 1 / 16 \mathrm{in}$.$] ) affixed to the outside of the pipeline wall sends ultrasound through the$ stainless steel. When the ultrasound strikes the liquid, some fraction of the ultrasound, denoted by the term "reflection coefficient," is reflected back to the transducer. That is, the stainless steel wall itself becomes the sensing material. The amount of ultrasound reflected at the stainless-steel-liquid interface depends upon the density of the liquid and the speed of sound in the liquid.

The focus of this research was to determine the acoustic impedance $(Z)$ of the liquid, defined as the product of the density $(\rho)$ and speed of sound (c). By measuring the speed of sound by well-known methods, the density can be determined. For these investigations, a square-wave pulser provided a high voltage pulse of short duration to the transducer. The self-calibrating feature that has been developed, a major step in this research, means that a change in the pulser voltage does NOT affect the measurement of 
the acoustic impedance. The data were obtained using a digital oscilloscope and saved to a disk. The sensor was calibrated using water. A separate Matlab ${ }^{\text {tm }}$ code was then used to analyze the data. Comparison of the voltages for the liquid and those for water yield the reflection coefficient. These measurements combined with the knowledge of the acoustic impedance of stainless steel yield the acoustic impedance of the liquid or slurry.

Laboratory measurements were carried out in which a transducer was mounted permanently upon a thin plate. The base of the plate was in contact with the liquid and the reflection of the ultrasound from the solid-liquid interface was also monitored by the same transducer. Data have been obtained using the following plates:

- $\quad 0.64-\mathrm{cm}-(0.25$-in.-) thick stainless steel plate

- 0.38 -cm- (0.15-in.-) thick stainless steel plate

- $\quad 0.64-\mathrm{cm}-(0.25$-in.-) thick aluminum plate

- $\quad 0.64-\mathrm{cm}-(0.25$-in.-) thick fused quartz plate (very similar to glass).

A clamp-on sensor suitable for a Schedule 40 stainless steel pipe $(\mathrm{O} . \mathrm{D} .=2.375 \mathrm{in}$. $[6 \mathrm{~cm}]$ and wall thickness $=0.154$ in. $[0.39 \mathrm{~cm}]$ ) is shown in Figure 9.1. Data will be obtained and compared with that from the very similar design using the 0.38 -cm- (0.15-in.-) thick stainless steel plate.

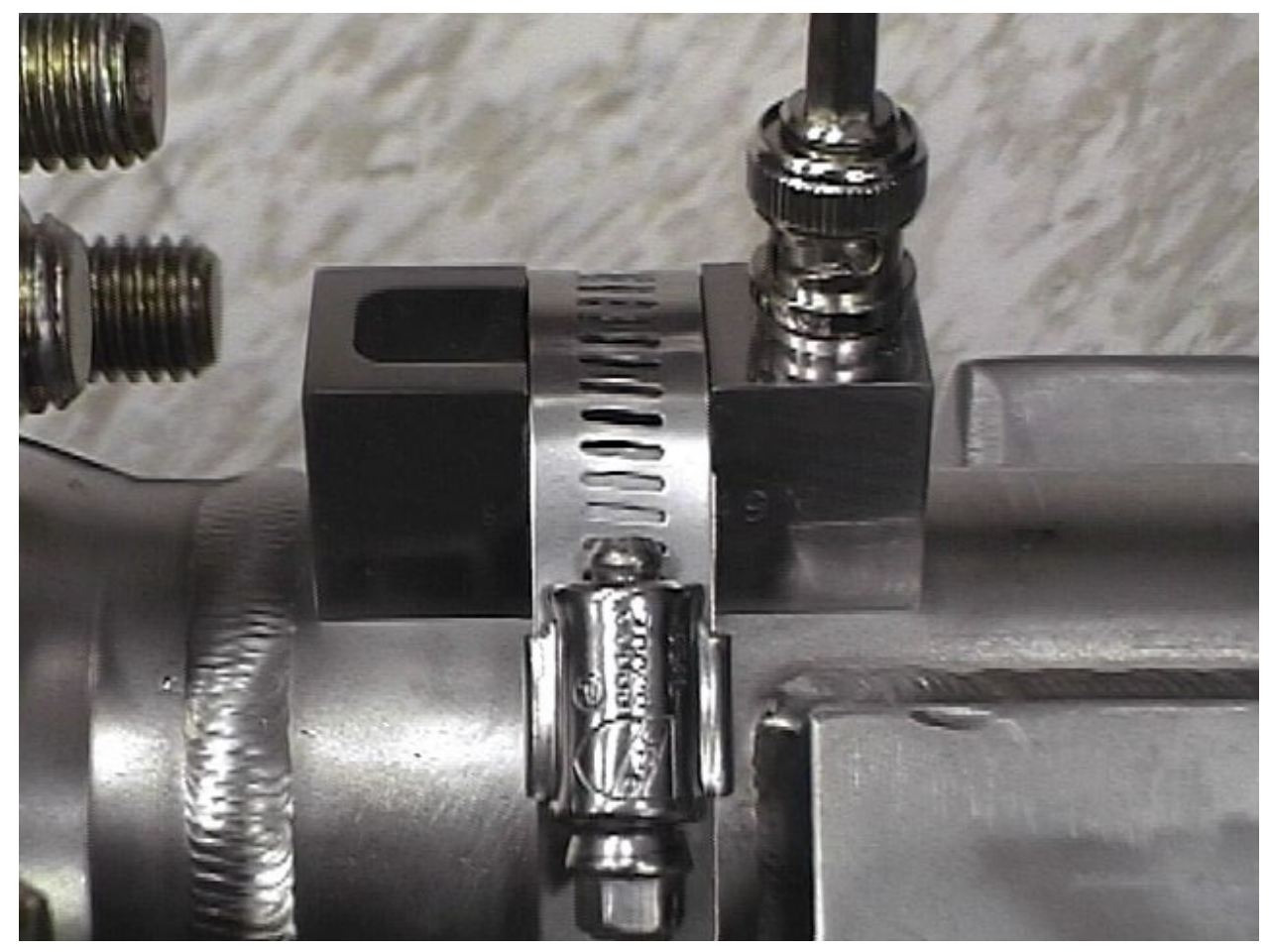

Figure 9.1 Clamp-on sensor applied to 2 -in. Schedule 40 pipe 
Tables 9.1 and 9.2 show the results for the two stainless steel plates. The performance was evaluated by measuring sugar water (SW) solutions of various concentrations. The concentration is indicated by the percentage of sugar in a given weight of the solution. The density of the solution, given in the second column, was obtained by measuring the weight of a known volume of liquid. The speed of sound in the liquid was also measured. These values lead to an independent value of the acoustic impedance of the liquid. Analysis of the signals from the transducer is used to determine the reflection coefficient, which, in turn, yields the acoustic impedance of the liquid. In the tables the acoustic impedance obtained using the sensor is compared with that obtained independently. The percentage error is also shown.

Table 9.1 Data obtained with the 0.0.64-cm- (0.25-in.-) thick stainless steel plate

\begin{tabular}{|c|c|c|c|c|c|}
\hline \multirow[t]{2}{*}{ Liquid } & $\begin{array}{c}\text { Measured } \\
\text { Density }\end{array}$ & \multirow{2}{*}{$\begin{array}{l}\text { Measured } \\
\text { Reflection } \\
\text { Coefficient }\end{array}$} & $\begin{array}{l}\text { Sensor Measurement of } \\
\text { Acoustic Impedance }\end{array}$ & $\begin{array}{l}\text { Independent Measurement } \\
\text { of Acoustic Impedance }\end{array}$ & $\begin{array}{l}\text { Percent } \\
\text { Error }\end{array}$ \\
\hline & $\left(\mathrm{kg} / \mathrm{m}^{3}\right)$ & & $\left(\mathrm{kg} / \mathrm{m}^{2} \mathrm{sec}\right) \times 10^{6}$ & $\left(\mathrm{~kg} / \mathrm{m}^{2} \mathrm{sec}\right) \times 10^{6}$ & $(\%)$ \\
\hline $2.5 \% \mathrm{SW}$ & 1006 & 0.9389 & 1.4622 & 1.4994 & -2.5 \\
\hline $5.0 \% \mathrm{SW}$ & 1016 & 0.9354 & 1.5489 & 1.5213 & 1.8 \\
\hline $7.5 \% \mathrm{SW}$ & 1026 & 0.9368 & 1.5146 & 1.5447 & -2.0 \\
\hline $10 \% \mathrm{SW}$ & 1038 & 0.9357 & 1.5425 & 1.5696 & -1.7 \\
\hline $15 \% \mathrm{SW}$ & 1065 & 0.9334 & 1.5982 & 1.6239 & -1.6 \\
\hline $20 \% \mathrm{SW}$ & 1097 & 0.9304 & 1.6726 & 1.6844 & -0.7 \\
\hline
\end{tabular}

Table 9.2 Data obtained with the 0.38-cm- (0.15-in.-) thick stainless steel plate

\begin{tabular}{|c|c|c|c|c|c|}
\hline \multirow[t]{2}{*}{ Liquid } & $\begin{array}{c}\text { Measured } \\
\text { Density }\end{array}$ & \multirow{2}{*}{$\begin{array}{l}\text { Measured } \\
\text { Reflection } \\
\text { Coefficient }\end{array}$} & $\begin{array}{l}\text { Sensor Measurement of } \\
\text { Acoustic Impedance }\end{array}$ & $\begin{array}{c}\text { Independent Measurement } \\
\text { of Acoustic Impedance }\end{array}$ & $\begin{array}{c}\text { Percent } \\
\text { Error }\end{array}$ \\
\hline & $\left(\mathrm{kg} / \mathrm{m}^{3}\right)$ & & $\left(\mathrm{kg} / \mathrm{m}^{2} \mathrm{sec}\right) \times 10^{6}$ & $\left(\mathrm{~kg} / \mathrm{m}^{2} \mathrm{sec}\right) \times 10^{6}$ & $(\%)$ \\
\hline $5 \% \mathrm{SW}$ & 1010 & 0.9359 & 1.5378 & 1.525 & 0.8 \\
\hline $10 \% \mathrm{SW}$ & 1027 & 0.9347 & 1.5668 & 1.5782 & -0.7 \\
\hline $15 \% \mathrm{SW}$ & 1057 & 0.9310 & 1.6581 & 1.6265 & 1.9 \\
\hline $20 \% \mathrm{SW}$ & 1074 & 0.9305 & 1.6709 & 1.6856 & -0.8 \\
\hline $30 \% \mathrm{SW}$ & 1115 & 0.9188 & 1.9652 & 1.8087 & 8.7 \\
\hline $40 \% \mathrm{SW}$ & 1170 & 0.9139 & 2.0885 & 1.9635 & 6.4 \\
\hline
\end{tabular}

The analysis method enables very small changes in the reflection coefficient to be measured and thus, to distinguish between very small changes in the density of the liquid or slurry. The effectiveness of these methods can be observed by noting that two different experiments give values of the reflection coefficients that are extremely close. That is, the amount of reflection is determined by the solid-liquid interface alone, and is not dependent upon the thickness of the plate. Thus, a $20 \%$ sugar water solution gives a reflection coefficient of 0.9304 in one experiment and 0.9305 in the second.

The data shown in the tables was obtained using signal averaging, but show only one set of data. Percentage errors can be reduced by averaging several sets of data performed in a very short time, if automated. The digital oscilloscope had a $100 \mathrm{MHz}$ digitizer with 8-bit resolution. Increased accuracy 
can be obtained by analyzing the signals with a higher digitizer rate and with 10-bit or 12-bit digitizer resolution.

Some conclusions are as follows:

- The analysis method provides a way to measure very small changes in reflection coefficient, and hence, very small changes in the density through stainless steel (or other solids).

- The self-calibrating feature makes it possible to design a clamp-on sensor.

- The self-calibrating feature means that changes in the pulser voltage do not affect the measurement.

- The self-calibrating feature reduces the calibrating time.

- Wireless technology could be used to design a sensor to measure density and speed of sound and thus eliminate the long cables from the sensor to the computer acquisition system.

\subsection{Clamp-on Sensor Applications}

This investigation has shown the path forward to develop clamp-on sensors for measurement of fluid and slurry density. This method is especially attractive for applications such as Hanford where radioactive fluids are routinely transported because the sensors could be applied to existing equipment without the need to penetrate the pipe pressure boundary or to open the system to install new equipment. The two plate thicknesses evaluated $(0.38$ and $0.64 \mathrm{~cm}$ [0.15 and $0.25 \mathrm{in}]$.$) are very similar to pipe wall$ thicknesses that are in use at Hanford. Schedule 402 in. pipe has a wall thickness of $0.39 \mathrm{~cm}(0.154$ in.) similar to the smaller thickness tested, and Schedule 404 -in. pipe has a wall thickness of $0.60 \mathrm{~cm}(0.237$ in.) similar to the larger thickness tested. 


\subsection{Economic Advantages of Slurry Monitoring}

Inclusion of slurry monitoring instrumentation into the slurry transfer lines will result in significant cost savings in preventing pipeline plugging by enabling early detection of plugging event occurrences and enabling the operators to take early steps to offset such occurrences. An economic assessment of the benefits of incorporating slurry monitoring at Hanford and other DOE Sites was conducted as a part of the ASTD analysis of pipeline slurry monitors (Bontha et al. 2000). Salient points from that analysis are reiterated here.

\subsection{Densimeter Cost Estimate}

Two densimeter probes shown in Figures 4.1 and 4.2c and Figures 4.5 and 4.6 have been constructed embedded in pipeline spool pieces for measuring density during pipeline transport. Two immersion probes have been constructed, one for measuring density in a tank shown in Figure 4.2a, and another table top system for measuring density of fluids when less than $100 \mathrm{ml}$ of fluid is required. Each of these densimeter systems includes two major components: the probe that houses the density sensor and the computer control system. The major components of the sensor are the plastic wedge, transducers, and cable connectors. The wedge must be constructed to withstand the temperature, pressure, chemical and physical characteristics of the fluid being interrogated. The computer control system must be constructed to withstand the physical and chemical environment in which it will be operated. An office or laboratory system may not be required to be as rugged as a system designed for installation in a plant or outdoor environment. These factors must be taken into account when assessing the cost of densimeter deployment.

\subsubsection{Cost of Initial Deployments}

After completion of the densimeter evaluation at ORNL (Hylton et al 1998) the costs of deployment of the densimeter were estimated. The spool piece was projected to have an off-the-shelf cost of $\$ 4 \mathrm{~K}$ and the computer-based controller was projected to have an off-the-shelf cost of $\$ 14 \mathrm{~K}$.

The densimeter probe designed for deployment at SY-101 is more complex than the system designed for deployment at ORNL. For SY-101 deployment, the densimeter design pressure increased from 690 $\mathrm{kPa}(\mathrm{g})$ to $2.8 \mathrm{MPa}$ (g) (100 psig to $400 \mathrm{psig}$ ). To meet this pressure requirement, the densimeter spool piece and wedge configuration were redesigned from the ORNL configuration. For the system to be deployed at SY-101, the costs are associated with four major components: the stainless steel spool piece with flanges, the transducer wedge, the customized computer board and the computer in which it is installed. In addition, for deployment at the site, radiation-hardened cables are required. The costs associated with each of these items are listed in Table 10.1. In addition to these procurement costs, the densimeter must be assembled, pressure tested, and calibrated. Costs for these items are in addition to the hardware listed in Table 10.1. 
Table 10.1 Cost of densimeter for SY-101 deployment

\begin{tabular}{||l|c|l||}
\hline \multicolumn{1}{|c|}{ Component } & $\begin{array}{c}\text { Hardware } \\
\text { Procurement Cost }\end{array}$ & \multicolumn{1}{||}{ Comments } \\
\hline $\begin{array}{l}\text { Stainless steel } \\
\text { spool piece }\end{array}$ & $\$ 7 \mathrm{~K}$ & $\begin{array}{l}\text { The spool piece is constructed and pressure tested to operate } \\
\text { at design conditions }\end{array}$ \\
\hline Transducer wedge & $\$ 3 \mathrm{~K}$ & $\begin{array}{l}\text { The transducer wedges are machined to fit in the spool piece. } \\
\text { The transducers are bonded to the wedge. }\end{array}$ \\
\hline $\begin{array}{l}\text { Custom computer } \\
\text { board }\end{array}$ & $\$ 4 \mathrm{~K}$ & $\begin{array}{l}\text { The major design for this board was initiated during } \\
\text { development of the system evaluated at ORNL. Some } \\
\text { upgrades were incorporated in this new board configuration. }\end{array}$ \\
\hline Cable & $\$ 1 \mathrm{~K}$ & $\begin{array}{l}\text { Radiation hardened co-axial cable is required in the pump pit. } \\
\text { A long cable run to the data acquisition location may be } \\
\text { required. }\end{array}$ \\
\hline Computer & $\$ 5 \mathrm{~K}$ & $\begin{array}{l}\text { This off-the-shelf computer must withstand plant operating } \\
\text { conditions and be designed to accommodate the custom } \\
\text { computer board. }\end{array}$ \\
\hline Hardware Cost & $\$ 20 \mathrm{~K}$ & \\
\hline \hline
\end{tabular}

\subsubsection{Estimates of Cost of Future Deployments}

The major cost of the densimeter system is associated with the pressure boundary. During development for deployment at SY-101 the following items have been identified and addressed. Materials were evaluated and selected for the probe body, O-ring seals, wedge, transducer and bonding material to permit continued operation at high $\mathrm{pH}$ and in a high radiation field. Designs for deployment in 5-cm- and 10-cm (2-in.- and 4-in.-) diameter piping systems have been developed. The length of the spool piece and the connecting flanges are dictated by the deployment configuration. These items may be customized for each deployment, or for mass production, a limited choice may be provided.

A significant savings may be associated with development of a mass-produced computer control system. Many ultrasonic components and functions are integrated into customized boards. In the future, the need for a computer-controller may be eliminated and the sensor control system may be a single board that is plugged into the existing plant data acquisition system. Estimates of the costs associated with future deployments are listed in Table 10.2. 
Table 10.2 Estimated cost of future density sensor deployments

\begin{tabular}{||l|c|l||}
\hline \multicolumn{1}{|c|}{ Component } & Procurement Cost & \multicolumn{1}{c|}{ Comments } \\
\hline $\begin{array}{l}\text { Stainless steel spool } \\
\text { piece }\end{array}$ & $\$ 5 \mathrm{~K}$ & $\begin{array}{l}\text { The spool piece is constructed and pressure tested to } \\
\text { operate at design conditions. A streamlined design } \\
\text { that incorporates a smaller wedge design or a clamp- } \\
\text { on wedge design is envisioned. }\end{array}$ \\
\hline Transducer wedge & $\$ 2 \mathrm{~K}$ & $\begin{array}{l}\text { A more streamlined wedge with fewer transducers is } \\
\text { envisioned. The transducers are bonded to the wedge. } \\
\text { The wedge material may be stainless steel for easy } \\
\text { mounting to the pipe wall. }\end{array}$ \\
\hline Custom computer board & $\$ 3 \mathrm{~K}$ & $\begin{array}{l}\text { A new board design will integrate pulser, digitization, } \\
\text { and analysis features for the sensor. . }\end{array}$ \\
\hline Computer & $\$ 0 \mathrm{~K}$ & $\begin{array}{l}\text { Not required. Computer board will insert into the } \\
\text { plant data acquisition system }\end{array}$ \\
\hline Wiring & $\$ 1 \mathrm{~K}$ & Radiation-hardened wire \\
\hline System Cost & $\$ 11 \mathrm{~K}$ & \\
\hline
\end{tabular}

\subsection{Impacts of Plugged Pipelines}

When a pipeline becomes plugged, efforts are made to unplug the line. These efforts include flushing with hot water and pressurizing the pipeline. To flush or to pressurize, connections must be made to the plugged pipeline in a contaminated zone. This results in exposure to radiation and/or contamination. If the unplugging efforts are unsuccessful, the pipeline must be replaced, and the new pipeline must have a hot tie-in to the existing system. Any time a radioactive pipeline must be cut and a hot tie-in made, people are exposed to radiation and contamination. Even with extensive flushing, significant dose may be incurred. A project at Hanford, sluicing of 241-C-106, incurred 25 person rems during construction (Bontha et al 2000). Construction of project W-320 included installation of a 460-m (1500-ft) pipeline with four hot tie-ins to contaminated systems as well as equipment installation in two tanks. Any replacement of plugged lines will require two hot tie-ins. If these hot tie-ins are made inside a tank farm, the excavation may encounter contaminated soil and additional human exposure and equipment contamination. 


\subsection{References}

Bamberger, J.A. and M.S. Greenwood. 2000. Measuring Slurry Density and Viscosity In-Situ in Real Time During Pipeline Transport Using an Ultrasonic Sensor. FEDSM00-11121, Proceedings of the ASME 2000 Fluids Engineering Division Summer Meeting, June 11-15, 2000, Boston, Massachusetts. American Society of Mechanical Engineers, New York, New York.

Bamberger, J. A., H. K. Kytomaa, and M. S. Greenwood. 1998. "Slurry Ultrasonic Particle Size and Concentration Characterization." In Science and Technology for Disposal of Radioactive Tank Wastes, WW Schulz and NJ Lombardo, eds. Plenum Press, New York, New York.

Bamberger, J.A., L.J. Bond, and M.S. Greenwood. 1999. Ultrasonic Measurements for On-line Realtime Food Process Monitoring. Sixth Conference on Food Engineering, 1999 AIChE Annual Meeting, Dallas, Texas.

Bamberger, J.A., M.S. Greenwood, and K.S. Witwer. 2001. Development of an Ultrasonic Sensor to Measure Density of Radioactive Waste Slurries during Pipeline Transport. ANS $9^{\text {th }}$ International Topical Meeting Robotics and Remote Systems, Seattle, Washington, March 4-8, 2001

Bamberger, J.A., M.S. Greenwood, and L.J. Bond. 1999. Real Time Process Characterization and Measurement Using Ultrasonics. The 26th Annual Conference of the Federation of Analytical Chemistry and Spectroscopy Societies, FACSS, Santa Fe, New Mexico, p. 279-280.

Bontha, J.R., J.A. Bamberger, T.D. Hylton, and T.H. May. 2000. Qualification of Three-On-Line Slurry Monitoring Devices for Application during Waste Retrieval Operations at DOE Sites. PNNL-13358. Pacific Northwest National Laboratory, Richland, Washington.

Engel, R.L., J. Greenborg, M.M. Hendrickson. 1966. ISOSHLD - A Computer Code for General Purpose Isotope Shielding Analysis. BNWL-236, Battelle Memorial Institute - Pacific Northwest Laboratory, Richland, Washington.

Erhart, M.F. 1999. Functional Requirements and Technical Criteria for the 241-SY-101 RAPID Mitigation System. HNF-3885. Lockheed Martin Hanford Company, Richland, Washington.

Fort, J.A., J.A. Bamberger, J.M. Bates, C.W. Enderlin, and C. W. Elmore. 1993. Final Report 1/12Scale Physical Modeling Experiments in Support of Tank 241-SY-101 Hydrogen Mitigation. NL8476, Pacific Northwest Laboratory, Richland, Washington.

Greenwood, M.S. 2000a. Ultrasonic fluid densitometer having liquid/wedge and gas/wedge interfaces. US Patent 6,082,181 issued July 4, 2000.

Greenwood, M.S. 2000b. Ultrasonic fluid densitometer for process control. US Patent 6,082,180 issued July 4, 2000. 
Greenwood, M.S. and J.C. Lail. 1998. Ultrasonic Fluid Densitometry and Densitometer, US Patent 5,708,191 issued January 13, 1998.

Greenwood, M.S. and R.V. Harris. 1999. Pitch-catch only ultrasonic fluid densitometer, US Patent 5,886,250 issued March 23, 1999.

Greenwood, M.S., J.R. Skorpik, J.A. Bamberger, and R.V. Harris. 1999. On-line ultrasonic density sensor for process control of liquids and slurries. Ultrasonics 37 (1999) 159-171.

Greenwood, M.S., J.R. Skorpik, and J.A. Bamberger. 1998. Online Sensor to Measure Density of a Liquid or Slurry. In Science and Technology for Disposal of Radioactive Tank Waste, WW Schulz and NJ Lombardo, Ed., Plenum Press, New York, NY 1998.

Greenwood, M.S., J. Skorpik, and J. Bamberger. 1997. On-Line Sensor to Measure Liquid density using Reflection Coefficients. ASNT Fall Conference and Quality Testing Show Paper Summaries, October 20-24.

Greenwood, M.S., J.R. Skorpik, and J.A. Bamberger. 1999. On-line Sensor for Density and Viscosity Measurement of a Liquid or Slurry for Process Control in the Food Industry. Sixth Conference on Food Engineering, 1999 AIChE Annual Meeting, Dallas, Texas.

Hylton, T.D., M.S. Anderson, D.C. Van Essen, and C.K. Bayne. 1998. Comparative Testing of Slurry Monitors. ORNL/TM-13587, Oak Ridge National Laboratory, Oak Ridge, Tennessee.

Krautkramer, J. and H. Krautkramer. 1983 Ultrasonic Testing of Materials, Springer-Verlag, New York, 1983, 3rd ed., p. 606.

Povey, M.J.W. 1997 Ultrasonic Techniques for Fluids Characterization, Academic Press, New York

Reynolds, B.A., E.A. Daymo, J.G.H. Geeting, and J. Zhang. 1996. Instrument Validation Facility, PNNL-11221, Pacific Northwest National Laboratory, Richland, Washington.

Witwer, K. 1999. An Engineering Work Plan for the Development and Testing of the 241-SY-101 Prefabricated Pump Pit Modified Process Manifold. RPP-6853, Rev. 0. Fluor Hanford, Inc., Richland, Washington.

Witwer, K.S, J.A. Bamberger, and M.S. Greenwood. 2001. Results Of Performance Testing of the Ultrasonic Densitometer Used in the 241SY-101 Prefabricated Pump Pit, RPP-7543, Rev. 0, Fluor Hanford, Inc., Richland, Washington. 


\subsection{Appendix Densimeter Prints}




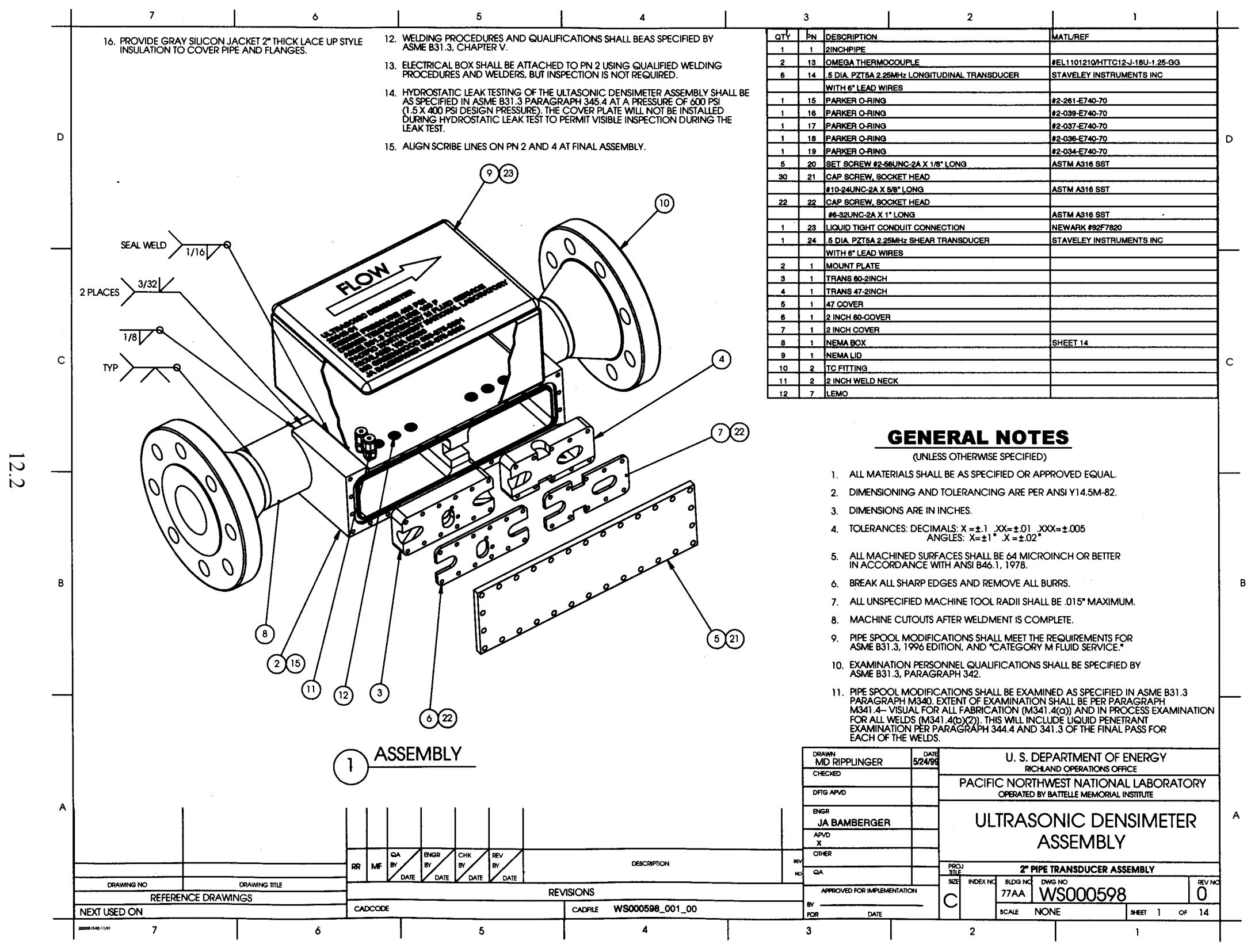




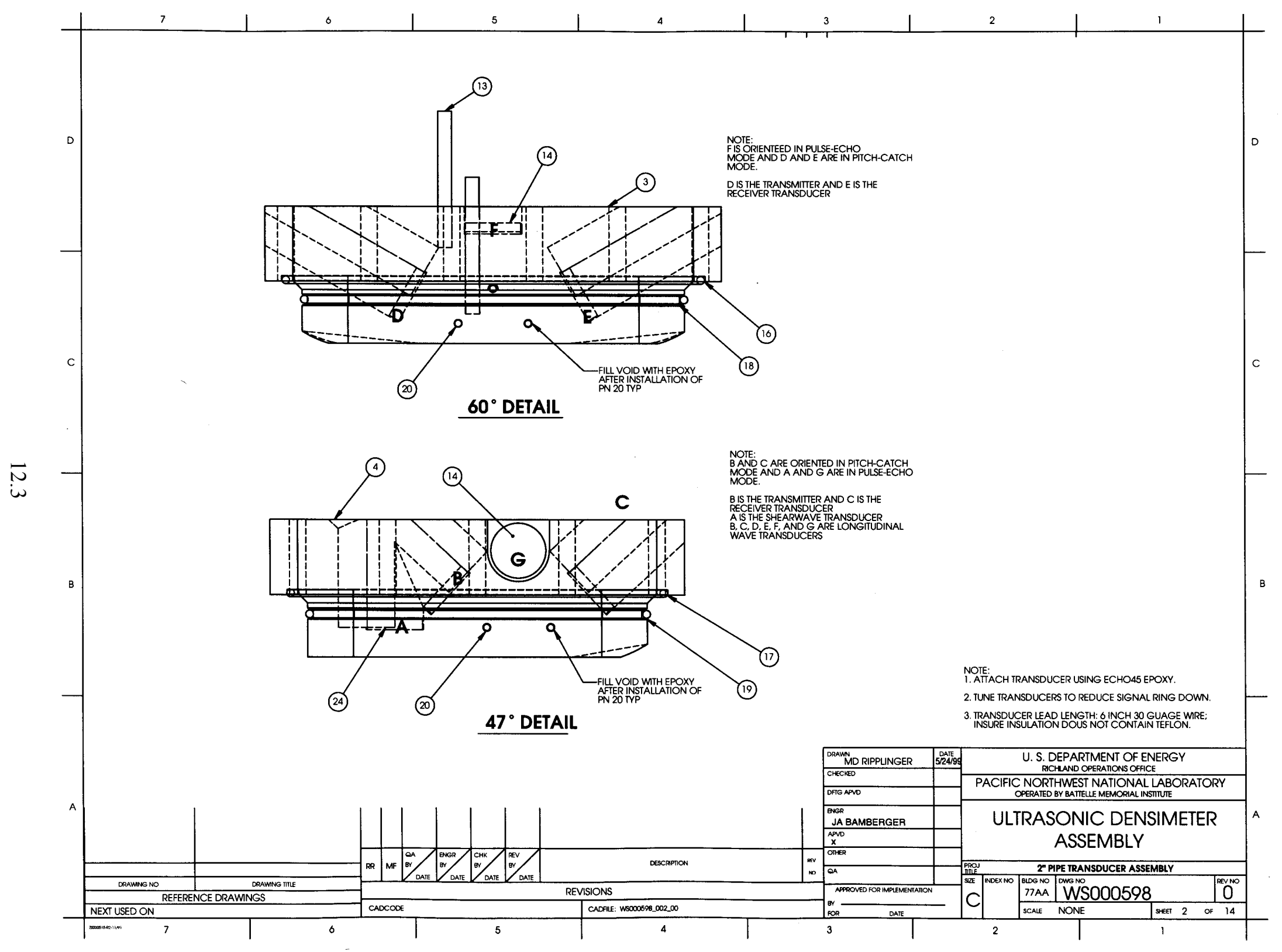




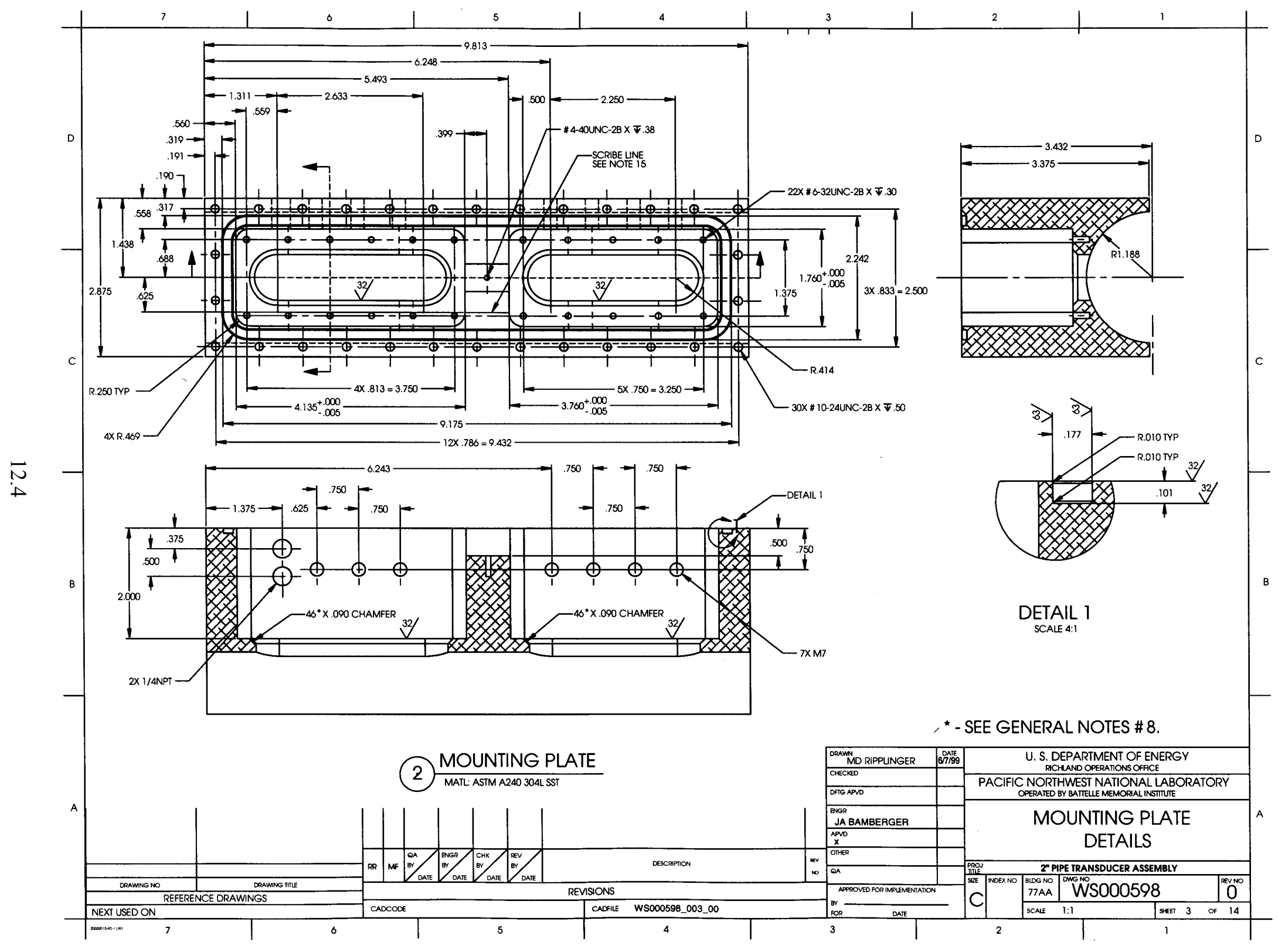




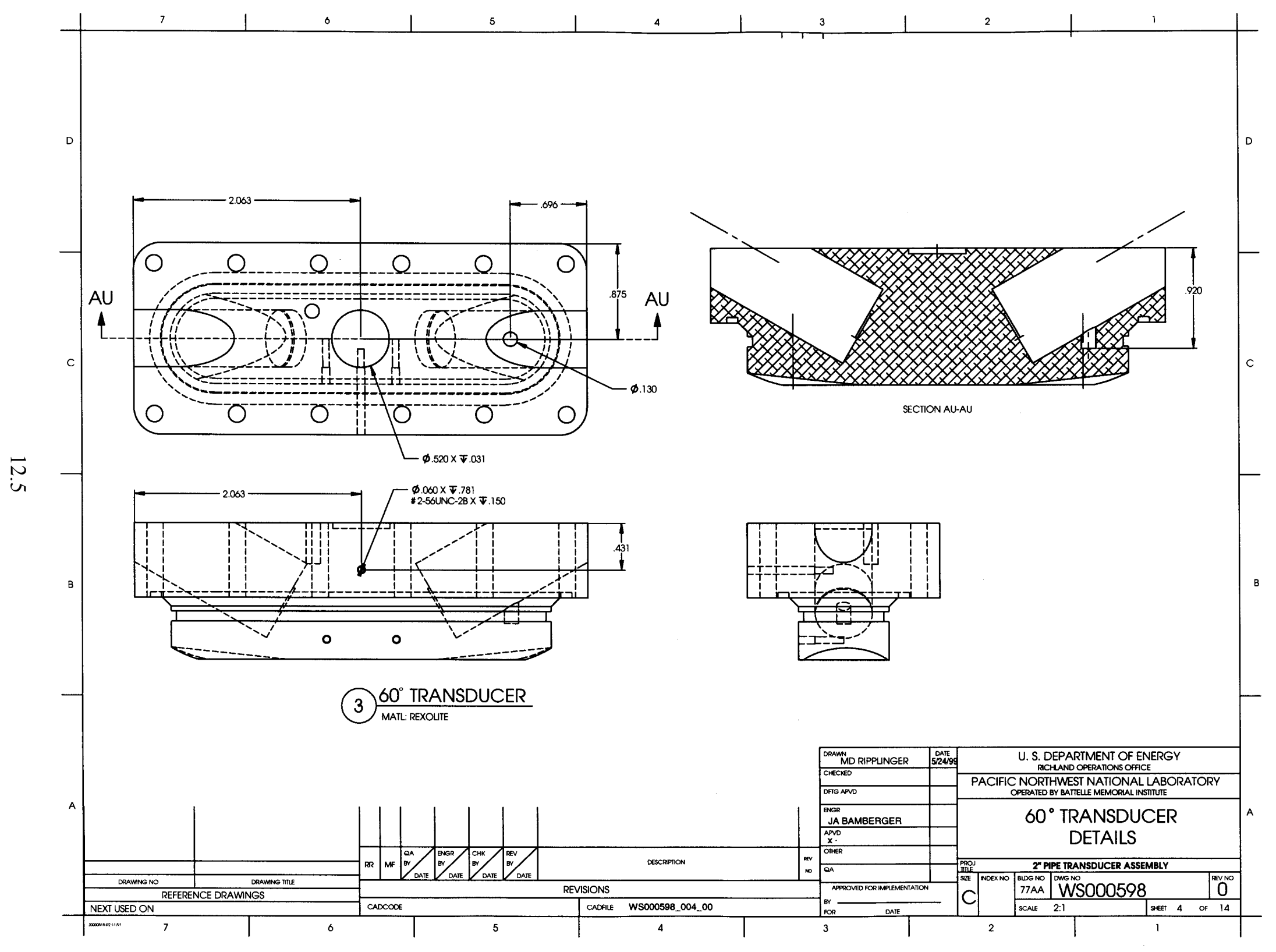




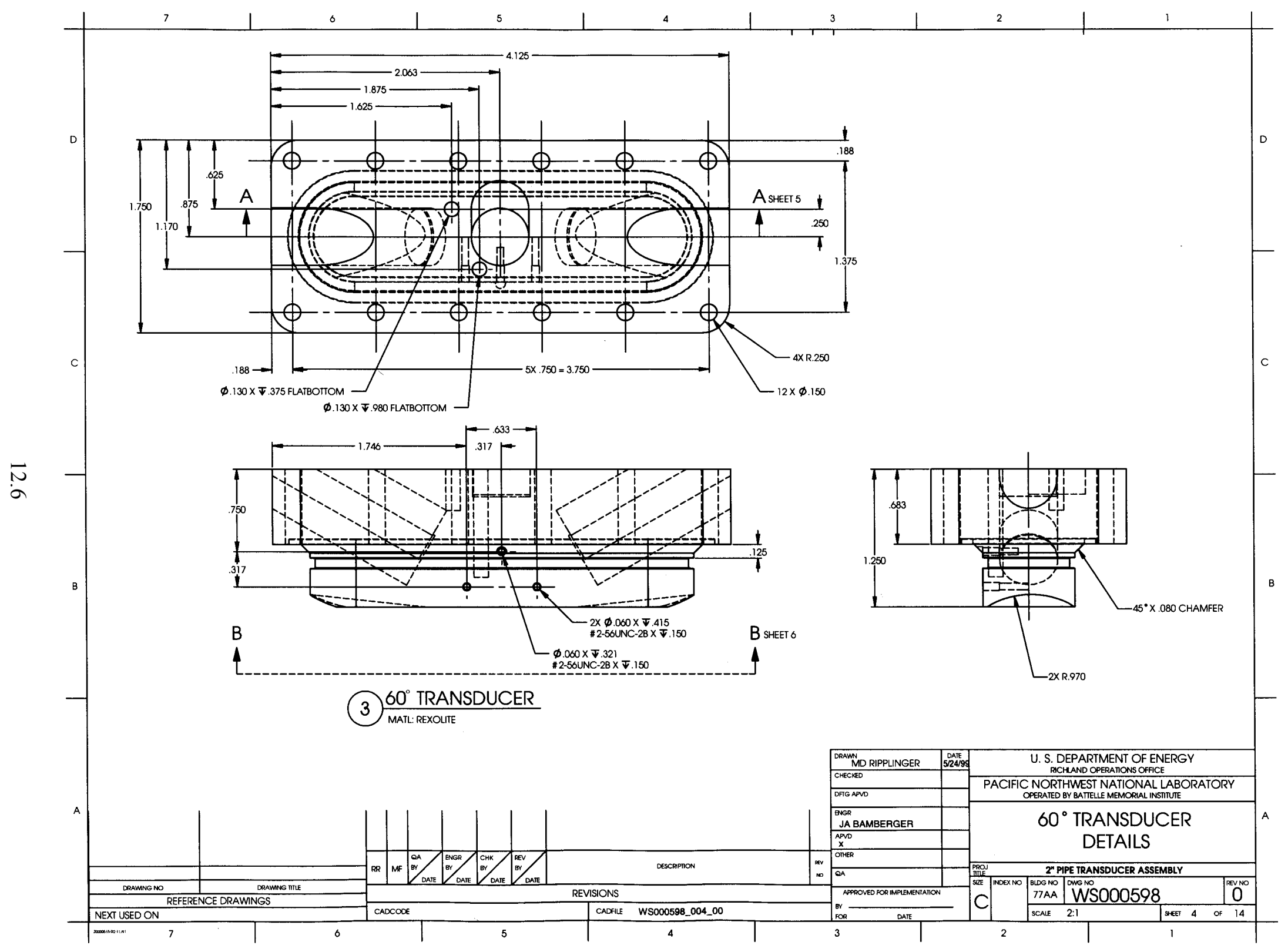




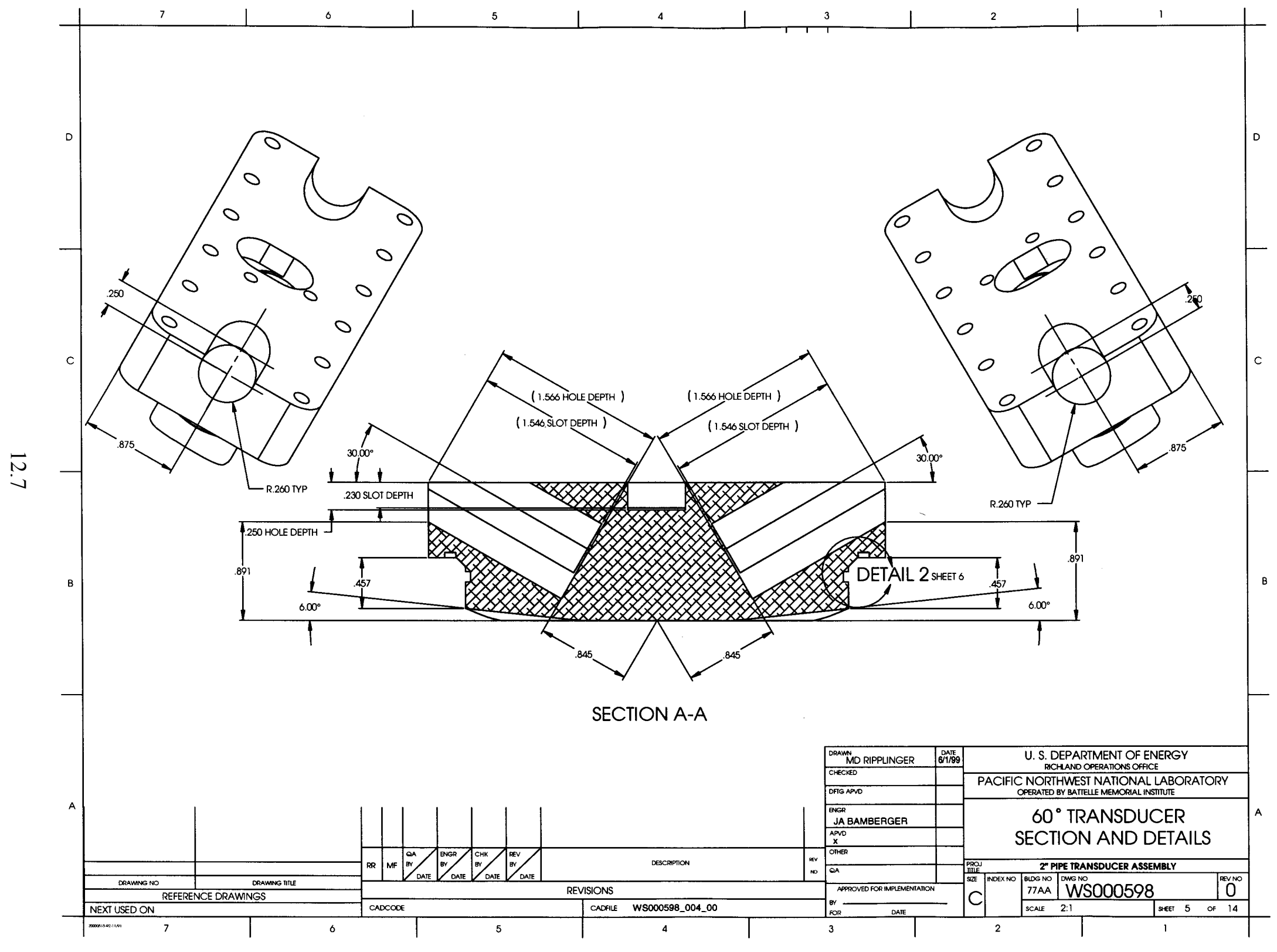




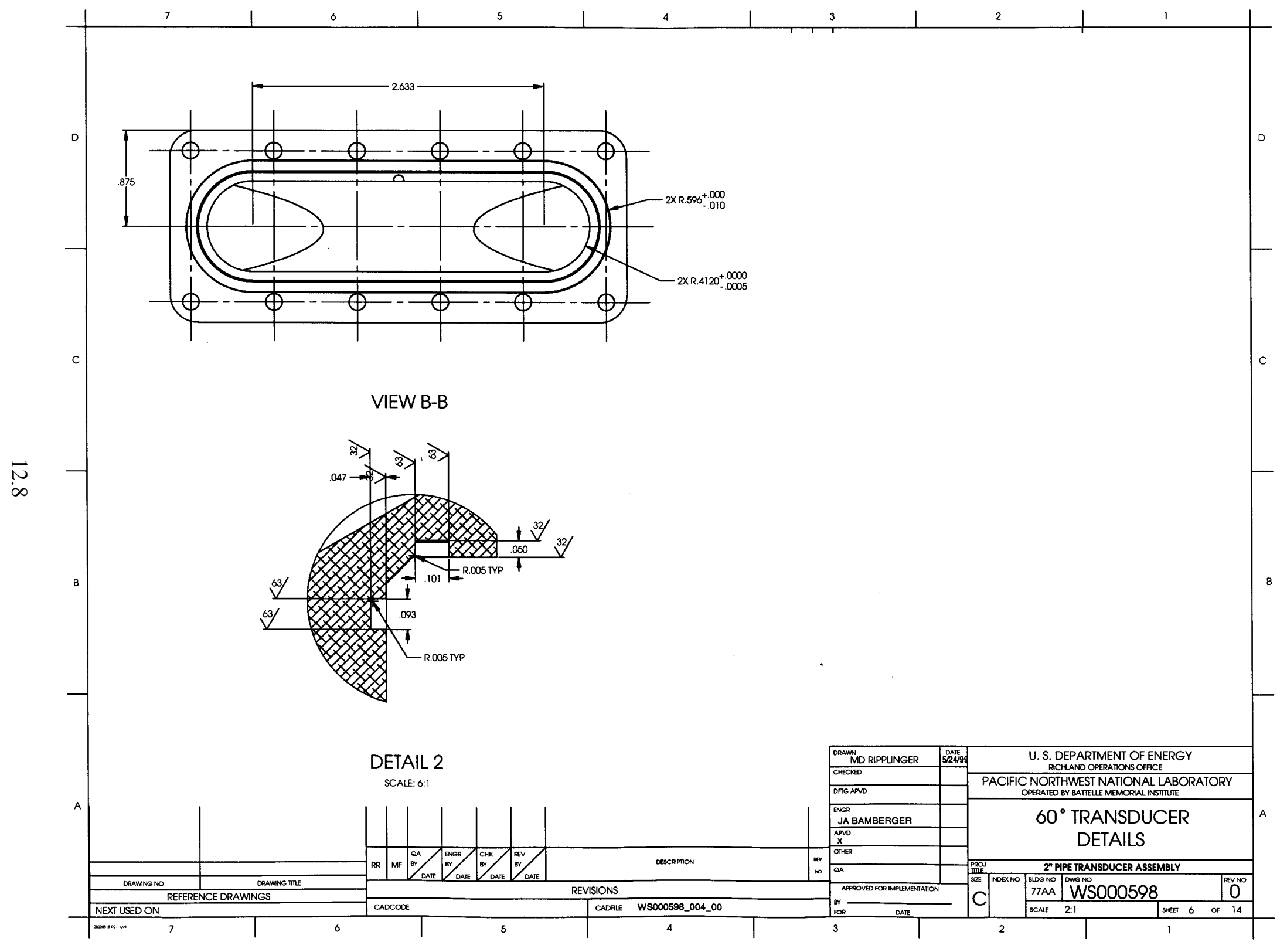




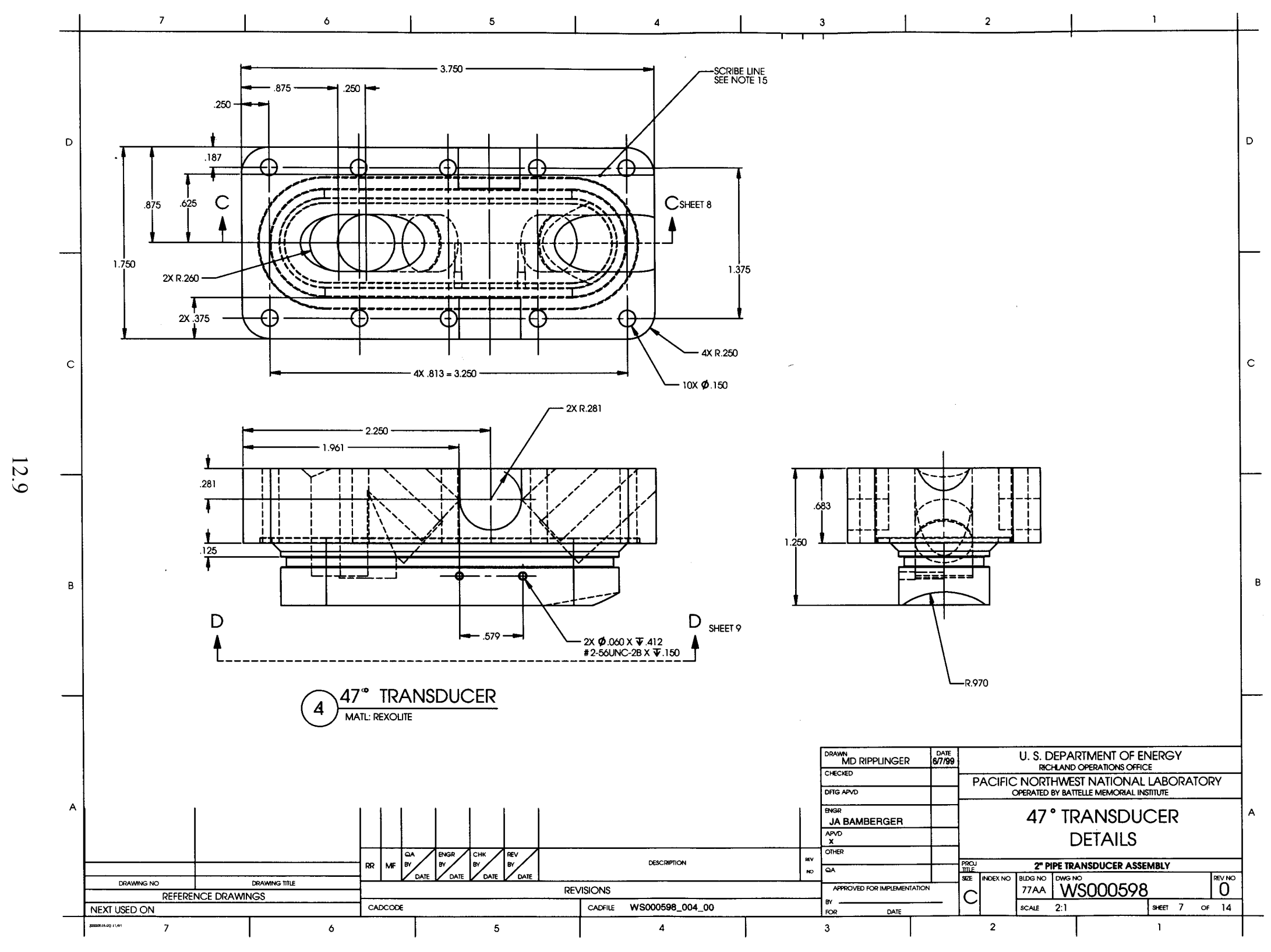




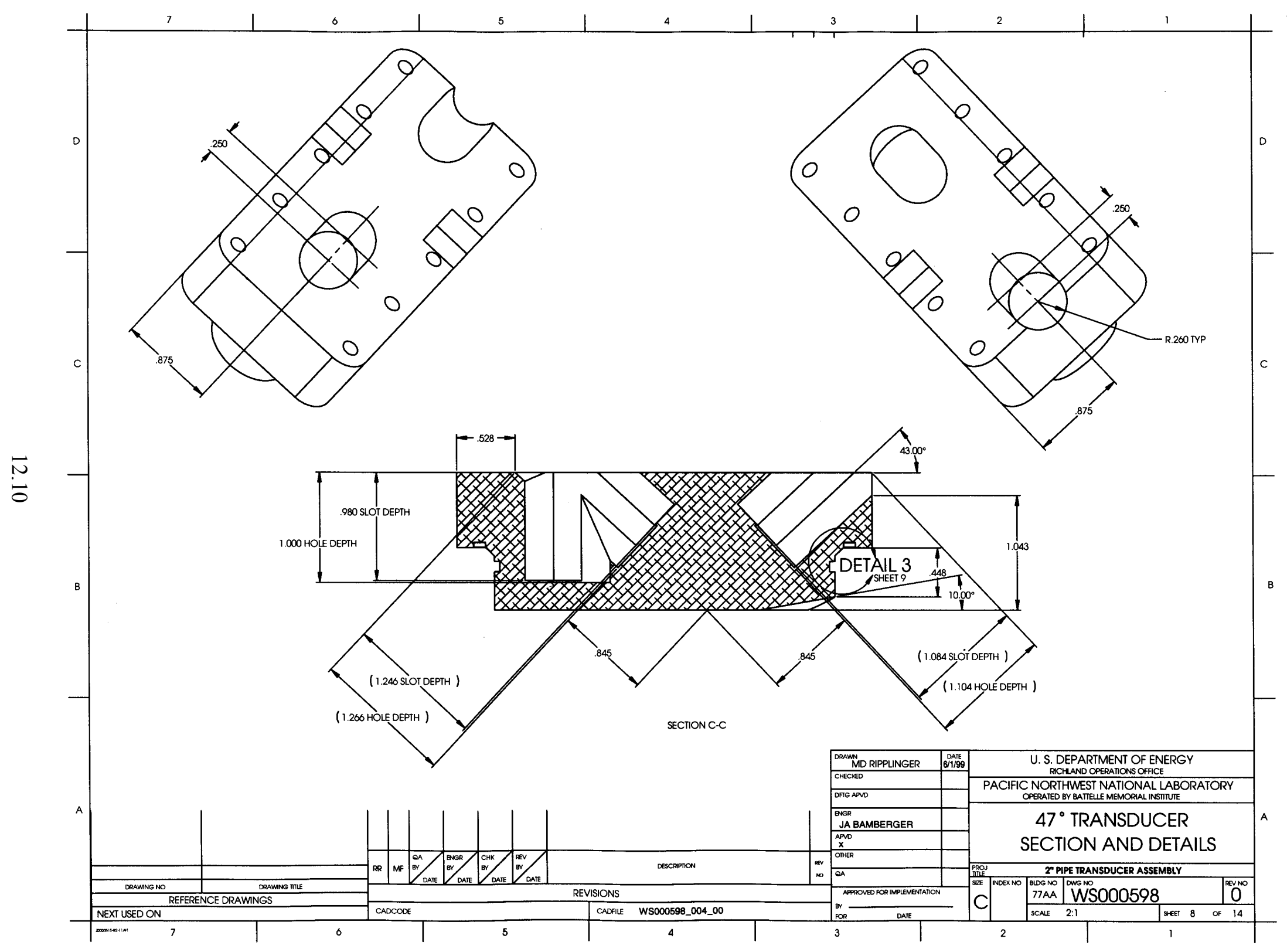




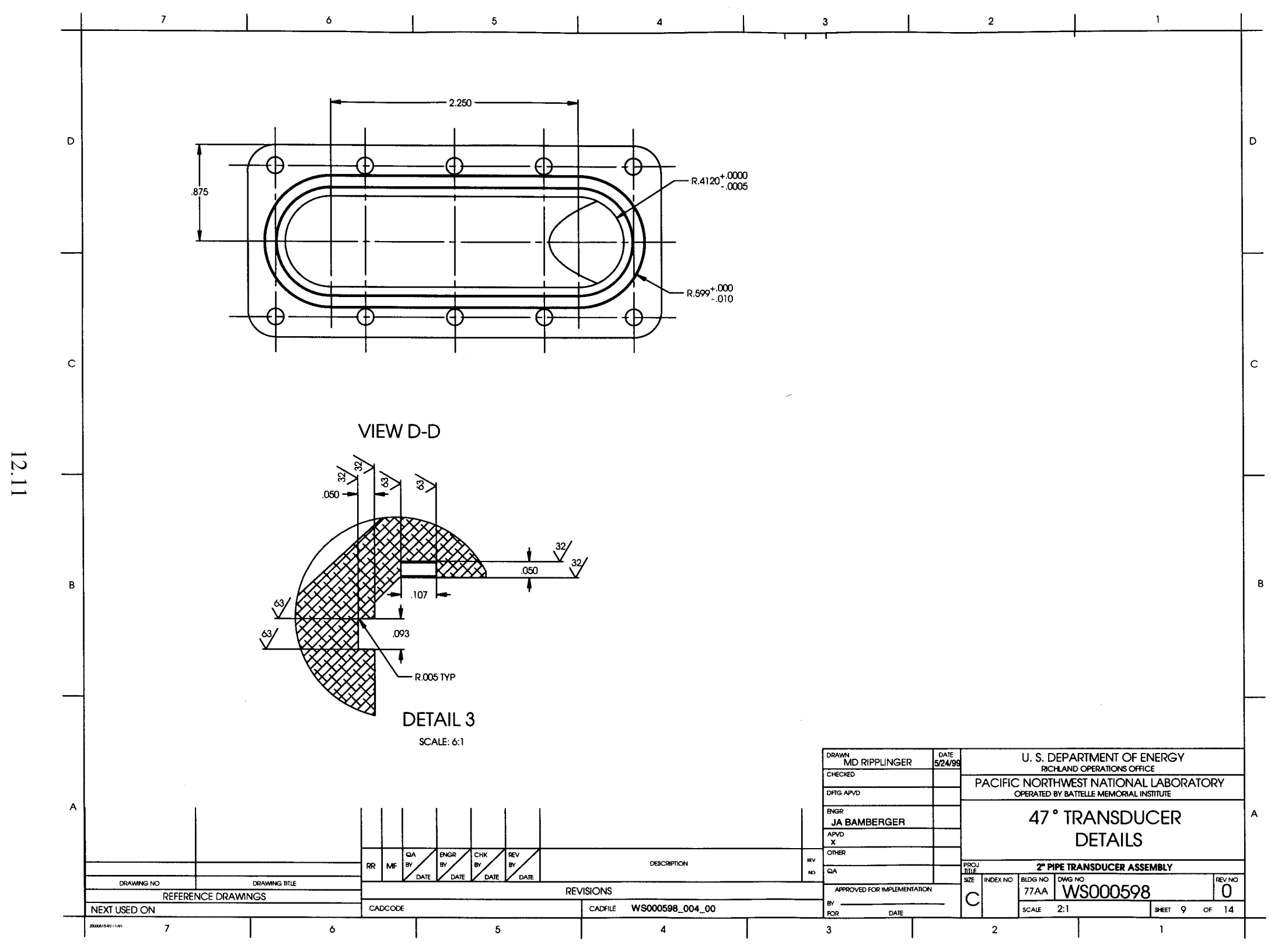




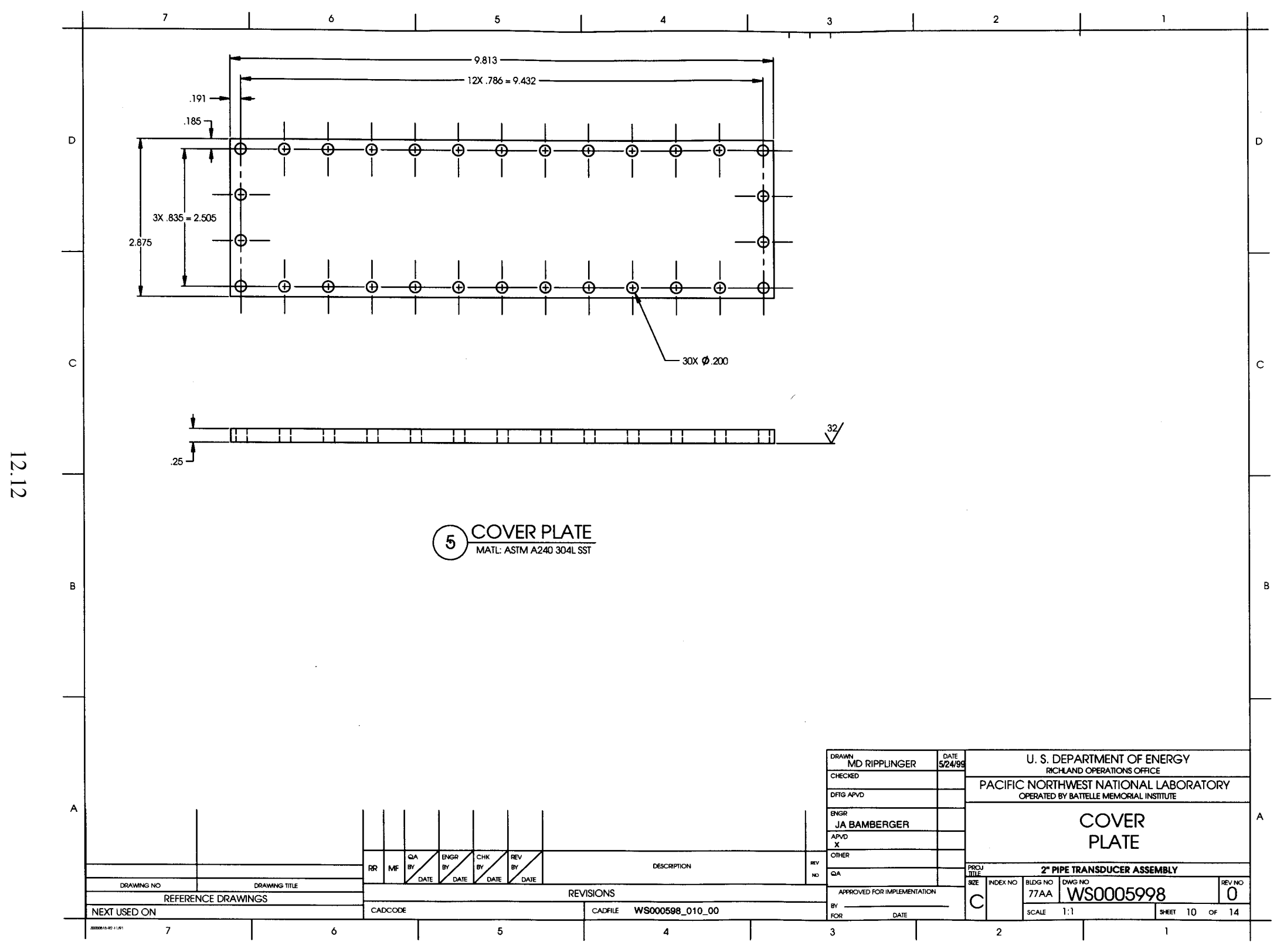




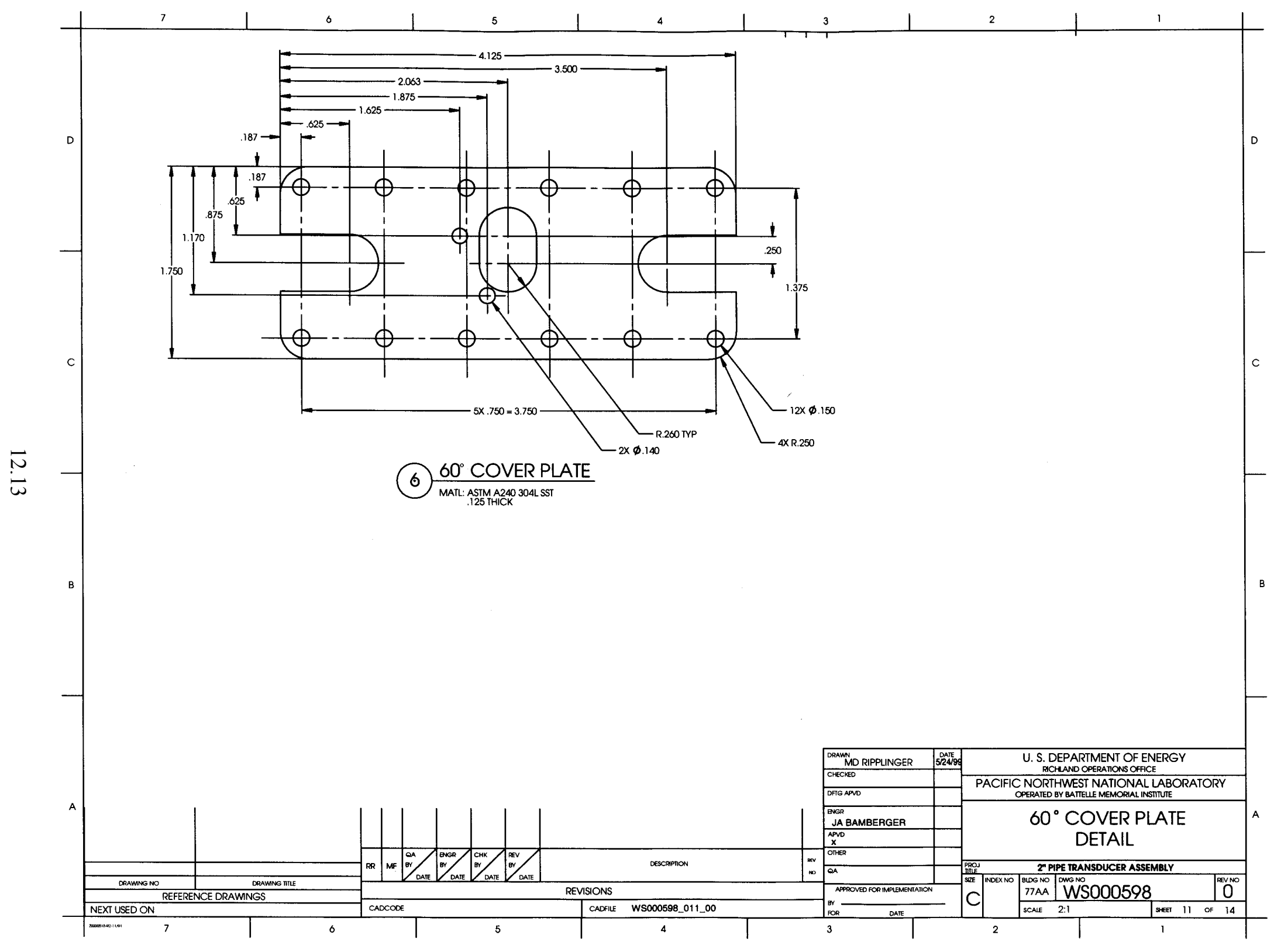




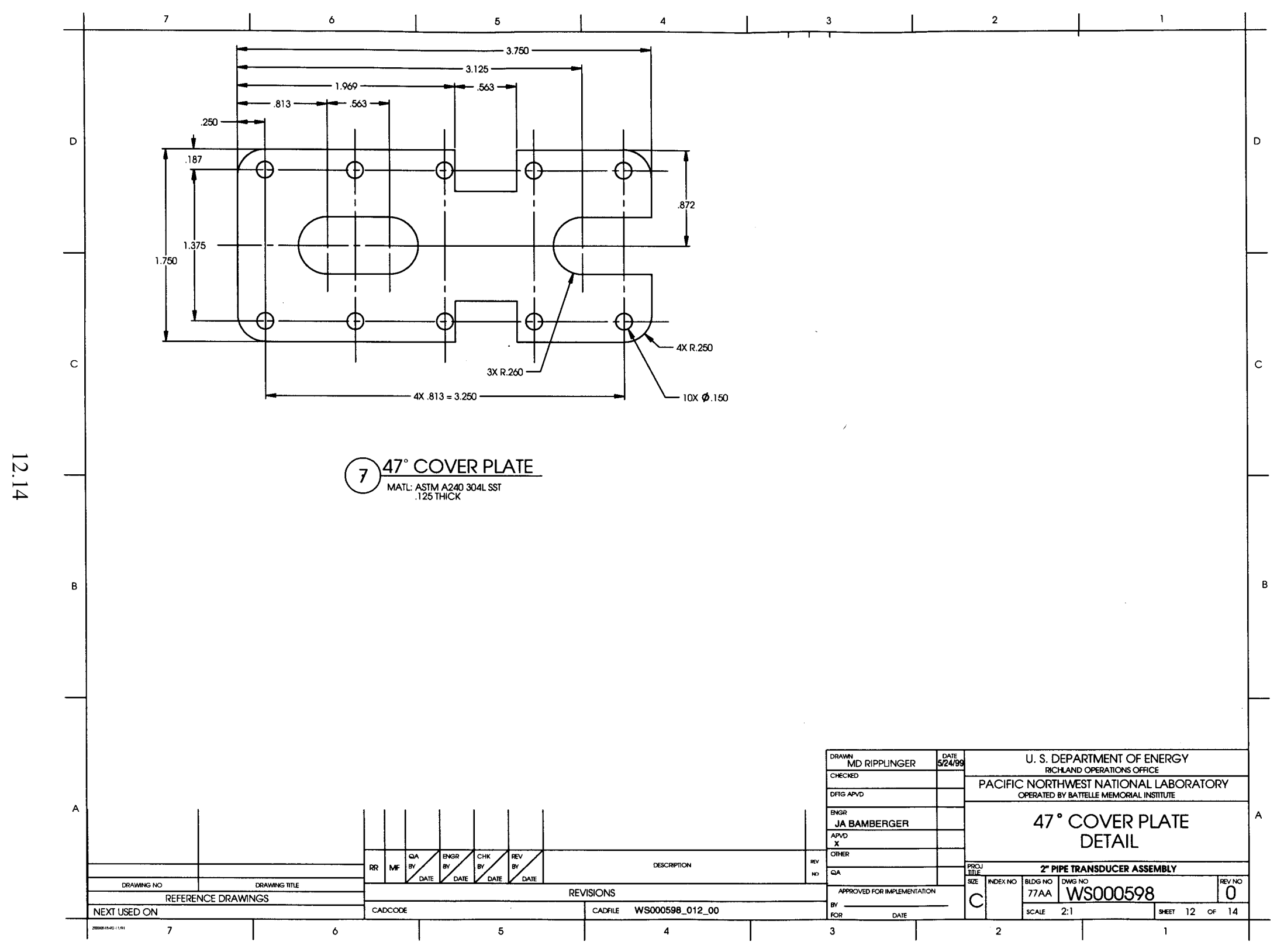




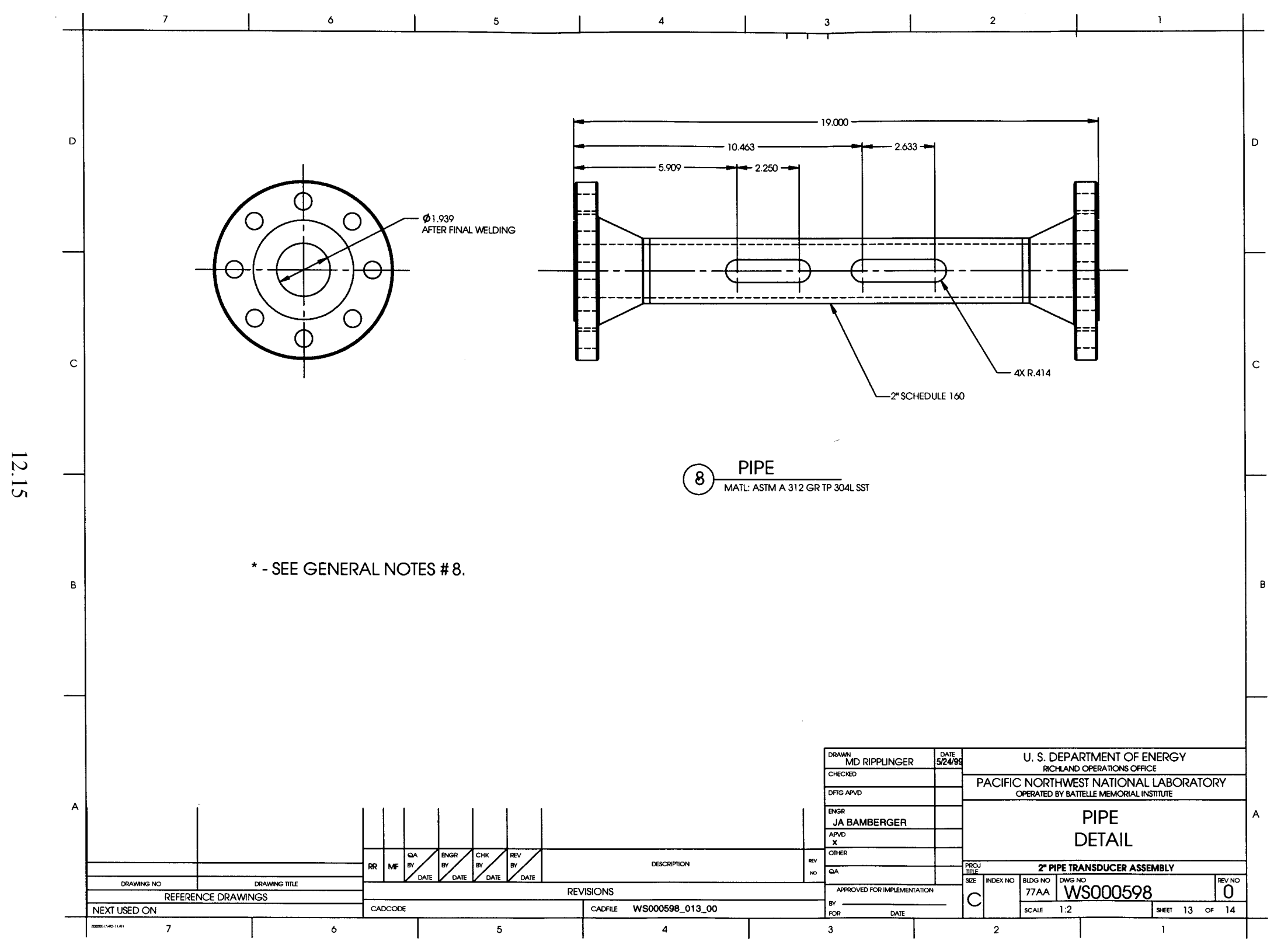




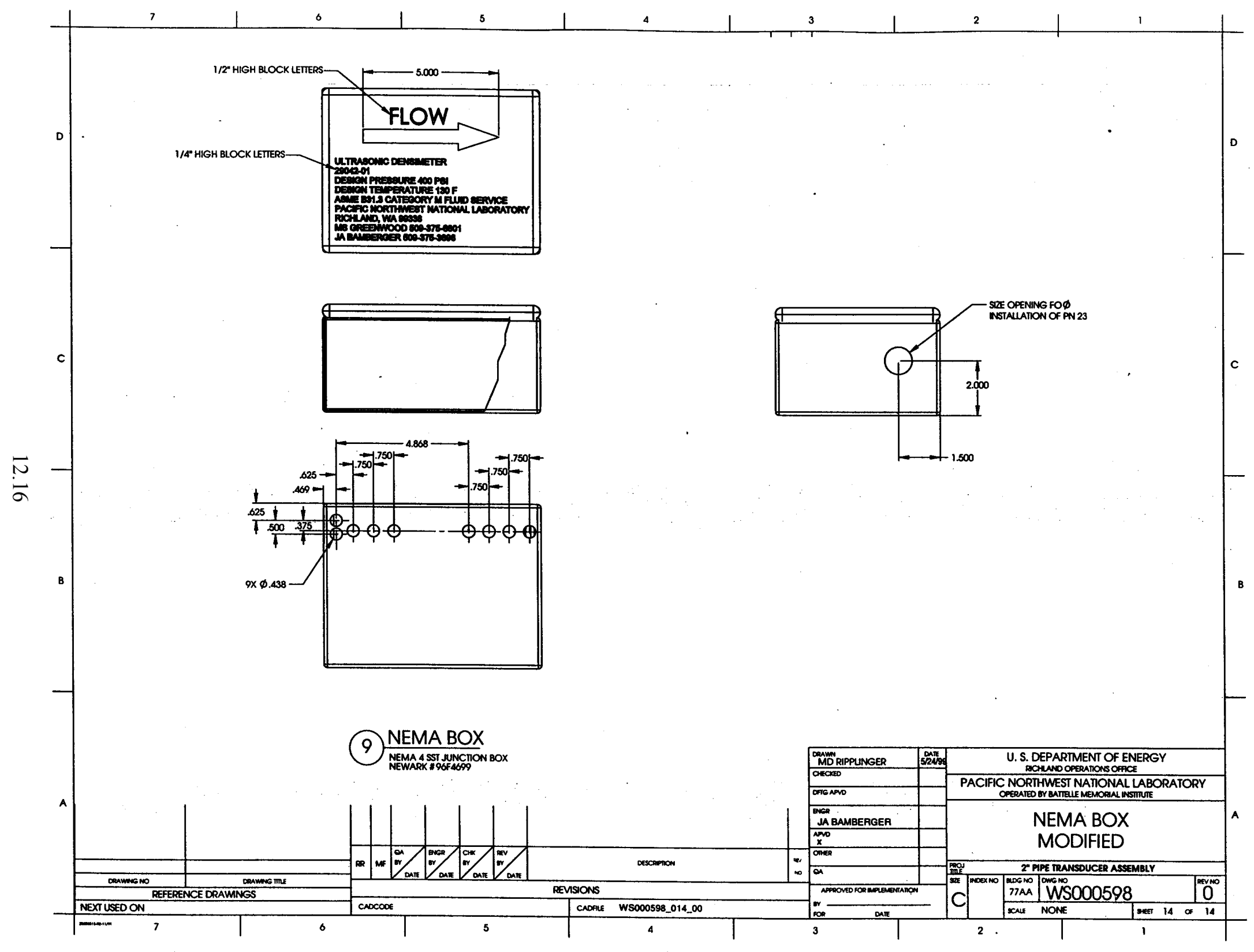




\subsection{Distribution}

No. of

Copies

OFFSITE

1 DOE/Office of Scientific and Technical Information and Information Release

1 G. J. Bastiaans

Ames Laboratory, 127 Spedding Hall Iowa State University

Ames IA 50011-3020

1 S. Barnes

10282 Rock Springs Rd. MSIN: WV-48

West Valley, NY 14171

1 B. L. Burks

TPG Applied Technology

10330 Technology Drive

Knoxville, TN 37932

1 S. W. Butterworth

Bechtel BWXT Idaho, Inc.

PO Box 1625, MSIN 3211

Idaho Falls, ID 83415-3211

1 F. Damerow

10282 Rock Springs Rd.

West Valley, NY 14171-9799

1 P. L. Davis

Westinghouse Savannah River Company

742-9G Bldg.

Aiken, SC 29801

1 J. R. Noble-Dial

U.S. Department of Energy

Oak Ridge Operations Office

P.O. Box 2001

Oak Ridge, TN 37830-8620
No. of

Copies

\section{OFFSITE}

1 K. Gerdes

Office of Science and Technology

Program Manager - Tanks Focus Area

19901 Germantown Road

1154/Cloverleaf Bldg.

Germantown, MD 20874-1290

1 D. W. Geiser, EM-50

US Department of Energy

Tanks Focus Area

Cloverleaf Building

19901 Germantown Road

Germantown, MD 20874-1290

1 T. S. Gutmann

U.S. Department of Energy

Savannah River Operations Office

P.O. Box A, Bldg. 704-S

Aiken, SC 29802

1 T. D. Hylton

Oak Ridge National Laboratory

P.O. Box 2008, Building 7601

Oak Ridge, TN 37831-6306

1 M. Jensen

Lockheed Martin Idaho Technologies

Company

P.O. Box 1625, MS 3204

Idaho, Falls, ID 83415-3204

1 M. A. Johnson

Oak Ridge National Laboratory

P.O. Box 2008, MS 6306

Oak Ridge, TN 37831-6306 
No. of

Copies

\section{OFFSITE}

1 B. E. Lewis, Jr.

Oak Ridge National Laboratory

P.O. Box 2008, MS6305

Oak Ridge, TN 37831-6305

1 K. A. Lockie

HLW Program Manager

US Department of Energy

Idaho Operations Office

750 Doe Place (MS 1145)

Idaho Falls, ID 83402

1 B. A. Martin

Westinghouse Savannah River Company 742-9G Bldg.

Aiken, SC 29801

\section{J. P. Morin}

Westinghouse Savannah River Co.

Savannah River Technology Center

703-H Building

Aiken, SC 29808

1 S. M. Robinson, MS-6044

Martin Marietta Energy Systems, Inc.

Oak Ridge National Laboratory

P.O. Box 2008

Oak Ridge, TN 37831
No. of

Copies

\section{OFFSITE}

1 T. R. Thomas, MSIN 3760

PO Box 1625

Idaho Falls, ID 83415-3760

1 K. D. Quigley

Bechtel BWXT Idaho, Inc.

PO Box 1625, MSIN 3211

Idaho Falls, ID 83415-3211

1 P. W. Wool, MS-1145

Idaho National Engineering and Environmental Laboratory

U.S. Department of Energy

750 DOE Place

Idaho Falls, ID 83402

\section{ONSITE}

1 Tanks Focus Area Program Lead

T. P. Pietrok K8-50

2 Retrieval Technology Integration Manager

P. W. Gibbons K9-91

1 Tanks Focus Area Technical Team

B. J. Williams

K9-69 
No. of

Copies

ONSITE

38 Hanford Site

K. J. Anderson

T4-07

R. R. Bafus

J. W. Bailey

R. E. Bauer

J. R. Biggs

B. E. Brendel

J. W. Cammann

A. B. Carlson

K. E. Carpenter

P. J. Certa

A. F. Choho

T. J. Conrads

C. DeFigh-Price

J. S. Garfield

K. A. Gasper

M. G. Glasper

D. W. Hamilton

C. E. Hanson

J. O. Honeyman

N. W. Kirch

C. S. Louie

T. H. May

G. W. McLellan

E. A. Pacquet

D. L. Powell

W. J. Powell

R. E. Raymond

R. W. Reed

R.H. Rifaey

C. P. Shaw

T. C. Schneider

D. B. Smet

W. T. Thompson

R. L. Treat

D. T. Vladimiroff

W. D. Wojtasek

W. L. Willis

K. S. Witwer
R3-73

R3-25

R4-01

R4-08

S7-90

R2-39

R3-73

S7-90

R3-73

R3-73

R3-73

T4-08

R3-73

L4-07

K8-50

L4-07

R4-09

H6-18

R3-73

H6-60

R2-11

S7-90

R3-47

L6-34

S5-13

R2-50

R3-83

S7-90

S7-70

L6-37

S7-90

R3-73

H6-19

S7-20

R2-39

R3-73

L6-34
No. of

\section{Copies}

\section{ONSITE}

28 Pacific Northwest National Laboratory

J. A. Bamberger (6) K7-15

L. J. Bond K5-26

W. F. Bonner K9-14

J. W. Brothers (2) K7-15

J. L. Buelt K9-09

B. A. Carteret K9-91

D. S. Daly K5-12

C. W. Enderlin K7-15

F. F. Erian K7-15

S. W. Gajewski K9-18

M. S. Greenwood (2) K5-26

B. K. Hatchell K5-22

J. L. Huckaby K7-15

W. L. Kuhn K7-15

P. A. Meyer K7-15

O. D. Mullen K5-22

L. D. Reid K5-17

M. W. Rinker K5-22

J. R. Skorpik K5-17

C. W. Stewart K7-15

W. C. Weimer K9-09 